\title{
FERTIRRIGAÇÃO POR GOTEJAMENTO SUPERFICIAL E SUBSUPERFICIAL NO MELOEIRO (Cucumis melo L.) SOB CONDIÇÕES PROTEGIDAS
}

\section{MANUEL ANTONIO NAVARRO VÁSQUEZ}

\author{
Tese apresentada à Escola Superior \\ de Agricultura "Luiz de Queiroz", \\ Universidade de São Paulo, para \\ obtenção do título de Doutor em \\ Agronomia, Área de Concentração: \\ Irrigação e Drenagem.
}

P I R A C I C A B A

Estado de São Paulo - Brasil

Maio - 2003 


\title{
FERTIRRIGAÇÃO POR GOTEJAMENTO SUPERFICIAL E SUBSUPERFICIAL NO MELOEIRO (Cucumis melo L.) SOB CONDIÇÕES PROTEGIDAS
}

\author{
MANUEL ANTONIO NAVARRO VÁSQUEZ \\ Engenheiro Agrônomo
}

Orientador: Prof. Dr. MARCOS VINÍCIUS FOLEGATTI

\begin{abstract}
Tese apresentada à Escola Superior de Agricultura "Luiz de Queiroz", Universidade de São Paulo, para obtenção do título de Doutor em Agronomia, Área de Concentração: Irrigação e Drenagem.
\end{abstract}

P I R A C I C A B A

Estado de São Paulo - Brasil

Maio - 2003 


\title{
Dados Internacionais de Catalogação na Publicação (CIP)
} DIVISÃO DE BIBLIOTECA E DOCUMENTAÇÃO - ESALQ/USP

\author{
Nava rro Vásquez, Manuel Antonio \\ Fertimgação porgotejamento superfic ial e subsuperficial no meloeiro \\ (Cucumismelo L) sob condiçõesprotegidas/ Manuel Antonio Navarro \\ Vásquez. - - Piracicaba, 2003. \\ $152 \mathrm{p}$. \\ Tese (doutorado) - Escola Superior de Agricultura Luiz de Queiroz, 2003. \\ Bibliografia. \\ 1. Cultivo protegido 2. Fertilizante potássico 3. Fertimigação 4. Imigação \\ porgotejamento 5. Melão I. Título
}

CDD 635.61

"Permitida a cópia total ou parcial deste documento, desde que citada a fonte - O autor" 
A minha mãe Adela Vásquez García e a meu pai Manuel Ignácio Navarro Soto (in memorian), a meus irmãos e familiares brasileiros e peruanos.

\section{OFEREÇO}

A minha esposa Edilza Felipe Vásquez e a mia filha Isabel Felipe Vásquez pelo carinho e compreensão. 


\section{AGRADECIMENTOS}

À DEUS, pela mia existência e por ter me dado inspiração e persistência nos momentos necessários;

À Escola Superior de Agricultura "Luiz de Queiroz" - Universidade de São Paulo, ao Departamento de Engenharia Rural e ao Curso de Pós-Graduação em Irrigação e Drenagem pela oportunidade e suporte concedida na realização deste curso e desenvolvimento da tese;

À Fundação de Amparo à Pesquisa do Estado de São Paulo - FAPESP, pela concessão da bolsa de estudo e pelo financiamento da pesquisa;

Ao Professor Dr. Marcos Vinícius Folegatti, pela valiosa orientação, colaboração, estímulo e confiança depositada pala realização deste tese;

Ao Dr. Valdemício Ferreira de Sousa pelas sugestões na concepção do projeto motivo desta pesquisa e aos Drs. Luis Fernando Campeche e Leonardo Duarte da Silva pelos serviços na coleta de informações meteorológicas;

Ao Dr. Luís Artur Alvarenga, pela valiosa assistência na montagem dos circuitos eletrônicos, contribuindo na automatização do sistema de irrigação;

Aos professores do Curso de Pós-Graduação em Irrigação e Drenagem: Dr. Marcos Vinícius Folegatti, Dr. José Antônio Frizzone, Dr. Sérgio Nascimento Duarte, Dr. Rubens Duarte Coelho, Dr. Tarlei Arriel Botrel, pelos ensinamentos e ao professor Dr.Nilson Augusto Villa Nova pelas informações e sugestões;

Aos professores Dr. Sergio Nascimento Duarte, Dr. Rubens Duarte Coelho e ao Dr. Ênio Farias de França e Silva pela revisão e valiosos aportes com sugestões que contribuíram para melhor este trabalho; 
Aos colegas de curso: Eliezer Santurdino, Roberto Atarassi, Flávio Favaro, Renê Brasil, Edivaldo Casarini, Marcelo Novaes, Denis Cararo, Alexandre Xavier, Olívio Soccol, Walter Rodríguez, Juan Delgado, Nildo Dias, Luis Gonzaga, René Rivera, Rubén Franco, Silvana Cardoso, Pablo Flecha e demais colegas pela amizade e cooperação durante o curso;

Aos funcionários da Prefeitura do campus 'Luiz de Queiroz” em especial a Beatriz, Márcia, Roseli e Estela pela atenção e simpatia;

Aos funcionários do Departamento de Engenharia Rural Davilmar Collevati, Sandra Thompson, Vanda Zambello, Antônio Gozzo, Antônio Cézar Rocha, Hélio Lemos, Osvaldo Rettore e Gilmar Grigolon pela colaboração;

Aos funcionários da Biblioteca pelo pronto atendimento e pelas sugestões na editoração da tese e correções das referências bibliográficas citadas;

Ao GPID (Grupo de Práticas em Irrigação e Drenagem) pela ajuda durante a execução do experimento;

Enfim, a todos aqueles que de alguma forma colaboraram para a realização deste trabalho. 


\section{SUMÁRIO}

Página

LISTA DE TABELAS.............................................................................. ix

LISTA DE FIGURAS ..................................................................... xiv

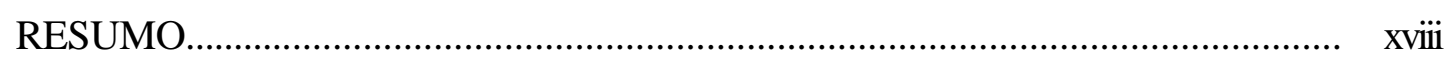

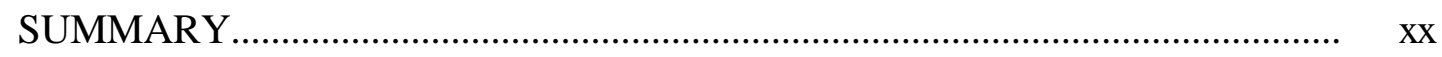

1 INTRODUÇÃO

2 REVISÃO DE LITERATURA.................................................................. 3

2.1 A cultura de melão......................................................................................... 3

2.1.1 Classificação e origem................................................................................ 3

2.1.2 Importância econômica................................................................................ 3

2.1.3 Clima e solo ............................................................................................. 4

2.1.4 Sistema de cultivo............................................................................................. 5

2.1.5 Adubação......................................................................................................... 6

2.1.6 Irrigação.................................................................................................. 7

2.1.7 Fertirrigação ...................................................................................... 10

2.1.8 Pós-colheita..................................................................................... 11

2.2 Irrigação por go tejamento subsuperficial........................................................ 12

2.2.1 Definição e desenvolvimento histórico.......................................................... 12

2.2.2 Profundidade e espaçamento das linhas laterais............................................ 14

2.2.3 Eficiência de uso de água por SDI.................................................................. 15

2.2.4 Formação do bulbo molhado......................................................................... 16

2.2.5 Manejo do sistema de SDI........................................................................... 16

2.2.6 Modelos de fluxo de água no solo por SDI.................................................. 17

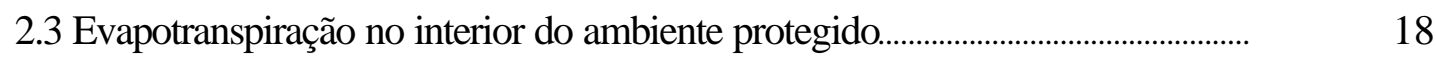


3 MATERIAL E MÉTODOS ......................................................................... 20

3.1 Caracterização da área experimental............................................................... 20

3.2 Delineamento experimental........................................................................ 22

3.3 Construção dos canteiros, correção e adubação do solo....................................... 25

3.4 Transplantio das mudas................................................................................... 27

3.5 Sistema de irrigação................................................................................... 28

3.5.1 Manejo da irrigação.................................................................................... 30

3.52 Controle da irrigação............................................................................. 31

3.5.3 Coeficiente de uniformidade...................................................................... 32

3.5.4 Tempos de irrigação...................................................................................... 32

3.5.5 Variação do armazenamento de água............................................................. 33

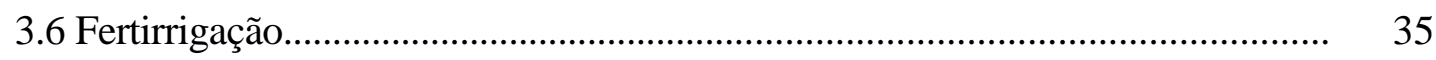

3.7 Dinâmica do potássio....................................................................................... 36

3.8 Manejo da cultura................................................................................. 38

3.8.1 Controle fitosanitário............................................................................... 38

3.8.2 Podas e condução da cultura...................................................................... 38

3.8.3 Polinização................................................................................................. 39

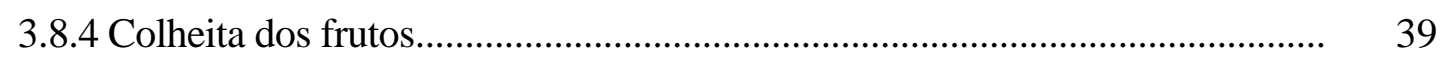

3.9 Parâmetros avaliados................................................................................. 39

3.9.1 Parâmetros de desenvolvimento das plantas.................................................. 40

3.9.2 Estado nutricional das plantas.................................................................... 41

3.9.3 Produtividade e classificação dos frutos........................................................... 41

3.9.4 Parâmetros de qualidade dos frutos.............................................................. 42

3.9.5 Eficiência de uso de água........................................................................ 42

3.9.6 Dados meteorológicos............................................................................ 43

3.9.7 Evapotranspiração e coeficiente da cultura........................................................ 44

3.9.7 Análise estatística dos resultados.................................................................... 44

4 RESULTADOS E DISCUSSÃO.............................................................. 45

4.1 Dados meteorológicos............................................................................. 45 


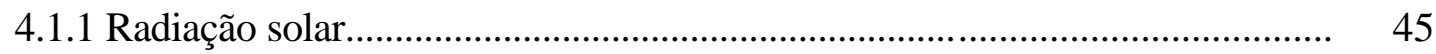

4.1.2 Fluxo de calor do solo............................................................................... 46

4.1.3 Temperatura do ar......................................................................................... 47

4.1.4. Umidade relativa do ar...................................................................................... 48

4.2 Manejo da irrigação........................................................................................... 49

4.3 Coeficiente de uniformidade............................................................................... 52

4.4.Dinâmica da água no solo................................................................................ 53

4.5 Dinâmica do potássio no solo............................................................................... 63

4. 6. Parâmetros de desenvolvimento da planta...................................................... $\quad 72$

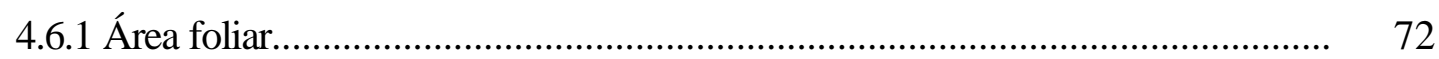

4.6.2 Número de folhas...................................................................................... 76

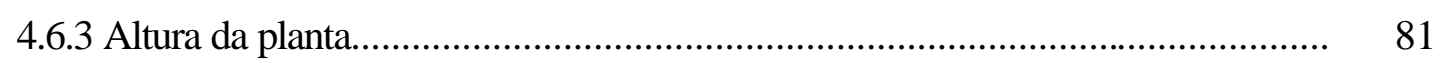

4. 7. Estado nutricional das plantas...................................................................... 85

4.7.1 Macronutrientes nas folhas.......................................................................... 86

4.8 Produtividade e classificação dos frutos............................................................ 92

4.8.1 Produtividade total e comercial..................................................................... 92

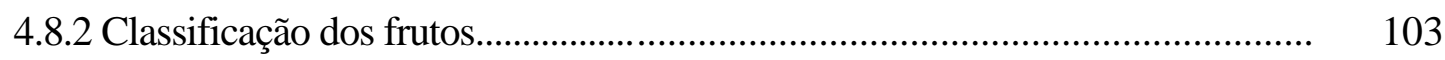

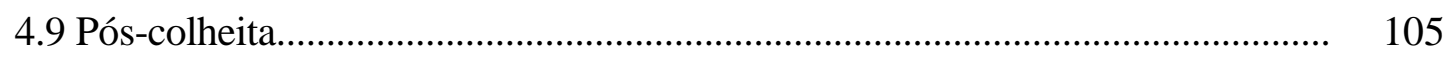

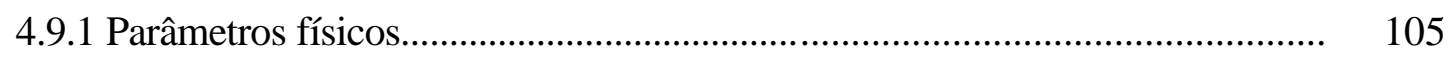

4.9.1.1 Peso médio dos frutos.................................................................................. 105

4.9.1.2 Diâmetro equatorial e polar dos frutos.......................................................... 107

4.9.1.3 Firmeza da polpa, espessura da casca e espessura da polpa........................... 112

4.9.2 Parâmetros químicos....................................................................................... 118

4.9.2.1 Sólidos solúveis totais ( ${ }^{\circ}$ Brix), $\mathrm{pH}$ e acidez total titulável (ATT)................. 119

4.10 Eficiência de uso de água.................................................................................. 124

4.11 Coeficiente e evapotranspiração da cultura.................................................... 126

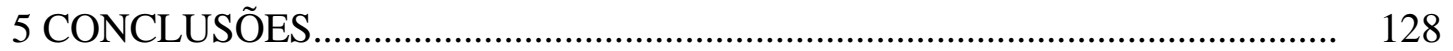

REFERÊNCIAS BIBLIOGRÁFICAS............................................................. 129 


\section{LISTA DE TABELAS}

Página

1 Valores médios mensais de radiação global $(\mathrm{RG})$, temperatura $(\mathrm{T})$, umidade relativa (UR), número de horas de insolação, precipitação pluviométrica $(\mathrm{P})$ e velocidade do vento $\left(\mathrm{U}_{2}\right)$ registrados no período do experimento........................................................................... 21

2 Resultados da análise química da água utilizada para irrigação......... 22

3 Esquema da análise de variância, com desdobramento dos graus de liberdade dos tratamentos, de acordo com o esquema fatorial $4 \times 3 \times 2$........

4 Análise química do solo utilizado para preenchimento das covas: $\mathrm{pH}$, matéria orgânica (M.O.), macronutrientes (P, K, Ca, Mg), alumínio trocável $(\mathrm{Al})$, acidez total $(\mathrm{H}+\mathrm{Al})$, soma de bases $(\mathrm{SB})$, capacidade de troca de cátions (T), saturação por bases $(\mathrm{V})$ e saturação por alumínio (m)

5 Análise química do solo utilizado para preenchimento das covas, micronutrientes: Boro (B), Cobre (Cu), Ferro (Fe), Manganês (Mn) e Zinco (Zn)

6 Análise física do solo do tipo "Sertãozinho" utilizado para preenchimento das covas: capacidade de campo (CC), ponto de murcha permanente (PMP), densidade global (Ds), argila, silte areia, floculação e classificação textural

7 Comprimento (m) e volume interno $\left(\mathrm{m}^{3}\right)$ da tubulação de cada trecho da rede hidráulica. 
8 Valores dos parâmetros de modelo de van Genuchten nas respectivas camadas do perfil do solo das covas................................. 35

9 Extração de $\mathrm{N}$ e $\mathrm{K}\left(\% \mathrm{ha}^{-1} \mathrm{dia}^{-1}\right)$ para o meloeiro cultivado com fertirrigação via gotejamento, em diferentes fases do ciclo de desenvolvimento.

10 Pulverizações realizadas durante a condução do experimento para o controle de pragas e doenças.

11 Vazões médias dos gotejadores dentro das parcelas experimentais....

12 Valores máximos, mínimos e médios de potencial matricial (-Mpa) e umidade volumétrica do solo $\left(\mathrm{cm}^{3} \mathrm{~cm}^{-3}\right)$ para os diferentes níveis de irrigação e posição das linhas portagotejadores nas profundidades de $0,15 \mathrm{~m}, 0,20 \mathrm{~m}$ e $0,40 \mathrm{~m}$

13 Comparação de médias de área foliar $\left(\mathrm{m}^{2}\right)$ para cada nível de fator isolado, nas diferentes fases de desenvolvimento da cultura.

14 Esquema da análise de variância para área foliar, com desdobramento dos graus de liberdade de tratamentos, de acordo com o esquema fatorial $2 \times 3 \times 4$.

15 Comparação de médias de número de folhas para cada nível de fator isolado, nas diferentes fases de desenvolvimento da cultura......

16 Esquema da análise de variância para número de folhas, com desdobramento dos graus de liberdade de tratamentos, de acordo com o esquema fatorial $2 \times 3 \times 4$

17 Resumo de significância para número de folhas pelo teste de Tukey para o fator de posição das linhas portagotejadores $(\mathrm{P})$, dentro dos níveis dos fatores de níveis de irrigação (L) e dose de potássio (K) aplicado.

18 Equações lineares e quadráticas resultados do teste de regressão para o fator lâmina de irrigação (L) e dose de potássio (K) aplicados ao número de folhas. 
19 Comparação de médias de altura de plantas (m) para cada nível de fator isolado, nas diferentes fases de desenvolvimento da cultura......

20 Esquema da análise de variância para altura de plantas, com desdobramento dos graus de liberdade de tratamentos, de acordo com o esquema fatorial $2 \times 3 \times 4$..

21 Resumo da análise de variância para os valores médios de nitrogênio $(\mathrm{N})$, fósforo $(\mathrm{P})$ e potássio $(\mathrm{K})$ com desdobramento dos graus de liberdade de tratamentos, de acordo com o esquema fatorial $4 \times 3 \times 2$.

22 Resumo da análise de variância para os valores médios de cálcio (Ca), magnésio ( $\mathrm{Mg}$ ) e enxofre (S) com desdobramento dos graus de liberdade de tratamentos, de acordo com o esquema fatorial $4 \times 3 \times 2$.

23 Comparação de médias de macronutrientes para cada nível de fator isolado, nas diferentes fases de desenvolvimento da cultura

24 Teores médios de macronutrientes para todos os tratamentos.............

25 Valores médios de produtividade total e comercial de frutos do híbrido de melão Bonus $\mathrm{n}^{\mathrm{o}} 2$, sob diferentes doses de potássio, níveis de irrigação e posição das linhas portagotejadores.

26 Resumo da análise de variância para os valores médios de produtividade total (PT) e comercial (PC), com desdobramento dos graus de liberdade de tratamentos, de acordo com o esquema fatorial $4 \times 3 \times 2$.

27 Comparação de médias de produtividade total, para cada nível de fator isolado.

28 Resumo de significância para rendimento total e comercial pelo teste de Tukey para o fator de posição das linhas portagotejadores (P), dentro dos níveis dos fatores de níveis de irrigação (L) e dose de potássio $(\mathrm{K})$ aplicado 
29 Equações lineares e quadráticas para rendimento total e comercial, resultados do teste de regressão para o fator lâmina de irrigação (L) e dose de potássio (K) aplicado.

30 Classificação de frutos comerciais por tamanho.

31 Comparação de médias para ñ de frutos comerciais ha ${ }^{-1}$, para cada nível de fator isolado.

32 Peso médio de frutos (PMF)

33 Peso médio de frutos (PMF)

34 Diâmetro equatorial e polar dos frutos ( $\mathrm{mm})$.

35 Resumo da análise de variância para os valores médios de diâmetro equatorial (DE) e diâmetro polar (DP), com desdobramento dos graus de liberdade de tratamentos, de acordo com o esquema fatorial $4 \times 3 \times 2$.

36 Comparação de médias para diâmetro equatorial e polar de frutos, para cada nível de fator isolado.

37 Resumo de significância para diâmetro equatorial (DE) e diâmetro polar (DT) pelo teste de Tukey para o fator de posição das linhas portagotejadores $(\mathrm{P})$, dentro dos níveis dos fatores de níveis de irrigação (L) e dose de potássio (K) aplicados

38 Equações lineares e quadráticas para diâmetro equatorial (DE) e diâmetro polar (DP), resultados do teste de regressão para o fator lâmina de irrigação (L) e dose de potássio (K) aplicados.

39 Valores médios de firmeza da polpa (FP), espessura da casaca (EC) e espessura da polpa (EP) de frutos do híbrido de melão Bonus $\mathrm{n}^{0}$ 2, sob diferentes doses de potássio, níveis de irrigação e posição das linhas portagotejadores

40 Resumo da análise de variância para os valores médios de firmeza da polpa (FP), espessura da casaca (EC) e espessura da polpa (EP), com desdobramento dos graus de liberdade de tratamentos, de acordo com o esquema fatorial $4 \times 3 \times 2$. 
41 Comparação de médias de firmeza da polpa, espessura da casca e espessura da polpa para cada nível de fator isolado

42 Resumo de significância para espessura da casca (EC) e espessura da polpa (EP) pelo teste de Tukey para o fator de posição das linhas portagotejadores $(\mathrm{P})$, dentro dos níveis dos fatores de níveis de irrigação (L) e dose de potássio (K) aplicado.

43 Equações lineares e quadráticas para espessura da casaca(EC) e espessura da polpa (EP), resultados do teste de regressão para o fator lâmina de irrigação $(\mathrm{L})$ e dose de potássio $(\mathrm{K})$ aplicados..........

44 Resumo da análise de variância para os valores médios de ${ }^{\circ} \mathrm{Brix}, \mathrm{pH}$ e ATT, com desdobramento dos graus de liberdade de tratamentos, de acordo com o esquema fatorial $4 \times 3 \times 2$.

45 Valores médios \&e sólidos solúveis totais (SST), pH e Acidez Total Titulável (ATT) de frutos de melão, para as diferentes doses de potássio, níveis de irrigação e posição das linhas portagotejadores...

46 Resumo de significância para SST e pH pelo teste de Tukey para o fator de posição das linhas portagotejadores $(\mathrm{P})$, dentro dos níveis dos fatores de níveis de irrigação (L) e dose de potássio (K) aplicados

47 Equações lineares e quadráticas para ${ }^{\circ}$ Brix e $\mathrm{pH}$, resultados do teste de regressão para o fator lâmina de irrigação $(\mathrm{L})$ e dose de potássio (K) aplicados

48 Coeficiente (Kc) e evapotranspiração da cultura (ETc), paras o híbrido de melão Bônus $\mathrm{n}^{\mathrm{o}} \quad 2$, nas diferentes fases de desenvolvimento. 


\section{LISTA DE FIGURAS}

Página

1 Ambiente protegido geminado: a) etapa de construção; b) disposição dos tratamentos no seu interior, com as plantas na fase de formação

2 Croqui do experimento e do detalhe da parcela experimental.

3 Construção de canteiros representados por covas, cobertos nas laterais com polietileno inerte

4 Curvas de retenção de água no solo prevista pelo modelo de van Genuchten, para $0,15 \mathrm{~m}, 0,30 \mathrm{~m}$ e $0,40 \mathrm{~m}$ de profundidade.

5 Mudas do híbrido de melão Bônus ñ 2: a) confeccionadas em tubos de polietileno; b) condição no momento do transplantio com duas folhas definitivas.

6 Cabeçal de controle: a) microcontrolador basic step; b) bomba hidráulica, regulador de pressão, filtro de discos, registros, hidrômetro, manômetro e válvulas solenóides.

7 Tensiômetros instalados em torno da planta.

8 Locais de amostragem do solo de cada tratamento a uma distância horizontal de 0,15 $\mathrm{m}$ ao redor da planta e nas camadas de $0-0,10 \mathrm{~m}$, 0,10 - 0, $20 \mathrm{~m}, 0,20-0,30 \mathrm{~m}$ e $0,30-0,40 \mathrm{~m}$.

9 Curva de ajuste de área foliar utilizando medidor de área foliar de mesa, modelo LI-3100.

10 Equipamento para aquisição de dados agroclimatológicos: a) datalogger (CR10) e mini tanque; b) radiômetro. 
11 Radiação solar global (Rsg) e líquida (Rsl) ao longo do ciclo da cultura de melão em condições protegidas.

12 Fluxo de calor na superfície do solo (FCS) e enterrado (FCE) ao longo do ciclo da cultura de melão em condições protegidas..

13 Temperaturas do ar mínimas (Tmín.), médias (Tméd.) e máximas (Tmáx.) ao longo do ciclo da cultura em condições protegidas

14 Valores de umidade relativa do ar médios (URméd.), mínimos (URméd.) e máximos (URmáx.) ao longo do ciclo da cultura em condições protegidas

15 Níveis de irrigação diários e acumulados: a) tratamento L1 (137,72 $\mathrm{mm})$; b) tratamento L2 (279,60 mm); c) tratamento L3 (417,32 mm).

16 Comparação da evaporação diária e acumulada dos mini tanques, no interior e exterior da estufa.

17 Variação do potencial mátrico do solo (-Mpa) a diferentes profundidades, para o tratamento de nível de irrigação L1 (137,72 $\mathrm{mm}$ ) durante o período vegetativo da cultura: a) $0,15 \mathrm{~m}$; b) $0,30 \mathrm{~m}$; c) $0,40 \mathrm{~m}$.

18 Variação da umidade do solo $\left(\mathrm{cm}^{3} \mathrm{~cm}^{-3}\right)$ a diferentes profundidades, para o tratamento de nível de irrigação L1 $(137,72 \mathrm{~mm})$ durante o período vegetativo da cultura: a) posição das linhas portagotejadores a $0,00 \mathrm{~m}$; b) posição das linhas portagotejadores a $0,20 \mathrm{~m}$

19 Variação do potencial mátrico do solo (-Mpa) a diferentes profundidades, para o tratamento de nível de irrigação L2 (279,60 $\mathrm{mm}$ ) durante o período vegetativo da cultura: a) $0,15 \mathrm{~m}$; b) $0,30 \mathrm{~m}$; c) $0,40 \mathrm{~m}$.

20 Variação da umidade do solo $\left(\mathrm{cm}^{3} \mathrm{~cm}^{-3}\right)$ a diferentes profundidades, para o tratamento de nível de irrigação L2 $(279,60 \mathrm{~mm})$ durante o período vegetativo da cultura: a) posição das linhas portagotejadores a $0,00 \mathrm{~m}$; b) posição das linhas portagotejadores a $0,20 \mathrm{~m}$. 
21 Variação do potencial mátrico do solo (-Mpa) a diferentes profundidades, para o tratamento de nível de irrigação L3 (417,32 mm) durante o período vegetativo da cultura: a) $0,15 \mathrm{~m}$; b) $0,30 \mathrm{~m}$; c) $0,40 \mathrm{~m}$.

22 Variação da umidade do solo $\left(\mathrm{cm}^{3} \mathrm{~cm}^{-3}\right)$ a diferentes profundidades, para o tratamento de nível de irrigação L3 $(417,32 \mathrm{~mm})$ durante o período vegetativo da cultura: a) posição dos portagotejadores a 0,00 $\mathrm{m}$; b) posição dos portagotejadores a $0,20 \mathrm{~m}$

23 Concentrações de $\mathrm{K}^{+}\left(\mathrm{mg} \mathrm{L}^{-1}\right)$ dentro dos extratores para as posições dos portagotejadores (P1 e P2), níveis de irrigação (L1, L2 e L3) e doses de potássio $(\mathrm{K} 0, \mathrm{~K} 1)$ aplicados.

24 Concentração de $\mathrm{K}^{+}\left(\mathrm{mg} \mathrm{L}^{-1}\right)$ dentro dos extratores para as posições dos portagotejadores (P1 e P2), níveis de irrigação (L1, L2 e L3) e doses de potássio $(\mathrm{K} 2, \mathrm{~K} 3)$ aplicados

25 Distribuição espacial de $\mathrm{K}^{+}\left(\mathrm{mg} \mathrm{kg}^{-1}\right)$ no perfil do solo sob as posições dos portagotejadores (P1 e P2), níveis de irrigação (L1, L2 e L3) e doses de potássio (K0, K1) aplicados.

26 Distribuição espacial de $\mathrm{K}^{+}\left(\mathrm{mg} \mathrm{kg}^{-1}\right)$ no perfil do solo sob as posições dos portagotejadores (P1 e P2), níveis de irrigação (L1, L2 e L3) e doses de potássio (K2, K3) aplicados.

27 Área foliar $\left(\mathrm{m}^{2}\right)$ nas diferentes fases de desenvolvimento da cultura, para os diferentes tratamentos: a) dose de potássio $\mathrm{K} 0\left(0 \mathrm{~g} \mathrm{~K}_{2} 0 \mathrm{pl}^{-1}\right)$; b) dose de potássio $\mathrm{K} 1\left(6 \mathrm{~g} \mathrm{~K}_{2} 0 \mathrm{pl}^{-1}\right)$

28 Área foliar $\left(\mathrm{m}^{2}\right)$ nas diferentes fases de desenvolvimento da cultura, para os diferentes tratamentos: a) dose de potássio $\mathrm{K} 3\left(9 \mathrm{~g} \mathrm{~K}_{2} 0 \mathrm{pl}^{-1}\right)$ : b) dose de potássio $\mathrm{K} 4\left(12 \mathrm{~g} \mathrm{~K}_{2} 0 \mathrm{pl}^{-1}\right)$.

29 Número de folhas nas diferentes fases de desenvolvimento da cultura, para os diferentes tratamentos: a) dose de potássio K0 (0 g $\left.\mathrm{K}_{2} 0 \mathrm{pl}^{-1}\right)$; b) dose de potássio $\mathrm{K} 1\left(6 \mathrm{~g} \mathrm{~K}_{2} 0 \mathrm{pl}^{-1}\right)$ 
30 Número de folhas nas diferentes fases de desenvolvimento da cultura, para os diferentes tratamentos: a) dose de potássio K2 (9 g $\left.\mathrm{K}_{2} 0 \mathrm{pl}^{-1}\right)$; b) dose de potássio $\mathrm{K} 3\left(12 \mathrm{~g} \mathrm{~K}_{2} 0 \mathrm{pl}^{-1}\right)$

31 Altura de plantas (m) nas diferentes fases de desenvolvimento da cultura, para os diferentes tratamentos: a) dose de potássio K0 (0 g $\left.\mathrm{K}_{2} 0 \mathrm{pl}^{-1}\right)$; b) dose de potássio $\mathrm{K} 1\left(6 \mathrm{~g} \mathrm{~K}_{2} 0 \mathrm{pl}^{-1}\right)$......

32 Altura de plantas (m) nas diferentes fases de desenvolvimento da cultura, para os diferentes tratamentos: a) dose de potássio K2 (9 g $\left.\mathrm{K}_{2} 0 \mathrm{pl}^{-1}\right)$; b) dose de potássio $\mathrm{K} 3\left(12 \mathrm{~g} \mathrm{~K}_{2} 0 \mathrm{pl}^{-1}\right)$

33 Produtividade total $\left(\mathrm{kg} \mathrm{ha}^{-1}\right)$ em combinação com três níveis de irrigação e duas posições de instalação das linhas laterais: a) dose de potássio $\mathrm{K} 0\left(0 \mathrm{~g}\right.$ de $\left.\mathrm{K}_{2} \mathrm{O} \mathrm{pl}{ }^{-1}\right)$; b) dose de potássio $\mathrm{K} 1$ (6 g de $\mathrm{K}_{2} \mathrm{O}$ $\left.\mathrm{pI}^{1}\right)$

34 Produtividade comercial $\left(\mathrm{kg} \mathrm{ha}^{-1}\right)$ em combinação com três ńveis de irrigação e duas posições de instalação das linhas laterais: a) dose de potássio $\mathrm{K} 2\left(9 \mathrm{~g}_{\text {de }} \mathrm{K}_{2} \mathrm{O} \mathrm{pl}{ }^{-1}\right)$; b) dose de potássio $\mathrm{K} 3\left(12 \mathrm{~g}\right.$ de $\mathrm{K}_{2} \mathrm{O}$ $\left.\mathrm{pI}^{1}\right)$.

35 Produtividade total $\left(\mathrm{kg} \mathrm{ha}^{-1}\right)$ em combinação com três níveis de irrigação e duas posições de instalação das linhas laterais: a) dose de potássio $\mathrm{K} 2\left(9 \mathrm{~g}_{\text {de }} \mathrm{K}_{2} \mathrm{O} \mathrm{pl}^{-1}\right)$; b) dose de potássio $\mathrm{K} 3$ (12 g de $\mathrm{K}_{2} \mathrm{O}$ $\left.\mathrm{pl}^{-1}\right)$.

36 Rendimento comercial $\left(\mathrm{kg} \mathrm{ha}^{-1}\right)$ em combinação com três níveis de irrigação e duas posições de instalação das linhas laterais: a) dose de potássio $\mathrm{K} 0\left(0 \mathrm{~g} \mathrm{de}_{2} \mathrm{O} \mathrm{pl}{ }^{-1}\right)$; b) dose de potássio $\mathrm{K} 1$ (6 g de $\mathrm{K}_{2} \mathrm{O}$ $\left.\mathrm{pI}^{1}\right)$.

37 Eficiência do uso da água em combinação com três níveis de irrigação e duas posições de instalação das linhas portagotejadores. a) Nível de irrigação L1 (132, $72 \mathrm{~mm})$; b) Nível de irrigação L2 (272,30 mm) Nível de irrigação L3 (417,32 mm). 
FERTIRRIGAÇÃO POR GOTEJAMENTO SUPERFICIAL E

SUBSUPERFICIAL NO MELOEIRO (Cucumis melo L.) SOB CONDIÇÕES

PROTEGIDAS

\author{
Autor: MANUEL ANTONIO NAVARRO VÁSQUEZ \\ Orientador: Prof. Dr. MARCOS VINÍCIUS FOLEGATTI
}

\title{
RESUMO
}

Este trabalho teve como objetivos determinar o efeito de duas profundidades de instalação dos tubogotejadores, três níveis de irrigação e quatro doses de potássio aplicados via fertirrigação por gotejamento superficial e subsuperficial no desenvolvimento, na produtividade e na qualidade de frutos do meloeiro sob condições protegidas, conduzido em sistema de espaldeira; avaliar a dinâmica de água e de potássio no perfil do solo e determinar a evapotranspiração da cultura (ETc) e o coeficiente de cultivo $(\mathrm{Kc})$ para o meloeiro nos diferentes estágios de desenvolvimento. O experimento foi realizado no período de setembro/2001 a janeiro/2002, na área experimental do Departamento de Engenharia Rural da ESALQ/USP, em uma área protegida de 420,0 m (28,0 m x 15,0 m), localizado no município de Piracicaba - São Paulo à latitude de $22^{\circ} 42^{\prime} 30^{\prime}$ 'S e longitude de 47³8'00'W. Foi utilizado o delineamento estatístico de blocos casualizados com 3 repetições, arranjados em esquema fatorial de $2 \times 3 \times 4$. Os tratamentos resultaram da combinação entre duas profundidades de instalação dos tubogotejadores, três níveis de irrigação e quatro doses de potássio. As 
profundidades dos tubogotejadores foram P1 e P2 (0,0 e 0,2 m da superfície do solo).Os níveis de irrigação foram L1, L2 e L3 $(0,33 ; 0,67$ e 1,0 vezes a evaporação diária do mini tanque evaporimétrico). As doses de potássio K0, K1, K2 e K3 (0, 6, 9 e 12 g de

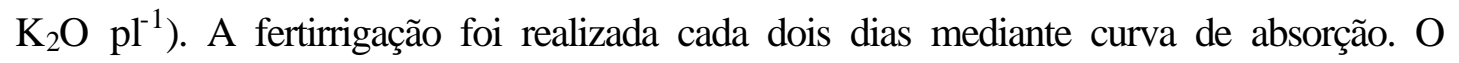
monitoramento da umidade e da concentração de potássio no solo foi feitos com tensiômetros e extratores de solução, respectivamente, instalados em torno da planta. Os valores totais de evaporação do mini tanque evaporimétrico durante o ciclo da cultura foi de 417,32 mm. Pelos valores de potencial mátrico, os níveis de irrigação L2 na posição P2, e L3 nas duas posições dos tubogotejadores, mantiverem o perfil de distribuição de água mais adequado para a cultura. As doses de potássio, os níveis de irrigação e as posições dos tubogotejadores influenciaram a concentração e a distribuição espacial e temporal de $\mathrm{K}^{+} \mathrm{A}$ aplicação das doses de potássio $\mathrm{K} 1$ e $\mathrm{K} 2$ em combinação com os níveis de irrigação L3 e posição dos tubogotejadores P2 favoreceu a obtenção de maiores produtividades totais $\left(65.108,33 \mathrm{~kg} \mathrm{ha}^{-1}\right.$ e $\left.69.646,00 \mathrm{~kg} \mathrm{ha}^{-1}\right)$ e comerciais (61.427,60 kg ha ${ }^{-1}$ e 66.224,31 kg ha $\left.{ }^{-1}\right)$. O Kc e ETc pode ser estimado com muita boa aproximação com ajuste de equações que levam em consideração a área foliar da planta. 


\title{
DRIP FERTIRRIGATION IN SURFACE AND SUBSURFACE IRRIGATION IN MELON CROP (Cucumis melo L.) UNDER PROTECTED CONDITIONS
}

\author{
Author: MANUEL ANTONIO NAVARRO VÁSQUEZ \\ Adviser: Prof. Dr. MARCOS VINÍCIUS FOLEGATTI
}

\section{SUMMARY}

The objectives of this work were: a) to determine the effect of two dripper installation depths, three irrigation depths and four potassium doses applied in surface and subsurface (SDI) irrigation on the productivity and quality of muskmelon frutis under protected conditions, b) to evaluate the water and potassium dynamics in the soil and c) to determine the muskmelon evapotranspiration (ETc) and crop coefficient $(\mathrm{Kc})$ at different growth stages. The experiment was realized between September/2001 and January 12002, at ESALQ/USP Experimental Field, in Piracicaba - São Paulo State, Brazil (Latitude 22042'30"S, Longitude 47038'00"W). The statistical test was realized in a randomized blocks with three repetitions, arranged in factorial outline of $2 \times 3 \times 4$. The treatments resulted from the combination among two depths of installation of the dripline, three irrigation levels and four potassium doses: Dripline depths were positioned 0,0 and $0,2 \mathrm{~m}$ from soil surface (P1 and $\mathrm{P} 2$ ); the irrigation 
levels L1, L2 and L3 were 33, 67 and 100 percent of daily evaporation from a modified pan, and the potassium doses $\mathrm{K} 0, \mathrm{~K} 1, \mathrm{~K} 2$ and $\mathrm{K} 3(0,6,9$ and $12 \mathrm{~g}$ of $\mathrm{K} 2 \mathrm{O}$ pl-1). The fertirrigation was applied every two days based on nutrient absorption curves. Tensiometers and solution extractors, were used to monitor soil moisture and to evaluate the potassium concentration in the soil. The total evaporation from the modified pan during the crop cycle was of $417,32 \mathrm{~mm}$. For the values of matric potential, the irrigation level L2 in the position P2 and L3 at both driplines depths (P1 and P2), maintained the best water conditions. The potassium doses, the irrigation levels and the driplines depths influenced the concentration and the spatial and time distribution of the $\mathrm{K}+$ ion. The application of the potassium doses $\mathrm{K} 1$ and $\mathrm{K} 2(6 \mathrm{~g}$ of $\mathrm{K} 2 \mathrm{O}$ pl-1 and $9 \mathrm{~g}$ of $\mathrm{K} 2 \mathrm{O}$ pl-1) in combination with the irrigation levels $\mathrm{L} 3(417,32 \mathrm{~mm})$ and dripline position P2 (0,2 m) resulted the best total productivity $(65.108,33 \mathrm{~kg}$ ha-1 and $69.646,00$ $\mathrm{kg}$ ha-1) and marketable productivity $(61.427,60 \mathrm{~kg}$ ha-1 and $66.224,31 \mathrm{~kg}$ ha-1). The $\mathrm{Kc}$ and ETc of the melon crop under greenhause conditions can be well estimated considering plant leaf area along the vegetative cycle. 


\section{INTRODUÇÃO}

A escassez de água e a necessidade de produzir bens de consumo exigem o desenvolvimento de tecnologias que permitam a otimização dos recursos hídricos disponíveis e atender as necessidades da humanidade. A utilização da irrigação por gotejamento e a condução de culturas de alto potencial produtivo permitem economizar água com bons lucros para o produtor.

O meloeiro é uma cultura rentável e de retorno rápido. Na região Nordeste do Brasil, onde é mais cultivada, a produtividade pode ultrapassar a 40 toneladas por hectare, com ciclo de apenas 60 a 70 dias, constituindo um ótimo negócio para os produtores, graças às condições climáticas dessa região. Nas regiões onde o clima não favorece o cultivo do meloeiro, é possível desenvolver técnicas para sua exploração em condições protegidas, que permitam a obtenção de altas produtividades com frutos de boa qualidade.

Aplicação de água e nutrientes através da irrigação por gotejamento é uma técnica já utilizada com sucesso nos países onde a agricultura irrigada é desenvolvida e por produtores de algumas regiões brasileiras, especialmente naquelas produtoras de frutas e hortaliças. Devido às suas vantagens referentes à economia de água e fertilizantes e formas de aplicação de água e nutrientes de maneira pontual junto à planta, a fertirrigação por gotejamento vem crescendo e despertando cada vez mais o interesse de produtores agrícolas de todo Brasil.

A utilização desta técnica na cultura do melão tem proporcionado a elevação da produtividade e da qualidade dos frutos. Entretanto, é possível desenvolver tecnologias na área de manejo de água, solo, nutriente e cultura capazes de maximizar ainda mais os 
insumos água e fertilizantes, com melhores retornos econômicos em sistema de produção do meloeiro.

A aplicação de água e nutrientes por gotejamento de forma subsuperficial, se projeta como uma alternativa para se obter maiores produtividades, pois, possibilita um melhor entendimento das relações solo, água, planta e fertilizantes, repercute de forma considerável na qualidade das culturas, permite a economia de recursos hídricos e contribui para a preservação do meio ambiente.

O cultivo de melão em condições protegidas constitui um sistema novo de produção no país e, são poucas as informações referentes a seu manejo, sobretudo, quando associado a fertirrigação por gotejamento subsuperficial, com lâminas de irrigação e doses adequadas de nutrientes, requerendo necessidade de pesquisa.

O potássio é extraído pela planta de melão em maiores proporções que o resto dos elementos nutritivos, mantendo-se sua necessidade depois que os frutos alcançam seu tamanho normal até a completa maturação, para conseguir uma boa qualidade. Sua deficiência produz melões ocos, com baixo conteúdo de açúcares.

Do ponto de vista biológico, o potássio é o elemento mais abundante nas células vegetal e animal, sendo essencial na constituição do organismo, sem o qual a vida não seria possível.

Os objetivos deste trabalho foram: (i) determinar o efeito de duas profundidades de instalação dos tubogotejadores, três níveis de irrigação e quatro doses de potássio aplicados via fertirrigação por gotejamento superficial e subsuperficial no desenvolvimento, na produtividade e na qualidade de frutos do meloeiro sob condições protegidas, conduzido em sistema de espaldeira; (ii) avaliar a dinâmica de água e de potássio no perfil do solo; (iii) determinar a evapotranspiração da cultura (ETc) e o coeficiente de cultivo $(\mathrm{Kc})$ para o meloeiro nos diferentes estágios de desenvolvimento. 


\section{REVISÃO DE LITERATURA}

\subsection{A cultura de melão}

\subsubsection{Classificação e origem}

O melão é uma olerícola, classificada dentro da família Cucurbitaceae, gênero Cucumis e espécie Cucumis melo, L. (Costa \& Pinto, 1977). É uma espécie considerada como derivada das formas selvagens, originárias da África e Ásia (Bernardi, 1974). Entretanto, de acordo com Sampaio \& Yamashiro (1979), a origem dessa espécie é ainda incerta.

No Brasil, o melão foi introduzido pelos imigrantes europeus no Estado de Rio Grande do Sul nos anos de 1960. Posteriormente seu cultivo expandiu-se por várias localidades do país, como São Paulo, Pará e Estado do Nordeste, e vem sendo cultivado em larga escala no sub-médio São Francisco (Costa \& Pinto, 1977; Ferreira et al., 1982) e microrregiões de Mossoró e Açu no Rio Grande do Norte (Sousa et al., 1999).

\subsubsection{Importância econômica}

Devido às condições de solo e clima bem como ao uso de tecnologias de irrigação, atualmente a região Nordeste é a grande produtora nacional de melão, destacando-se os Estados do Rio Grande do Norte, Pernambuco, Bahia e Ceará (Sousa et al., 1999). Esse avanço faz da região a principal exportadora de melão, especialmente, para Europa e Estados Unidos, exportando cerca de 72 mil toneladas 
por ano (FNP Consultoria \& Comércio, 2002).

O melão tem-se constituído em um ótimo negócio para os produtores do Nordeste brasileiro. Após o avanço das explorações nos vales do São Francisco e Açu e na região de Mossoró para fins de exportação, o Brasil passou a destacar-se mundialmente como produtor de melão. As exportações brasileiras atingiram em 2001, cerca de 99,43 Mg de melão, e um faturamento de US\$ 39,3 milhões. Nos anos de 1998 a 2000, as exportações caíram para 65,1, 65,5 e 60,9 Mg, para um faturamento de US\$ 28,3, 28,7 e 25,1 milhões, respectivamente (Anuário Estatístico do Brasil, 2002; FNP Consultoria \& Comércio, 2002).

Nas regiões produtoras de melão, o pico de safra situa-se entre agosto e dezembro, onde os preços obtidos pelos produtores são menores. Os melhores preços deste produto são obtidos nos meses de abril a junho (FNP Consultoria \& Comércio, 2002), com máximos valores registrados no mês de maio. Assim, produzir melão nesse período, é um ótimo negócio, contudo, é preciso desenvolver e ajustar tecnologias capazes de proporcionar ótimas produtividades nas entressafras.

No centro sul do Brasil, especialmente o Estado de São Paulo, maior centro consumidor do país, é possível produzir melão sob condições protegidas e abastecer parte desse mercado na entressafra. Com o uso de tecnologias adequadas de manejo de cultura, irrigação e fertilidade em condições protegidas, é possível elevar a produtividade a níveis superiores a $100 \mathrm{Mg} \mathrm{ha}^{-1}$, como as registradas no Egito (El-Aidy, 1989).

\subsubsection{Clima e solo}

A faixa térmica ideal, para uma produção comercial de melão bem sucedida, situa-se entre 25 e $32{ }^{\circ} \mathrm{C}$, durante todo o seu ciclo, entretanto, a planta suporta temperaturas mais elevadas (Filgueira, 1981). Sob temperaturas do solo e do ar abaixo de $18{ }^{\circ} \mathrm{C}$, as sementes não germinam e as flores não abrem (Knott, 1951; Filgueira, 1981). Os túneis de plástico, que tem sido bastante empregados tanto para proteger a cultura das chuvas torrenciais e geadas, quanto para elevar a temperatura do meio, têm 
aumentado a produção de melão no Egito (El-Aidy, 1989).

O tipo de solo ideal para o cultivo do meloeiro, é reportado por Bernardi (1974) e Filgueira (1981), como sendo de textura franco-arenosa ou areno-argilosa, leves, soltos, profundos, bem drenados e com $\mathrm{pH}$ que deve variar entre 5,4 e 7,2. Ono ${ }^{1}$ citado por Araújo (1979), menciona que solo semi-ácidos favorecem o desenvolvimento do cancro das hastes, sendo o pH ideal para a cultura, acima de 6,4. Filgueira (1981) relata que, de acordo com observações realizadas nas regiões produtoras de Brasil, a cultura prospera melhor com $\mathrm{pH}$ na faixa de 6,4 a 7,2, sendo desaconselhável o plantio em terrenos com grau de acidez fora desses limites.

Os solos arenosos, considerados areias quartzosas, têm se mostrados bons para o cultivo de meloeiro, como o caso das regiões de Mossoró e Açu no Rio Grande do Norte (Dusi, 1992) e a região dos Tabuleiros Costeiros (Sousa et al., 1999).

\subsubsection{Sistema de cultivo}

A influencia do espaçamento entre plantas e a densidade de plantio, sobre a produção e tamanho dos frutos, foi verificada em trabalhos realizado por Prado (1960), Davis \& Meinert (1965), Borrelli (1971) e Didenko (1976).

Pesquisas desenvolvidas por Sousa et al. (1999) e Pinto et al., (1996) mostram que o aumento da densidade de plantio eleva a produtividade do meloeiro, sendo populações entre 25000 e 30000 plantas por hectare as mais adequadas.

O sistema de condução e o desbaste na cultura do melão influem sensivelmente na qualidade e na uniformidade dos frutos. Sob condições de cultivo normal em campo, Bernardi (1974) e Filgueira (1981) recomendam conduzir meloeiro deixando três ramos por planta e um fruto por ramo. Esta pratica, segundo os autores, é realizada eliminando as flores e desbrotando os ramos secundários até o quarto ou quinto nó, escolhendo os frutos formados entre o quinto e o oitavo nó, dando preferência aqueles que apresentam melhor desenvolvimento, formato regular e sanidade.

\footnotetext{
${ }^{1}$ ONO, J. Palestra sobre a cultura de melão. CPATSA. Petrolina, 6 p. (mimeografado). 1977.
} 
De acordo com Hibbard² citado por Araújo (1979), a limitação de um fruto por planta, o tamanho do fruto, não compensou o decréscimo da produção. Respostas semelhantes foram verificados por Cavalcante \& Araújo (1977). Sousa et al., (1999) mencionam que em cultivos densos e em grandes áreas essa prática sistemática de condução de ramo não é utilizada pelos produtores.

A polinização deficiente das flores produz frutos deformados, ou provoca queda desses logo no inicio do seu desenvolvimento (Filgueira, 1981). Nos casos em que a cultura é conduzida em estufas ou túneis, com a presença insignificante ou ausência quase que total das abelhas, é necessário fazer polinização manual, sempre pela manhã, quando as flores encontram-se totalmente abertas.

\subsubsection{Adubação}

A disponibilidade de nutrientes no solo, principalmente macronutrientes, é fator decisivo para obtenção de altas produtividades do meloeiro com frutos de boa qualidade. Em trabalhos realizados por Brantley \& Warren (1961), verificaram que a aplicação de altas doses de $\mathrm{N}$ no meloeiro, provocou florescimento abundante e frutificação precoce, provocando também redução na produtividade de frutos comerciais.

Resultados obtidos por Williams (1978), mostram um aumento significativo na produtividade de melão quando se elevou a dose de $\mathrm{N}$ para $280 \mathrm{~kg} \mathrm{ha}^{-1}$. Entretanto, para Bhella \& Wilcox (1989) o rendimento do melão decresceu com o aumento da quantidade de nitrogênio. Além do $\mathrm{N}$, o $\mathrm{K}$ tem um papel importante na translocação de carboidratos (Prabhaker et al., 1985), contudo, existem resultados controversos, tanto quanto seu efeito isolado, quanto na interação com nitrogênio. Bratley \& Warren (1961) constataram um aumento na produtividade de meloeiro com o aumento de $\mathrm{K}$, e a interação $\mathrm{N}$ x K, promoveu um aumento no peso médio de frutos.

Sousa et al., (1998) pesquisando doses de nitrogênio e potássio por fertirrigação na produtividade do meloeiro, concluíram que a maior produtividade comercial (44,34

\footnotetext{
2 HIBBARD, A. D. Fruit thinning the watermelon. Proceedings Missoury: American Society for
} Horticultural Science, 1939. v. 37, p. 825-826. 
$\mathrm{Mg} \mathrm{ha}^{-1}$ ) do meloeiro é obtida com a combinação de $160 \mathrm{~kg}$ de $\mathrm{N} \mathrm{ha}^{-1}$ mais $190 \mathrm{~kg}$ de $\mathrm{K}_{2} \mathrm{O} \mathrm{ha}{ }^{-1}$. Doses de nitrogênio e potássio superiores a $160 \mathrm{~kg} \mathrm{ha}^{-1}$ e $190 \mathrm{~kg} \mathrm{ha}^{-1}$, respectivamente, proporcionaram queda na produtividade de frutos comerciais. Contudo, com $100 \mathrm{~kg}$ de $\mathrm{N} \mathrm{ha}^{-1}$ há uma tendência no aumento da produtividade com doses de $\mathrm{K}$ maiores de $190 \mathrm{~kg} \mathrm{ha}^{-1}$.

$\mathrm{Na}$ Califórnia (EUA), reporta-se o uso de 162 a $267 \mathrm{~kg}$ de $\mathrm{N} \mathrm{ha}^{-1}$ com uma eficiência de utilização de $5 \mathrm{~kg}$ de $\mathrm{N}$ por tonelada de fruta produzida (Wfh, 1975). Em Colima, México, os rendimentos regionais de melão são de 25 a $28 \mathrm{Mg} \mathrm{ha}^{-1}$, com eficiência de uso de $\mathrm{N}$ muito baixa (14 $\mathrm{kg}$ por tonelada de fruta produzida). A reposta do melão a aplicação de $\mathrm{N}$ já foi estudada (Pérez et al., 1995; Zermeño et al., 1999).

Os rendimentos ótimos (45 $\mathrm{Mg} \mathrm{ha}^{-1}$ ) foram obtidos com aplicações de $45 \mathrm{~kg}$ de N $\mathrm{ha}^{-1}$, complementando-se com incorporação de adubos verdes como crotalaria (Crotalaria intermedia L.), clitória (Clitoria terneatea L.) e sorgo (Sorgum bicolor (L) Moench); não entanto, sem adubos verdes é necessário aplicar 0,4 a $0,5 \mathrm{Mg}$ de $\mathrm{N} \mathrm{ha}^{-1}$ (Pérez, 1994).

No estado do Kansas (EUA), Singogo et al., (1991) reportaram rendimentos de melão de $90 \mathrm{Mg} \mathrm{ha}^{-1}$ com aplicações de $80 \mathrm{~kg}$ de $\mathrm{N}$ e a incorporação ao sulco de 4 a 6 $\mathrm{Mg} \mathrm{ha}^{-1}$ de adubos verdes como alfafa (Medicago sativa L) e trigo (Triticum aestivum L.).

\subsubsection{Irrigação}

O meloeiro responde bem a irrigação. Entretanto, a irrigação por gotejamento tem-se mostrado bastante eficiente para o aumento da produtividade dessa cultura, quando comparada com outros métodos de irrigação (Goldberg \& Shmueli, 1970; Shmueli \& Goldberg, 1971; Halevy et al., 1973; Olitta et al., 1978).

O método de irrigação por gotejamento foi desenvolvido para alta frequiência de irrigação e níveis de água no bulbo úmido estáveis e próximo do limite superior de água disponível (Rawlins, 1973; Bresler, 1978). Em pesquisas realizadas por Phene et al., (1979) e Phene et al., (1991), com aplicações de água por gotejamento em regime de alta 
freqüência em batata e milho-doce, respectivamente, constataram melhores respostas com freqüências de irrigação diária ou inferior a um dia. No meloeiro, com intervalos de irrigação acima de três dias, a produtividade de frutos se reduz e os efeitos da irrigação por gotejamento tendem a igualar-se aos dos outros métodos de irrigação (Willardson et al., 1974; Coelho et al., 1978).

Shmueli \& Golberg (1971) registraram redução de $30 \%$ na produtividade de melão, quando a frequiência de irrigação passou de um para cinco dias. Aragão Júnior et al., (1971) relacionaram frequiência de irrigação, teor de água no solo e produtividade do meloeiro cultivado em solo arenoso. $\mathrm{O}$ maior rendimento foi obtido com teor de água no solo próximo da capacidade de campo, o qual foi mantido, com aplicações de água diárias.

Mancina (1977) analisando diferentes freqüências e diferentes laminas de água no cultivo de melão irrigado por gotejamento, verificou que a maior produção foi obtida com aplicações diárias e âminas correspondentes a $80 \%$ da evaporação do tanque classe A.

Coelho et al., (1978) aplicando lâminas de água por gotejamento na cultura do melão, obtiveram maior produção com lâminas equivalentes a $75 \%$ e $100 \%$ da evaporação do tanque Classe A, com intervalos de irrigação de 2 dias. Entretanto, com intervalos de irrigação de 5 dias, as produções não diferiram daquelas obtidas nas parcelas irrigadas por sulco.

Dusi (1992) recomenda para o meloeiro irrigado por gotejamento, no período que vai da semeadura à emergência das plantas, onde a freqüência de aplicação de água deve ser diária e de baixa intensidade. No período de frutificação, essa frequiência pode ser reduzida, porém com maior intensidade de irrigação. Sob condições protegidas e de campo, em solos arenosos, Sousa et al. (1999), obtiveram melhores respostas com aplicação de água na frequiência entre um e dois dias.

A reposta do melão Cantaloupe à irrigação esta bem documentada (Loy \& Wells, 1975; Bhella, 1978; Phene \& Beale, 1976; Clough et al., 1990), visto que a freqüência e oportunidade de aplicação da água influem marcadamente sobre a qualidade do fruto (Bhella \& Wilcox, 1986; Bar-Yosef \& Sagiv, 1986a e 1986b). 
Pérez \& Rivero (2001), estudando lâminas totais de irrigação de 390 mm, 325 $\mathrm{mm}$ e $279 \mathrm{~mm}$ para as tensões registradas a $0,3 \mathrm{~m}$ de profundidade do solo de $-10 \mathrm{kPa}$, $25 \mathrm{kPa}$ e $-45 \mathrm{kPa}$, respectivamente, com híbrido de melão Cantaloupe, Ovation, obtiveram para o tratamento de $-10 \mathrm{kPa}$ rendimentos de $50 \mathrm{Mg} \mathrm{ha}^{-1}$ de fruta de exportação das categorias 9 e 12. Assim mesmo, os níveis de umidade de $-25 \mathrm{kPa}$ e -45 $\mathrm{kPa}$ afetaram negativamente a produção total de frutas e dos calibres 9 e 12; a diminuição com respeito ao tratamento de $-10 \mathrm{kPa}$ foi de $26 \%$ a $30 \%$, respetivamente. Por outro lado, a tendência foi diminuir de $10{ }^{\circ}$ Brix para $9,2{ }^{\circ}$ Brix ao incrementar-se o conteúdo de umidade do solo, isto é, ao elevar o estresse de umidade para mais de -35 $\mathrm{kPa}$, se incrementou a percentagem de sólidos solúveis.

A mínima lâmina de irrigação recomendada para a cultura de melão segundo Hudson et al., (1981) fica em torno de $500 \mathrm{~mm}$.

Rodríguez \& Ochoa (1999), estudando a eficiência no uso de água pelo cultivar de melão Laredo, medindo o potencial mátrico do solo a $0,3 \mathrm{~m}$ de profundidade, encontraram que o rendimento comercial foi afetado significativamente por o fator irrigação, mostrando que o tratamento com melhor rendimento comercial, de $24 \mathrm{Mg} \mathrm{ha}^{-1}$, correspondeu ao mais úmido (-14,2 $\mathrm{kPa}$ ), seguido pelo rendimento médio de $17 \mathrm{Mg} \mathrm{ha}^{-1}$, com -28,4 kPa e com o rendimento mais baixo de $14 \mathrm{Mg} \cdot \mathrm{ha}^{-1}$, com -32,8 kPa. Para estes níveis de potencial matricial da água do solo, a quantidade de água aplicada ao cultivo foi $423,45 \mathrm{~m}^{3} \mathrm{ha}^{-1}, 320,99 \mathrm{~m}^{3} \mathrm{ha}^{-1}$ e 233,66 $\mathrm{m}^{3} \mathrm{ha}^{-1}$, respectivamente.

Gurovich (1979) afirma que o melão pode ser manejado até um nível de $-50 \mathrm{kPa}$ a -60 kPa de potencial matricial sem que a produção sofra perdas consideráveis.

Hartz (1997), reportaram que taxas de irrigação por gotejamento normal (100\% de irrigação), procedentes de interrupção da irrigação (50\% e 20\%) e finalização da aplicação da irrigação (10 ou 20 dias antes da colheita) não afetaram a produção, qualidade da colheita e tamanho de frutos em três cultivares de melão de plantio direto na Califórnia.

Pequenos volumes de água podem ser aplicados por sistemas de irrigação por gotejamento superficial, que entregam água à medida da necessidade da cultura, evitando estresse por falta ou excesso de água, deste modo reduzindo a aplicação de 
água em torno de 70\% comparado com irrigação por sulco (Goldberg et al., 1976).

\subsubsection{Fertirrigação}

A fertirrigação pode ser adaptada em qualquer sistema de irrigação, todavia, de acordo com Goldber \& Shmuell (1970), é mais indicada para sistemas de irrigação por gotejamento, seguido pela aspersão, principalmente em sistemas fixos. O meloeiro responde bem a fertirrigação, e a utilização desta técnica nesta cultura tem proporcionado a elevação da produtividade e da qualidade dos frutos. Bhella \& Wilcox (1986), analisando a influencia do $\mathrm{N}$ aplicado no pré-plantio $\left(0,67\right.$ e $\left.100 \mathrm{~kg} \mathrm{ha}^{-1}\right)$ e aplicado na água de irrigação por gotejamento $\left(0,50\right.$ e $\left.100 \mathrm{~kg} \mathrm{ha}^{-1}\right)$, na cultura do melão em solo de textura argilo-arenosa, concluíram que a resposta da fertirrigação na produção de frutos aumentou quando a cultura não recebeu $\mathrm{N}$ no pré-plantio.

Em estudos sobre fertirrigação por gotejamento em meloeiro, as máximas produtividades comerciais, $26,40 \mathrm{Mg} \mathrm{ha}^{-1}$ e $20,20 \mathrm{Mg} \mathrm{ha}^{-1}$, foram obtidas por Pinto et al. (1993) e Pinto et al. (1994) com frequiência de irrigação diária, e $20,09 \mathrm{t} \mathrm{ha}^{-1}$ obtida por Sousa (1993) com irrigações realizadas a cada dois dias. Os autores verificaram também, que os períodos de fertirrigação que favoreceram melhores respostas foram 42 e 55 dias.

Em solo arenoso, onde as perdas de água e nutrientes ocorrem com maior intensidade, o uso da fertirrigação permite reduzir significativamente essas perdas com aplicações mais freqüentes de forma pontual, principalmente na adubação nitrogenada (Bhella \& Wilcox, 1986; Sousa, 1993; Pinto et al., 1993).

Como a irrigação por gotejamento foi desenvolvida para funcionar sob altas frequiências de aplicação de água (Phene et al., 1989), pode-se aplicar nutrientes com as mesmas frequiências de irrigação, o que possibilita uma maior eficiência na adubação e no uso dos nutrientes pelas plantas.

Trabalhos de pesquisa, como os realizados por Hernandez \& Aso (1991) têm mostrado que a maior produtividade do meloeiro pode ser obtida com doses crescentes de nutrientes aplicados via água de irrigação. 
Pearson \& Adams ${ }^{3}$ citados por Araújo, (1979), revelam que níveis excessivos de $\mathrm{K}$ e $\mathrm{N}$ tem acelerado a acidez dos solos como também a toxicidade por Mn. Dentro deste contexto Kuznetsova \& Agazamova (1974), estudando os efeitos do potássio na cultura do melão, verificaram que altas doses de potássio ocasionaram decréscimo na produção de frutos, sendo o nível ótimo em torno dos $100 \mathrm{~kg} \mathrm{ha}^{-1}$ de óxido de potássio $\left(\mathrm{K}_{2} \mathrm{O}\right)$. De igual forma, Pinto et al., (1986) estudando os efeitos das doses 0, 45, 90, $135 \mathrm{~kg}$ de $\mathrm{K}_{2} \mathrm{O}$ $\mathrm{ha}^{-1}$, sobre a produção do meloeiro verificaram que as maiores produtividades de frutos comerciais (28 $\mathrm{Mg} \mathrm{ha}^{-1}$ ) foram obtidas com a dose de $100{\mathrm{~kg} \text { de } \mathrm{K}_{2} \mathrm{O} \mathrm{ha}}^{-1}$ aplicados por meio da fertirrigação e que a fertirrigação diária superou em produção a frequiência a cada dois dias.

Outros resultados como os de Sagdullaev \& Umarov (1974) e Jassal et al., (1970) mostraram aumento na qualidade e produção do melão quando aplicaram $100 \mathrm{~kg} \mathrm{de} \mathrm{N}$ $\mathrm{ha}^{-1}$ e $150 \mathrm{~kg}$ de $\mathrm{K}_{2} \mathrm{O} \mathrm{ha}^{-1}$, embora a interação $\mathrm{N}$ x K não tenha ocasionado um aumento significativo no peso dos frutos.

Estresse salino geralmente reduz o número e tamanho de frutos em proporção à inibição de crescimento vegetativo (Mass \& Hoffman, 1997). Em melões a salinidade reduz o rendimento comercial, mas do que o rendimento total, e reduz o peso de frutos, mais do que o peso vegetativo (Shannon \& Francois, 1978).

\subsubsection{Pós-colheita}

Welles \& Buitelaar (1988), relataram que o conteúdo de sólidos solúveis diminui significativamente com a diminuição da área foliar; uma maior área foliar de plantas pode incrementar sua capacidade fotossintética.

Irrigação excessiva pode prejudicar o crescimento das plantas de melão, durante a colheita ou amadurecimento é mais propensa a queimadura com prejuízo para o fruto, conseqüentemente, a redução em rendimento de mercado e conteúdos de sólidos

\footnotetext{
${ }^{3}$ PEARSON, R. W.; ADAMS, W. E; JORDAN, H. V. et al. Residual effects of fall-and spring -applied nitrogen fertilizers on crop yields in the southeastern United State. Washigton: USDA, ARS, 1961. (Technical Bulletin, 1254).
} 
solúveis do fruto (Pew \& Garnwer, 1983).

A classificação do meloeiro em função do teor de sólidos solúveis totais (SST) pode ser representada por uma escala que varia de 9 a 12, onde o melão com grau 9 é classificado como não comercializável, na faixa de 9 a 12 é considerado comercializável e acima de 12 considerado extra. (Gayet, s.d).

O tipo de amostragem para determinação do teor de SST está condicionado ao tipo do fruto (Gayet, s/d); o local para realização da amostragem é dependente da localização dos ácidos orgânicos que se encontram principalmente na placenta e na polpa interna do fruto (Vieira, 1984).

A qualidade do melão associa-se também ao teor de açúcar, porém a aplicação de $100 \mathrm{~kg}$ de $\mathrm{K}_{2} \mathrm{O}$ ha $^{-1}$ e $90 \mathrm{~kg}$ de $\mathrm{N} \mathrm{ha}^{-1}$ via água de irrigação em um Latossolo VermelhoAmarelo em Petrolina-PE, não proporcionou diferenças significativas para a característica do teor de SST de frutos de melão (Pinto, 1996).

\subsection{Irrigação por gotejamento subsuperficial}

\subsubsection{Definição e desenvolvimento histórico}

A irrigação por gotejamento subsuperficial (SDI - subsurface drip irrigation), também denominada de irrigação por gotejamento subterrâneo ou enterrada, é definida como "aplicação de água com emissores abaixo da superfície do solo, com vazões próximas às utilizadas na irrigação por gotejamento superficial. Esta forma de aplicação de água não deve ser confundida com a subirrigação, que é definida, como aplicação de água de irrigação abaixo da superfície do solo, elevando o lençol freático próximo da zona radicular"' (ASAE Standards S 526.1, 1996).

O desenvolvimento do SDI teve início com irrigação por gotejamento nos EUA, aproximadamente em 1959, especialmente na Califórnia (Davis, 1967) e Hawai (Vaziri \& Gibson, 1972). Nos anos sessenta na Califórnia, foram construídas linhas laterais de polietileno ou PVC com furos ou cortes internos (Braud, 1970; Hanson et al., 1970; Zetzsche \& Newman, 1966), ou com inserções de emissores dentro dos tubos perfurados 
(Whitney, 1970). Em 1970, ensaios com cana-de-açúcar foram realizados usando tipo de emissores nas linhas laterais (Davis \& Nelson, 1970; Davis \& Pugh, 1974; Gibson, 1974; Hanson \& Patterson, 1974). Na mesma época, em Israel, estavam sendo desenvolvidos sistemas de SDI, juntamente com sistemas de injeção de fertilizantes (Goldberg \& Shmueli, 1970).

Vários autores constataram vantagens do SDI sobre outros sistemas de irrigação e em várias condições de manejo. No Estado da Virgínia, a produtividade da pêra foi maior com a SDI do que com irrigação por aspersão quando foi utilizada água sódica, mas não houve nenhum aumento com água de boa qualidade. Produções de batata com SDI foram maiores quando comparadas com irrigação por aspersão na Califórnia, mas o sistema de SDI requereu entre 50\% e 70\% da máxima necessidade de água da cultura (Detar et al., 1996).

Segundo Phene et al., (1992 a,b), a produtividade de algodão foi maior com SDI do que com irrigação por sulco em um solo siltoso, mas não foi diferente em um solo arenoso; no entanto, o consumo de água com o SDI reduziu-se em $40 \%$.

Também com a cultura do algodão, Henggeler (1995), obteve aumento de $20 \%$ na produtividade com SDI quando comparado com irrigação por sulco em vários municípios no Texas ocidental.

Em estudos comparativos com SDI e irrigação por aspersão, Henggeler (1995) constatou que as produtividades de alfafa foram semelhantes nos dois sistemas. Resultados semelhantes foram obtidos por Bui \& Osgood (1990), no entanto o sistema de aspersão requereu mais mão de obra para operar. Zoldoske et al., (1995) apresentaram resultados semelhantes para a cultura de grama em uma área com SDI e aspersão, mas o custo de manutenção e uso de água foram maiores com o sistema de aspersão.

Pesquisas mostraram que as produtividades com SDI foram de $12 \%$ a $14 \%$ maior do que com irrigação por sulco e aspersão para milho doce (Phene \& Beale, 1976) e $20 \%$ maior que com irrigação por sulco para tomate (Bogle et al., 1989; Rose et al., 1982), mas foi semelhante em melão, cebola e cenoura (Bucks et al., 1981) e milho doce (Wendt et al., 1977). 
Comparando SDI com sistemas de irrigação por gotejamento superficial, pesquisas desenvolvidas em várias partes do mundo constataram aumento na produtividade das culturas cultivadas sob SDI (Bar-Yosef et al., 1989; Phene et al., 1987; Bucks et al., 1981; Camp et al., 1993; Oron et al., 1991; Oron et al., 1995; Sammis, 1980; El-Gindy e El-Araby, 1996; Hutmacher et al., 1985).

\subsubsection{Profundidade e espaçamento das linhas laterais}

A profundidade das linhas laterais raramente é uma variável de tratamento, na maioria dos casos. Profundidades de instalação das linhas laterais, foram aperfeiçoadas provavelmente para condições de local prevalecentes e conhecimento do solo e suas características de água. Nesses casos, onde foram avaliadas várias profundidades de instalação de linhas laterais, era evidente pequena diferença de produção.

As profundidades das linhas laterais variam de $0,02 \mathrm{~m}$ a $0,70 \mathrm{~m}$ dependendo do solo e da cultura. Em casos em que a cultura não é considerada (por exemplo: grama, alfafa), profundidades às vezes variam de $0,10 \mathrm{~m}$ a $0,40 \mathrm{~m}$. A germinação das sementes, o estabelecimento, o crescimento de mudas e a existência de camadas de solo que interferem o movimento ascendente da água, também são outros fatores que afetam a profundidade lateral. (Phene \& Sanders, 1976).

Para batata, Detar et d., (1996) encontraram profundidades de laterais de 0,08 m sobre semente e 0,46 m abaixo das sementes, melhor que uma profundidade intermediária ou maiores profundidades.

Schwankel et al., (1990) investigaram três profundidades de instalações de linhas laterais, três profundidades de semeadura de tomate e três lâminas de irrigação em um solo argiloso na Califórnia, concluíram que a melhor combinação foi de $0,15 \mathrm{~m}$ ou 0,23 m para as linhas laterais e de $0,012 \mathrm{~m}$ ou $0,038 \mathrm{~m}$ para semeadura, com uma irrigação inicial por aspersão para molhar a superfície do solo e logo uma irrigação diária de 0,5 da ETm.

O espaçamento das linhas laterais também varia consideravelmente de 0,25 $\mathrm{m}$ até $5,0 \mathrm{~m}$. Espaçamentos estreitos são utilizados principalmente para cultivos de gramas, 
enquanto que espaçamentos longos foram utilizados para legumes e fruteiras no Estado de Nevada. Devitt \& Miller (1988), pesquisando vários espaçamentos das linhas laterais em dois solos utilizando água salina para irrigar grass bermuda, concluíram que um espaçamento de $0,6 \mathrm{~m}$ foi aceitável para um solo argilo-arenoso, no entanto para um solo arenoso os espaçamentos devem ser reduzidos.

Algumas culturas de alto valor econômico podem requerer espaçamentos menores entre linhas laterais em solos arenosos e/ou em áreas áridas, para assegurar um adequado equilíbrio de sal e qualidade de colheita e produção consistente (Phene \& Sanders, 1976). Maiores espaçamentos entre linhas laterais podem ser possíveis em áreas úmidas, com produções aceitáveis em anos com chuva moderada e reduzindo em anos com períodos significativos de seca, especialmente em culturas suscetíveis como milho.

\subsubsection{Eficiência de uso de água por SDI}

Phene et al. (1992) listou varias características de sistemas de irrigação por gotejamento subsuperficial que podem contribuir para maximizar o uso eficiente de água, inclusive desprezando a evaporação do solo, percolação e escoamento superficial.

Pesquisas realizadas polo USDA demostram que o padrão de umedecimento ao redor do emissor enterrado pode ser manejado pela frequiência de irrigação (Phene, et al., 1987). Por exemplo, se o interesse é movimentar a água para maior superfície, a frequiência de irrigação deverá ser aumentada.

A capacidade do sistema de irrigação por gotejamento subsuperficial deveria ser desenhada para reunir de $110 \%$ a $120 \%$ da maior taxa de evapotranspiração (Et) esperada de sete dias (ASAE, 1991) e (Conrad, 1992).

Adicional economia de água e alta eficiência no seu uso, podem ser obtidas por sistemas de irrigação por gotejamento subsuperficial. Estes sistemas aplicam água através de emissores posicionados entre $2 \mathrm{~cm}$ e $5 \mathrm{~cm}$ a $40 \mathrm{~cm}$ e $50 \mathrm{~cm}$ por debaixo da superfície do solo (Bogle \& Hartz, 1986; Hanson et al., 1994).

Estudos realizados por Phene (1990), demonstram que um pulso de sistema de 
irrigação por gotejamento subsuperficial pode ter $46 \%$ de volume e $62 \%$ da área de interface de umedecimento maior, do que um pulso de sistema de irrigação por gotejamento superficial, para a mesma amostra equivalente de água. Aassim o padrão de umedecimento ao redor do emissor enterrado pode ser manejado pela freqüência de irrigação (Phene, et al., 1987).

\subsubsection{Formação do bulbo molhado}

Segundo estudos desenvolvidos por Ben-Asher (1993), num solo de textura franco argilosa, o volume do bulbo molhado do sistema de SDI foi $46 \%$ maior que do bulbo molhado do sistema de irrigação por gotejamento superficial. Da mesma forma a superfície molhada para uso das raízes, que corresponde ao bulbo do sistema de SDI foi $62 \%$ maior que no sistema de irrigação por gotejamento superficial.

\subsubsection{Manejo do sistema de SDI}

Os sistemas de SDI exigem boa filtragem e é imprescindível o uso de ventosas de duplo efeito em todos os pontos altos do sistema para prevenir sucção e entrada de solo na tubulação, especialmente em declives acentuados. Dessa forma, o sistema SDI requer limpeza freqüiente. A instalação de tubos secundários de lavagem que conectam os finais de todas as laterais facilita a limpeza rápida das mesmas.

Nogueira (1997), menciona que já existem gotejadores com dispositivos anti sucção que evitam obstrução e estes gotejadores são constituídos de uma esfera que se movimenta dentro do pequeno tubo que compõe o corpo do gotejador. Quando há pressão de operação no gotejador, a água empurra a esfera em direção à sua saída bloqueando a passagem para a água. Quando deixa de haver pressão de operação, as primeiras sucções trazem a esfera para dentro do corpo do gotejador, vedando totalmente a entrada de ar e de solução de solo. Assim mesmo, manifesta que todos os sistemas de SDI devem ser operados em alta freqüência porque ajuda a prevenir a intrusão de raízes nos gotejadores, já que se o solo estiver úmido, as raízes não necessitarão procurar o 
ponto da fonte de água.

Warrick \& Shani (1996), consideraram o limite de fuxo no solo para emissores de SDI e sugeriram o uso de baixas vazões e mais emissores na linha lateral, e pressão compensada para a maioria dos solos especialmente heterogêneos.

ElGindy \& El-Araby (1996), obtiveram maior rendimento para tomate e pepino com SDI na freqüência diária quando comparado com aplicações a cada três dias em solos calcários no Egito. Da mesma forma Bucks et al., (1981) encontraram melhores respostas com aplicação de lâminas diárias do que semanais na cultura da cebola, contudo, para o meloeiro, aplicações semanais foram melhores que diárias.

\subsubsection{Modelos de fluxo de água no solo por SDI}

Existem alguns modelos matemáticos específicos, entretanto não estão bem compreendidos e precisam ser testados e avaliados para diferentes condições do ambiente.

Um modelo unidimensional e dinâmico de simulação para automatização de um sistema de SDI foi desenvolvido por Van Bavel et al., (1973).

Gilley \& Allred (1974 a) e Gilley \& Allred (1974 b), combinaram uma solução analítica com um modelo de extração pelas plantas para determinar a profundidade das linhas laterais e espaçamentos predeterminados.

Dirksem (1978) descreveu um fluxo estacionário e transiente para 4 linhas igualmente espaçadas com pressão constante e valores prefixados, comparados com aqueles medidos em uma calha de solo usando a atenuação de raios gama.

Warrick et al., (1980) relataram um modelo matemático para descrever a umidade linearizada em fluxo em 3 dimensões, com a extração das raízes sob condições estacionárias (constante) para várias fontes de SDI.

Bem-Asher \& Phene (1993), apresentaram um modelo numérico para análise bi dimensional do fluxo da água na irrigação por gotejamento superficial e no sistema de SDI: os autores sugerem que pode ser usado como uma primeira aproximação em projeto, especialmente para determinar a profundidade da linha lateral e o espaçamento 
entre emissores.

\subsection{Evapotranspiração no interior do ambiente protegido}

Van der Post et al., (1974); Montero et al., (1985); Prados, (1986); Rosenberg et al., (1989) afirmam que a evapotranspiração no interior da estufa em geral, é menor do que a verificada externamente, o que se atribui, basicamente, à parcial opacidade da cobertura plástica à radiação solar e à redução da ação dos ventos, que são os principais fatores da demanda evaporativa da atmosfera. A diferença entra a evapotranspiração interna e externa varia de acordo com as condições meteorológicas, resultando ser em geral a evapotranspiração no interior da estufa em torno de 60-80 \% da verificada no exterior.

Bouças et al., (1994) verificaram que a ETo no interior de estufas plásticas foi sempre menor do que no ambiente exterior, ficando entre $45 \%$ e $77 \%$ da verificada na parte externa, manifestam também que as estimativas de ETo interna, a partir do tanque reduzido, apresentaram elevadas correlações com as obtidas pelo tanque Classe A ( $\mathrm{r}$ de 0,84 a 0,90 ), e que os maiores valores de ETo foram obtidos pelo método de Penman e os menores pelo tanque Classe A.

Prados (1986), trabalhando com tomateiro em estufas com cobertura de polietileno de baixa densidade (PEBD), concluiu que o método do tanque evaporimétrico com coeficientes de tanque iguais a 1,0, juntamente com os métodos da radiação solar (FAO) e de Priestley-Taylor, são os melhores para estimar a evapotranspiração de referencia no interior da estufa. Comparando os valores de evaporação em tanque Classe A, ocorridos no interior e no exterior da estufa, obteve correlação de 0,38 e 0,86, para períodos semanais de baixa e alta demanda evaporativa, respectivamente, 0,96 para períodos de duas semanas.

Segundo Guttormsen (1974), a evaporação normalmente decresce com o aumento da superfície de água, devido a fatores aerodinâmicos e às diferenças na transferência de energia entre a superfície de água e a atmosfera.

Marcon et al., (1997) manifesta que consumo de água pelas plantas depende 
fundamentalmente da qualidade de água disponível no solo e da demanda atmosférica. A demanda atmosférica é condicionada principalmente pela radiação solar, velocidade do vento, emperatura e déficit de saturação do ar. Todos estes elementos sofrem alterações no interior das estufas, resultando em diferença de consumo de água em relação ao ambiente protegido.

No interior da estufa o consumo de água é menor, principalmente pela atenuação que ocorre na densidade de fluxo da radiação solar incidente e da menor velocidade de renovação do ar junto às plantas (Robledo \& Martin, 1981; Reisser, 1991; Buriol et al., 1995).

Caron et al., (2000) trabalhando com melão híbrido Galia em estufa plástica, mediante balanço hídrico simplificado do solo, obtiverem coeficiente de cultura pelo razão entre o consumo de água e a evaporação de referencia, calculadas a partir de métodos de Penman e Penman-Monteith, de 0,34 no subperíodo vegetativo, compreendido desde o transplante até o inicio do florescimento, de 0,70 no período compreendido entre a abertura da primeira flor feminina e a colheita do primeiro fruto e de 0,76 durante a colheita. 


\section{MATERIAL E MÉTODOS}

\subsection{Caracterização da área experimental}

O experimento foi conduzido no campo experimental do Departamento de Engenharia Rural da Escola Superior de Agricultura "Luiz de Queiroz", ESALQ - USP, em uma área protegida de 420,0 $\mathrm{m}^{2}$ (28,0 m x 15,0 m), localizada no município de

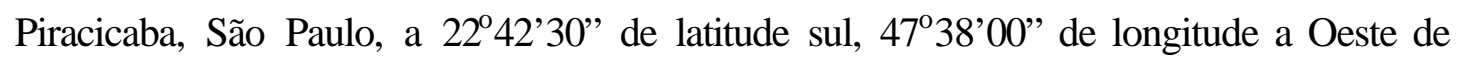
Greenwinch e $576 \mathrm{~m}$ de altitude.

O clima, segundo classificação de Köppen, é do tipo Cwa, ou seja, clima subtropical úmido com estiagem no inverno, com precipitação pluviométrica média de $1.247 \mathrm{~mm}$, temperatura de $21,1{ }^{\circ} \mathrm{C}$, umidade relativa média de $74 \%$ e velocidade do vento de 2,2 $\mathrm{m} \mathrm{s}^{-1}$. O solo é classificado como Argissolo Vermelho (Alfisol), fase argilosa, denominada de "Série Luiz de Queiroz", com uma declividade média de 1,0\%.

O experimento foi desenvolvido no período de 16 de setembro de 2001 a 17 de janeiro de 2002, em um ambiente protegido geminado de dois vãos totalizando 15,0 m de largura e 28,0 m de comprimento, com estrutura metálica galvanizada, altura na parte central de 4,6 m e pé direito de 3,0 m, constituído de 4 janelas frontais, cobertas com um filme de polietileno transparente de alta densidade (PEAD), com aditivo ultravioleta e espessura de $150 \mu \mathrm{m}$. As laterais da estufa foram fechadas com tela plástica de proteção tipo clarite $50 \%$, com tratamento ultravioleta, transparente e revestida de cortinas para regular as temperaturas e fluxo de ar (Figura 1a, b).

Os dados climáticos referentes ao período de setembro de 2001 a janeiro de 2002 (Tabela 1) foram obtidos na estação meteorológica do Departamento de Ciências Exatas da ESALQ/USP localizada a cerca de $500 \mathrm{~m}$ de distância da área experimental. 


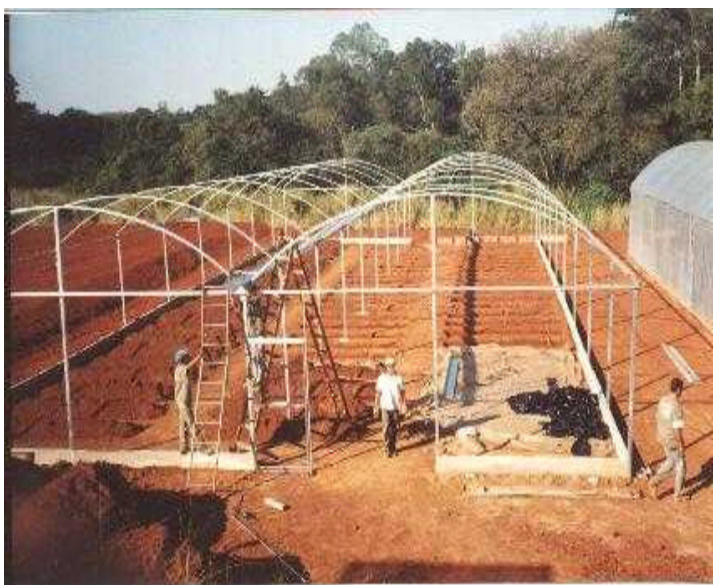

(a)

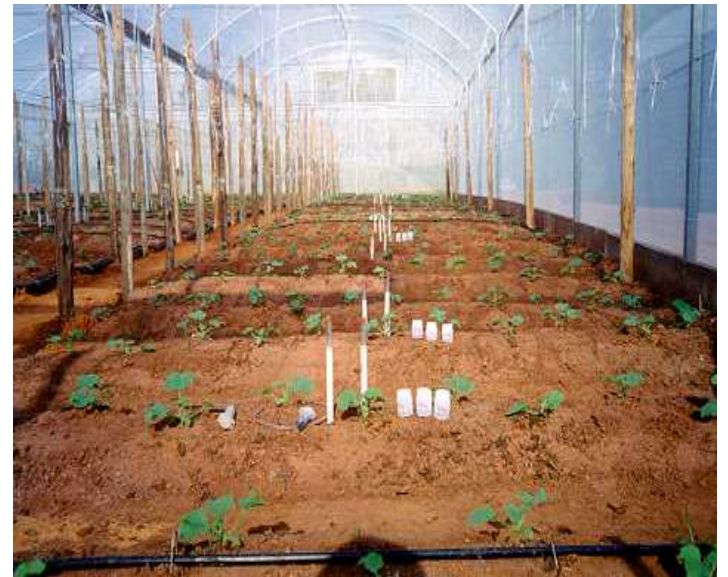

(b)

Figura 1 - Ambiente protegido geminado: a) etapa de construção; b) disposição dos tratamentos no seu interior, com as plantas na fase de formação.

A água utilizada para irrigação foi proveniente do sistema de abastecimento de água potável da ESALQ/USP, cujas características de qualidade encontram-se descritas na Tabela 2. As amostras de água foram coletadas após o sistema de filtragem da estação de controle do sistema de irrigação. De modo geral, os resultados dessa análise não indicaram limitações à irrigação do meloeiro quando comparados com as recomendações FAO: Irrigação e Drenagem, 29 (Ayers, 1999).

Tabela 1. Valores médios mensais de radiação global (RG), temperatura (T), umidade relativa (UR), número de horas de insolação, precipitação pluviométrica $(\mathrm{P})$ e velocidade do vento $\left(\mathrm{U}_{2}\right)$ registrados no período do experimento

\begin{tabular}{lcccccc}
\hline \multicolumn{1}{c}{ Meses } & $\begin{array}{c}\mathrm{RG} \\
\mathrm{cal} \mathrm{cm}{ }^{-2} \mathrm{~d}^{-1}\end{array}$ & $\begin{array}{c}\mathrm{T} \\
{ }^{\circ} \mathrm{C}\end{array}$ & $\begin{array}{c}\mathrm{UR} \\
\%\end{array}$ & $\begin{array}{c}\text { Insolação } \\
\mathrm{h} \mathrm{dia}^{-1}\end{array}$ & $\begin{array}{c}\mathrm{P} \\
\mathrm{mm}\end{array}$ & $\begin{array}{c}\mathrm{U}_{2} \\
\mathrm{~m} \mathrm{~s}^{-1}\end{array}$ \\
\hline Setembro & 299,0 & 20,8 & 77,3 & 7,2 & 515,7 & 1,5 \\
Outubro & 636,1 & 22,1 & 79,0 & 7,9 & 153,7 & 1,3 \\
Novembro & 613,2 & 23,6 & 81,9 & 6,7 & 138,7 & 1,4 \\
Dezembro & 596,2 & 23,0 & 87,0 & 5,4 & 196,8 & 1,3 \\
Janeiro & 555,2 & 23,1 & 91,0 & 4,8 & 275,1 & 1,0 \\
\hline
\end{tabular}


Tabela 2. Resultados da análise química da água utilizada para irrigação

\begin{tabular}{lcc}
\hline \multicolumn{1}{c}{ Parâmetros } & Unidade & Resultados \\
\hline Alcalinidade $\left(\mathrm{CO}_{3}{ }^{2-}+\mathrm{HCO}^{3-}\right)$ & $\mathrm{mg} \mathrm{L}^{-1}$ & 36,4 \\
Cloreto $(\mathrm{Cr})$ & $\mathrm{mg} \mathrm{L}^{-1}$ & 8,1 \\
Nitrato $\left({\left.\mathrm{N}-\mathrm{NO}_{3}\right)}\right)$ & $\mathrm{mg} \mathrm{L}^{-1}$ & 4,1 \\
Sulfato $\left(\mathrm{SO}_{4}{ }^{2-}\right)$ & $\mathrm{mg} \mathrm{L}^{-1}$ & 48,1 \\
Fósforo $(\mathrm{P})$ & $\mathrm{mg} \mathrm{L}^{-1}$ & 0,2 \\
Nitrogênio amônio $\left(\mathrm{N}-\mathrm{NH}_{3}\right)$ & $\mathrm{mg} \mathrm{L}^{-1}$ & 0,3 \\
Sódio $\left(\mathrm{Na}^{+}\right)$ & $\mathrm{mg} \mathrm{L}^{-1}$ & 8,9 \\
Potássio $\left(\mathrm{K}^{+}\right)$ & $\mathrm{mg} \mathrm{L}^{-1}$ & 3,4 \\
Cálcio $(\mathrm{Ca}$ & $2+$ \\
Magnésio $\left(\mathrm{Mg}^{2+}\right)$ & $\mathrm{mg} \mathrm{L}^{-1}$ & 12,7 \\
Ferro $(\mathrm{Fe})$ & $\mathrm{mg} \mathrm{L}^{-1}$ & 7,3 \\
Cobre $(\mathrm{Cu})$ & $\mathrm{mg} \mathrm{L}^{-1}$ & 0,02 \\
Manganês $(\mathrm{Mn})$ & $\mathrm{mg} \mathrm{L}^{-1}$ & 0,04 \\
Zinco $(\mathrm{Zn})$ & $\mathrm{mg} \mathrm{L}^{-1}$ & 0,05 \\
Condutividade elétrica $(\mathrm{CE})$ & $\mathrm{mg} \mathrm{L}^{-1}$ & 0,03 \\
pH & $\mathrm{mS} \mathrm{cm}^{-1}$ & 0,16 \\
Acidez & --- & 7,2 \\
Dureza $(\mathrm{CaCO}$ & 4,0 \\
\hline
\end{tabular}

\subsection{Delineamento experimental}

$\mathrm{O}$ experimento foi conduzido no delineamento experimental em blocos casualizados com arranjo fatorial de $4 \times 3 \times 2$. Os tratamentos foram quatro doses de potássio aplicado via fertirrigação, três níveis de irrigação e duas profundidades de instalação dos tubogotejadores.

As doses de potássio definidas a partir das recomendações médias de fertirrigação (Pinto et al., 1986; Bar-Yosef, 1999) e quantidades extremas para testar sua aplicação foram: (K0) - dose de potássio equivalente a $0 \mathrm{~g}$ de $\mathrm{K}_{2} \mathrm{O} \mathrm{pl}^{-1}$; (K1) - dose de 
potássio equivalente a $6 \mathrm{~g}$ de $\mathrm{K}_{2} \mathrm{O} \mathrm{pl}{ }^{-1}$; (K2) - dose de potássio equivalente a 9 g de $\mathrm{K}_{2} \mathrm{O}$

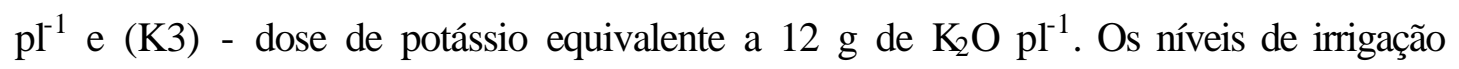
determinados em função da evaporação do tanque Classe A modificado (Evp) localizado no interior do ambiente protegido, foram: (L1) - nível de irrigação equivalente a 0,33 de Evp; (L2) - nível de irrigação equivalente a 0,67 de Evp e (L3) - nível de irrigação equivalente a 1,0 de Evp. As profundidades de instalação dos tubogotejadores foram: (P1) - superficial, 0,0 m e (P2) - subsuperficial, 0,2 m.

As combinações dos fatores resultaram em 24 tratamentos em cada bloco, constituindo cada um deles uma parcela experimental. A Tabela 3 mostra o esquema da análise de variância associado ao delineamento experimental, e a Figura 2 mostra o croqui do experimento e detalhe da parcela experimental.

Tabela 3. Esquema da análise de variância, com desdobramento dos graus de liberdade dos tratamentos, de acordo com o esquema fatorial $4 \times 3 \times 2$

\begin{tabular}{lll}
\hline & C.V & \\
\hline Repetição & $\mathrm{r}-1$ \\
Fator K & $\mathrm{k}-1$ \\
Fator L & $1-1$ \\
Fator KL & $(\mathrm{k}-1)(\mathrm{l}-1)$ \\
Fator P & $(\mathrm{p}-1)$ \\
KP & $(\mathrm{k}-1)(\mathrm{p}-1)$ \\
LP & $(\mathrm{l}-1)(\mathrm{p}-1)$ \\
KLP & $(\mathrm{k}-1)(1-1)(\mathrm{p}-1)$ \\
Resíduos & $(\mathrm{r}-1)(\mathrm{klp}-1)$ \\
Total & \\
\hline
\end{tabular}

Cada parcela experimental teve $3,6 \mathrm{~m}$ de comprimento e 0,6 $\mathrm{m}$ de largura, compreendendo $2,16 \mathrm{~m}^{2}$ de área, distanciadas de $0,5 \mathrm{~m}$, com duas fileiras de plantas, espaçadas de 0,6 m entre plantas e 0,20 m entre fileiras, em esquema alternado, com nove plantas úteis. 


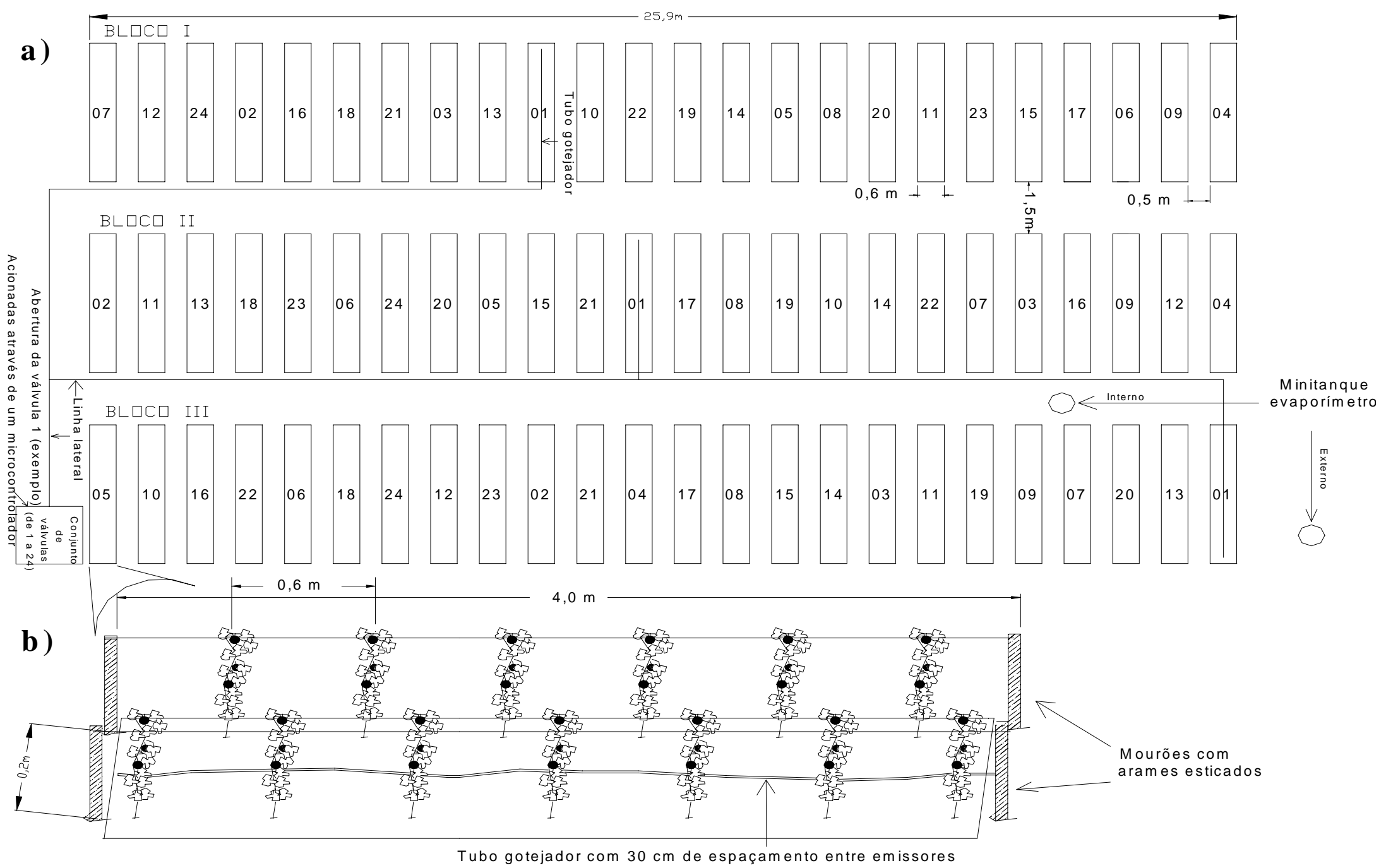

Figura 2 - Croqui do experimento (a) e detalhe da parcela experimental (b). 


\subsection{Construção dos canteiros, correção e adubação do solo}

Após a sistematização da área foram construídos canteiros representados por covas nas dimensões de 3,6 $\mathrm{m}$ de comprimento, 0,6 $\mathrm{m}$ de largura e 0,20 $\mathrm{m}$ de profundidade, espaçadas a cada $0,5 \mathrm{~m}$, coberto nas laterais com polietileno inerte para prevenir a passagem de água e solutos para os outros tratamentos (Figura 3).

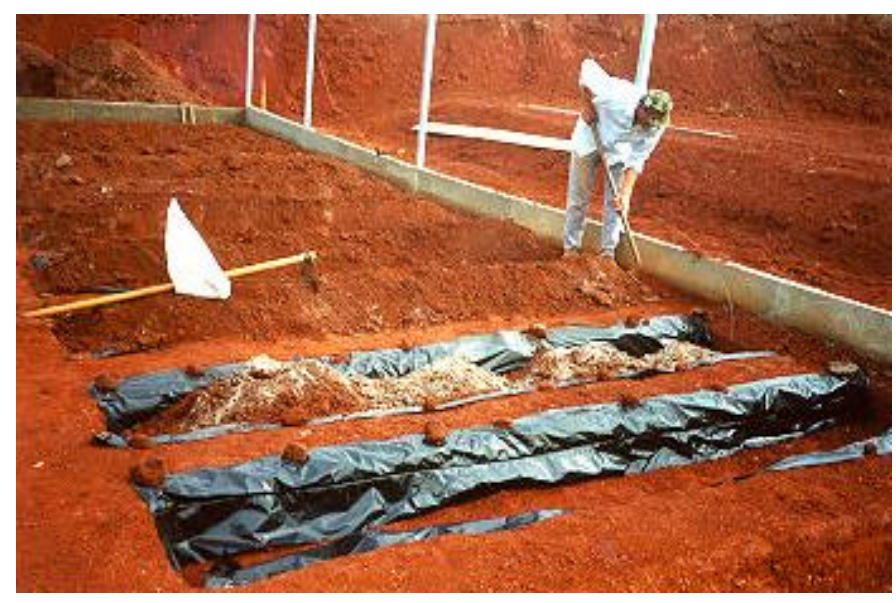

Figura 3 - Construção de canteiros representados por covas, cobertos nas laterais com polietileno inerte.

Depois as covas foram preenchidas com solo classificado como Latossolo Vermelho Amarelo, fase arenosa, localizado no Campus da ESALQ - USP denominado "Série Sertãozinho" até uma altura de 0,20 m acima da superfície do solo do ambiente protegido, totalizando um volume de solo explorado pelas raízes das plantas de $0,86 \mathrm{~m}^{3}$ $(0,6 \mathrm{~m} \times 3,6 \mathrm{~m} \times 0,4 \mathrm{~m})$.

Foram retiradas amostras de solo na camada de $00,20 \mathrm{~m}$ para a análise química (Tabelas 4 e 5) e física (Tabela 6). Para construção das curvas de retenção de água no solo foram retiradas amostras de solo às profundidades de $0,15 \mathrm{~m}, 0,20 \mathrm{~m}$ e $0,30 \mathrm{~m}$ (Figura 4). 
Tabela 4. Análise química do solo utilizado para preenchimento das covas: $\mathrm{pH}$, matéria orgânica (M.O.), macronutrientes (P, K, Ca, Mg), alumínio trocável (Al), acidez total $(\mathrm{H}+\mathrm{Al})$, soma de bases $(\mathrm{SB})$, capacidade de troca de cátions $(\mathrm{T})$, saturação por bases (V) e saturação por alumínio (m)

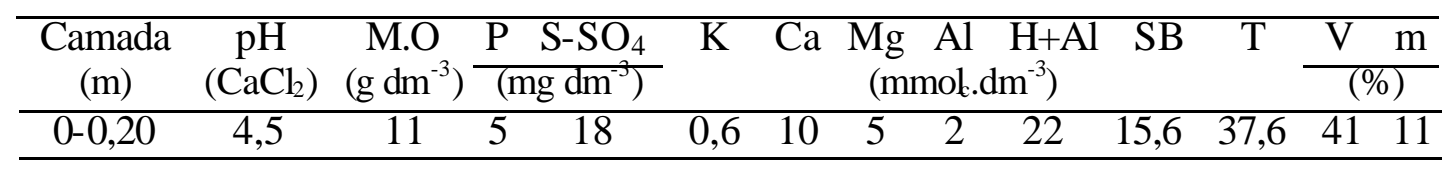

Tabela 5. Análise química do solo utilizado para preenchimento das covas, micronutrientes: Boro (B), Cobre $(\mathrm{Cu})$, Ferro $(\mathrm{Fe})$, Manganês $(\mathrm{Mn})$ e Zinco ( $\mathrm{Zn})$

\begin{tabular}{cccccc}
\hline $\begin{array}{c}\text { Camada } \\
(\mathrm{m})\end{array}$ & $\mathrm{B}$ & $\mathrm{Cu}$ & $\begin{array}{c}\mathrm{Fe} \\
\left(\mathrm{mg} \mathrm{dm}^{-3}\right)\end{array}$ & $\mathrm{Mn}$ & $\mathrm{Zn}$ \\
\hline $0-0,20$ & - & 0,7 & 15 & 8,4 & 0,7 \\
\hline
\end{tabular}

Tabela 6. Análise física do solo da serie "Sertãozinho" utilizado para preenchimento das covas: capacidade de campo (CC), ponto de murcha permanente (PMP), densidade global (Ds), argila, silte areia, floculação e classificação textural

\begin{tabular}{ccccccccc}
\hline $\begin{array}{c}\text { Camada } \\
(\mathrm{m})\end{array}$ & $\begin{array}{c}\mathrm{CC} \\
\mathrm{cm}^{3} \mathrm{~cm}^{-3}\end{array}$ & $\begin{array}{c}\text { PMP } \\
\mathrm{Kg} \mathrm{dm}^{-3}\end{array}$ & $\begin{array}{c}\text { Argila } \\
\text { (S.lte } \\
\text { g.kg }\end{array}$ & $\begin{array}{c}\text { Areia } \\
\begin{array}{c}\text { Flocul. } \\
\%\end{array}\end{array}$ & $\begin{array}{c}\text { Classe } \\
\text { textural }\end{array}$ \\
\hline $0-0,20$ & 0,194 & 0,125 & 1,4 & 280 & 80 & 640 & 100 & fr-are. \\
\hline
\end{tabular}

De acordo com o resultado da análise química do solo (Tabelas 4 e 5), foi aplicado e incorporado para o volume de solo da cova 7,12 t ha ${ }^{-1}$ de calcário dolomítico (39\% de $\mathrm{CaO}, 13 \%$ de $\mathrm{MgO}$ e PRNT de 67\%) 60 dias antes do transplantio das mudas, para elevação da saturação por bases a 80\% (Raij et al., 1996). A adubação de fundação foi feita por cova com $12 \mathrm{~kg}$ de esterco bovino curtido (Kiehl, 1985) e 0,052 $\mathrm{kg}$ de $\mathrm{P}_{2} \mathrm{O}_{5}$, na forma de termofosfatado $\left(17,5 \%\right.$ de $\mathrm{P}_{2} \mathrm{O}_{5}, 0,10 \%$ de $\mathrm{B}$ e $0,55 \%$ de $\left.\mathrm{Zn}\right)$. 


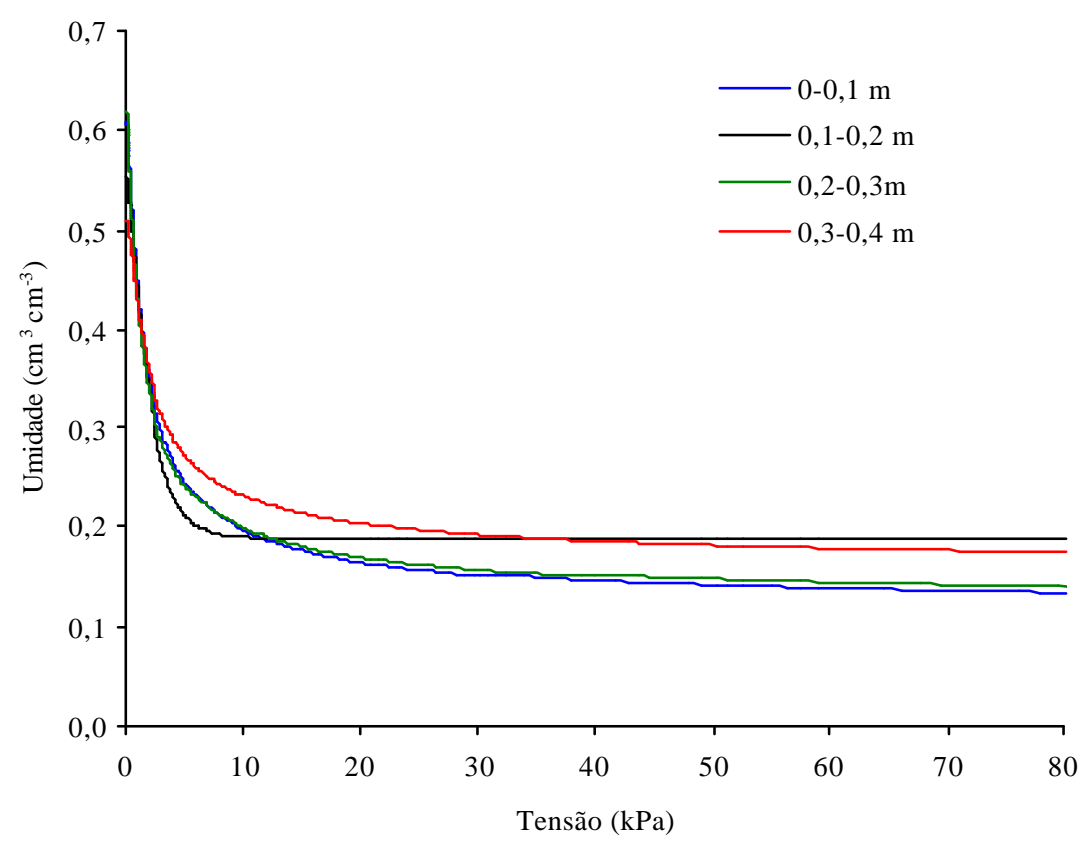

Figura 4 - Curvas de retenção de água no solo prevista pelo modelo de van Genuchten, para $0,15 \mathrm{~m}, 0,30 \mathrm{~m}$ e $0,40 \mathrm{~m}$ de profundidade.

\subsection{Transplantio das mudas}

Foram utilizadas sementes de melão rendilhado (Cucumis melo, L), híbrido Bônus In 2, as quais foram semeadas em tubos de polietileno com 0,04 m de diâmetro e $0,12 \mathrm{~m}$ de comprimento que continham substrato comercial organo-mineral.

Durante a fase de germinação e emissão das duas primeiras folhas, compreendendo um período de 4 a 10 dias, permaneceram em um sombrite, cuja umidade interna foi controlada com auxilio de irrigação, evitando-se seu ressecamento. Após esse período as mudas foram transportadas para uma área exposta ao sol, onde permaneceram durante 7 dias, passando assim para uma fase de adaptação para as condições do ambiente protegido. O plantio foi realizado em 5 de outubro de 2001, 19 dias após a semeadura (DAS), quando as plantas apresentavam duas folhas definitivas (Figura 5). 


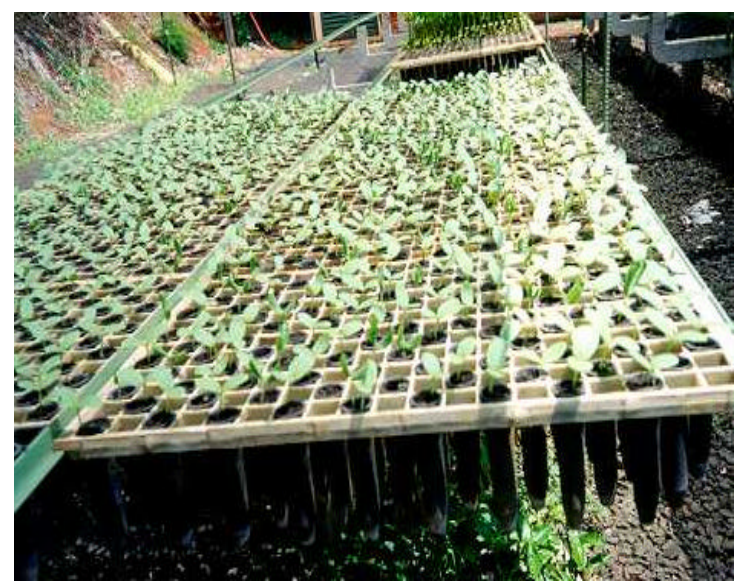

(a)

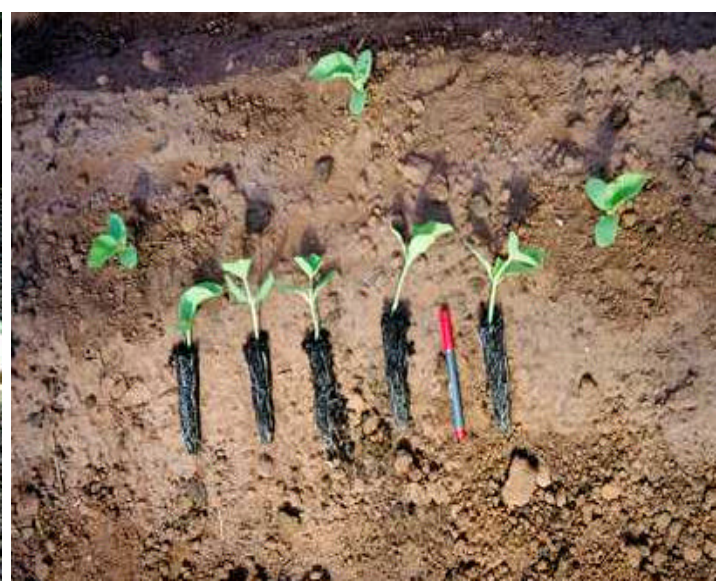

(b)

Figura 5 - Mudas do híbrido de melão Bônus $\mathrm{n}^{0}$ 2: a) confeccionadas em tubos de polietileno; b) condição no momento do transplantio com duas folhas definitivas.

\subsection{Sistema de irrigação}

Foi utilizado um sistema de irrigação por gotejamento, cuja rede hidráulica consistiu de 24 trechos de polietileno com $16 \mathrm{~mm}$ de diâmetro nominal, pressões nominais entre $100-200 \mathrm{kPa}$, comprimento total entre 39,6 m e 97,5 m, e volume total entre $0,032 \mathrm{~m}^{3}$ e $0,078 \mathrm{~m}^{3}$, os quais são apresentados na Tabela 7.

Os gotejadores na linha lateral foram autocompensantes com mecanismo diferencial de pressão, espessura da parede 1,2 mm, diâmetro interno de 14,6 mm e diâmetro externo de $17 \mathrm{~mm}$, vazão $1,6 \mathrm{~L} \mathrm{~h}^{1}$, pressão de trabalho entre 50 a $400 \mathrm{kPa}$, espaçados de $0,30 \mathrm{~m}$ e dispostos no centro das duas fileiras de plantas.

O cabeçal de controle constou de microcontrolador basic step, bomba hidráulica de $0,5 \mathrm{Hp}$, regulador de pressão, filtro de disco, registros, hidrômetro, manômetro e válvulas solenóides (Figura 6). 
Tabela 7. Comprimento $(\mathrm{m})$ e volume interno $\left(\mathrm{m}^{3}\right)$ da tubulação de cada trecho da rede hidráulica

\begin{tabular}{cccccccccc}
\hline \multirow{2}{*}{$\mathrm{N}^{\mathrm{o}}$} & \multirow{2}{*}{ Tratamento } & \multicolumn{2}{c}{ Comprimento/Bloco $(\mathrm{m})$} & \multicolumn{2}{c}{ Total } & \multicolumn{3}{c}{ Volume/Bloco $\left(\mathrm{m}^{3}\right)$} & Total \\
& & $\mathrm{I}$ & $\mathrm{II}$ & $\mathrm{III}$ & $\mathrm{m})$ & $\mathrm{I}$ & $\mathrm{II}$ & $\mathrm{III}$ & $\left(\mathrm{m}^{3}\right)$ \\
\hline 1 & KOL1P1 & 34,0 & 19,3 & 22,2 & 75,5 & 0,027 & 0,016 & 0,018 & 0,061 \\
2 & KOL1P2 & 16,8 & 7,2 & 15,6 & 39,6 & 0,014 & 0,006 & 0,013 & 0,032 \\
3 & K0L2P1 & 26,3 & 28,1 & 20,0 & 74,4 & 0,021 & 0,023 & 0,016 & 0,060 \\
4 & K0L2P2 & 20,8 & 32,5 & 37,6 & 90,9 & 0,017 & 0,026 & 0,030 & 0,073 \\
5 & K0L3P1 & 8,7 & 16,0 & 27,7 & 52,4 & 0,007 & 0,013 & 0,022 & 0,042 \\
6 & K0L3P2 & 13,1 & 12,7 & 35,4 & 61,2 & 0,011 & 0,010 & 0,028 & 0,049 \\
7 & K1L1P1 & 30,7 & 27,0 & 12,3 & 70,0 & 0,025 & 0,022 & 0,010 & 0,056 \\
8 & K1L1P2 & 23,0 & 21,5 & 28,8 & 73,3 & 0,018 & 0,017 & 0,023 & 0,059 \\
9 & K1L2P1 & 29,6 & 31,4 & 36,5 & 97,5 & 0,024 & 0,025 & 0,029 & 0,078 \\
10 & K1L2P2 & 9,8 & 23,7 & 23,3 & 56,8 & 0,008 & 0,019 & 0,019 & 0,046 \\
11 & K1L3P1 & 27,4 & 8,3 & 31,0 & 66,7 & 0,022 & 0,007 & 0,025 & 0,054 \\
12 & K1L3P2 & 16,4 & 31,4 & 13,4 & 61,2 & 0,013 & 0,025 & 0,011 & 0,049 \\
13 & K2L1P1 & 32,9 & 9,4 & 21,1 & 63,4 & 0,026 & 0,008 & 0,017 & 0,051 \\
14 & K2L1P2 & 25,2 & 24,8 & 26,6 & 76,6 & 0,020 & 0,020 & 0,021 & 0,062 \\
15 & K2L2P1 & 24,1 & 17,1 & 33,2 & 74,4 & 0,019 & 0,014 & 0,027 & 0,060 \\
16 & K2L2P2 & 10,9 & 29,2 & 16,7 & 56,8 & 0,009 & 0,023 & 0,013 & 0,046 \\
17 & K2L3P1 & 21,9 & 20,4 & 34,3 & 76,6 & 0,018 & 0,016 & 0,028 & 0,062 \\
18 & K2L3P2 & 14,2 & 10,5 & 17,8 & 42,5 & 0,011 & 0,008 & 0,014 & 0,034 \\
19 & K3L1P1 & 28,5 & 22,6 & 25,5 & 76,6 & 0,023 & 0,018 & 0,021 & 0,062 \\
20 & K3L1P2 & 31,8 & 14,9 & 29,9 & 76,6 & 0,026 & 0,012 & 0,024 & 0,062 \\
21 & K3L2P1 & 19,7 & 18,2 & 18,9 & 56,8 & 0,016 & 0,015 & 0,015 & 0,046 \\
22 & K3L2P2 & 12,0 & 25,9 & 24,4 & 62,3 & 0,010 & 0,021 & 0,020 & 0,050 \\
23 & K3L3P1 & 17,5 & 11,6 & 32,1 & 61,2 & 0,014 & 0,009 & 0,026 & 0,049 \\
24 & K3L3P2 & 15,3 & 13,8 & 14,5 & 43,6 & 0,012 & 0,011 & 0,012 & 0,035 \\
\hline
\end{tabular}




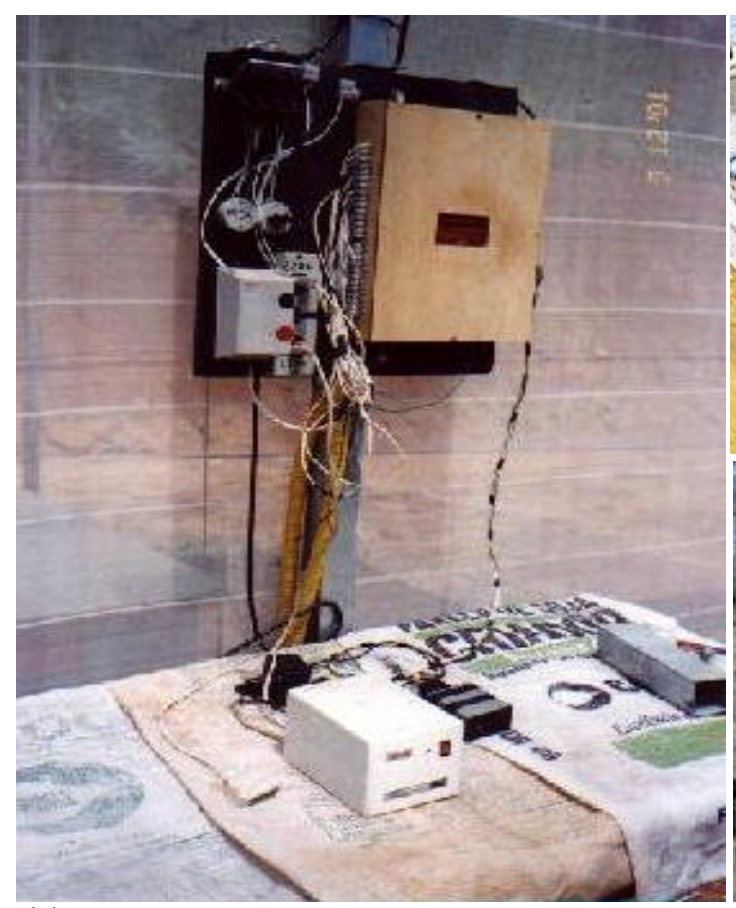

(a)

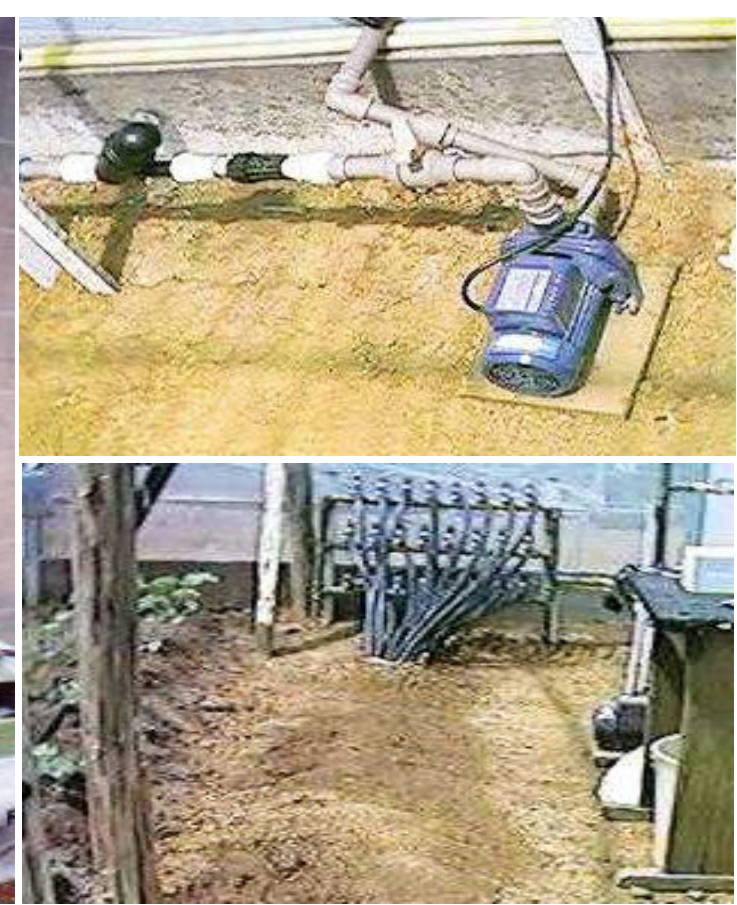

(b)

Figura 6 - Cabeçal de controle: a) microcontrolador basic step; b) bomba hidráulica, regulador de pressão, filtro de disco, registros, hidrômetro, manômetro e válvulas solenóides.

\subsubsection{Manejo da irrigação}

O manejo da irrigação foi realizado com um mini tanque, com dimensões de 0,60 $\mathrm{m}$ de diâmetro e $0,25 \mathrm{~m}$ de altura instalado no terço médio dentro do ambiente protegido, entre os blocos I e II, permanecendo ate 30 dias após o transplantio das mudas (DAT) sob suporte de madeira a $0,2 \mathrm{~m}$ da superfície do solo, logo após este período foi levantado ate uma altura de $0,60 \mathrm{~m}$ da superfície do solo devido ao sombreamento que exerciam as plantas de melão em seu entorno, permaneceu nesta posição até final do ciclo da cultura. As leituras de evaporação do mini tanque (Evp) foram medidas diariamente às 8 horas durante tudo o período do experimento as quais definiram os níveis de irrigação estudados: (L1: 0,33 Evp; L2: 0.67 Evp; L3: 1 Evp). 


\subsubsection{Controle da irrigação}

A aplicação das diferentes lâminas diárias deutse por meio de um controlador de irrigação desenvolvido especialmente para esta finalidade. Constituiu-se de um microcontrolador e de um periférico, que operando conjuntamente, acionaram válvulas do tipo solenóide, possibilitando o fluxo líquido para atender a irrigação de cada um dos tratamentos.

O microcontrolador empregado foi Basic Step - $2 \mathrm{~K}$, fabricado pela Tato Equipamentos Eletrônicos Ltda. Este equipamento possui 15 pinos (I/Oport), que podem ser configurados, de acordo com a programação, como entradas ou saídas de sinais digitais. O programa implementado na memória permanente do microcontrolador foi desenvolvido em um programa emulador (Bascom), o qual foi instalado num computador padrão IBM PC.

O envio do programa para o microcontrolador foi feito por intermédio de um cabo de comunicação especial conectado à impressora. Como o número de saídas do microcontrolador é insuficiente para a irrigação dos 24 tratamentos, desenvolveu-se um periférico, constituído basicamente de multiplexadores (encoders) e relês, cuja finalidade foi ampliar o número de saídas do microcontrolador, permitindo o acionamento individual de cada uma das válvulas solenóides, além de manter o conjunto motobomba em operação. Realizoutse o controle do fluxo hidráulico para os diferentes tratamentos por meio de válvulas solenóides modelo EVP-02, do tipo normalmente fechado, fabricado pela Emicol Eletro-Eletrônca S/A.

A operação do controlador, a cada irrigação, deu-se da seguinte maneira: após o estabelecimento das lâminas de irrigação e dos correspondentes tempos de operação de cada válvula, estes eram alterados, empregando-se o programa emulador instalado no computador. Esta versão do programa, contento os novos tempos de operação a serem implementados, era então, transmitida para memória do microcontrolador que, quando acoplado ao periférico e ligado, realizava a irrigação seqüencial da primeira para a última válvula. 


\subsubsection{Coeficiente de uniformidade}

A coleta de dados para análise da uniformidade de aplicação de vazão dos gotejadores foi conduzida de acordo com a metodologia proposta por Keller e Karmeli (1974), descrita por Bernardo (1987), os quais recomendam a utilização de linhas e gotejadores localizados na posição inicial, a $1 / 3$ e a $2 / 3$ da posição inicial e na posição final. Considerando 24 linhas no experimento, foram coletados valores de volumes de 8 gotejadores de cada bloco por tratamento, para análise e desempenho do sistema de irrigação.

O coeficiente de uniformidade foi determinado por meio da equação de Christiansen (1972), apresentada a seguir:

$$
\mathrm{CUC}=100\left(1-\frac{\sum_{\mathrm{i}=1}^{\mathrm{n}}|\mathrm{qi}-\mathrm{q}|}{\mathrm{nq}}\right)
$$

em que:

CUC - coeficiente de uniformidade de Christiansen, \%;

qi - vazão do i-ésimo gotejador, $\mathrm{L} \cdot \mathrm{h}^{-1}$;

q - vazão média dos gotejadores, $L . h^{-1}$;

$\mathrm{n}$ - número de gotejadores.

\subsubsection{Tempos de irrigação}

Os tempos de irrigação correspondentes a cada lâmina de irrigação estabelecida pela Evp, localizado no interior do ambiente protegido, para cada um dos tratamentos, foram determinada pela equação (2). 


$$
\mathrm{Ti}=\frac{\operatorname{Lr} 60 \mathrm{Ac} \mathrm{Amf} \% \mathrm{Ei} \%}{\operatorname{Qp} 10000}
$$

em que:

Ti - tempo de irrigação por cada tratamento, min;

$\mathrm{Lr}$ - lâmina real de irrigação, mm;

Ac - área do canteiro, $\mathrm{m}^{2}$;

Amf - percentagem da área molhada dentro das duas fileiras de plantas para a lâmina máxima de irrigação (\%);

Ei - eficiência de irrigação (\%);

Qp. - vazão total do tubogotejador, $\mathrm{L} \mathrm{h}^{-1}$.

A lâmina real de irrigação $(\mathrm{Lr})$ refere-se à quantidade de água de irrigação aplicada (mm), multiplicada pelas percentagens fixadas para cada tratamentos, segundo a equação 3.

$$
\operatorname{Lr}=\operatorname{Evp} \operatorname{Le}
$$

em que:

Evp - evaporação do mini tanque, mm;

Le - percentagem da Evp, segundo os tratamentos.

\subsubsection{Variação do armazenamento de água}

O monitoramento da umidade e da dinâmica de água no solo foi feito com 3 tensiômetros instalados em torno de uma planta para cada nível de irrigação por bloco, distantes da planta de $0,10 \mathrm{~m}, 0,15 \mathrm{~m}$ e $0,20 \mathrm{~m}$ e nas profundidades de $0,40 \mathrm{~m}, 0,30 \mathrm{~m}$ e $0,15 \mathrm{~m}$, respectivamente (Figura 7). As leituras nos tensiômetros foram realizadas 
diariamente entre as 8 e 9 horas, utilizando tensímetro digital de punção.
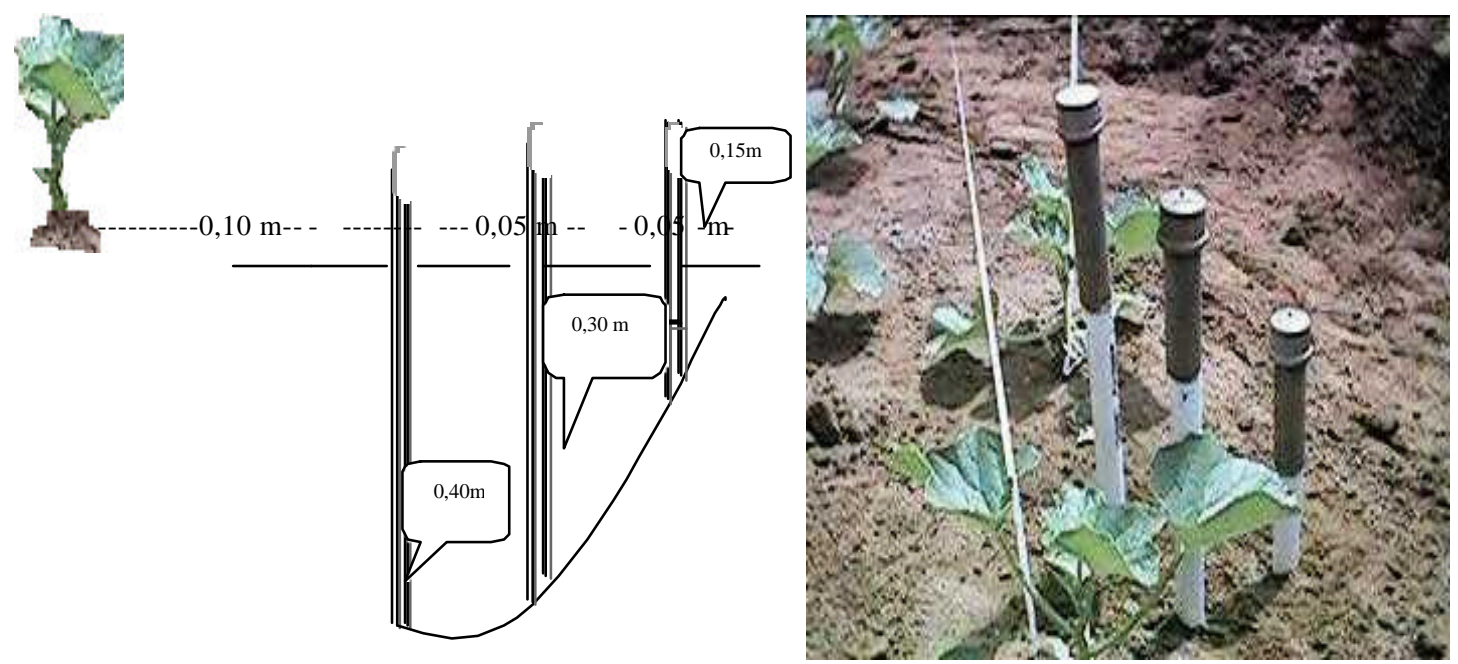

(a)

(b)

Figura 7 - Tensiômetros instalados em torno da planta: a) esquema de instalação; b) disposição nos tratamentos.

Os valores das leituras foram convertidos em potencial matricial de água no solo ( $\Psi \mathrm{m})$, utilizando a Equação 4 e posteriormente, com os parâmetros do modelo descrito por van Genuchten (1980) (Equação 5), obtidos por meio das curvas de retenção de água no solo (Figura 4), cujos parâmetros são descritos na Tabela 8, determinou-se os respectivos teores de umidade nas camadas.

$$
\Psi \mathrm{m}=\mathrm{Lt}+\mathrm{hc}
$$

em que:

Øm - potencial de água no solo, cmca;

L t - leitura no tensiômetro, cmca;

hc - pressão equivalente a altura da coluna de água no tensiômetro, cmca. 


$$
\theta=\theta_{r}+\frac{\theta_{s}-\theta_{r}}{\left[1+\left(\Psi_{m} \alpha\right)^{n}\right]^{m}}
$$

em que:

$\theta$ - umidade a base de volume, $\mathrm{cm}^{3} \mathrm{~cm}^{-3}$;

$\theta_{\mathrm{r}}$ - umidade residual, $\mathrm{cm}^{3} \mathrm{~cm}^{-3}$;

$\theta^{\mathrm{s}}$ - umidade de saturação, $\mathrm{cm}^{3} \mathrm{~cm}^{-3}$;

$\Psi$ - potencial de água no solo, $-\mathrm{kPa}$;

$\alpha-\left(\mathrm{kPa}^{-1}\right)$, m e n - parâmetros empíricos do modelo matemático.

Tabela 8. Valores dos parâmetros do modelo de van Genuchten nas respectivas camadas do perfil do solo das covas

\begin{tabular}{cccccc}
\hline Camada $(\mathrm{m})$ & $\theta \mathrm{r}\left(\mathrm{cm}^{3} \mathrm{~cm}^{-3}\right)$ & $\theta \mathrm{s}\left(\mathrm{cm}^{3} \mathrm{~cm}^{-3}\right)$ & $\alpha-\left(\mathrm{kPa}^{-1}\right)$ & $\mathrm{m}$ & $\mathrm{n}$ \\
\hline $0-0,15$ & 0,100 & 0,590 & 0,1510 & 0,3033 & 1,9996 \\
$0,15-0,30$ & 0,117 & 0,620 & 0,1611 & 0,4254 & 1,5171 \\
$0,30-0,40$ & 0,147 & 0,490 & 0,0960 & 0,4055 & 1,5980 \\
\hline
\end{tabular}

\subsection{Fertirrigação}

A fertirrigação durante o ciclo da cultura foi feita na freqüência de aplicação de 2 dias. A fertirrigação nitrogenada foi feita a base de $150 \mathrm{~kg} \mathrm{ha}^{-1}$ de nitrogênio para todos os tratamentos, utilizando-se como fonte o nitrato de amônia ( $34 \%$ de $\mathrm{N}$ ) e o nitrato de potássio ( $44 \%$ de $\mathrm{K}_{2} \mathrm{O}$ e $14 \%$ de $\mathrm{N}$ ). A fertirrigação potássica correspondeu a cada dose estabelecida dos tratamentos, utilizando como fonte o nitrato de potássio ( $44 \%$ de $\mathrm{K}_{2} \mathrm{O}$ e $14 \%$ de N). A aplicação dos fertilizantes foi realizada mediante sucção direta de um tanque de $0,5 \mathrm{~m}^{3}$ de capacidade e com mecanismo de agitação permanente, onde se preparava a calda, instalada na estação de controle do sistema de irrigação do experimento. 
A aplicação do nitrogênio e potássio foi feita de acordo com o acúmulo pela cultura durante seu ciclo, recomendados pela Embrapa, adaptado de Bar-Yosef (1999), mostrados na Tabela 9.

A distribuição dos fertilizantes foi feita em 34 aplicações com a mesma linha de irrigação, computando os tempos necessários para aplicar toda a calda correspondente a cada tratamento, sem alterar as lâminas estabelecidas, procurando evacuar todo os fertilizantes da tubulação com a irrigação subseqüente.

Tabela 9. Extração de $\mathrm{N}$ e $\mathrm{K}\left(\% \mathrm{ha}^{-1}\right.$ dia $\left.^{-1}\right)$ para o meloeiro cultivado com fertirrigação via gotejamento, em diferentes fases do ciclo de desenvolvimento.

\begin{tabular}{ccc}
\hline $\begin{array}{c}\text { Dias após a germinação } \\
\text { (DAG) }\end{array}$ & \multicolumn{2}{c}{ Extração $\left(\%\right.$ ha $^{-1}$ dia $\left.^{-1}\right)$} \\
Pitrogênio $(\mathrm{N})$ & ${\text { Potássio }\left(\mathrm{K}_{2} \mathrm{O}\right)}$ \\
\hline $1-5$ & 1 & 1 \\
$6-11$ & 2 & 1 \\
$12-16$ & 3 & 4 \\
$17-22$ & 6 & 8 \\
$23-27$ & 9 & 16 \\
$28-33$ & 17 & 18 \\
$34-38$ & 28 & 20 \\
$39-43$ & 16 & 18 \\
$44-49$ & 7 & 9 \\
$50-54$ & 6 & 2 \\
$55-60$ & 3 & 1 \\
$61-65$ & 2 & \\
\hline
\end{tabular}

\subsection{Dinâmica do potássio}

Para o estudo da dinâmica da água e do potássio no perfil do solo, foram instaladas baterias de tensiômetros e extratores de solução providos de cápsulas cerâmica em sua extremidade inferior e borrachas especiais com vedação de silicone na extremidade superior, na distância vertical de $0,40 \mathrm{~m}, 0,30 \mathrm{~m}$ e $0,15 \mathrm{~m}$ e na horizontal de $0,10 \mathrm{~m}, 0,15 \mathrm{~m}$ e $0,20 \mathrm{~m}$, em relação ao tronco da planta.

A coleta de solução nos extratores foi realizada com auxílio de uma seringa 
descartável de $60 \mathrm{~mL}$, acoplado a um tubo flexível de $6 \mathrm{~mm}$ de diâmetro. As amostras de solução nos extratores foram coletadas após a aplicação de fertilizantes. Nos extratores foram promovidos vácuo com tensão em torno de - $80 \mathrm{kPa}$, por meio do uso da seringa; neste momento foi também verificado a umidade do solo por meio de tensiômetros.

Ao término do ciclo da cultura foram coletadas amostras de solo para cada tratamento a uma distância horizontal de $0,15 \mathrm{~m}$ ao redor da planta, nas camadas de 0 0,10 m, 0,10 - 0, 20 m, 0,20 - 0,30 m e 0,30 - 0,40 m, tal como mostra a Figura 8.

Os dados de teores de potássio $(\mathrm{K})$ nos extratores e no solo fram analisados em gráficos de perfis transversais de contorno, descrevendo as distribuições espacial e temporal desses parâmetros.

As amostras de solução coletadas nos extratores e as amostras do perfil do solo foram submetidas à análise para determinação dos teores de potássio solúvel por fotometria de chama seguindo as recomendações do Manual de Métodos de Análise de Solo da EMBRAPA (1997).

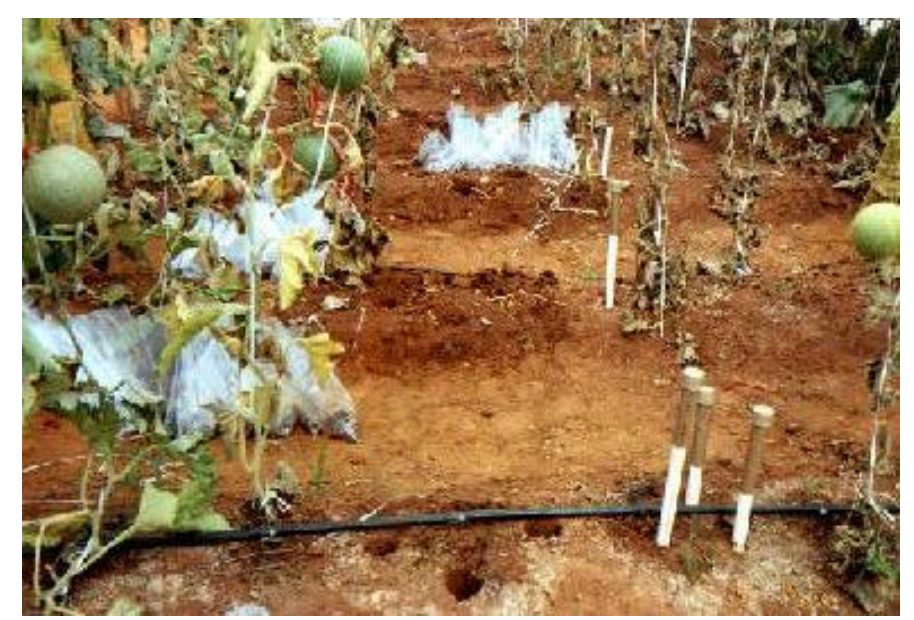

Figura 8 - Locais de amostragem do solo de cada tratamento a uma distância horizontal de $0,15 \mathrm{~m}$ ao redor da planta e nas camadas de 0 - 0,10 m, 0,10 - 0,20 m, 0,20 - 0,30 m e $0,30-0,40 \mathrm{~m}$. 


\subsection{Manejo da cultura}

\subsubsection{Controle fitossanitário}

As plantas estiveram sempre isentas de plantas invasoras. $\mathrm{O}$ controle de pragas e doenças foi feito com pulverizações preventivas, com inseticidas e fungicidas específicos para a cultura e adequado a cada situação e condição do ambiente, sendo quatro aplicações com inseticidas e cinco com fungicidas (Tabela 10).

Tabela 10. Pulverizações realizadas durante a condução do experimento para o controle de pragas e doenças.

\begin{tabular}{|c|c|c|c|}
\hline Data & Produtos & Dosagem & Observações \\
\hline $12 / 10 / 01$ & Trichlorfon & $0,3 \mathrm{~L}_{100 \mathrm{~L}^{-1}}$ de água & Inseticida \\
\hline $12 / 10 / 01$ & Fenarimol & $20 \mathrm{ml} 100 \mathrm{~L}^{-1}$ de água & Fungicida \\
\hline $20 / 10 / 01$ & Deltamethrin & 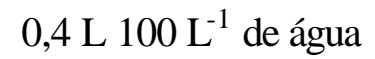 & Inseticida \\
\hline $20 / 10 / 01$ & Mancozeb & 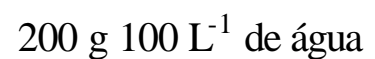 & Fungicida \\
\hline $1 / 11 / 01$ & Trichlorfon & $0,3 \mathrm{~L} 100 \mathrm{~L}^{-1}$ de água & Inseticida \\
\hline $1 / 11 / 01$ & Benzimidozo & 70 g $100 \mathrm{~L}^{-1}$ de água & Fungicida \\
\hline $15 / 11 / 01$ & Fenarimol & $20 \mathrm{ml} 100 \mathrm{~L}^{-1}$ de água & Fungicida \\
\hline $26 / 11 / 01$ & Fenarimol & $20 \mathrm{ml} 100 \mathrm{~L}^{-1}$ de água & Fungicida \\
\hline 26/11/01 & Trichlorfon & $0,3 \mathrm{~L}_{100 \mathrm{~L}^{-1}}$ de água & Inseticida \\
\hline
\end{tabular}

\subsubsection{Podas e condução da cultura}

A condução da cultura foi feita com espaldeiras verticais de 2,0 m de altura com dois fios de arame liso n 12 por tratamento, presos e esticados por mourões. Quando as plantas iniciaram a emissão de gavinhas foram tutoradas conduzindo-as em haste única com fita de ráfia presa a um gancho de arame cravado no solo e, na outra extremidade, presa ao último fio de arame da espaldeira. 
$\mathrm{Na}$ poda utilizourse tesoura apropriada para cortes em brotações, que foram mergulhadas numa solução fungicida-bactericida para desinfecção, antes de passar de uma planta para outra, para evitar a disseminação de doenças. Eliminaram-se todos os ramos secundário até $\mathrm{o} 11^{\circ}$ nó por meio de podas, a cerca de $0,7 \mathrm{~m}$ do cólon da planta, deixando os demais brotos laterais com três folhas. Quando a haste principal atingiu cerca de 2,20 m de altura procedeutse a poda apical para estimular maior vigor das ramas laterais. Os frutos foram conduzidos em cestas de plástico presas às linhas de arame.

\subsubsection{Polinização}

A polinização ocorreu entre os 30 a 50 dias após o transplantio (DAT) de forma manual e também se utilizou um enxame de abelhas especiais para esta finalidade, localizado no centro do ambiente protegido.

\subsubsection{Colheita dos frutos}

Foram realizados três colheitas, em 10/1/2002, 12/1/2002 e 15/1/2002, aos 97 DAT, 99 DAT e 102 DAT, respectivamente. Os frutos foram colhidos quando atingiram o ponto de maturação fisiológica com o teor de sólidos solúveis totais em torno de 10 ${ }^{\circ}$ Brix e identificados pela mudança de coloração da casca para acinzentada e rendilhamento em volta do pedúnculo.

\subsection{Parâmetros avaliados}

Os parâmetros de desenvolvimento foram observados e medidos nas diferentes fases de seu desenvolvimento, sendo crescimento inicial (8 DAT), floração de polinização (24 a 31 DAT), frutificação (54 DAT) e maturação (60 a 74 DAT). O estado nutricional das plantas foi avaliado no período de colheita dos frutos. 


\subsubsection{Parâmetros de desenvolvimento das plantas}

Os parâmetros morfológicos de desenvolvimento da planta avaliados foram: área foliar, número de folhas e altura da planta.

Para o cálculo da área foliar utilizoutse o medidor de área foliar de mesa, modelo LI 3100, medindo as folhas de quatro plantas em forma destrutiva em todos os estádios de desenvolvimento da cultura, com o qual confeccionousse uma curva de ajuste entre área foliar calculada com medidor de área foliar de mesa L1 3100 (área real da folha) e área foliar calculada com auxílio de regra (área característica), considerando as folhas como sendo de formato retangular. Por meio de regressão linear foi obtidas a curva de ajuste (Figura 9) e o respectivo fator de ajuste.

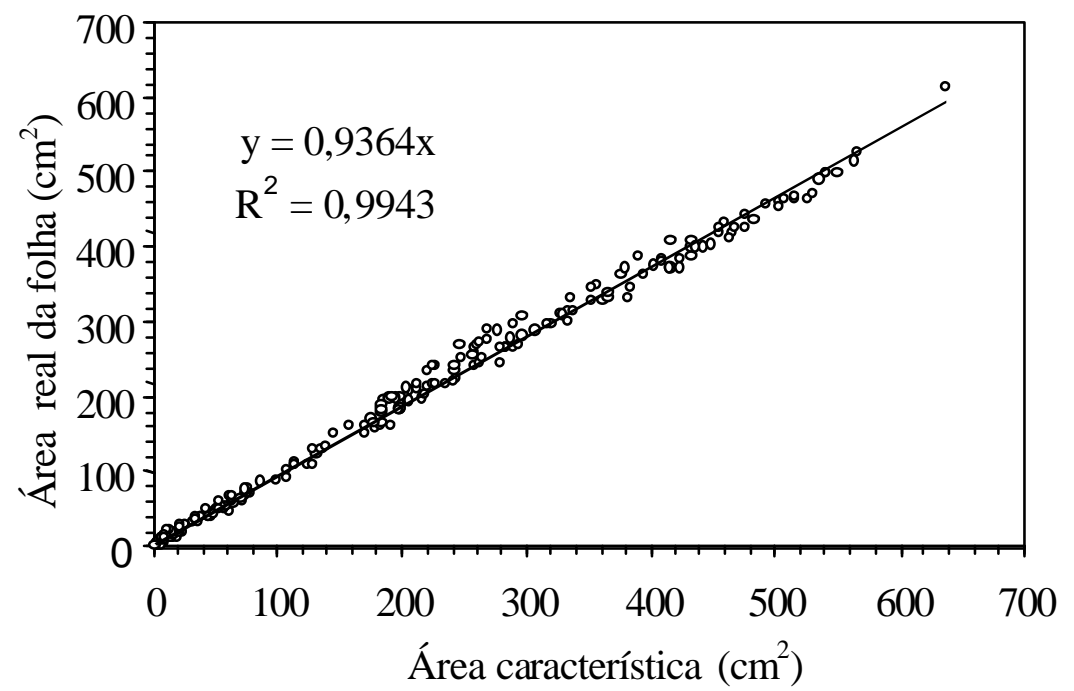

Figura 9 - Curva de ajuste de área foliar utilizando medidor de área foliar de mesa, modelo LI-3100.

O número de folhas foi computado com todas as folhas que ficaram depois das podas, realizadas devido à necessidade de condução das plantas.

As medições de altura das plantas foram realizadas com o auxílio de uma trena graduada em centímetros, tomando como referência superior o ápice do ramo mais alto e como referência inferior à superfície do solo do canteiro. 


\subsubsection{Estado nutricional de plantas}

O estado nutricional das plantas foi avaliado por intermédio de diagnose foliar de todas as folhas da planta, realizado no período de colheita de frutos. Para isto coletaramse duas plantas centrais em cada tratamento, por cada bloco, constituindo um total de seis plantas. Posteriormente, as amostras foram levadas para o Laboratório de Nutrição Mineral de Plantas da USP/ESALQ, sendo devidamente lavadas em solução de água com detergente, água de torneira, água deionizada com $\mathrm{HCl}\left(0,01 \mathrm{~mol} \mathrm{~L}^{-1}\right)$ e por último somente com água deionizada. Removidos o excesso de água da lavagem por secagem ao ar, foram colocadas em saco de papel e levadas para secagem em estufa de circulação forçada de ar a $65-70{ }^{\circ} \mathrm{C}$, até atingir peso constante. As analises químicas para a determinação dos teores de macronutrientes presentes nas folhas foram feitas nos extratos obtidos pela digestão sulfúrica (nitrogênio), nítrico-pelclórica (fósforo, potássio, cálcio, magnésio e enxofre) segundo metodologia proposta por Sarruge \& Haag (1974). O nitrogênio foi quantificado pelo método semi-micro Kjeldahl, fósforo por calorimetria, potássio por fotometria de chama e cálcio, magnésio e enxofre por espectrofotometria de absorção atômica, conforme recomendado por Sarruge \& Haag (1974).

\subsubsection{Produtividade e classificação de frutos}

Após cada colheita, os frutos foram contados e pesados em balança de precisão. Os frutos foram classificados e a produção dividida em física (frutos comercial e não comercial) e econômica (frutos comerciais). Foram considerados frutos de valor comercial aqueles não deformados e/ou estragados com peso acima de 0,55 kg, conforme Filgueiras et al., (2000). A produtividade comercial foi estimada com base na média aritmética e na distribuição de freqüência de peso de frutos. 


\subsubsection{Parâmetros de qualidade de frutos}

Elegeram-se para estas medições um fruto comercial por cada planta, por ocasião da primeira colheita e no qual fizeram-se as análises descritas a seguir.

Os parâmetros físicos de qualidade foram: peso médio, em balança de precisão; diâmetro e comprimento de fruto, espessura de casca e polpa, mediante paquímetro digital, além da de firmeza da polpa em dois pontos da zona equatorial do fruto mediante penetrômetro (de $8,0 \mathrm{~mm}$ ).

Nas mesmas amostras utilizadas para a determinação dos parâmetros físicos dos frutos foram analisados os seguintes parâmetros químicos: conteúdo de sólidos solúveis totais ( ${ }^{\mathrm{B}}$ Brix), acidez total titulável e $\mathrm{pH}$. O conteúdo de sólidos solúveis totais foi medido por meio de um refratômetro digital de bolso (resolução de 0,2) após filtragem do homogenato em gaze, sendo os resultados expressos em ${ }^{\circ}$ Brix. A acidez total titulável foi determinado com $\mathrm{NaOH} 0,1 \mathrm{~N}$ até o $\mathrm{pH}$ atingir 8,1 sendo os resultados expressos em \% de ácido cítrico. $\mathrm{O}$ pH foi medido com um pehagâmetro digital de bancada.

\subsubsection{Eficiência de uso de água}

A eficiência do uso da água foi determinada pela relação entre a produtividade comercial de frutos obtidos com as doses de potássio e os diferentes níveis de água aplicados pela irrigação, como mostra a Equação 6, conforme descrito por Dorenbos \& Kassan (1994):

$$
\mathrm{EUA}=\frac{\mathrm{PC}}{\mathrm{L}}
$$

em que:

EUA - eficiência do uso da água, $\mathrm{kg} \mathrm{m}^{-3}$;

PC - produtividade comercial, $\mathrm{kg} \mathrm{ha}^{-1}$;

$\mathrm{L}$ - nível de água aplicado pela irrigação, $\mathrm{m}^{3} \mathrm{ha}^{-1}$. 


\subsubsection{Dados meteorológicos}

Foi instalado uma estação agrometeorológica automática portátil da Elle International, modelo MM 900, equipada com sensores de determinação da radiação solar global e líquida, temperatura e umidade relativa do ar, e fluxo de calor no solo. Os dados meteorológicos, programados no Datalogger - CR10, foram medidos a cada segundo com média de 30 minutos.

Os equipamentos utilizados podem ser visualizados na Figura 10.

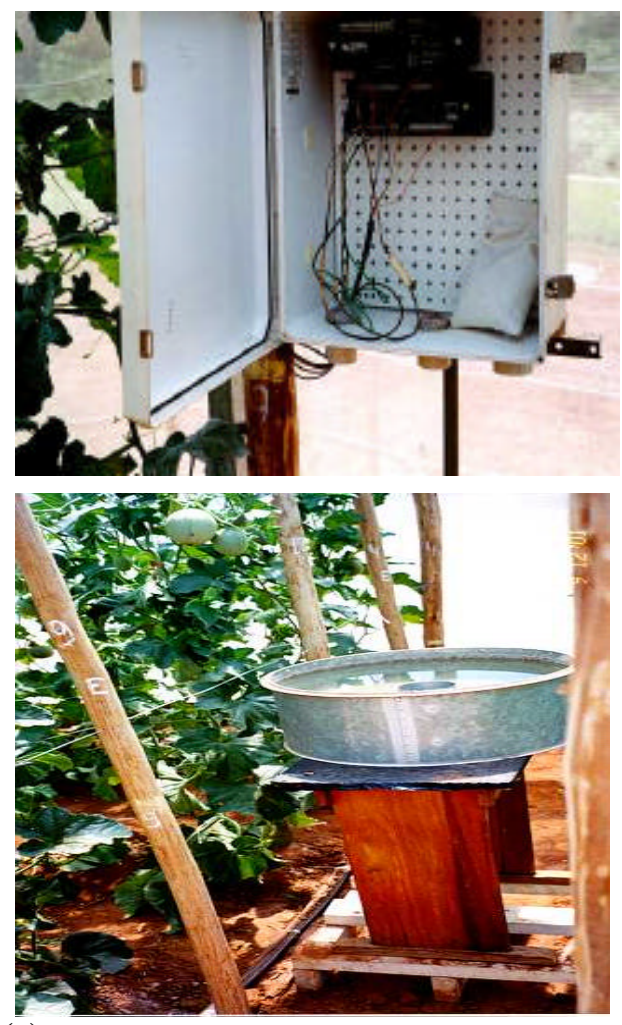

(a)

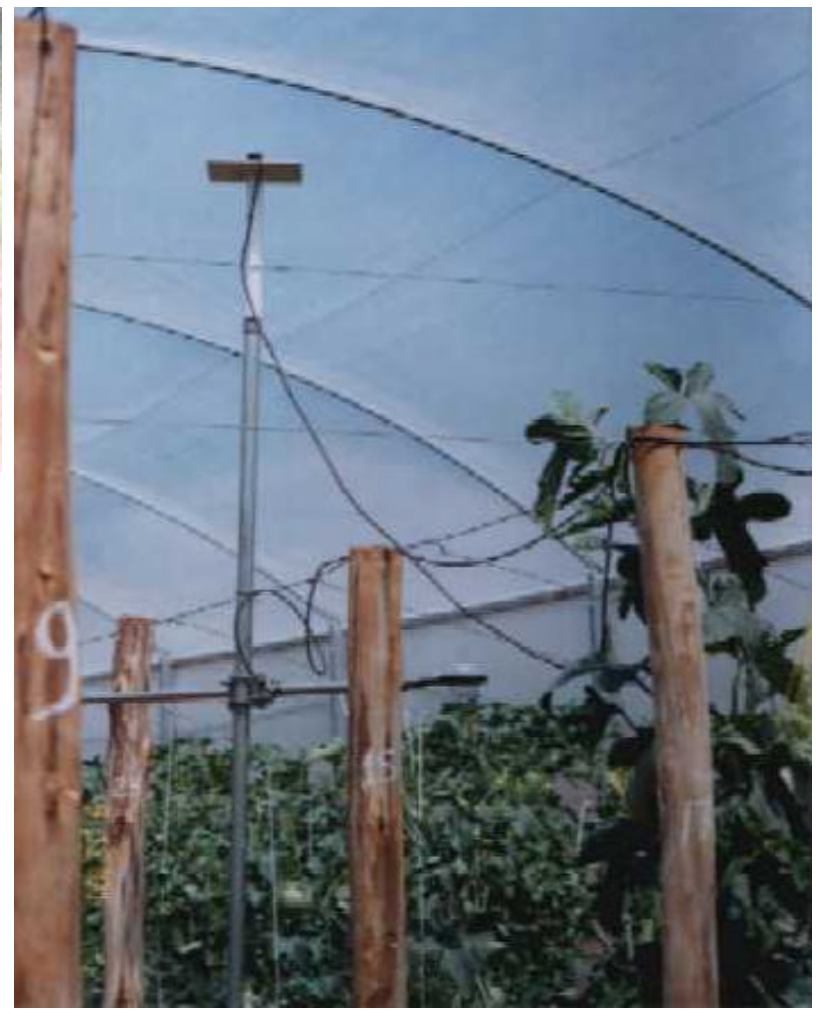

(b)

Figura 10 - Equipamento para aquisição de dados agroclimatológicos: a) datalogger (CR10) e mini tanque; b) radiômetro. 


\subsubsection{Evapotranspiração e coeficiente da cultura}

Para o coeficiente da cultura $(\mathrm{Kc})$ do melão rendilhado nos diferentes períodos de desenvolvimento, utilizou-se o modelo polinomial $\mathrm{y}=-0,0003 \mathrm{X}^{2}+0.0431 \mathrm{X}-0,4148$ $\left(\mathrm{R}^{2}=0,756\right)$, obtidos por Silva et al., ${ }^{4}$ para o mesmo híbrido de melão Bônus $\mathrm{n}^{\mathrm{o}} 2 \mathrm{em}$ ambiente protegido. Este modelo permitiu estimar valores de Kc para todos os DAT.

A equação 7 representa o modelo polinomial sugerido, resultante da derivada ${ }^{\mathrm{a}}$ da equação original.

$$
\mathrm{Kc}=-0,0427 \mathrm{AF}^{2}+0,3401 \mathrm{AF}+0,3757
$$

em que:

$\mathrm{AF}$ - área foliar da planta.

\subsubsection{Análise estatística dos resultados}

Foram realizadas análises de variância para cada parâmetro avaliado e teste de médias para cada fator separadamente. As interações dos três fatores que mostraram significância estatística $(\mathrm{P}<0,01$ e 0,05$)$ foram desdobradas pelo teste de Tukey para a variável qualitativa de posição de instalação dos tubogotejadores e pelo teste de regressão múltipla para as variáveis quantitativas de níveis de irrigação e doses de potássio, o que permitiu determinar o efeito dos tratamentos de forma independente e $\mathbb{\Phi}$ respectivas interações.

\footnotetext{
4 SILVA, T. J. A.; MACHADO, C. C.; PRADO, N.I. et al. Consumo de água por meloeiro tipo rendilhado cultivado em ambiente protegido./Trabalho apresentado ao 32. CONGRESSO BRASILEIRO DE ENGENHARIA AGRICOLA. Goiâna. 2003/.
} 


\section{RESULTADOS E DISCUSSÃO}

\subsection{Dados meteorológicos}

\subsubsection{Radiação solar}

A Figura 11 apresenta a variação da radiação solar global (Rsg) e líquida (Rsl) ao longo do ciclo do híbrido de melão Bônus no 2 para as condições de cultivo protegido com cobertura de polietileno difusor de luz espessura 150 ì m. Os valores integrados (99 dias) das energias diárias totalizaram 1.314,007 $\mathrm{MJ} \mathrm{m}^{-2}$ para Rsg com uma média de 13,273 $\mathrm{MJ} \mathrm{m}^{-2} \mathrm{dia}^{-1}$ e 917,963 $\mathrm{MJ} \mathrm{m}^{-2}$ para Rsl, com um média de 9,272 MJ m $\mathrm{dia}^{-1}$.

Cardoso (2002) no período de setembro a dezembro de 2001 para o mesmo híbrido de melão Bônus no 2 encontrou Rsg média de 29,392 MJ m dia $^{-1}$ e de Rsl média de $9,518 \mathrm{MJ} \mathrm{m}^{-2} \mathrm{dia}^{-1}$.

Observa-se que os valores de Rsg e Rsl tendem a um mínimo em condições de baixa energia (dias nublados). 


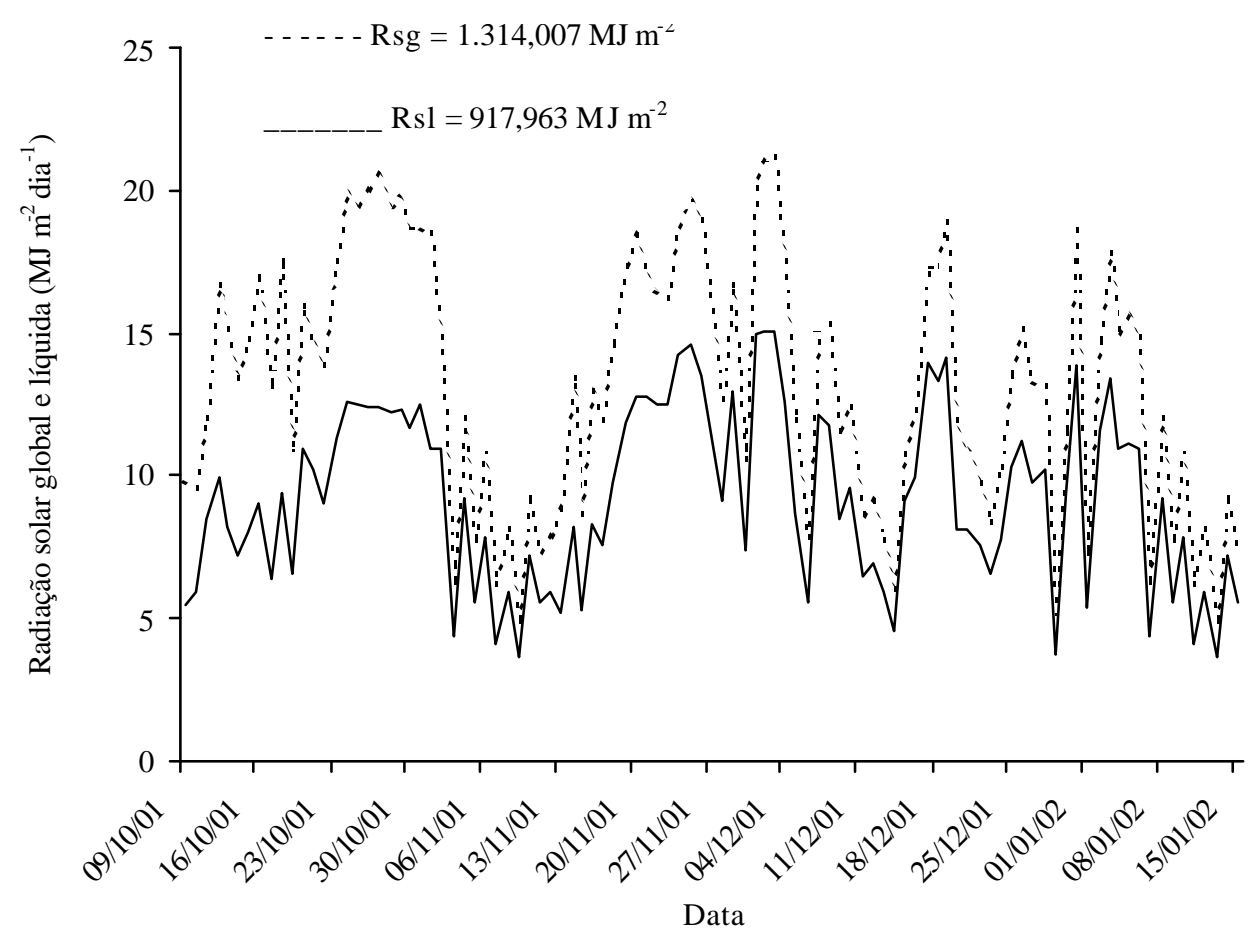

Figura 11 - Radiação solar global (Rsg) e líquida (Rsl) ao longo do ciclo da cultura de melão em condições protegidas.

\subsubsection{Fluxo de calor do solo}

A Figura 12 apresenta a variação de fluxo de calor na superfície do solo (FCS) e enterrado 0,20m da superfície do solo (FCE) ao longo do ciclo do híbrido de melão Bônus $\mathrm{n}^{2}$ para as condições de cultivo protegido. Os valores integrados das energias diárias totalizaram -8,213 $\mathrm{MJ} \mathrm{m}^{-2}$ para FCS e $-69,684 \mathrm{MJ} \mathrm{m}^{-2}$ para FCE. Representando um fluxo de energia do sistema para o interior do solo (valores negativos), enquanto que representando um fluxo de calor no sentido do solo para o sistema (valores positivos). 


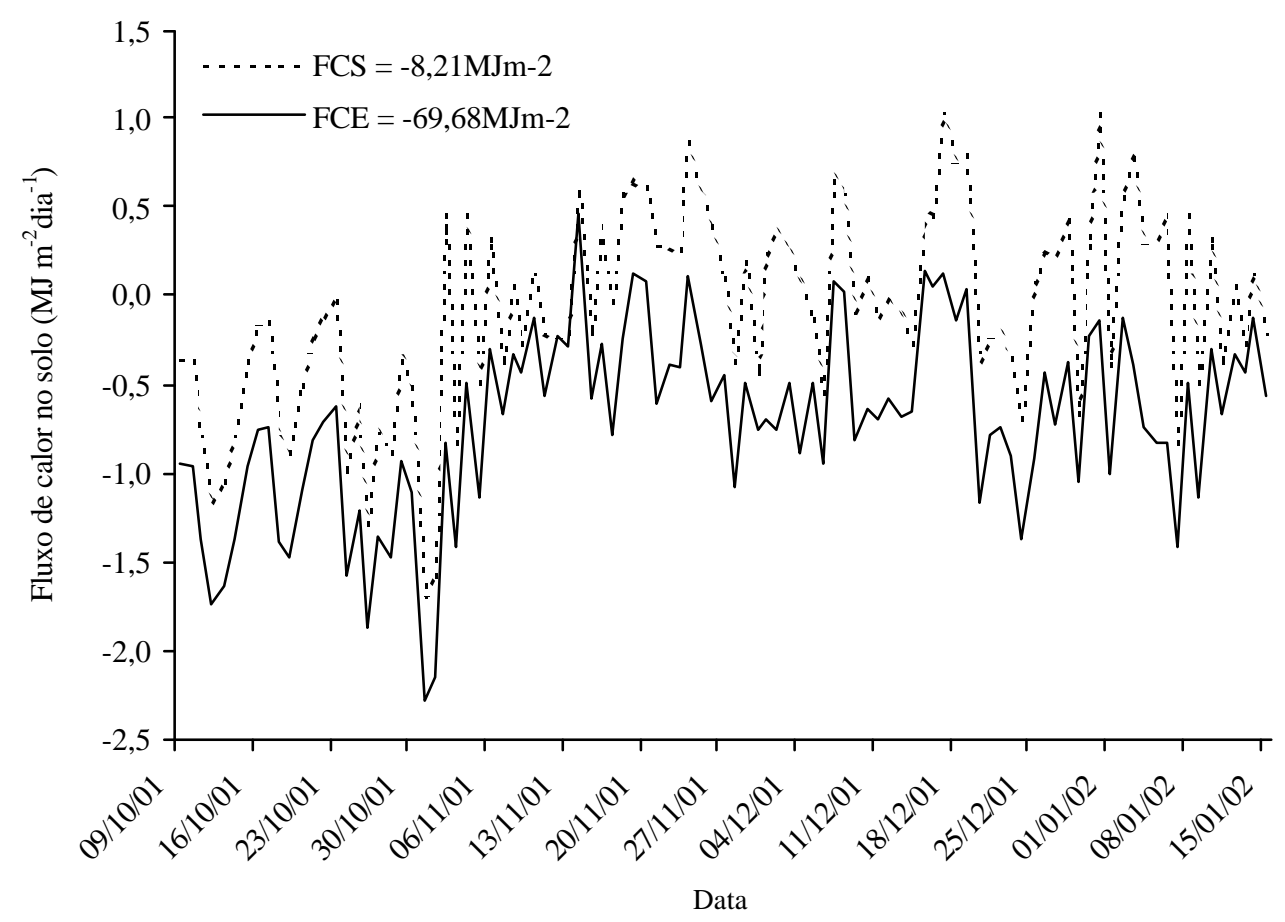

Figura 12 - Fluxo de calor na superfície do solo (FCS) e enterrado (FCE) ao longo do ciclo da cultura de melão em condições protegidas.

\subsubsection{Temperatura do ar}

A Figura 13 apresenta valores diários de temperatura do ar médios (Tméd), mínimos (Tmín) e máximos (Tmáx.) com médias ao longo do ciclo de 24,922 ${ }^{\circ} \mathrm{C}, 18,089$ ${ }^{\circ} \mathrm{C}$ e $33,497^{\circ} \mathrm{C}$, respectivamente.

Cardoso (2002) no período de setembro a dezembro de 2001 para o mesmo híbrido de melão Bônus $\mathrm{n}^{\mathrm{o}} 2$ encontrou Tméd, Tmín e Tmáx de $23,8{ }^{\circ} \mathrm{C}, 12,9{ }^{\circ} \mathrm{C}$ e $35,4^{\circ} \mathrm{C}$, respectivamente. 


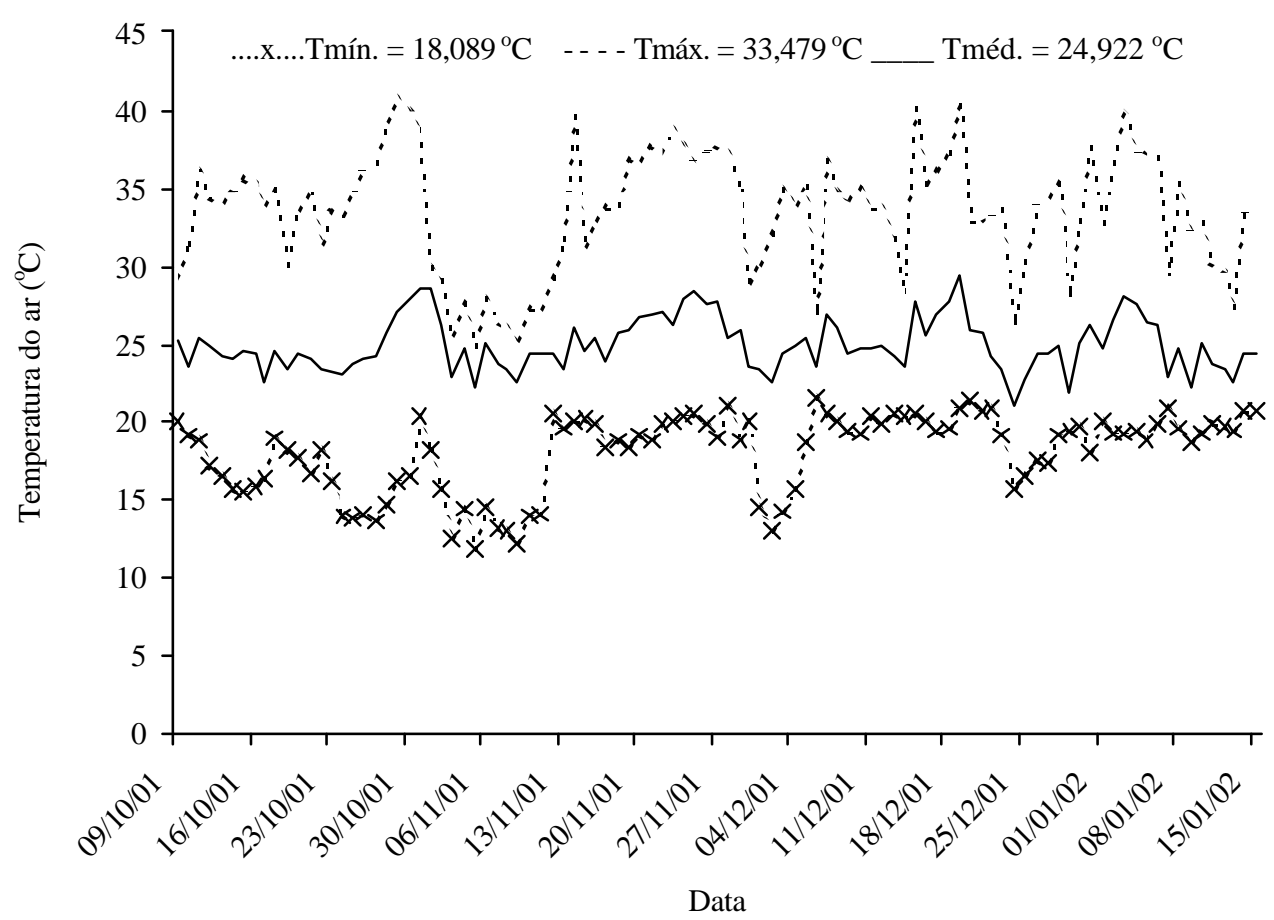

Figura 13 - Temperaturas do ar mínimas (Tmín.), médias (Tméd.) e máximas (Tmáx.) ao longo do ciclo da cultura em condições protegidas.

\subsubsection{Umidade relativa do ar}

A Figura 14 apresenta valores de umidade relativa do ar médios (URméd.), mínimos (URméd.) e máximos (URmáx.) com médias ao longo do ciclo de 72,582 \%, $49,771 \%$ e $89,807 \%$, respectivamente. O valor totalizado de chuva fora do ambiente protegido durante o período de desenvolvimento da cultura foi de $551,5 \mathrm{~mm}$.

Cardoso (2002) no período de setembro a dezembro de 2001 para o mesmo híbrido de melão Bônus $n^{0} 2$ encontrou URméd. de 75,5\%. 


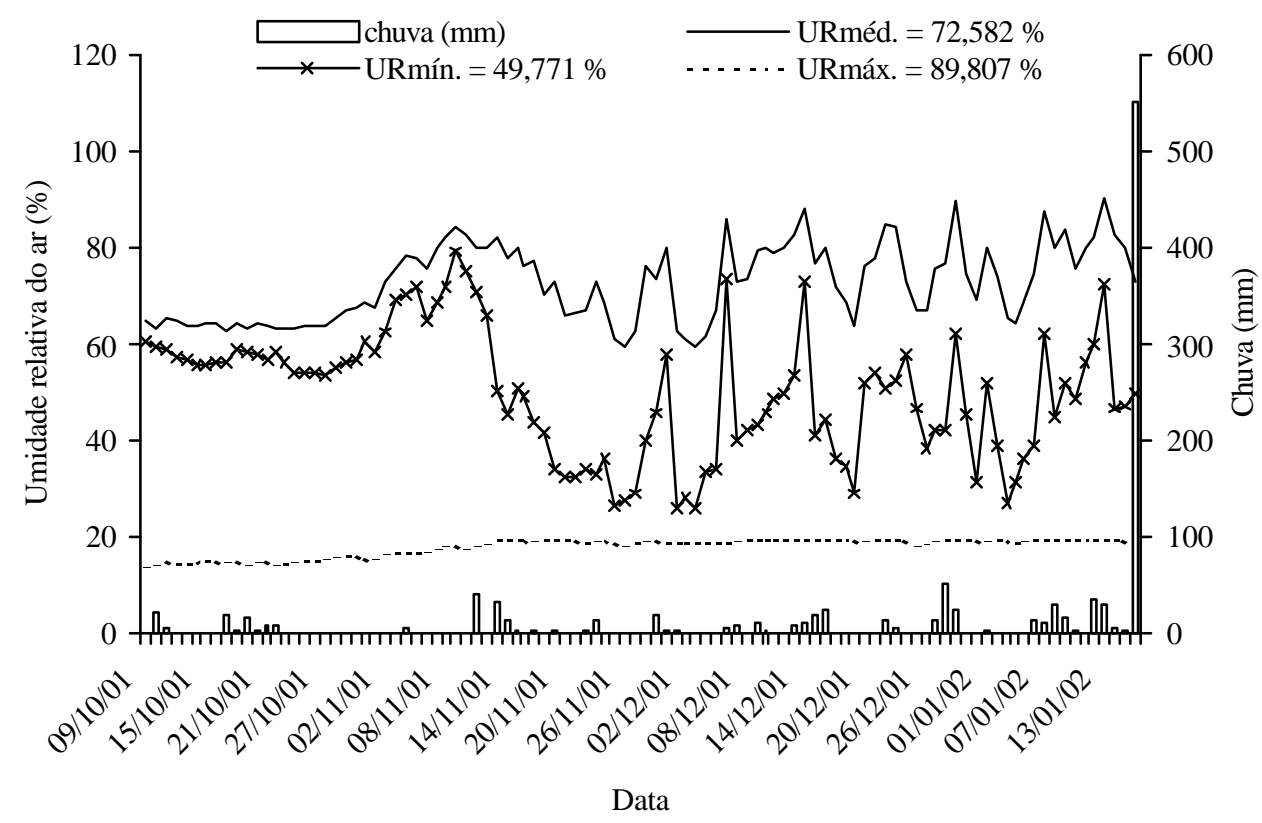

Figura 14 - Valores de umidade relativa do ar médios (URméd.), mínimos (URméd.) e máximos (URmáx.) ao longo do ciclo da cultura em condições protegidas.

\subsection{Manejo da irrigação}

O critério de manejo da irrigação foi baseada na evaporação diária do mini tanque no interior do ambiente protegido (Evpde). A menor e maior Evpde foi de 0,65 mm e 7,34 mm registrados 5 DAT e 47 DAT, respectivamente. A média geral de Evpde foi de 4,39 mm e a evaporação acumulada (Evpdeac) durante o período de irrigação foi de 417,32 mm; a irrigação foi suspensa aos 94 DAT, 3 dias antes da primeira colheita.

Os níveis de irrigação L1, L2 e L3, decorrentes da Evpde são mostrados na Figura 15, correspondendo a 137,72 mm, 279,60 mm e 417,32 mm, respectivamente. A partir destes níveis de irrigação, da performance do sistema, da área molhada e da área total da parcela, foi calculado, com auxílio das Equações 2 e 3, os volumes totais de água aplicados por planta durante o ciclo da cultura. Os cálculos de consumo de água por planta por ciclo para os níveis L1, L2 e L3, resultaram em 21,54 L, 43,72 L e 65,26 L, equivalendo a $1.296,09 \mathrm{~m}^{3} \mathrm{ha}^{-1}, 2.631,48 \mathrm{~m}^{3} \mathrm{ha}^{-1}$ e $3.927,63 \mathrm{~m}^{3} \mathrm{ha}^{-1}$, respectivamente. 
a)

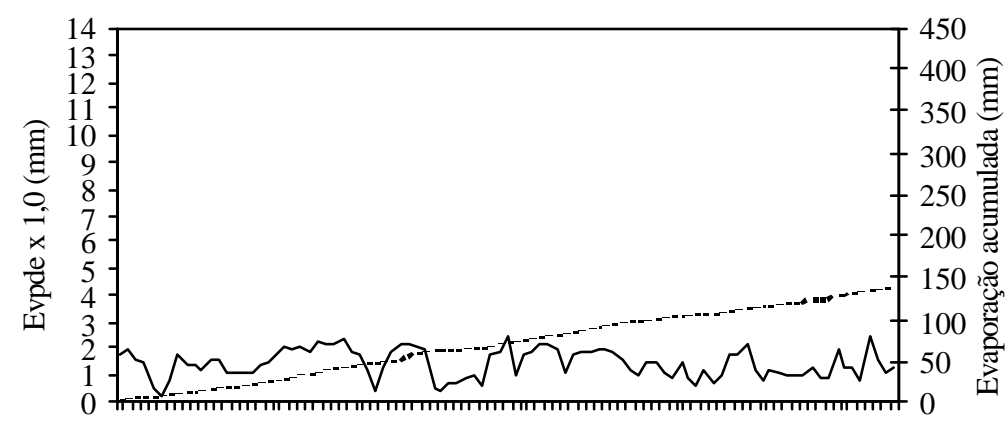

$\begin{array}{llllllllllllllll}1 & 7 & 13 & 19 & 25 & 31 & 37 & 43 & 49 & 55 & 61 & 67 & 73 & 79 & 85 & 91\end{array}$

Dias anós o transnlantio

- Evpde x $1,0 \ldots \ldots$. Evpdeac 1,0

b)

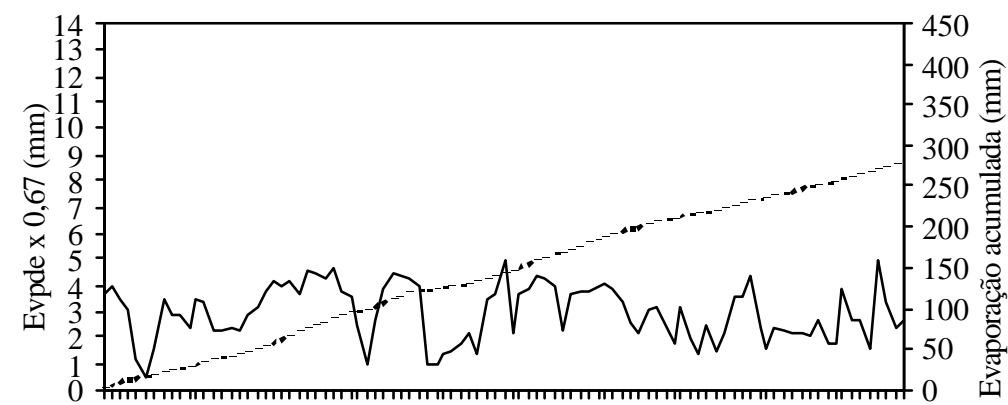

$1 \quad 61116212631364146515661667176818691$

\begin{tabular}{ccc} 
Dias após transplantio & & \\
\hline & Evpde x 0,67 & Evpdeac x 0,67
\end{tabular}

c)

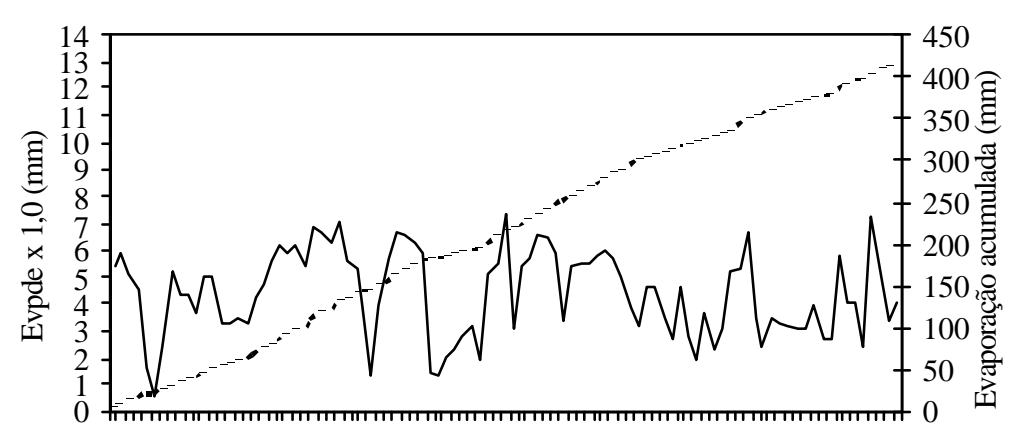

$\begin{array}{llllllllllllllll}1 & 7 & 13 & 19 & 25 & 31 & 37 & 43 & 49 & 55 & 61 & 67 & 73 & 79 & 85 & 91\end{array}$

Dias após o transplantio

— Evpde x $1,0 \cdots \cdots$ Evpdeac 1,0

Figura 15 - Níveis de irrigação diários e acumulados: a) tratamento L1 (137,72 mm); b) tratamento L2 (279,60 mm); c) tratamento L3 (417,32 mm). 
Pesquisas reportadas por Dorenbos \& Pruitt (1976), mostram que o requerimento total de água para o altivo de melão ao ar livre durante o seu ciclo de desenvolvimento (100 dias), esta na faixa de $400 \mathrm{~mm}$ a $600 \mathrm{~mm}$. A mínima lâmina de irrigação recomendada para a cultura de melão ao ar livre segundo Hudson et al., (1981) fica em torno de $500 \mathrm{~mm}$; de igual forma Peñalber (1997) reporta que as necessidades totais de água para a cultura de melão produzido ao ar livre estão entre $3.000 \mathrm{a} 4.000 \mathrm{~m}^{3} \mathrm{ha}^{-1}$.

Pesquisas realizadas por Hartz (1997), relatam que taxas de irrigação por gotejamento procedente da completa interrupção, $20 \%$ e $50 \%$ de interrupção da irrigação aos 10 ou 20 dias antes da colheita, não afetaram a produção e qualidade da colheita, tamanho de frutos, em três cultivares de melão na Califórnia.

Instaloutse também um mini tanque fora do ambiente protegido, com a finalidade de fazer comparações de evaporação ao ar livre e dentro do ambiente protegido, cujos resultados são apresentados na Figura 16. A menor e maior evaporação diária do mini tanque fora do ambiente protegido (Evpfe), foi de 1,24 $\mathrm{mm}$ e 12,7 mm, registrado aos 42 DAT e 35 DAT, respectivamente. A média geral de Evpfe foi de 6,90 mm e a Evpfe acumulada durante o período de irrigação (94 dias), foi de 655,55 mm.

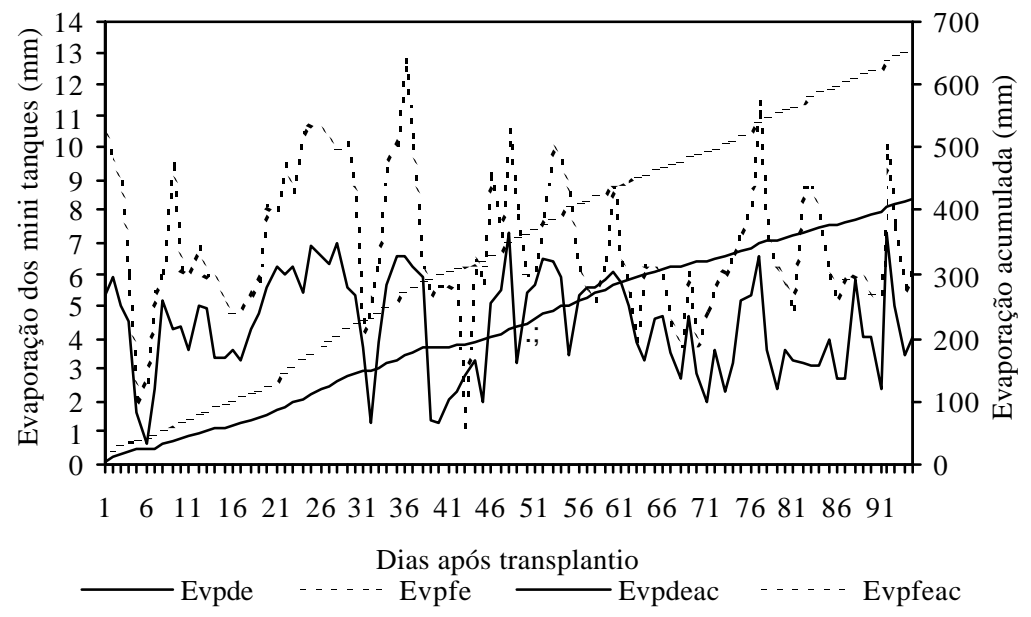

Figura 16 - Comparação da evaporação diária e acumulada dos mini tanques, no interior e exterior da estufa. 
De forma geral verificatse que a Evpfe foi 57,09\% maior que a Evpde, devido às condições climáticas inerentes ao local (Tabela 1) e às características de construção do ambiente protegido. Deve-se ressaltar que o experimento foi realizado no período do 4/10/01 a 17/01/02, sendo esta época de máxima evaporação e maior chuva.

\subsection{Coeficiente de uniformidade}

Os valores médios das vazões dos gotejadores selecionados para a determinação do coeficiente de uniformidade estão apresentados na Tabela 11.

Tabela 11. Vazões médias dos gotejadores dentro das parcelas experimentais

\begin{tabular}{cccc}
\hline Trecho/Tratamento & Vazão média $\left(\mathrm{L} \mathrm{h}^{-1}\right)$ & Trecho/Tratamento & Vazão média $\left(\mathrm{L} \mathrm{h}^{-1}\right)$ \\
\hline 1/K0L1P1 & 1,672 & 13/ K2L1P1 & 1,740 \\
2/ K0L1P2 & 1,635 & 14/ K2L1P2 & 1,638 \\
3/ KOL2P1 & 1,631 & 15/ K2L2P1 & 1,668 \\
4/ K0L2P2 & 1,749 & 16/ K2L2P2 & 1,615 \\
5/ K0L3P1 & 1,568 & 17/ K2L3P1 & 1,781 \\
6/ K0L3P2 & 1,695 & 18/ K2L3P2 & 1,774 \\
7/ K1L1P1 & 1,600 & 19/ K3L1P1 & 1,672 \\
8/ K1L1P2 & 1,623 & 20/ K3L1P2 & 1,664 \\
9/ K1L2P1 & 1,508 & 21/ K3L2P1 & 1,653 \\
10/ K1L2P2 & 1,577 & 22/ K3L2P2 & 1,632 \\
11/ K1L3P1 & 1,625 & 23/ K3L3P1 & 1,700 \\
12/ K1L3P2 & 1,685 & 24/ K3L3P2 & 1,794 \\
\hline
\end{tabular}

Com os resultados médios das vazões obtidos, determinou-se o CUC, que ficou em torno de $95,5 \%$, se enquadrando dentro do esperado para este sistema de irrigação. Com este valor elevado de uniformidade, as variações ocorridas na distribuição do fertilizante não seriam provocados pela variação na uniformidade do sistema. Sammis \& Wu (1985) citam que a uniformidade de distribuição depende da uniformidade de fabricação do emissor, do projeto hidráulico e da manutenção do sistema de irrigação.

Foi observado que as vazões dos gotejadores do sistema de irrigação empregado no experimento tinham distribuição normal enquadrados nos manifesto de Solomon (1984), Bralts \& Kesner (1983), Wu \& Gitlin (1983) e Wu (1988) que afirmam que o 
fluxo emissor de um sistema de irrigação por gotejamento pode ser considerado como tendo uma distribuição normal, porque este é de alta uniformidade.

\subsection{Dinâmica da água no solo}

De forma geral, o comportamento do potencial mátrico e conteúdo de umidade do solo nas profundidades estudadas para os três níveis de irrigação e as duas posições de instalação dos portagotejadores, foram similares até os 19 DAT das mudas (24/10/2001), encontrando-se em torno de $-0,010 \mathrm{MPa}$ e $0207 \mathrm{~cm}^{3} \mathrm{~cm}^{-3}$, próximos da capacidade de campo (C. C.). Este fato se deve à aplicação preliminar de água para a reação do calcário e a estabilidade do solo transportado, ao menor consumo de água pela planta nesta etapa e à presença do plástico inerte cobrindo as laterais das covas e da camada de impedimento localizado a $0,20 \mathrm{~m}$ de profundidade (solo in situ). Pode-se observar que a condição de umidade inicial do solo para os diferentes tratamentos foi também similar.

A partir desta data até o final da irrigação, verificou-se comportamento diferenciado, cujos valores máximos, mínimos e médios de potencial matricial (-MPa) e umidade volumétrica do solo $\left(\mathrm{cm}^{3} \mathrm{~cm}^{-3}\right)$ para os diferentes níveis de irrigação e posição dos tubogotejadores nas profundidades de $0,15 \mathrm{~m}, 0,20 \mathrm{~m}$ e $0,40 \mathrm{~m}$, estão apresentados na Tabela 12. 
Tabela 12. Valores máximos, mínimos e médios de potencial matricial (-MPa) e umidade volumétrica do solo $\left(\mathrm{cm}^{3} \mathrm{~cm}^{-3}\right)$ para os diferentes níveis de irrigação e posição das linhas portagotejadores nas profundidades de 0,15 m, 0,20 m e 0,40 m.

\begin{tabular}{|c|c|c|c|c|c|c|c|c|}
\hline \multirow{2}{*}{$\begin{array}{c}\text { Níveis } \\
\text { (L) }\end{array}$} & \multirow{2}{*}{$\begin{array}{c}\text { Posição } \\
\text { (P) }\end{array}$} & \multirow{2}{*}{$\begin{array}{l}\text { Prof. } \\
\text { (m) }\end{array}$} & \multicolumn{3}{|c|}{ Potencial Matricial (-MPa) } & \multicolumn{3}{|c|}{ Umidade volumétrica $\left(\mathrm{cm}^{3} \mathrm{~cm}^{-3}\right)$} \\
\hline & & & Máximo & Mínimo & Média & Máximo & Mínimo & Média \\
\hline \multirow{7}{*}{ L1 } & \multirow{4}{*}{$\mathrm{P} 1$} & 0,15 & 0,022 & 0,061 & 0,043 & 0,158 & 0,131 & 0,141 \\
\hline & & 0,30 & 0,030 & 0,079 & 0,055 & 0,158 & 0,139 & 0,146 \\
\hline & & 0,40 & 0,028 & 0,071 & 0,047 & 0,187 & 0,169 & 0,176 \\
\hline & & 0,15 & 0,045 & 0,080 & 0,062 & 0,141 & 0,125 & 0,132 \\
\hline & \multirow[t]{3}{*}{$\mathrm{P} 2$} & 0,30 & 0,058 & 0,080 & 0,070 & 0,150 & 0,137 & 0,141 \\
\hline & & 0,40 & 0,053 & 0,080 & 0,064 & 0,181 & 0,166 & 0,171 \\
\hline & & 0,15 & 0,024 & 0,080 & 0,045 & 0,155 & 0,126 & 0,139 \\
\hline \multirow{4}{*}{$\mathrm{L} 2$} & \multirow[t]{3}{*}{$\mathrm{P} 1$} & 0,30 & 0,008 & 0,065 & 0,038 & 0,209 & 0,142 & 0,156 \\
\hline & & 0,40 & 0,011 & 0,076 & 0,039 & 0,220 & 0,168 & 0,183 \\
\hline & & 0,15 & 0,035 & 0,063 & 0,050 & 0,161 & 0,131 & 0,137 \\
\hline & \multirow[t]{3}{*}{$\mathrm{P} 2$} & 0,30 & 0,025 & 0,062 & 0,045 & 0,171 & 0,143 & 0,150 \\
\hline & & 0,40 & 0,039 & 0,063 & 0,041 & 0,214 & 0,171 & 0,180 \\
\hline \multirow{6}{*}{ L3 } & & 0,15 & 0,006 & 0,062 & 0,035 & 0,231 & 0,131 & 0,152 \\
\hline & \multirow[t]{3}{*}{$\mathrm{P} 1$} & 0,30 & 0,006 & 0,057 & 0,027 & 0,231 & 0,144 & 0,171 \\
\hline & & 0,40 & 0,006 & 0,057 & 0,027 & 0,257 & 0,173 & 0,199 \\
\hline & & 0,15 & 0,008 & 0,020 & 0,024 & 0,213 & 0,136 & 0,163 \\
\hline & \multirow[t]{2}{*}{$\mathrm{P} 2$} & 0,30 & 0,008 & 0,021 & 0,021 & 0,222 & 0,151 & 0,174 \\
\hline & & 0,40 & 0,006 & 0,030 & 0,023 & 0,246 & 0,175 & 0,200 \\
\hline
\end{tabular}

Os perfis de distribuição temporal do potencial mátrico e do conteúdo de umidade do solo a diferentes profundidades, para os três níveis de irrigação L1, L2 e L3, e as duas posições de instalação dos tubogotejadores P1 e P2, são apresentados nas Figuras 17, 18, 19, 20, 21 e 22. 
Para o nível de irrigação L1, aplicado nas duas posições dos tubogotejadores (P1, P2), para os tensiômetros instalados a $0,15 \mathrm{~m}, 0,30 \mathrm{~m}$ e $0,40 \mathrm{~m}$ de profundidade (Figuras 17a, b, c e 18a, b), os valores do potencial mátrico estiveram acima da capacidade de campo (C. C.) para tudo o período de irrigação e o conteúdo de umidade do solo registraram valores abaixo da C. C. também para tudo o período de irrigação.

Para o nível de irrigação L2 aplicado nas duas posições dos tubogotejadores (P1, P2), para os tensiômetros instalados a $0,15 \mathrm{~m}, 0,30 \mathrm{~m}$ e 0,40 $\mathrm{m}$ de profundidade (Figuras 19a, b, c e 20a, b), os valores do potencial mátrico estiveram acima da capacidade de campo (C. C.) para tudo o período de irrigação com exceção do período $2 / 11$ a 9/11 para a posição P1 em que estes valores estiveram abaixo da C. C. O conteúdo de umidade do solo registraram valores abaixo da C. C. na maior parte do período de irrigação, com algumas exceções para a posição P1 no período de 30/10 a 9/11 para os tensiômetros instalados na profundidade de 0,40 m e no período de 5/11 a 7/11 para os tensiômetros instalados a $0.30 \mathrm{~m}$ de profundidade, onde os valores estiveram acima da C. C.; para a posição P2 registraram-se valores de conteúdo de umidade também acima da C. C. entre o período 8/11 a 11/11 para os tensiômetros instalados na posição $0,40 \mathrm{~m}$.

Para o nível de irrigação L3 (Figuras 21a, b, c e 22a, b) aplicados nas duas posições dos tubogotejadores (P1 e P2) e nas profundidades de $0,15 \mathrm{~m}, 0,30 \mathrm{~m}$ e $0,40 \mathrm{~m}$ dos tensiômetros os valores de potencial mátrico e de umidade do solo registraram flutuações perto da C. C. em todo o período de irrigação o que demonstra que foi a melhor condição de umidade para toda a fase de desenvolvimento da cultua.

Como manifestado acima, os tratamentos de níveis de irrigação L2 e L3, na posição da linha lateral P2, propiciaram melhores condições de umidade para as plantas nas três profundidades estudadas, pois os valores médios de potencial mátrico e de umidade do solo, de forma geral, estiveram flutuando perto da capacidade de campo. 
a)

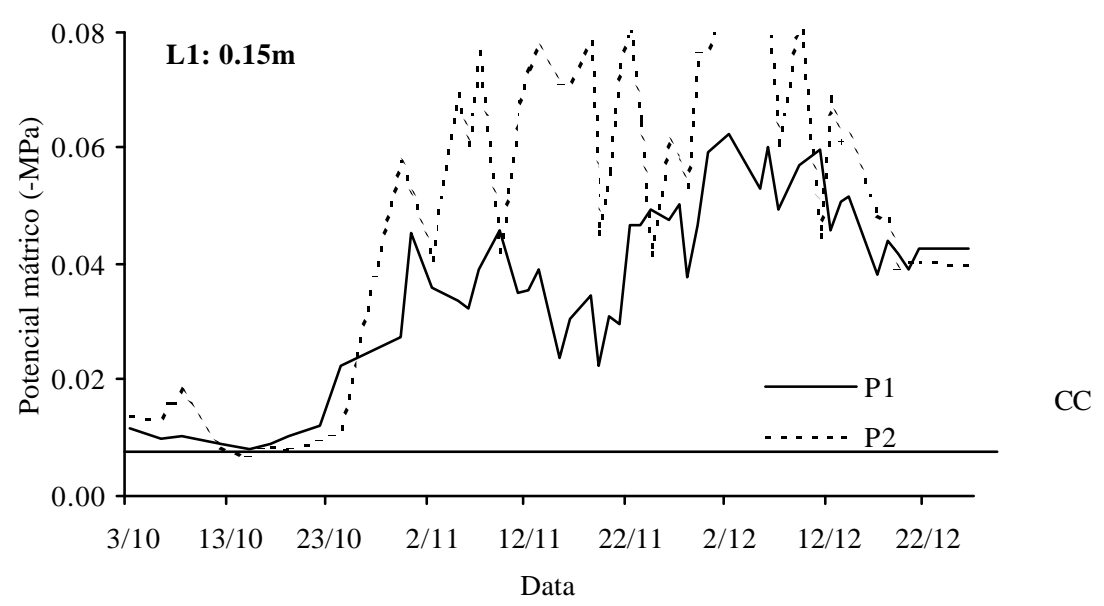

b)

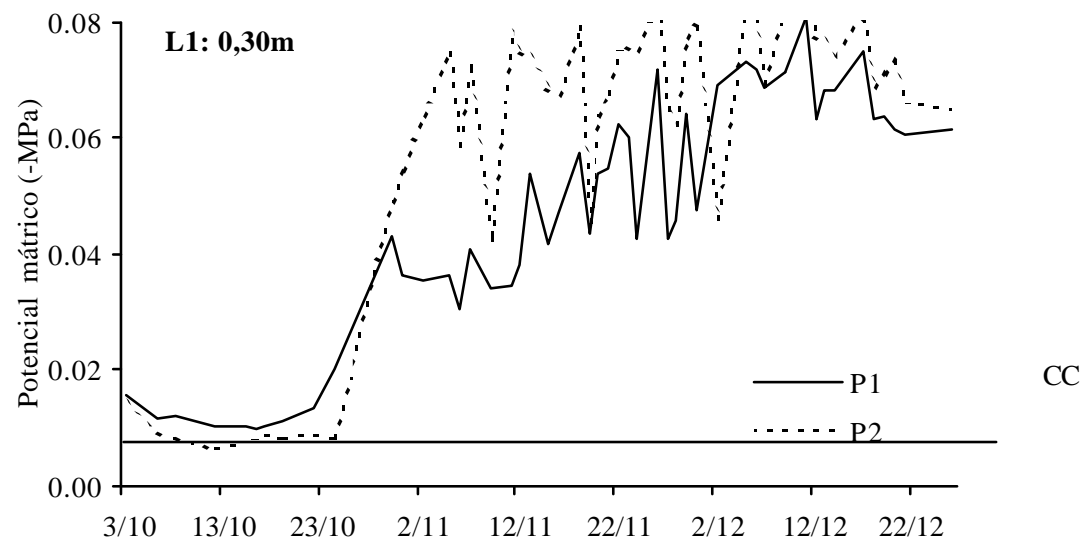

c)

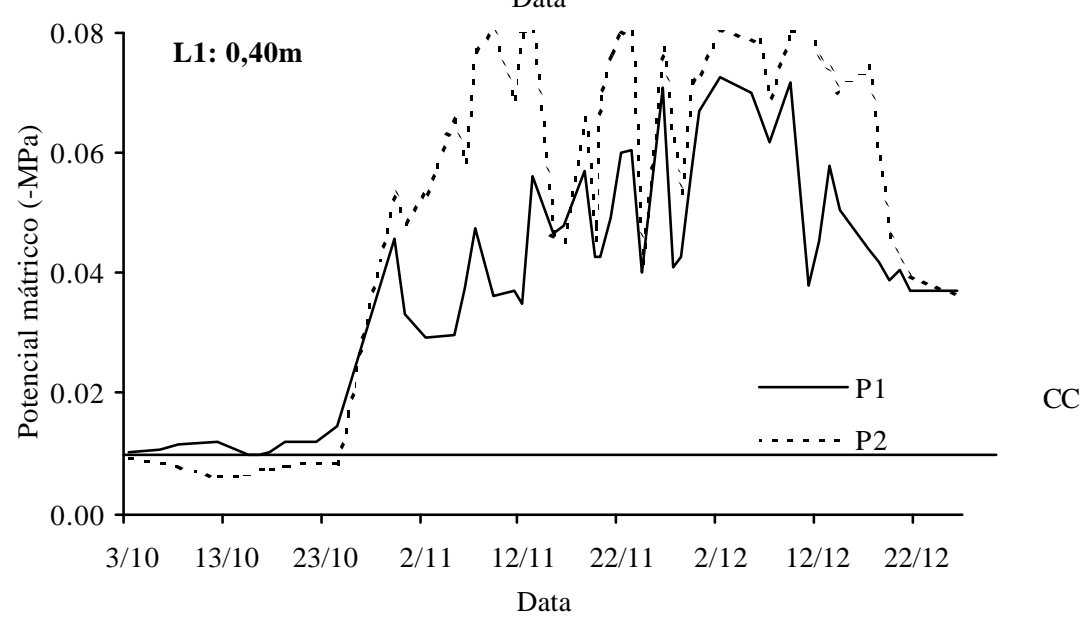

Figura 17 - Variação do potencial mátrico do solo (-Mpa) a diferentes profundidades, para o tratamento de nível de irrigação L1 $(137,72 \mathrm{~mm})$ durante o período vegetativo da cultura: a) $0,15 \mathrm{~m}$; b) $0,30 \mathrm{~m}$; c) $0,40 \mathrm{~m}$. 
a)

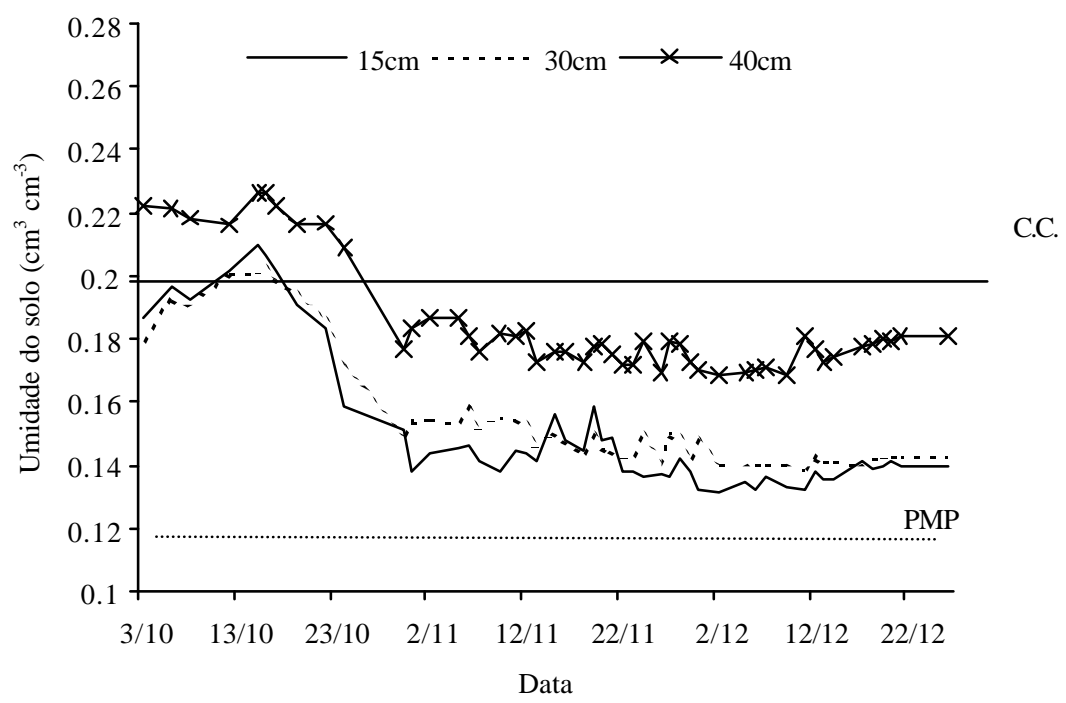

b)

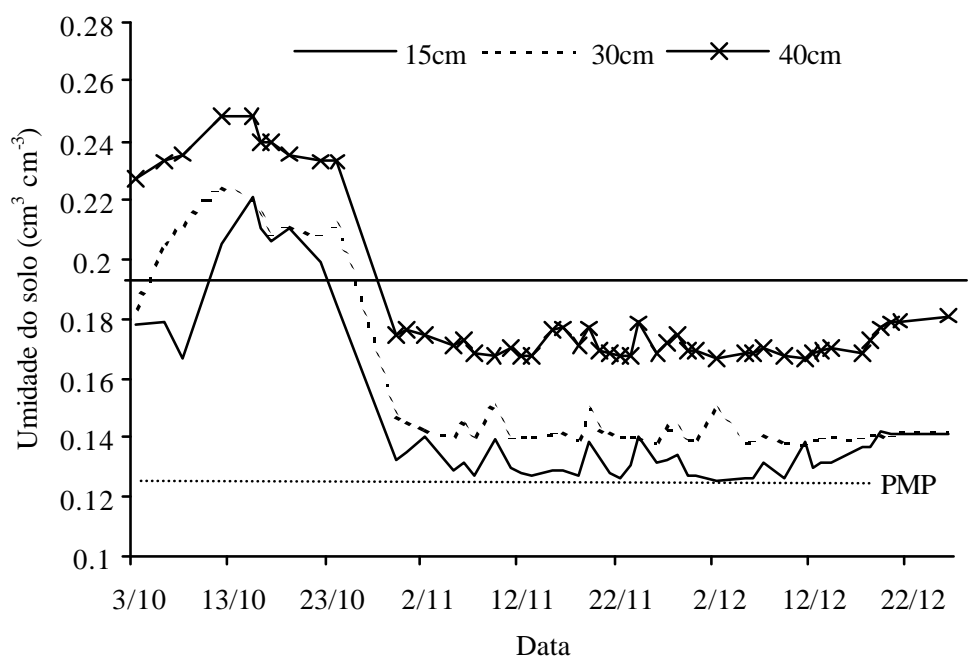

CC.

Figura 18 - Variação da umidade do solo $\left(\mathrm{cm}^{3} \mathrm{~cm}^{-3}\right)$ a diferentes profundidades, para o tratamento de nível de irrigação L1 $(137,72 \mathrm{~mm})$ durante o período vegetativo da cultura: a) posição dos tubogotejadores a $0,00 \mathrm{~m}$; b) posição dos tubogotejadores a $0,20 \mathrm{~m}$. 
a)

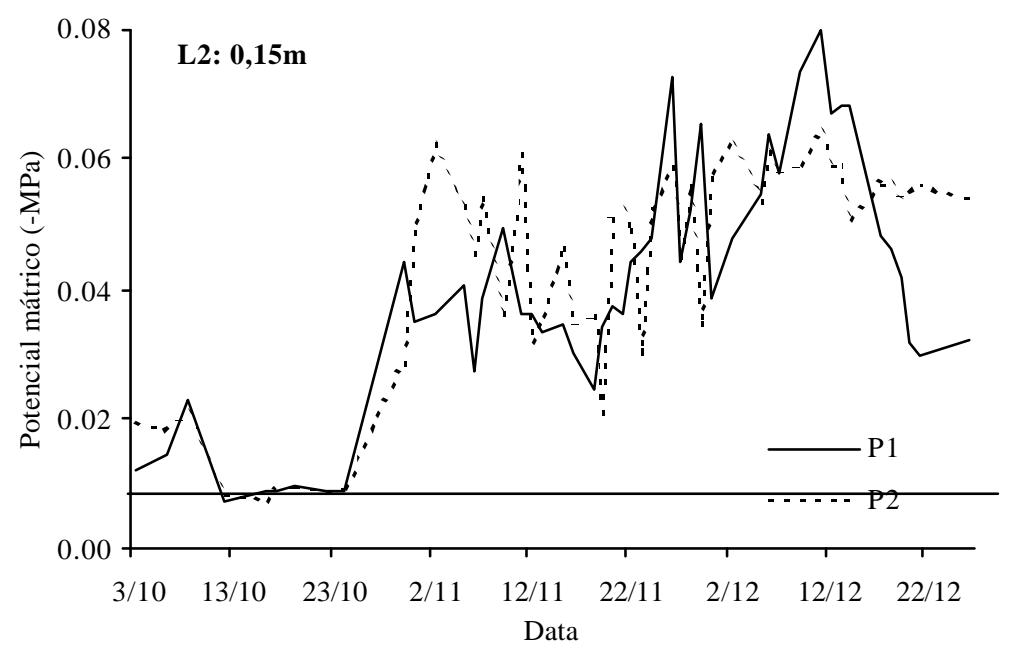

CC

b)

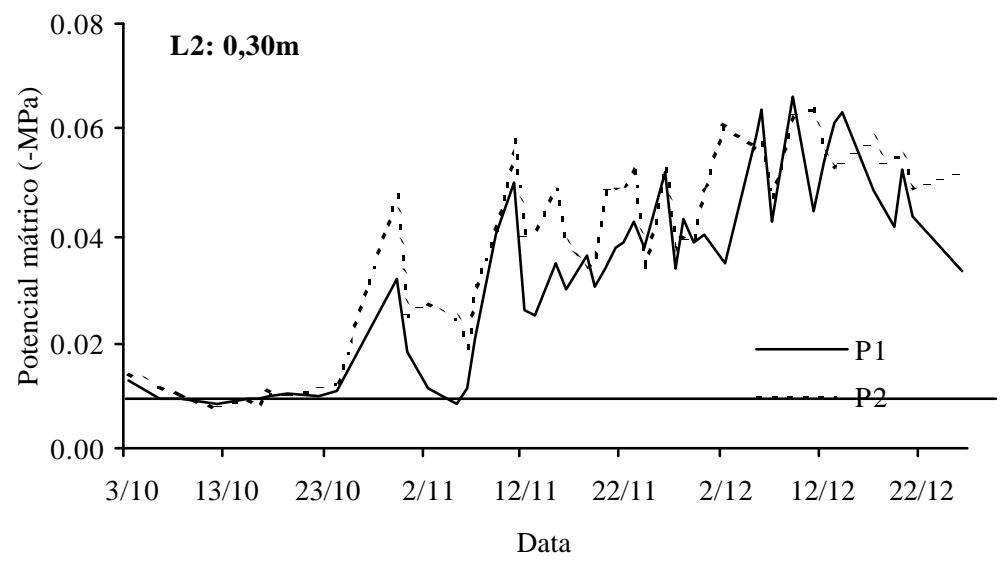

CC

c)

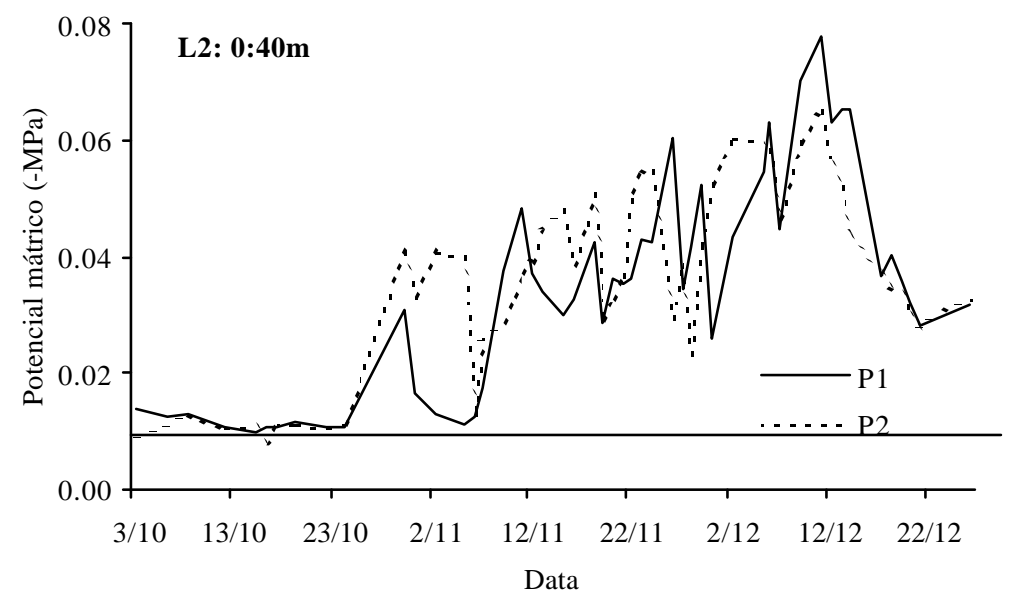

$\mathrm{CC}$

Figura 19 - Variação do potencial mátrico do solo (-MPa) a diferentes profundidades, para o tratamento de nível de irrigação L2 $(279,60 \mathrm{~mm})$ durante o período vegetativo da cultura: a) $0,15 \mathrm{~m}$; b) $0,30 \mathrm{~m}$; c) $0,40 \mathrm{~m}$. 
a)

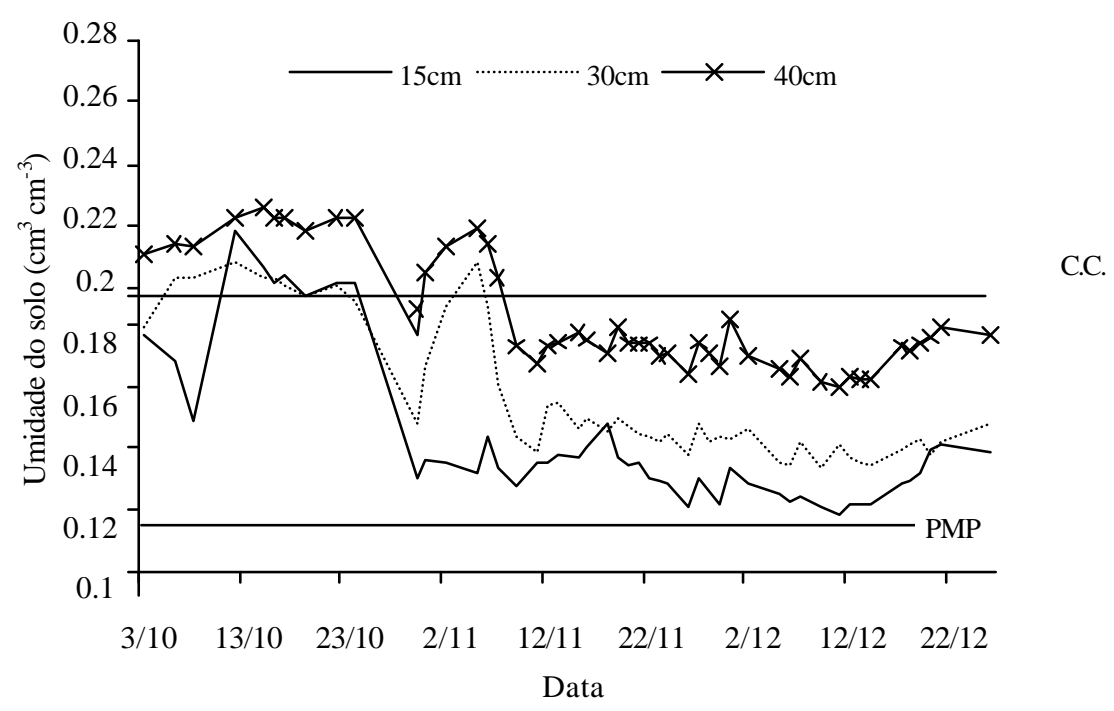

b)

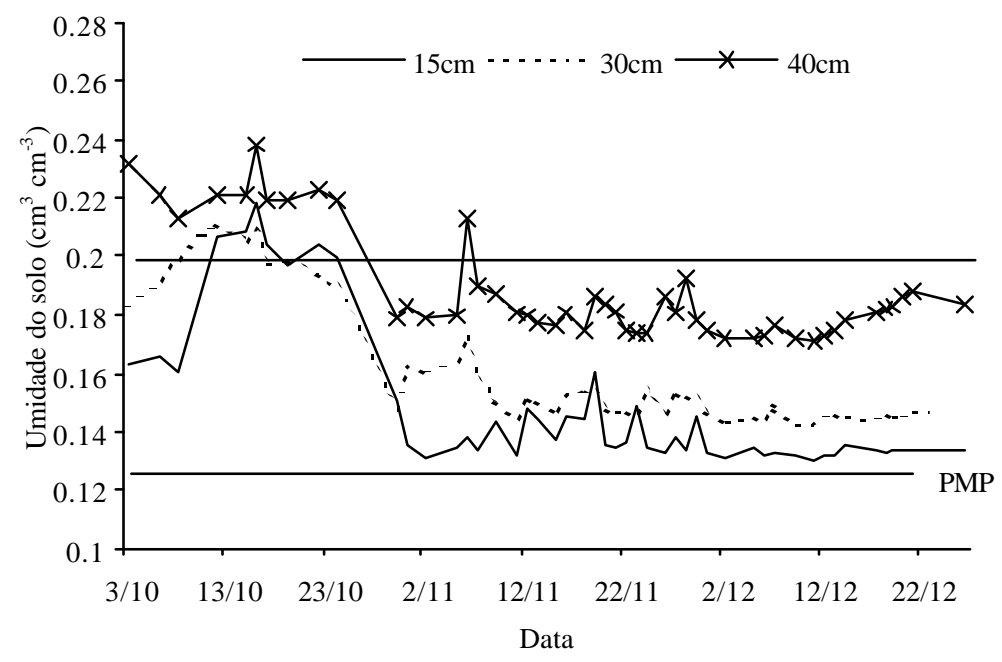

C.C.

Figura 20 - Variação da umidade do solo $\left(\mathrm{cm}^{3} \mathrm{~cm}^{-3}\right)$ a diferentes profundidades, para o tratamento de nível de irrigação L2 $(279,60 \mathrm{~mm})$ durante o período vegetativo da cultura: a) posição dos tubogotejadores a $0,00 \mathrm{~m}$; b) posição dos tubogotejadores a $0,20 \mathrm{~m}$. 
a)

b)

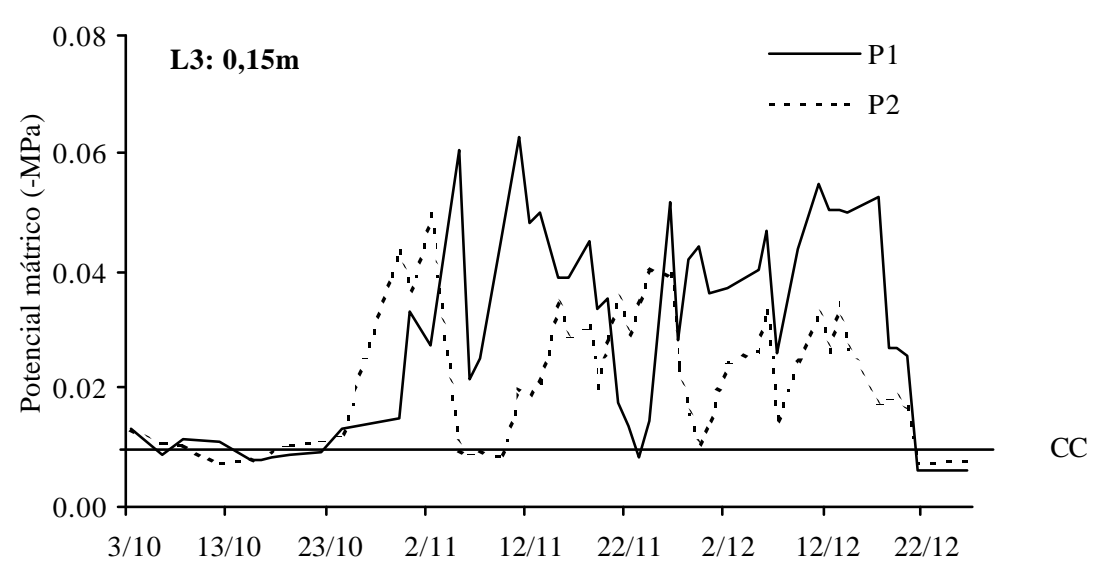

c)

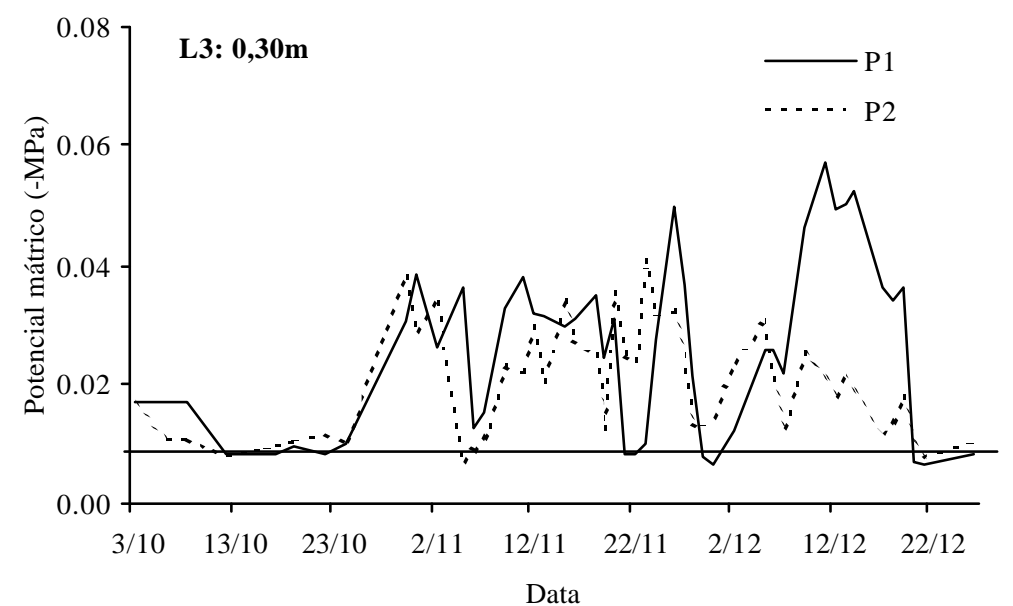

CC

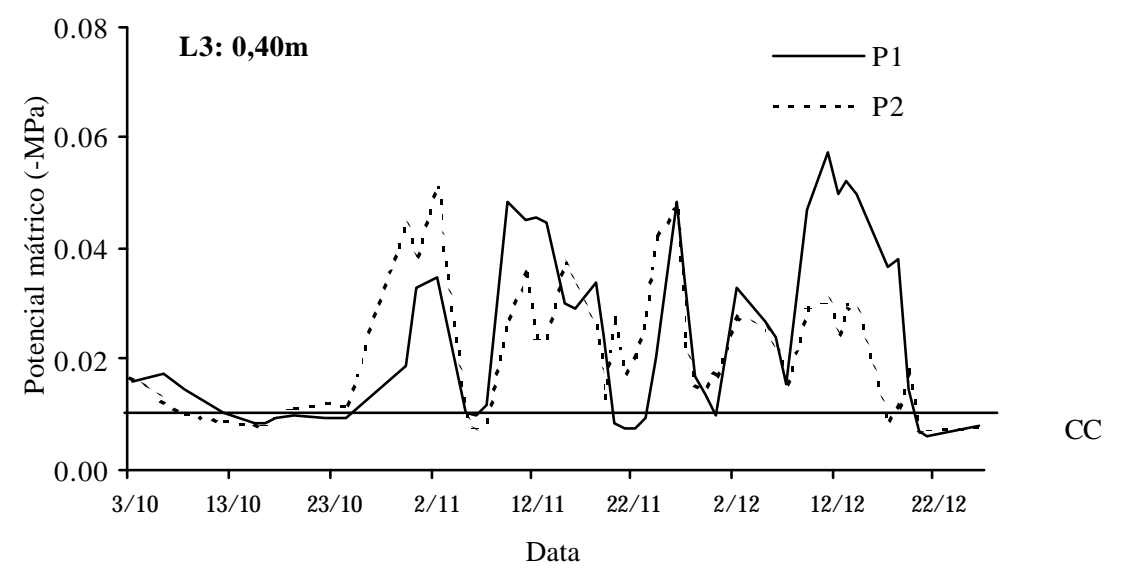

Figura 21 - Variação do potencial mátrico do solo (-MPa) a diferentes profundidades, para o tratamento de nível de irrigação L3 $(417,32 \mathrm{~mm})$ durante o período vegetativo da cultura: a) $0,15 \mathrm{~m}$; b) $0,30 \mathrm{~m}$; c) $0,40 \mathrm{~m}$. 
a)

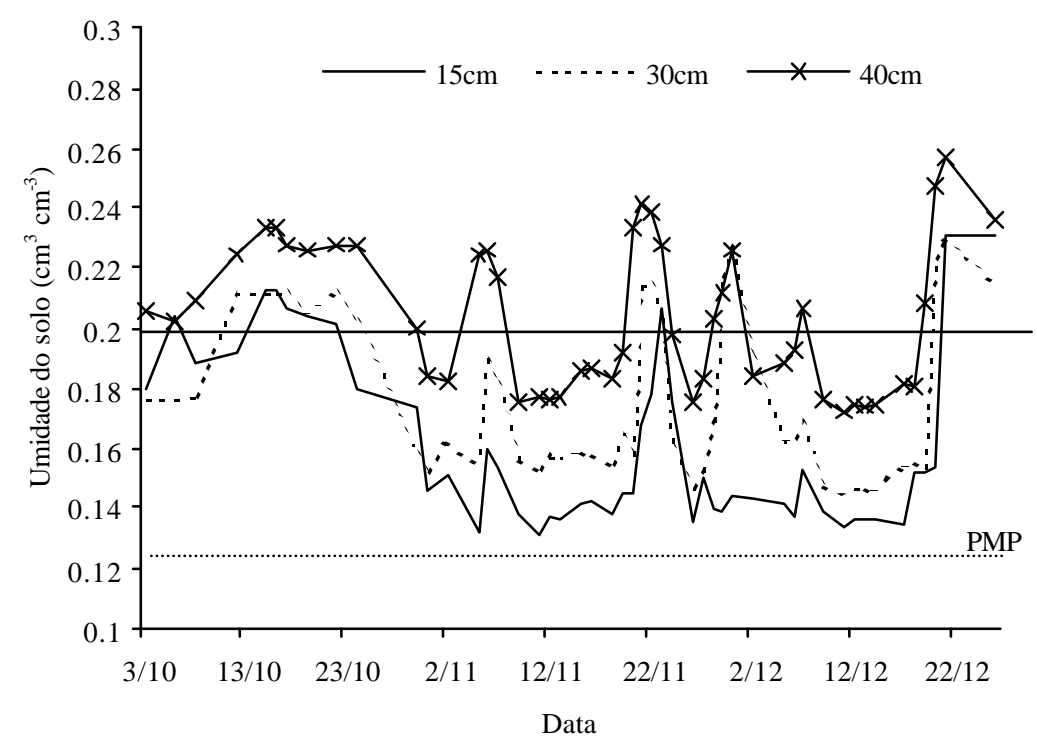

C.C.

b)

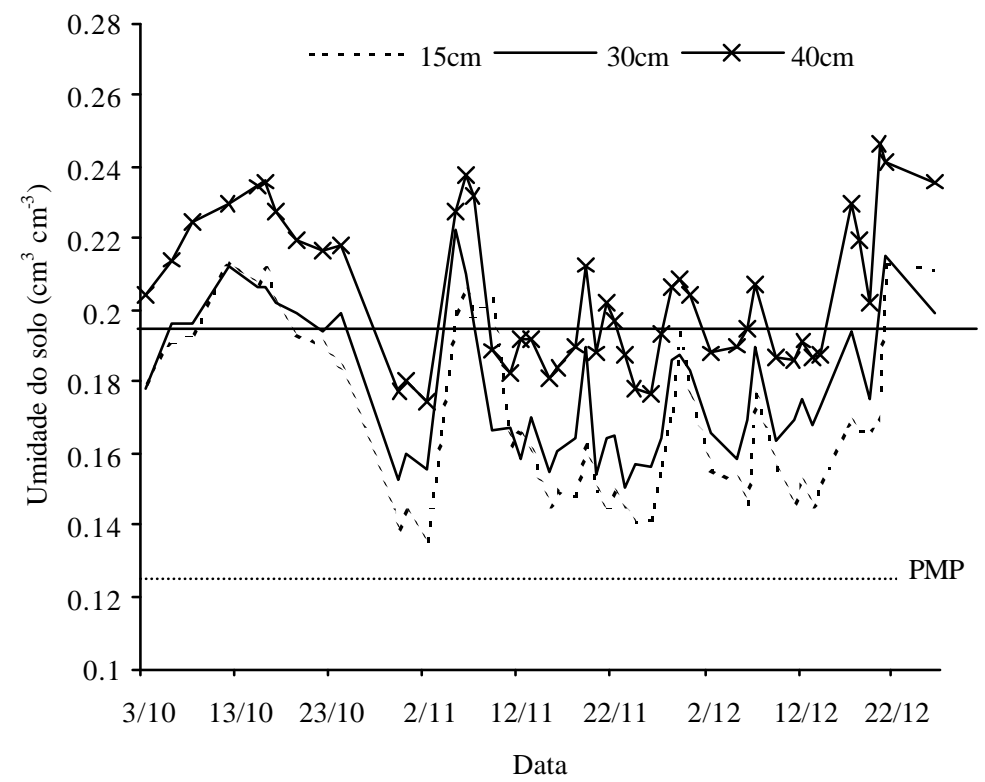

Figura 22 - Variação da umidade do solo $\left(\mathrm{cm}^{3} \mathrm{~cm}^{-3}\right)$ a diferentes profundidades, para o tratamento de nível de irrigação L3 $(417,32 \mathrm{~mm})$ durante o período vegetativo da cultura: a) posição dos tubogotejadores a $0,00 \mathrm{~m}$; b) posição dos tubogotejadores a $0,20 \mathrm{~m}$. 
Mediante uma analise dos diferentes gráficos pode-se comprovar a dificuldade de se manter um potencial matricial próximo do $-10 \mathrm{kPa}$, durante o ciclo da cultura. Durante a fase inicial da cultura, com um consumo de água baixo, é comum a aproximação da umidade atual a valores próximos da saturação, enquanto que na fase de frutificação, é comum que com apenas 24 horas entre uma irrigação e a outra, que se atinja potenciais matriciais por volta de $-40 \mathrm{kPa}$, pois o consumo de água pelas plantas é muito intenso. As flutuações severas entrem a C. C. e o P. M. P dos valores de potencial mátrico e de conteúdo de umidade do solo registrado, podem dever-se à posição de instalação dos tensiômetros que correspondeu praticamente aos extremos do bolbo molhado.

Dourenbos \& Pruit (1976) sugerem um potencial matricial de manejo entre -30 e $-81 \mathrm{kPa}$, enquanto Miller (1984) sugere $-50 \mathrm{kPa}$. Hernandez (1995) trabalhando a campo aberto com melão em Ilha Solteira, comenta que ao se praticar um manejo com um potencial matricial de $-45 \mathrm{kPa}$ a CAD tem se esgotado em mais de $60 \%$ e que Dourenbos \& Kassam (1988), recomendam um esgotamento da apenas 45\% da CAD.

Resultados obtidos por Rodríguez \& Ochoa (1999), estudando a eficiência no uso de água pelo cultivar de melão Laredo, medindo o potencial mátrico do solo a 0,3 $\mathrm{m}$ de profundidade, mostraram que o rendimento comercial foi afetado significativamente pela irrigação. $\mathrm{O}$ tratamento com melhor rendimento comercial, de $24 \mathrm{Mg} \mathrm{ha}{ }^{-1}$, correspondeu ao mais úmido com -0,014 $\mathrm{MPa}$, seguido pelo rendimento médio de 17 $\mathrm{Mg} \mathrm{ha}^{-1}$, com $-0,028 \mathrm{MPa}$, e com o rendimento mais baixo de $14 \mathrm{Mg} \mathrm{ha}^{-1}$, com o mais seco, ou seja -0,033 MPa. As quantidades de água aplicadas durante o cultivo equivalente a estes potencias mátricos respectivamente foram de $423,45 \mathrm{~m}^{3} \mathrm{ha}^{-1}, 320,99$ $\mathrm{m}^{3} \mathrm{ha}^{-1}$ e $233,66 \mathrm{~m}^{3} \mathrm{ha}^{-1}$.

De igual forma Pérez \& Cigales (2001), estudando lâminas totais de irrigação de $390 \mathrm{~mm}, 325 \mathrm{~mm}$ e $279 \mathrm{~mm}$ para as tensões registradas a 0,3 $\mathrm{m}$ de profundidade do solo de $-0,010 \mathrm{MPa},-0,025 \mathrm{MPa}$ e -0,045 MPa com híbrido de melão Cantaloupe, Ovation obtiveram rendimentos de fruta de exportação de $50 \mathrm{Mg} \mathrm{ha}^{-1}$ das categorias 9 e 12 para o tratamento de $-0,010 \mathrm{MPa}$, indicando que os níveis de umidade de $-0,025 \mathrm{MPa}$ e $-0,045$ $\mathrm{MPa}$ afetaram negativamente a produção total de frutas e dos calibres 9 e 12; a diminuição destes com respeito ao tratamento de $-0,010 \mathrm{MPa}$ foi de $26 \%$ a $30 \%$, 
respectivamente. Os valores do módulo de potencial matricial de água no solo registrados acima da capacidade de campo para algumas etapas de desenvolvimento da cultura no presente experimento, especialmente quando aplicados as laminas L1 e L2 na posições P1, coincidem com o manifestado por Gurovich (1979), o qual afirma que o melão pode ser manejado até um nível de $-0,05 \mathrm{MPa}$ a $-0,06 \mathrm{MPa}$ de potencial matricial sem que a produção sofra perdas consideráveis.

\subsection{Dinâmica do potássio no solo}

As concentrações de potássio $\left(\mathrm{mg} \mathrm{L}^{-1}\right)$ dentro dos extratores nas posições instaladas em relação a ponto de emissão, para cada nível de irrigação, dose de potássio e posição dos tubogotejadores em cada período de observação (15 DAT, 20 DAT, 25 DAT, 30 DAT, 35 DAT, 40 DAT, 50 DAT, 60 DAT e 70 DAT) são apresentados nos perfis transversais mostrados nas Figura 23 e 24.

As concentração de potássio para a dose $\mathrm{K} 0\left(0 \mathrm{gr}\right.$ de $\left.\mathrm{KO} \mathrm{pl}^{-1}\right)$ indicam que o valor mínimo e máximo de potássio encontrados foram de $2 \mathrm{mg} \mathrm{L}^{-1}$ e $25 \mathrm{mg} \mathrm{L}^{-1}$, respectivamente. As maiores concentrações de potássio foram: tratamento K0L3P1 para os períodos 15 DAT e 40 DAT, tratamento K0L1P2 para os períodos 20 DAT e 35 DAT, tratamento K0L2P2 para o período 25 DAT, tratamento K0L2P1 para o período 30 DAT e tratamento K0L3P2 para os períodos 45 DAT, 50 DAT e 60 DAT.

Para a dose $\mathrm{K} 1$ (6 gr de $\mathrm{K}_{2} \mathrm{O}_{\mathrm{pl}^{-1}}$ ) o valor mínimo e máximo de potássio encontrados foram de $4 \mathrm{mg} \mathrm{L}^{-1}$ e $200 \mathrm{mg} \mathrm{L}^{-1}$, respectivamente. Verifica-se que as concentrações de potássio foram maiores no tratamento K1L1P2 para os períodos 15 DAT e 30 DAT, no tratamento K1L2P2 para os períodos 20 DAT e 25 DAT, no tratamento K1L3P1 para os períodos 35 DAT, 40 DAT e 45 DAT e no tratamento K1L3P2 para os períodos 50 DAT e 60 DAT. 
Para a dose $\mathrm{K} 2\left(9\right.$ gr de $\mathrm{K}_{2} \mathrm{O} \mathrm{pl}^{-1}$ ) os valores mínimo e máximo de potássio encontrados foram de $6 \mathrm{mg} \mathrm{L}^{-1}$ e $250 \mathrm{mg} \mathrm{L}^{-1}$, respectivamente. As concentrações de potássio foram maiores no tratamento K2L1P1 para os períodos 15 DAT, 25 DAT e 30 DAT, no tratamento K2L1P2 para os períodos 20 DAT e 45 DAT e no tratamento K2L2P2 para os períodos 35 DAT, 40 DAT, 50DAT e 60 DAT.

Para a dose $\mathrm{K} 3$ (12 gr de $\mathrm{K}_{2} \mathrm{O} \mathrm{pl}^{-1}$ ) os valores mínimo e máximo de potássio encontrados foram de $6 \mathrm{mg} \mathrm{L}^{-1}$ e $121 \mathrm{mg} \mathrm{L}^{-1}$, respectivamente. As concentrações de potássio foram maiores no tratamento K3L1P2 para os períodos 15 DAT, 25 DAT e 30 DAT; no tratamento K3L3P1 para os períodos 20 DAT e 45 DAT; no tratamento K3L3P2 para os períodos 35 DAT e 40 DAT; no tratamento K3L2P1 para o período 50 DAT e no tratamento K3L2 P2 para o período de 60 DAT.

Em uma análise geral do comportamento do potássio nos diferentes intervalos de coletas de dados nos extratores, a diferentes profundidades, pode se notar que as doses $\mathrm{K} 1$ e $\mathrm{K} 2$ (6 e $9 \mathrm{~g}$ de $\mathrm{K}_{2} \mathrm{O} \mathrm{pl}^{-1}$ ) apresentaram maior concentração de potássio. Este fato se deve provavelmente a uma melhor disposição das superfícies de adsorção dos colóides do solo em dispor quantidades de potássio dentro da denominada camada difusa, possibilitando sua entrada junto com a água de irrigação nas cápsulas de porcelanas.

De igual forma as menores concentrações de potássio foram encontradas com as doses $\mathrm{K} 0$ e $\mathrm{K} 3\left(0\right.$ e $\left.12 \mathrm{~g} \mathrm{e} \mathrm{K}_{2} \mathrm{O} \mathrm{pl}^{-1}\right)$ devido, no primeiro caso à ausência de aplicação de potássio na água de irrigação e no segundo caso devido possivelmente a uma saturação de potássio no meio circundante o que permitiu sua lixiviação as camadas de solo más profundas. As diferenças de concentrações podem se dever também ao acúmulo entre coletas, ao estado fenológico da cultura, às doses aplicadas, etc., coincidindo com o observado por Kofoed, (1979), que afirma que a lixiviação de potássio no perfil de solo depende de vários fatores, tais como: tipo de solo, teor de argila, CTC do solo, saturação de bases, $\mathrm{pH}$ do solo, precipitação, evapotranspiração, temperatura e coberta vegetal. 
K0L1P1

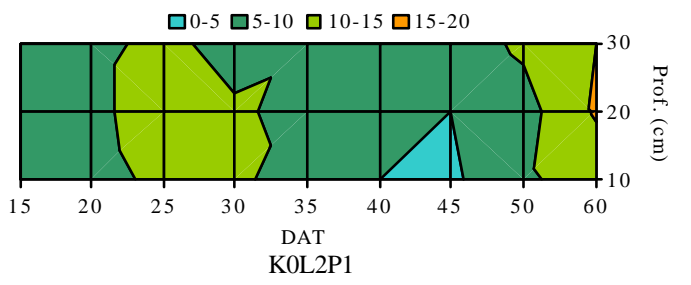

$\square$ 0-5 $\square$ 5-10 $\square$ 10-15 $\square$ 15-20

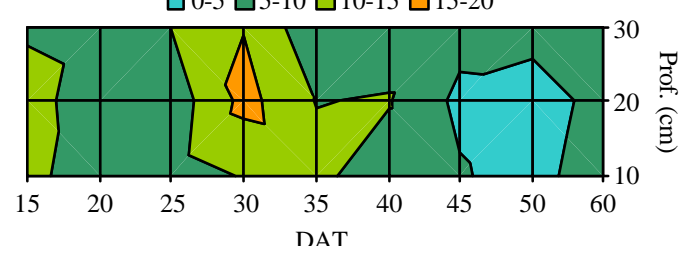

KOI 3D1

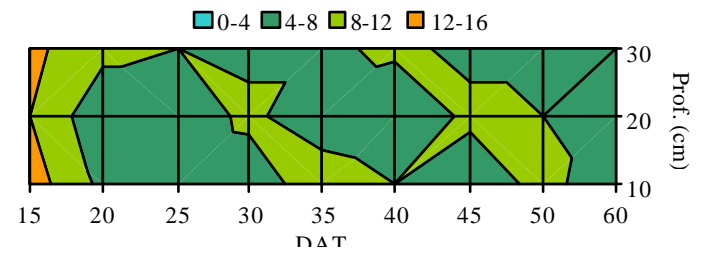

K1L1P1

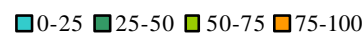

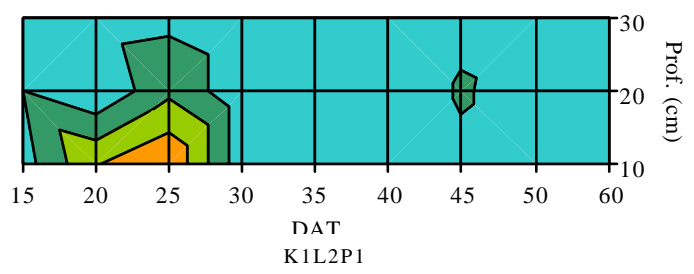

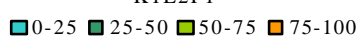

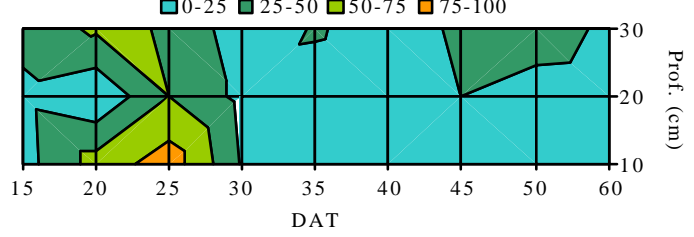

K1L3P1

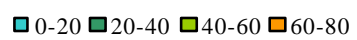

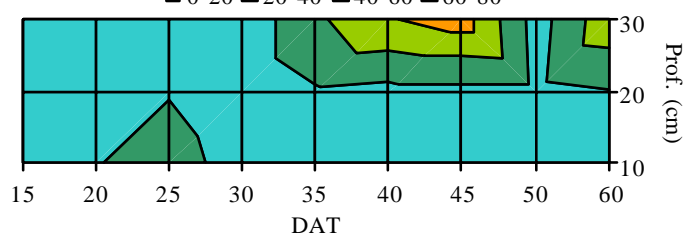

K0L1P2

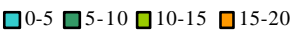

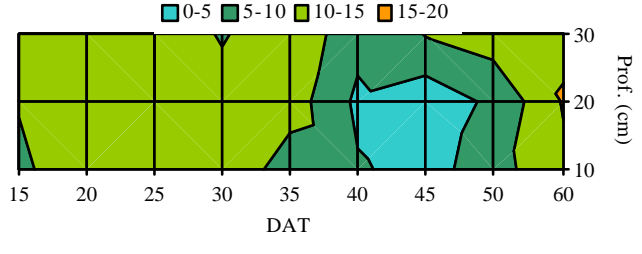

K0L2P2

$\square$ 0-6 $\square$ 6-12 $\square$ 12-18 $\square$ 18-24

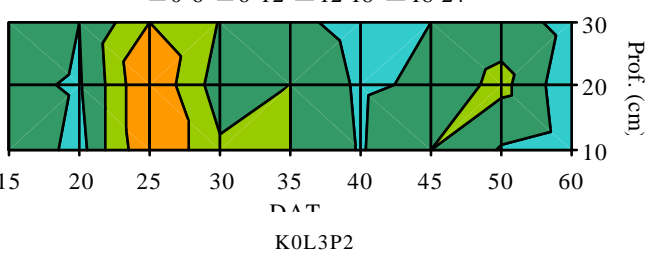

口0-5 घ5-10 $\square^{10-15} \square^{15-20}$

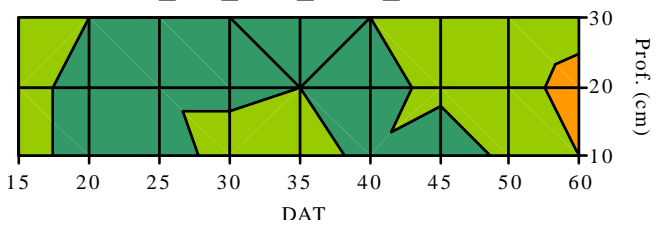

K1L1P2

$\square$ 0-30 $\square$ 30-60 $\square 60-90 \square 90-120$

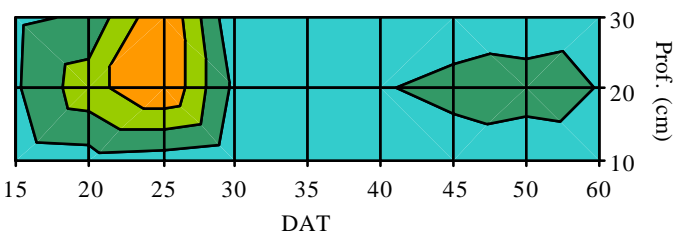

K1L2P2

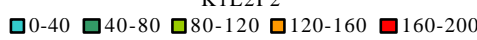

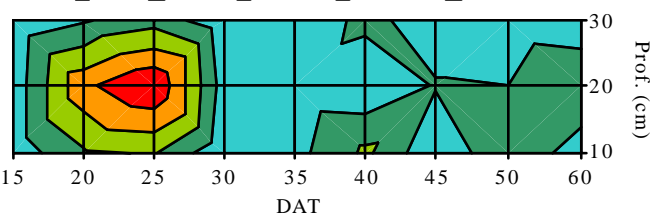

K1L3P2

$\square$ 0-20 $\square$ 20-40 $\square$ 40-60 $\square$ 60-80

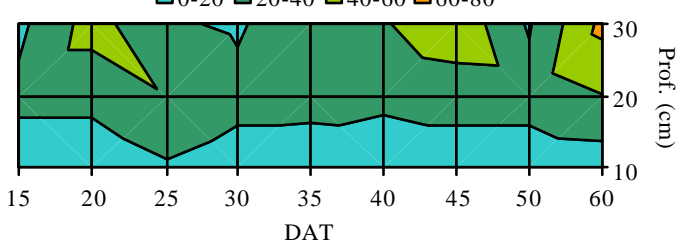

Figura 23 - Concentrações de $\mathrm{K}^{+}\left(\mathrm{mg} \mathrm{L}^{-1}\right)$ dentro dos extratores para as posições dos tubogotejadores (P1 e P2), níveis de irrigação (L1, L2 e L3) e dose de potássio $(\mathrm{K} 0, \mathrm{~K} 1)$ aplicados. 
K2L1P1

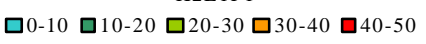

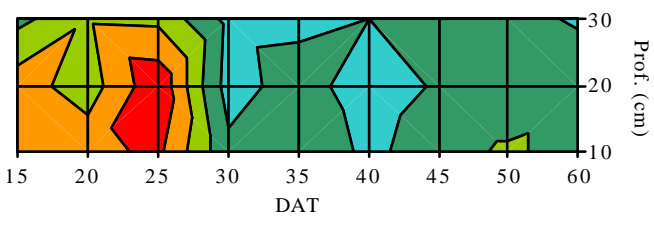

K2L2P1

$\square$ 0-50 $\square$ 50-100 $\square$ 100-150 $\square$ 150-200 $\square_{200-250}$

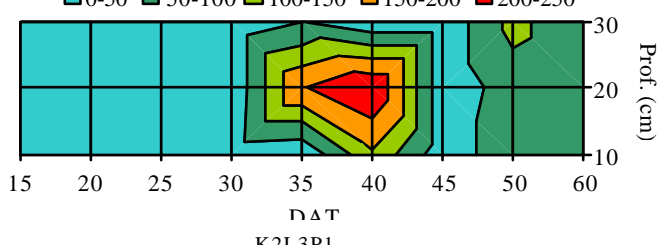

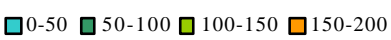

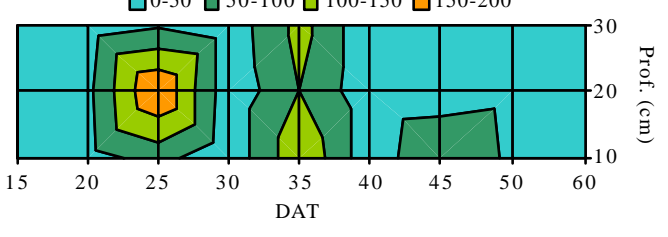

K3L1P1

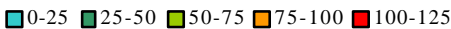

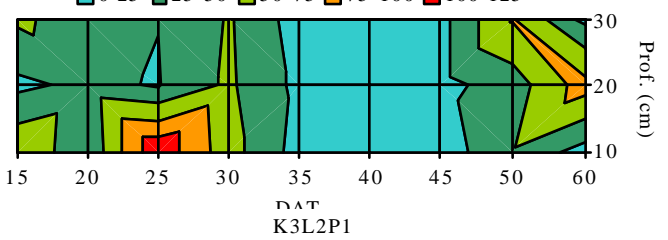

口0-15 $\square$ 15-30 $\square$ 30-45 प45-60

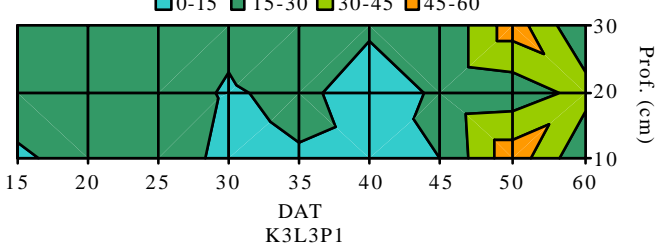

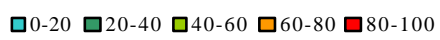

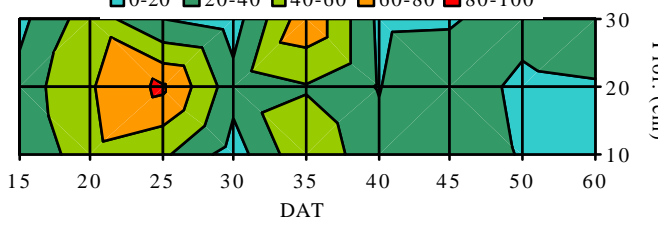

$\mathrm{K} 2 \mathrm{~L} 1 \mathrm{P} 2$

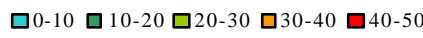

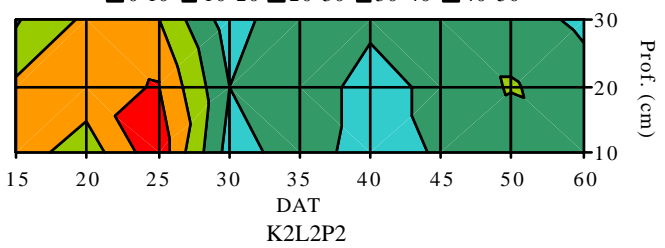

$\square$ 0-50 $\square$ 50-100 $\square$ 100-150 $\square$ 150-200 $\square$ 200-250

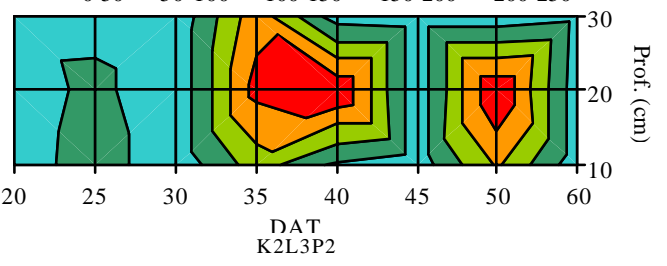

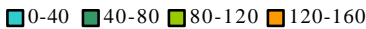

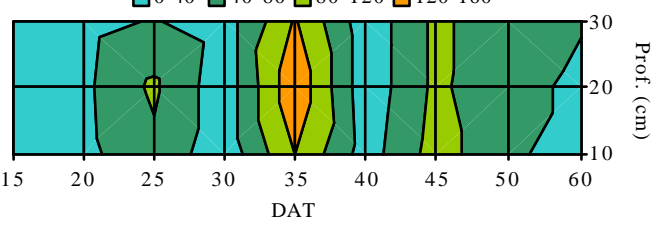

K3L1P2

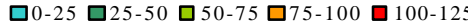

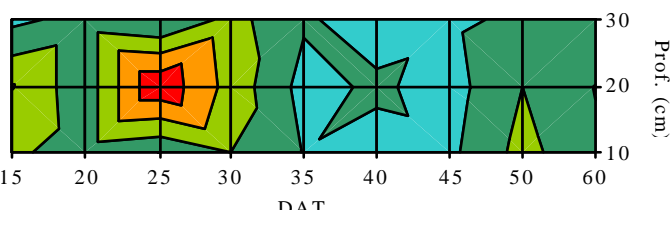

$\mathrm{K} 3 \mathrm{~L} 2 \mathrm{P} 2$

$\square$ 0-15 $\square$ 15-30 $\square$ 30-45 $\square$ 45-60

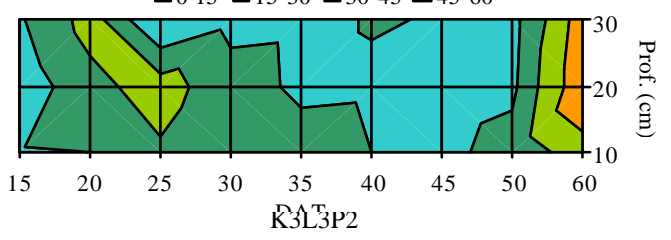

$\square$ 0-20 $\square$ 20-40 $\square$ 40-60 $\square$ 60-80 $\square$ 80-100

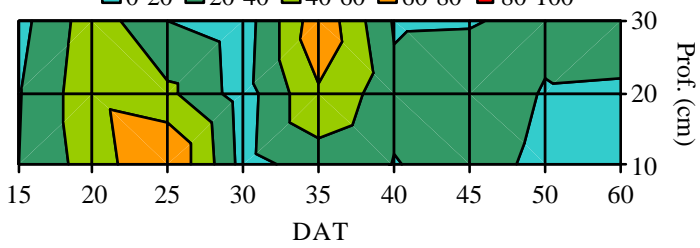

Figura 24 - Concentração de $\mathrm{K}^{+}\left(\mathrm{mg} \mathrm{L}^{-1}\right)$ dentro dos extratores para as posições dos tubogotejadores (P1 e P2), níveis de irrigação (L1, L2 e L3) e dose de potássio (K2, K3) aplicados. 
Devido ao solo apresentar alto conteúdo de areia também pode ter havido lixiviação do potássio tal como foi constado por Konfoed (1979) trabalhando com lisímetros e solos de diferentes texturas. Este autor verificou que o potássio é mais facilmente lixiviado em solos arenosos ou com alta percentagem de húmus e obteve perdas de até $25 \mathrm{~kg}_{\text {de } \mathrm{k} \mathrm{ha}^{-1} \text { ano }}{ }^{-1}$ por lixiviação, em solos com predominância da fração areia.

Nye (1972), utilizando a equação de Nernst-Eistein para o cálculo do coeficiente de difusão de um íon, estimou que o potássio tem índice de $2.10^{-5} \mathrm{~cm}^{2} \mathrm{~s}^{-1}$ em solução aquosa. Em termos práticos, isso significa uma mobilidade de $1 \mathrm{~mm}$ a cada $250 \mathrm{~s}$ para o potássio em solução.

Observas-se também que os maiores níveis de irrigação aplicados pelos tubogotejadores, especialmente quando enterradas, propiciaram uma maior disponibilidade do potássio que pode favorecer a absorção pelas raízes das plantas devido a uma maior oportunidade do cátion em manter-se perto das raízes da planta. Diferentes autores (Barber, 1978; Mengel \& Von Braunschweig, 1972; Diest, 1979) relatam que a velocidade de difusão do potássio é influenciada pelo teor de água do solo e pela concentração do nutriente no solo. A umidade do solo e a velocidade de difusão são diretamente proporcionais, porque o caminho até a raiz torna-se menos tortuoso e há diminuição dos poros ocupados pelo ar, aumentando assim a área disponível à difusão.

Segundo Gianello \& MielniCzuk (1981), o aumento no teor de água no solo proporcionou um aumento significativo na absorção do potássio pela cultura de milho. $\mathrm{O}$ aumento do teor de água no solo diminui a distância do trajeto íon-raiz, aumenta a área transversal disponível à difusão e a superfície de contato da raiz com a solução do solo, resultando maior na absorção de potássio. Os acréscimos na absorção de potássio devido ao maior teor de água no solo foram superiores àqueles ocasionados pela maior concentração de potássio na solução do solo, principalmente quando o teor de água correspondeu ao índice de capacidade de campo de cada solo.

Mangel \& Von Braunschweig (1972) estudando quatro níveis de umidade no solo e cinco níveis de potássio, na cultura de milho, concluíram que não foi a deficiência hídrica que ocasionou menor absorção de potássio pelas plantas e menor produção, visto 
que os valores utilizados ocorrem freqüentemente em condições de campo. Por outro lado afirmam que o aumento na tensão da água no solo inibiu a difusão de potássio às raízes, concluindo também que a difusão do potássio para as raízes é diretamente proporcional àdensidade destas.

As concentrações médias de potássio $\left(\mathrm{mg} \mathrm{kg}^{-1}\right)$ obtidas nas amostras de solo dos respectivos tratamentos depois da colheita e suspensão da irrigação, são apresentados nos perfis transversais das Figuras 25 e 26.

Para a dose $\mathrm{K} 0$ ( 0 gr de $\left.\mathrm{KO} \mathrm{pl}^{-1}\right)$ os valores mínimo e máximo de potássio encontrados foram de $1,9 \mathrm{mg} \mathrm{kg}^{-1}$ e $15,1 \mathrm{mg} \mathrm{kg}^{-1}$, respectivamente, com uma distribuição uniforme dentro perfil do solo. Com referência a estes valores de potássio encontrados no solo dos tratamentos onde não foram aplicados potássio conjetura-se que possa ser devido à incubação do calcário dolomítico, à solubilização do termosfofato com micronutrientes, ao adubo orgânico aplicados em fundação 30 dias antes no transplantio, ao conteúdo inicial de potássio no solo que foi de 0,6 mmol $_{c} \mathrm{dm}^{-3}$ (Tabela 4) e ao teor de potássio na água de irrigação que foi de $3,4 \mathrm{mg} \mathrm{L}^{-1}$ (Tabela 2).

Para a dose $\mathrm{K} 1$ (6 gr de $\mathrm{K}_{2} \mathrm{O} \mathrm{pl}^{-1}$ ) os valores mínimo e máximo de potássio encontrados foram de $3,2 \mathrm{mg} \mathrm{kg}^{-1}$ e $59,7 \mathrm{mg} \mathrm{kg}^{-1}$, respectivamente, correspondendo a menor distribuição no perfil do solo ao tratamento K1L1P1 e maior no tratamento K1L1P2. 

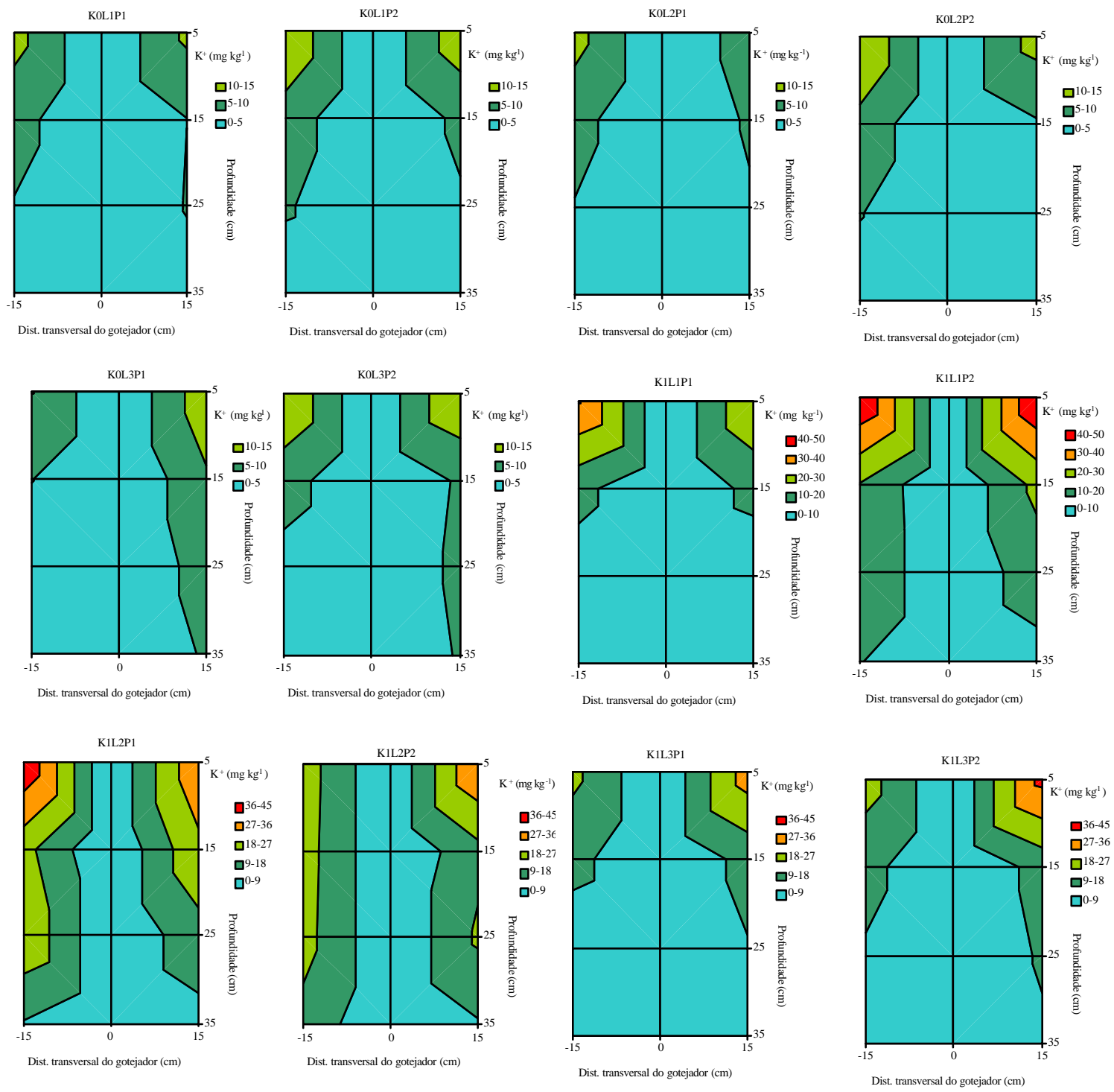

Figura 25 - Distribuição espacial de $\mathrm{K}^{+}\left(\mathrm{mg} \mathrm{kg}^{-1}\right)$ no perfil do solo em função das posições dos tubogotejadores (P1 e P2), níveis de irrigação (L1, L2 e L3) e doses de potássio (K0, K1) aplicados, após colheita. 
Os perfis transversais dos tratamentos onde foram aplicados a dose K2 (9 gr de $\mathrm{K}_{2} \mathrm{O} \mathrm{pl}^{-1}$ ) revelam que o valor mínimo e máximo de potássio encontrados foram de 5,1 $\mathrm{mg} \mathrm{kg}^{-1}$ e 44,5 mg kg${ }^{-1}$, respectivamente, correspondendo a menor distribuição no perfil do solo no tratamento K2L3P1 e maior no tratamento K2L1P2.

Para a dose $\mathrm{K} 3$ (12 gr de $\mathrm{K}_{2} \mathrm{O} \mathrm{pl}^{-1}$ ) os valores mínimo e máximo de potássio encontrados foram de 4,6 $\mathrm{mg} \mathrm{kg}^{-1}$ e 49,9 $\mathrm{mg} \mathrm{L}^{-1}$, respectivamente, correspondendo a menor distribuição no perfil do solo no tratamento K3L3P2 e maior no tratamento K3L2P1.

Observa-se que existe para alguns tratamentos e épocas de aplicação das doses de potássio uma distribuição quase uniforme, porém para a maioria dos tratamentos as concentrações são diferenciadas ao logo dos pontos de amostragem, mostrando uma tendência determinada de maior concentração próxima da superfície do solo. Para a posição subsuperficial dos tubogotejadores, se observa uma concentração maior de potássio ao redor do ponto de emissão devido às proximidades dos pontos de amostragem em relação com os tubogotejadores na superfície.

Estes resultados podem se dever aos diferentes pontos da amostragem, à variação de cada tramento isolado, aos materiais orgânicos e inorgânicos aplicados ao solo e a estado fenológico da cultura. De forma geral todos os tratamentos tiveram maior concentração de potássio na superfície do solo, embora com diferentes valores; esta condição deve-se à perda de umidade por evaporação já que as amostras de solo foram coletadas 15 dias após o término da irrigação. A maior adsorção correspondeu aos tratamentos de dose $\mathrm{K} 1\left(6\right.$ gr de $\left.\mathrm{K}_{2} \mathrm{pl}^{-1}\right)$ e $\mathrm{K} 2\left(9\right.$ gr de $\left.\mathrm{K}_{2} \mathrm{O} \mathrm{pl}^{-1}\right)$ devido à melhor condição de fluxo de massa de íon $\mathrm{K}^{+}$motivado pela evaporação do solo. 

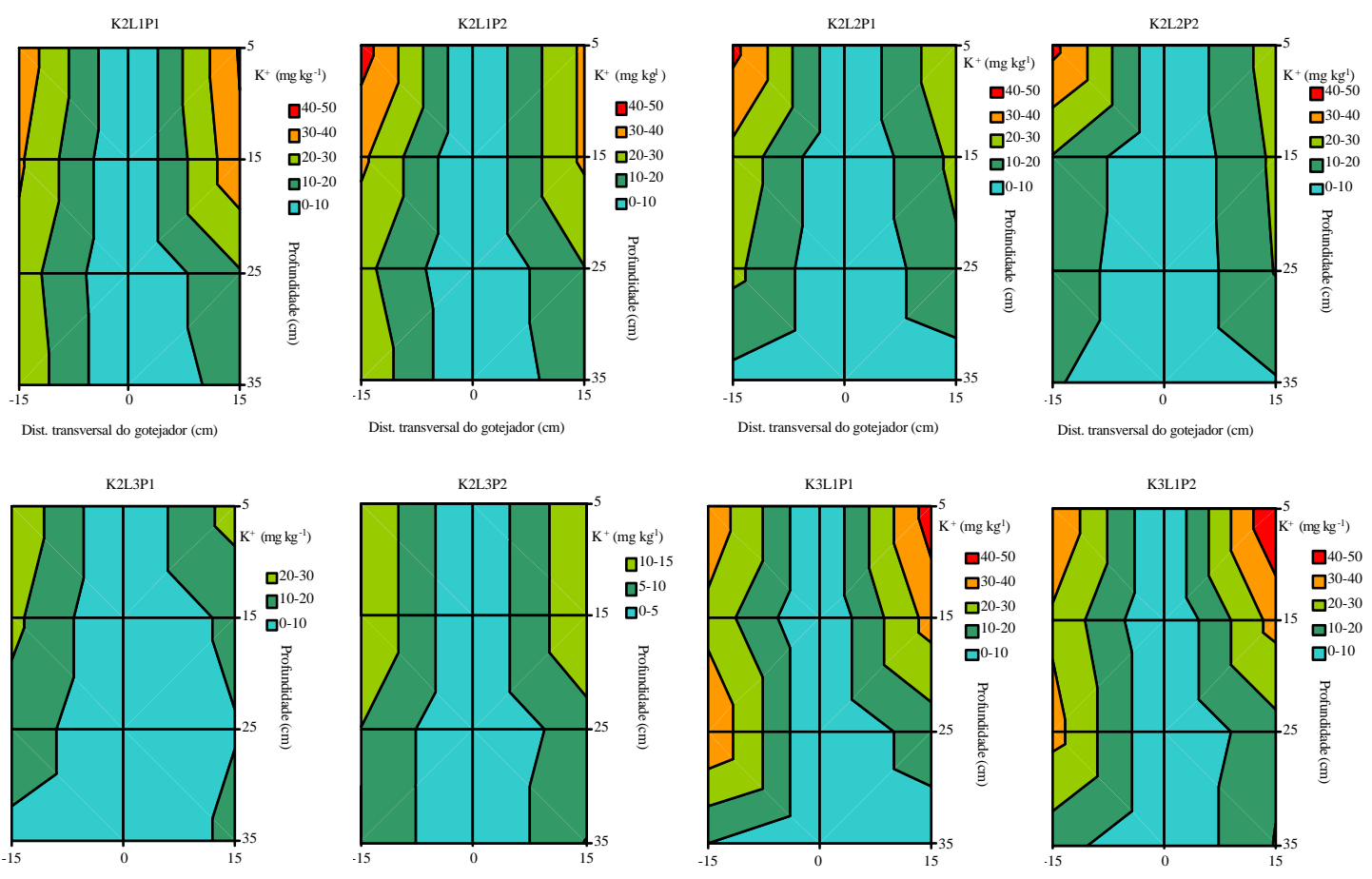

Dist. transversal do gotejador (cm)

Dist. transversal do gotejador $(\mathrm{cm})$

Dist. transversal do gotejador $(\mathrm{cm})$

Dist. transversal do gotejador $(\mathrm{cm})$
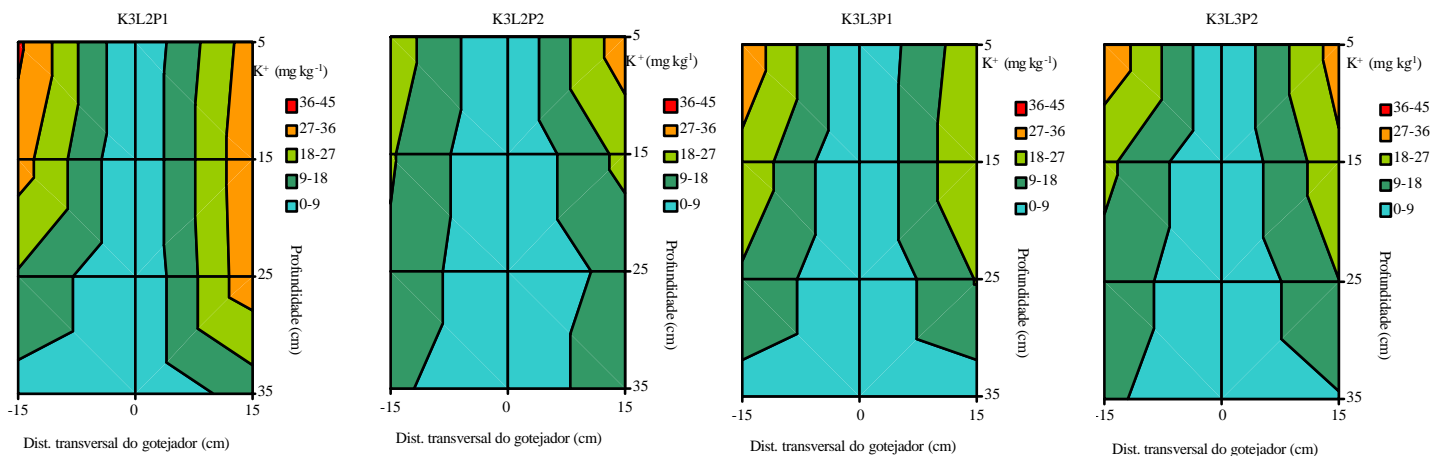

Figura 26 - Distribuição espacial de $\mathrm{K}^{+}\left(\mathrm{mg} \mathrm{kg}^{-1}\right)$ no perfil do solo em função das posições dos tubogotejadores (P1 e P2), níveis de irrigação (L1, L2 e L3) e doses de potássio (K2, K3) aplicados, após colheita. 


\section{6 Parâmetros de desenvolvimento da planta}

\subsection{1 Área foliar}

As medidas de área foliar do híbrido de melão Bonus n $2 \mathrm{em}$ diferentes fases de crescimento, são representados pelas Figuras 27 e 28, para os respectivos tratamentos.

Os efeitos das duas menores doses de potássio em combinação com os níveis de irrigação e posição dos tubogotejadores estão apresentados na Figura 27 (a, b). Para a dose de potássio $\mathrm{K} 0\left(0 \mathrm{~g}\right.$ de $\left.\mathrm{K}_{2} 0 \mathrm{pl}^{-1}\right)$, a menor área foliar correspondeu ao tratamento K0L3P1 para as fases 8 DAT e 24 DAT e ao tratamento K0L1P2 para as demais fases; a maior área foliar correspondeu ao tratamento K0L3P2 para a fase de 8 DAT e ao tratamento K0L2P2 paras as demais fases. Para a dose de potássio $\mathrm{K} 1\left(6 \mathrm{~g} \mathrm{de} \mathrm{K}_{2} 0 \mathrm{pl}^{-1}\right)$, a menor área foliar correspondeu ao tratamento K1L3P1 para todas as fase de desenvolvimento da cultura; a maior área foliar correspondeu ao tratamento K1L1P2 para a fase de 8 DAT e ao tratamento K1L3P2 para as demais fases.
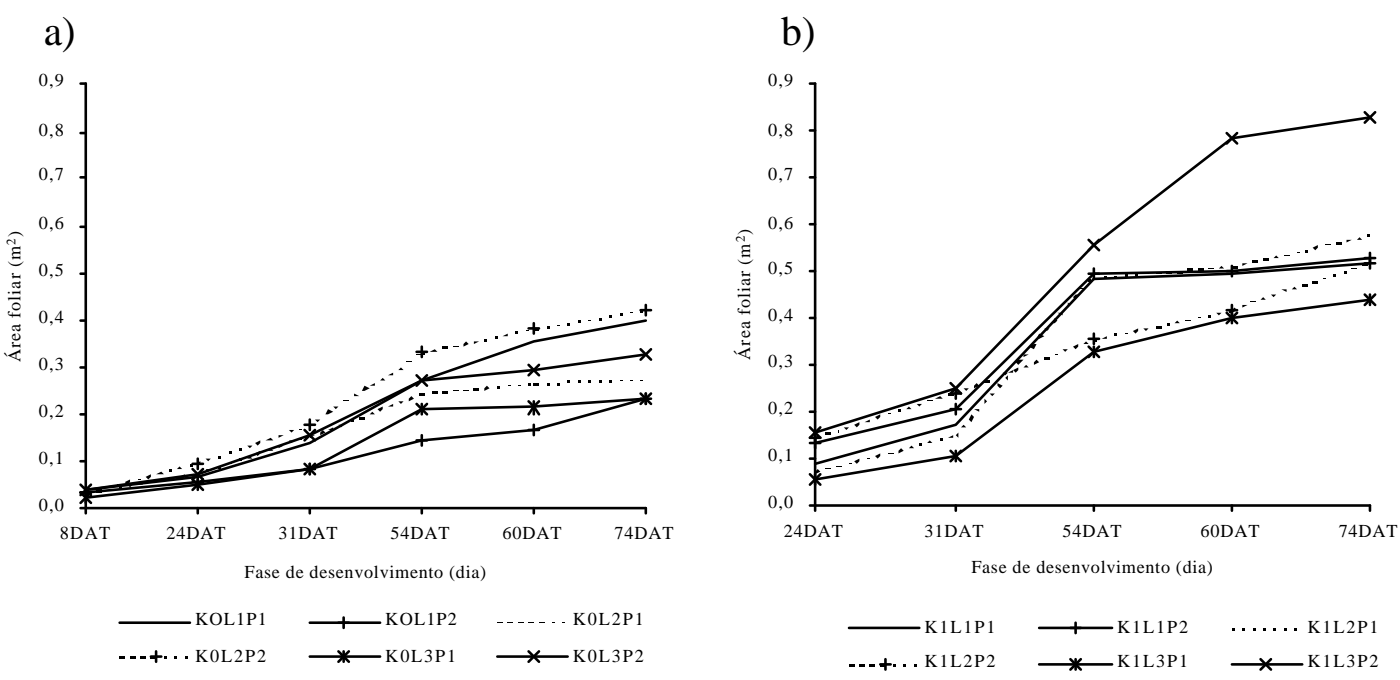

Figura 27 - Área foliar $\left(\mathrm{m}^{2} \mathrm{pl}^{-1}\right)$ nas diferentes fases de desenvolvimento da cultura, para os diferentes tratamentos: a) dose de potássio $\mathrm{K} 0\left(0 \mathrm{~g} \mathrm{~K} 0 \mathrm{pl}^{-1}\right)$; b) dose de potássio $\mathrm{K} 1\left(6 \mathrm{~g} \mathrm{~K}_{2} 0 \mathrm{pl}^{-1}\right)$. 
Para as duas maiores doses de potássio, em combinação com os níveis de irrigação e posição dos tubogotejadores, os efeitos são apresentadas na Figura 28 (a, b). Para a dose de potássio $\mathrm{K} 3\left(9 \mathrm{~g}\right.$ de $\left.\mathrm{K}_{2} 0 \mathrm{pl}^{-1}\right)$, a menor área foliar correspondeu ao tratamento K2L2P1 para todas as fases de desenvolvimento; a maior área foliar correspondeu ao tratamento K2L1P2 para a fase de 8 DAT e ao tratamento K2L3P2 para as demais fases. Para a dose de potássio $\mathrm{K} 4\left(12 \mathrm{~g} \mathrm{de}_{\mathbf{2}} 0 \mathrm{pl}^{-1}\right)$, a menor e maior área foliar em todas as fases de desenvolvimento, correspondeu ao tratamento K3L1P1 e K3L2P2, respectivamente.
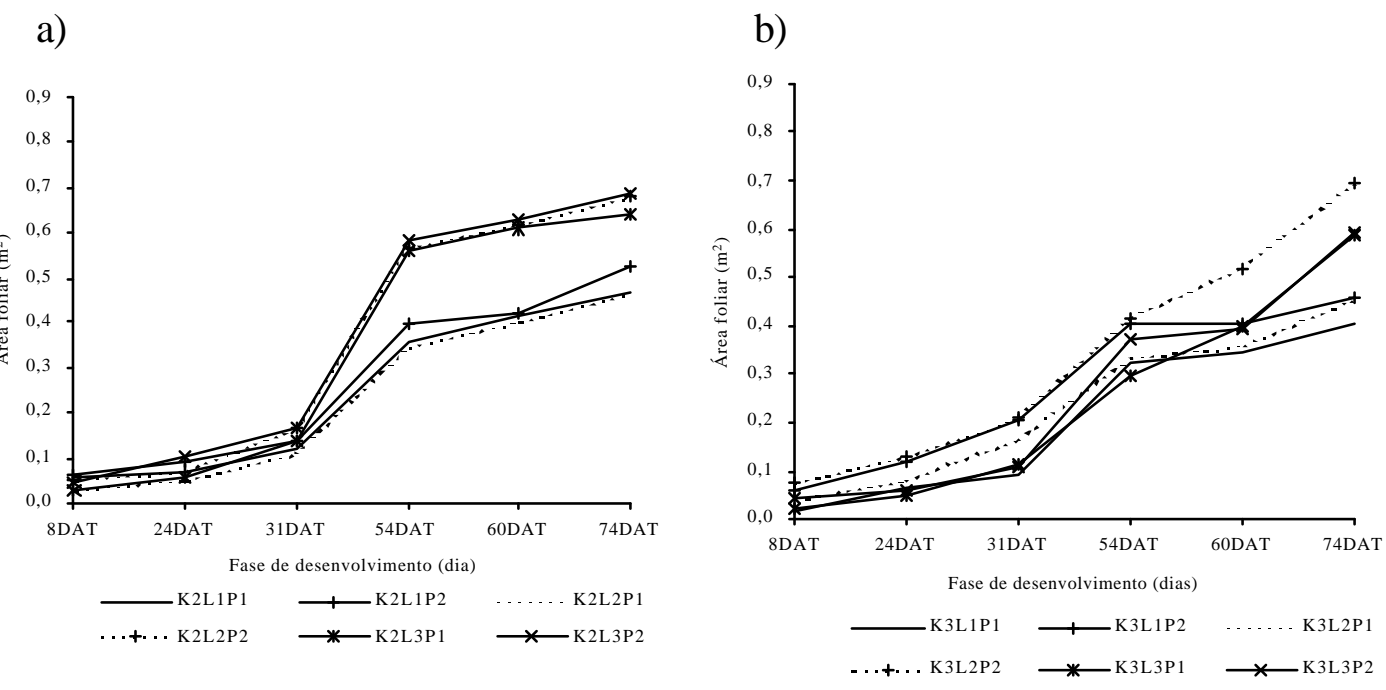

Figura 28 - Área foliar $\left(\mathrm{m}^{2} \mathrm{pl}^{-1}\right)$ nas diferentes fases de desenvolvimento da cultura, para os diferentes tratamentos: a) dose de potássio $\mathrm{K} 3\left(9 \mathrm{~g} \mathrm{~K}_{2} 0 \mathrm{pl}^{-1}\right)$ : b) dose de potássio $\mathrm{K} 4\left(12 \mathrm{~g} \mathrm{~K}_{2} 0 \mathrm{pl}^{-1}\right)$.

As comparações de médias de área foliar para cada fator por separado, são apresentadas na Tabela 13. A área foliar é menor para a dose de potássio $\mathrm{K} 0\left(0 \mathrm{~g}\right.$ de $\mathrm{K}_{2} \mathrm{O}$ $\mathrm{pl}^{-1}$ ) em todas as fases de desenvolvimento da cultura e é maior para a dose de potássio K1 (6 g de $\mathrm{K}_{2} \mathrm{O} \mathrm{pl}^{-1}$ ) nas fases 8 DAT, 24 DAT, 31 DAT e 60 DAT, e para dose de potássio $\mathrm{K} 2\left(9 \mathrm{~g}_{\text {de }} \mathrm{K}_{2} \mathrm{O} \mathrm{pl}^{-1}\right)$ nas fases 54 DAT e 74 DAT.

Para o fator níveis de irrigação, a área foliar é menor para o nível L3 (417,32 mm) 
nas fases 8 DAT, 24 DAT e 31 DAT, e para o nível L1 $(137,72 \mathrm{~mm})$ nas fases de 54 DAT, 60 DAT e 74 DAT; enquanto foi maior para o nível de irrigação L1 (137,72 mm) na fase de 8 DAT, para o nível L2 nas fases de 24 DAT e 31 DAT, e para o nível L3 (417,32mm) nas fase 54 DAT, 60 DAT e 74 DAT. Para o fator posições de instalação dos tubogotejadores em todas as fases de desenvolvimento da cultura, a posição P1 $(0,0 \mathrm{~m})$ mostrou menor área foliar em relação a posição P2 (0,2 m).

Tabela 13. Comparação de médias de área foliar $\left(\mathrm{m}^{2} \mathrm{pl}^{-1}\right)$ para cada nível de fator isolado, nas diferentes fases de desenvolvimento da cultura.

\begin{tabular}{ccccccc}
\hline \multirow{2}{*}{ Nível de fator } & \multicolumn{5}{c}{ Area foliar $\left(\mathrm{m}^{2} \mathrm{pl}^{-1}\right)$ para as diferentes fases de desenvolvimento } \\
& 8DAT & 24DAT & 31DAT & 54DAT & 60DAT & 74DAT \\
\hline K0 & 0,033 & 0,070 & 0,133 & 0,245 & 0,281 & 0,314 \\
K1 & 0,050 & 0,109 & 0,187 & 0,452 & 0,518 & 0,568 \\
K2 & 0,045 & 0,073 & 0,139 & 0,468 & 0,515 & 0,578 \\
K3 & 0,044 & 0,084 & 0,149 & 0,358 & 0,403 & 0,533 \\
L1 & 0,048 & 0,086 & 0,145 & 0,360 & 0,387 & 0,442 \\
L2 & 0,045 & 0,090 & 0,170 & 0,385 & 0,434 & 0,511 \\
L3 & 0,036 & 0,076 & 0,140 & 0,397 & 0,466 & 0,542 \\
P1 & 0,035 & 0,066 & 0,128 & 0,354 & 0,397 & 0,455 \\
P2 & 0,051 & 0,102 & 0,175 & 0,408 & 0,461 & 0,541 \\
\hline
\end{tabular}

Os valores de área foliar que não mostram aumentos seqüenciais durante as fases de desenvolvimento da cultura para as interações dos tratamentos, assim como para os fatores por separados, podem dever-se à superposição de folhas de plantas de outros tratamentos, a horas de sol e inclusive àoportunidade de irrigação.

A analise de variância realizoutse com as médias da área foliar da última fase desenvolvimento da cultura (74 DAT) e são apresentados na Tabela 14. Ocorreu efeito significativo $(\mathrm{P}<0,01)$ para dose de potássio e posição de instalação dos tubogotejadores e também $(\mathrm{P}<0,05)$ para níveis de irrigação, as interações não revelaram efeito significativo ao mesmo nível de probabilidade. 
Tabela 14. Esquema da análise de variância para área foliar, com desdobramento dos graus de liberdade de tratamentos, de acordo com o esquema fatorial $2 \times 3 \times 4$.

\begin{tabular}{lccccc}
\hline \multicolumn{1}{c}{ Causa da variação } & G.L & S.Q & Q.M & F & Prob \\
\hline K & 3 & 0,837 & 0,279 & $13,350^{* *}$ & 0,0047 \\
$\mathrm{~L}$ & 2 & 0,126 & 0,063 & $3,021^{*}$ & 0,0571 \\
$\mathrm{P}$ & 1 & 0,134 & 0,134 & $6,396^{* *}$ & 0,0001 \\
$\mathrm{KxL}$ & 6 & 0,104 & 0,017 & $0,826^{*}$ & 0,0555 \\
$\mathrm{KxP}$ & 3 & 0,022 & 0,007 & 0,357 & 0,7871 \\
PxL & 2 & 0,087 & 0,044 & 2,087 & 0,1341 \\
KxLxP & 6 & 0,245 & 0,041 & 1,955 & 0,0911 \\
(Tratamento) & $(23)$ & & & & \\
Blocos & 2 & 0,068 & 0,034 & 1,618 & 0,2071 \\
Resíduo & 46 & 0,961 & 0,021 & & \\
Total & 71 & 2,584 & & & \\
Média (m $\left.{ }^{2}\right)$ & 0,498 & & & & \\
CV $(\%)$ & 29,026 & \multicolumn{5}{l}{} \\
** e* indicam que o teste de F, foi significativo ao nível de 1\% e de 5\% de probabilidade, respectivamente.
\end{tabular}

Em decorrência dos resultados obtidos e analisados, pode-se concluir que a área foliar aumenta com as doses de potássio $\mathrm{K} 1\left(6 \mathrm{~g} \mathrm{de}_{2} \mathrm{O} \mathrm{pl}^{-1}\right)$ e $\mathrm{K} 2\left(9 \mathrm{~g}\right.$ de $\left.\mathrm{K}_{2} \mathrm{O} \mathrm{pl}{ }^{-1}\right)$ e reduz-se com doses mínima $\mathrm{K} 0\left(0 \mathrm{~g}\right.$ de $\left.\mathrm{K}_{2} \mathrm{O} \mathrm{pl}^{-1}\right)$ ou máxima $\mathrm{K} 3\left(12 \mathrm{~g} \mathrm{de} \mathrm{K}_{2} \mathrm{O} \mathrm{p}{ }^{-1}\right)$. De igual forma os valores de área foliar aumentam a medida em que se incrementa a quantidade de água aplicada e quando os tubogotejadores estão na superficial.

A diminuição na área foliar pode ser consequiência da salinidade do solo provocado pela aplicação de altas doses de potássio e os níveis baixos de água de alguns tratamentos. Maruyama et al., (2000), estudando o mesmo híbrido de melão Bônus ñ 2, sob cultivo protegido, obtiveram maior área foliar por planta, na floração $\left(0,3613 \mathrm{~m}^{2}\right) \mathrm{e}$ colheita aos $98 \operatorname{DAT}\left(0,7701 \mathrm{~m}^{2}\right)$.

Rizzo \& Raz (2001), encontraram área 6liar no período reprodutivo do meloeiro (floração/frutificação) mais especificamente aos 52 DAT de 0,42 m². Acok et al., (1990) encontraram área foliar de 0,0164 aos 24 DAT e de 0,1421 $\mathrm{m}^{2}$ aos 35 DAT. Cardoso (2000) obtiveram para os períodos de 24 DAT, 31 DAT e 52 DAT área foliar de 0,1327 $\mathrm{m}^{2}, 0,3743 \mathrm{~m}^{2}$ e $1,693 \mathrm{~m}^{2}$ respectivamente.

Welles \& Buitelaar (1988), relataram que o conteúdo de sólidos solúveis diminui significativamente com a diminuição da área foliar, pois uma maior área foliar pode 
incrementar a capacidade fotossintética da planta.

\subsubsection{Número de folhas}

As variações temporaias dos valores médios de número de folhas são apresentados nas Figuras 29 e 30, para os respectivos tratamentos.

Os efeitos das duas menores doses de potássio $\left(\mathrm{K} 0=0 \mathrm{~g}\right.$ de $\mathrm{K}_{2} \mathrm{O} \mathrm{pl}{ }^{-1}$ e $\mathrm{K} 1=6 \mathrm{~g}$ de $\mathrm{K}_{2} \mathrm{O} \mathrm{pl}{ }^{-1}$ ) em combinação com os níveis de irrigação e posição dos tubogotejadores são apresentados na Figura 29 (a, b). Para a dose K0, o menor número de folhas correspondeu ao tratamento K0L3P1 para as fases 8 DAT e 24 DAT e ao tratamento K0L1P2 para as demais fases; o maior número de folhas correspondeu ao tratamento K0L3P2 para a fase de 8 DAT e ao tratamento K0L2P2 para as demais fases. Para a dose $\mathrm{K} 1$, o menor número de folhas correspondeu ao tratamento K1L1P1 para a fase de 8 DAT e ao tratamento K1L3P1 para as demais fases; o maior número de folhas correspondeu ao tratamento K1L1P2 para a fase de 8 DAT e ao tratamento K1L3P2 para as demais fases.

a)

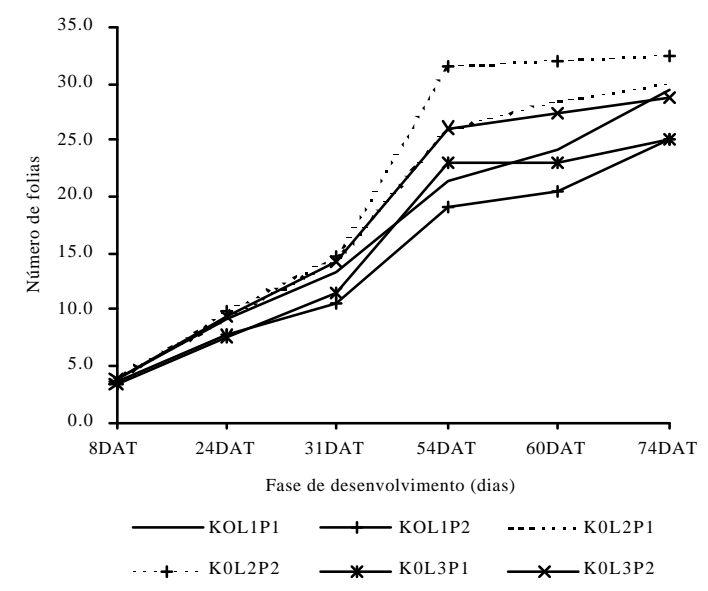

b)

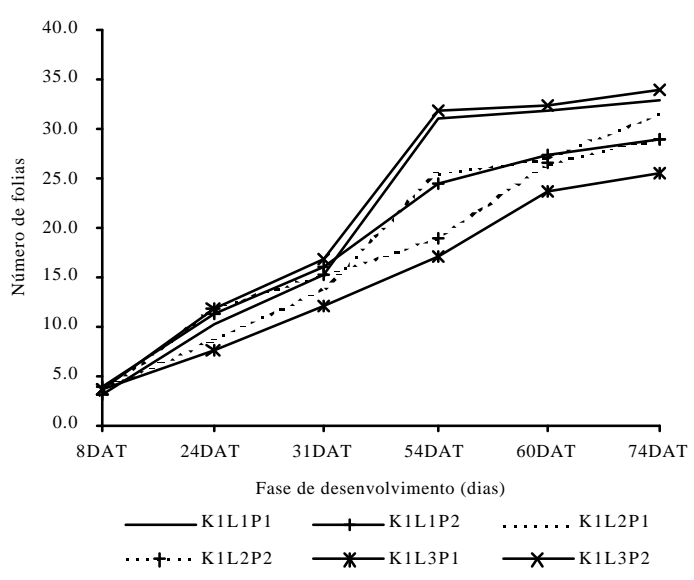

Figura 29 - Número de folhas $\mathrm{pl}^{-1}$ para as diferentes fases de desenvolvimento da cultura, para os diferentes tratamentos: a) dose de potássio $\mathrm{K} 0\left(0 \mathrm{~g} \mathrm{~K}_{2} 0 \mathrm{pl}^{-1}\right)$; b) dose de potássio $\mathrm{K} 1\left(6 \mathrm{~g} \mathrm{~K}_{2} 0 \mathrm{pl}^{-1}\right)$. 
Os efeitos das duas maiores doses de potássio $\left(\mathrm{K} 2=9 \mathrm{~g}\right.$ de $\mathrm{K}_{2} \mathrm{O}$ planta $^{-1}$ e $\mathrm{K} 3=$ $12 \mathrm{~g}$ de $\mathrm{K}_{2} \mathrm{O}$ planta $^{-1}$ ) em combinação com os níveis de irrigação e posição dos tubogotejadores são apresentados na Figura 30 (a, b). Para a dose K2, o menor número de folhas correspondeu ao tratamento K2L2P1 para as fases 8 DAT, 24 DAT e 31 DAT e ao tratamento K2L1P1para as demais fases; o maior número de folias correspondeu ao tratamento K2L1P1 para a fase de 8 DAT e ao tratamento K2L3P2 para as demais fases.

Para a dose K3, o menor número de folias correspondeu ao tratamento K3L2P2 para a fase de 8 DAT, ao tratamento K3L1P2 para as fases de 24 DAT e 31 DAT, e ao tratamento K3L3P1 para as demais fases; o valor máximo correspondeu ao tratamento K3L1P2 para a fase de 8 DAT, ao tratamento K3L1P1 para a fase 24 DAT, ao tratamento K3L2P2 para a fase de 31 DAT e 60 DAT, ao tratamento K3L3P2 para a fase 54 DAT e ao tratamento K3L2P1 para a fase 74 DAT.

a)

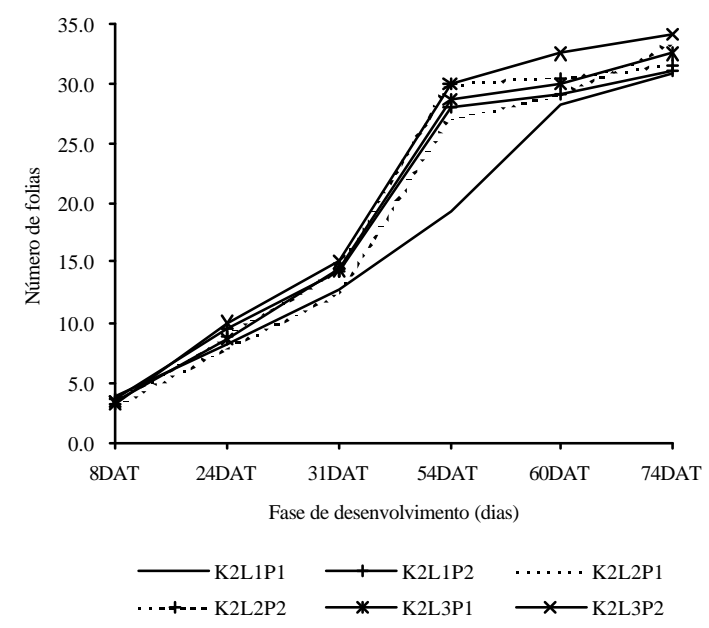

b)

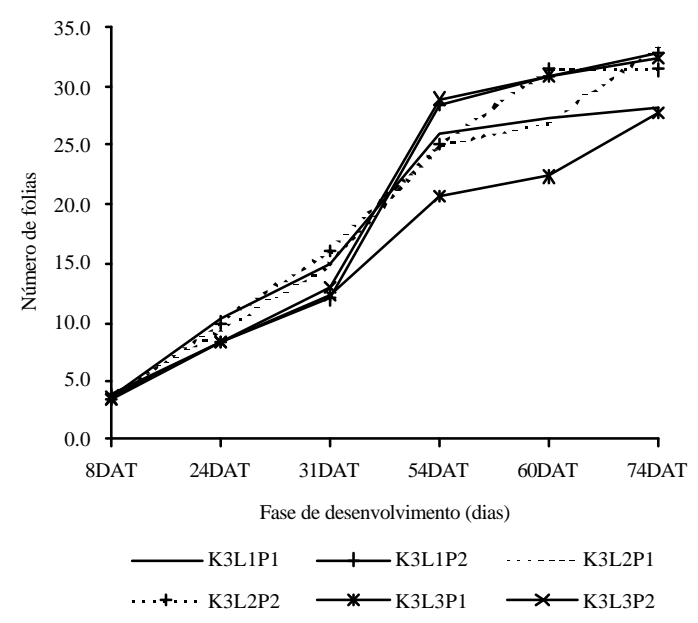

Figura 30 - Número de folhas $\mathrm{pI}^{1}$ para as diferentes fases de desenvolvimento da cultura, para os diferentes tratamentos: a) dose de potássio $\mathrm{K} 2\left(9 \mathrm{~g} \mathrm{~K}_{2} 0 \mathrm{pl}^{-1}\right)$; b) dose de potássio $\mathrm{K} 3\left(12 \mathrm{~g} \mathrm{~K}_{2} \mathrm{Opl}^{-1}\right)$. 
As comparações de médias de número de folhas para cada fator separadamente são apresentadas na Tabela 15. Considerando as três últimas fases de desenvolvimento da planta, o número de folhas é menor para a dose de potássio $\mathrm{K} 2\left(9 \mathrm{~g}\right.$ de $\mathrm{K}_{2} \mathrm{O}$ planta $\left.^{-1}\right)$ e

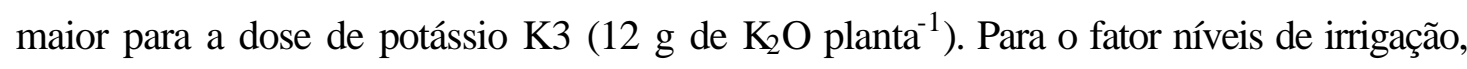
o número de folhas é menor para o nível L1 (137,72 mm) e maior o nível L2 (279,60 $\mathrm{mm}$ ). Para o fator posições de instalação dos tubogotejadores o número de folhas foi menor para a posição $\mathrm{P} 1(0,0 \mathrm{~m})$ e maior para a posição $\mathrm{P} 2(0,2 \mathrm{~m})$.

Tabela 15. Comparação de médias de número de folhas para cada nível de fator isolado, nas diferentes fases de desenvolvimento da cultura.

\begin{tabular}{ccccccc}
\hline \multirow{2}{*}{ Nível de fator } & \multicolumn{5}{c}{ Numero de folhas para as diferentes fases de desenvolvimento } \\
& 8DAT & 24DAT & 31DAT & 54DAT & 60DAT & 74DAT \\
\hline K0 & 3,691 & 8,806 & 13,069 & 24,500 & 25,917 & 28,458 \\
K1 & 3,490 & 10,250 & 14,917 & 24,808 & 28,200 & 30,333 \\
K2 & 1,724 & 4,417 & 6,944 & 13,588 & 14,933 & 16,083 \\
K3 & 3,577 & 9,028 & 13,861 & 25,683 & 28,400 & 31,042 \\
L1 & 3.690 & 9.313 & 13.656 & 24,700 & 27.488 & 29.906 \\
L2 & 3.429 & 9.438 & 14.479 & 26,094 & 29.000 & 31.594 \\
L3 & 3.536 & 8.938 & 13.667 & 25,831 & 27.800 & 30,000 \\
P1 & 3,552 & 8,736 & 13,493 & 24,221 & 27,875 & 30,042 \\
P2 & 3,528 & 9.722 & 14,375 & 26,863 & 29,317 & 30,958 \\
\hline
\end{tabular}

Os valores médios de número de folhas que não mostraram aumentos seqüenciais durante as fases de desenvolvimento da cultura para as interações dos tratamentos, assim como para os fatores separadamente, podem dever-se a superposição de folhas de plantas de outros tratamentos, a podas, a horas de sol, a oportunidade de irrigação e ao balanço nutricional inerentes a fatores fisiológicos da própria planta do meloeiro.

De forma geral pode-se deduzir que o número de folhas foi menos para a dose de potássio $\mathrm{K} 2\left(9{\mathrm{~g} \text { de } \mathrm{K}_{2} \mathrm{O} \mathrm{pl}}^{-1}\right)$ e foi maior para doses de potássio $\mathrm{K} 0\left(0 \mathrm{~g}\right.$ de $\left.\mathrm{K}_{2} \mathrm{O} \mathrm{pl}^{-1}\right), \mathrm{K} 1$ (6 $\mathrm{g}$ de $\left.\mathrm{K}_{2} \mathrm{O} \mathrm{pl}{ }^{-1}\right)$ e $\mathrm{K} 3\left(12{\mathrm{~g} \mathrm{de} \mathrm{K}_{2} \mathrm{O} \mathrm{pl}}^{-1}\right)$. De igual forma o número de folhas aumenta a 
medida em que se incrementa a quantidade de água aplicada e quando o tubogotejador estava na subsuperfície.

A analise de variância foi realizada com as médias do número de folhas da última fase de desenvolvimento da cultura (74 DAT) e é apresentada na Tabela 16. Verifica-se que houve efeito significativo $(\mathrm{P}<0,01)$ para dose de potássio, níveis de irrigação e para a interação níveis de irrigação e posição de instalação dos tubogotejadores, com baixo coeficiente de variação $(7,59 \%)$.

Tabela 16. Esquema da análise de variância para número de folhas, com desdobramento dos graus de liberdade de tratamentos, de acordo com o esquema fatorial $2 \times 3 \times 4$.

\begin{tabular}{lccclc}
\hline Causa da variação & G.L & S.Q & Q.M & F & Prob. \\
\hline K & 3 & 127,266 & 42,422 & $7,988^{* *}$ & 0,0002 \\
$\mathrm{~L}$ & 2 & 56,340 & 28,170 & $5,304 * *$ & 0,0085 \\
$\mathrm{P}$ & 1 & 7,508 & 7,508 & 1,414 & 0,2405 \\
KxL & 6 & 88,424 & 14,737 & $2,775^{*}$ & 0,0218 \\
KxP & 3 & 30,510 & 10,170 & 1,915 & 0,1404 \\
PxL & 2 & 90,250 & 45,125 & $8,497 * *$ & 0,0007 \\
KxLxP & 6 & 87,972 & 14,662 & $2,761^{*}$ & 0,0224 \\
(Tratamento) & $(23)$ & & & & \\
Blocos & 2 & 1,468 & 0,734 & 0,138 & \\
Resíduo & 46 & 244,296 & 5,311 & & \\
Total & 71 & 734,033 & & & \\
Média (n & & & & & \\
CV $(\%)$ & 30,358 & & & & \\
** e* indicam que o teste de F, foi significativo ao nível de 1\% e de 5\% de probabilidade, respectivamente.
\end{tabular}

Tendo em vista que os resultados da análise de variância para o número de folhas do meloeiro mostraram efeitos significativos para as interações das variáveis estudadas (KxLxP), procedeu-se ao desdobramento da variável qualitativa de posição das linhas laterais (P1 e P2) pelo teste de Tukey (Tabela 17) mostrando que o número de folhas aumenta quando se aplica fertirrigação na subsuperfície com um desvio mínimo significativo (DMS) de 3,664 (P<0,05) e 4,886 (P<0,01) em relação a aplicação de fertirrigação na superfície. 
Tabela 17. Resumo de significância para número de folhas pelo teste de Tukey para o fator de posição das linhas portagotejadores $(\mathrm{P})$, dentro dos níveis dos fatores de níveis de irrigação (L) e doses de potássio (K) aplicado.

\begin{tabular}{cccc}
\hline \multirow{2}{*}{ Causas de variação } & Média original & $5 \%$ & (significância-Prob. > F) \\
& & $5 \%$ & $\mathrm{~A}$ \\
\hline P1(L1xK0) & 29,500 & $\mathrm{a}$ & $\mathrm{A}$ \\
P2(L1xK0) & 25,000 & $\mathrm{~b}$ & $\mathrm{~A}$ \\
P1(L1xK1) & 23,000 & $\mathrm{a}$ & $\mathrm{A}$ \\
P2(L1xK1) & 29,000 & $\mathrm{~b}$ & $\mathrm{~A}$ \\
P1(L1xK3) & 28,500 & $\mathrm{a}$ & $\mathrm{A}$ \\
P2(L1xK3) & 32,750 & $\mathrm{~b}$ & $\mathrm{~A}$ \\
P1(L3xK0) & 25,000 & $\mathrm{a}$ & $\mathrm{A}$ \\
P2(L3xK0) & 28,750 & $\mathrm{~b}$ & $\mathrm{~A}$ \\
P1(L3xK1) & 25,500 & $\mathrm{a}$ & $\mathrm{B}$ \\
P2(L3xK1) & 34,000 & $\mathrm{~b}$ & $\mathrm{~A}$ \\
P1(L3xK3) & 27,750 & $\mathrm{a}$ & $\mathrm{A}$ \\
P2(L3xK3) & 32,500 & $\mathrm{~b}$ & \\
\hline
\end{tabular}

Medias seguida por letras distintas deferem entre si ao nível de significância indicado.

D.M.S. $5 \%=3,664$; D. M. S. $1 \%=4,886$.

As interações pelo teste da regressão para as variáveis qualitativas de níveis de irrigação (L) e doses de potássio $(\mathrm{K})$ aplicado apresentam efeito linear e quadrático $(\mathrm{P}<0,01)$. As equações de regressão são amostradas na Tabela 18 , revelando maior relação da interação $\mathrm{K}(\mathrm{P} 2 \times \mathrm{xL})\left(\mathrm{R}^{2}=0,99\right)$ e regressão quadrática para a interação $\mathrm{K}(\mathrm{P} 1 \mathrm{xL1})\left(\mathrm{R}^{2}=0,99\right)$. De modo geral o número de folhas foi dependente dos níveis de irrigação, dose de potássio e posição das linhas portagotejadores, segundo a última fase de desenvolvimento da cultura. 
Tabela 18. Equações lineares e quadráticas resultantes do teste de regressão para o fator lâmina de irrigação (L) e dose de potássio (K) aplicados para o número de folhas

\begin{tabular}{|c|c|c|c|}
\hline Causas de variação & Equação. & $\mathrm{R}^{2}$ & (significância - Prob. F) \\
\hline $\mathrm{L}(\mathrm{P} 1 \mathrm{xK} 0)$ & $Y=32,617-0,0159 x$ & 0,65 & $* *$ \\
\hline $\mathrm{L}(\mathrm{P} 1 \mathrm{xK} 1)$ & $Y=37,440-0,027 x$ & 0,89 & $* *$ \\
\hline $\mathrm{L}(\mathrm{P} 2 \mathrm{xK} 0)$ & $Y=24,963+0,014 x$ & 0,26 & $*$ \\
\hline $\mathrm{L}(\mathrm{P} 2 \mathrm{xK} 1)$ & $Y=25,717+0,018 x$ & 0,74 & $* *$ \\
\hline $\mathrm{K}(\mathrm{P} 1 \mathrm{xL} 1)$ & $Y=29,566+1,139 x-0,105 x^{2}$ & 0,96 & $* *$ \\
\hline $\mathrm{K}(\mathrm{P} 1 \mathrm{~L} 2)$ & $Y=29,957+0,312 x$ & 0,95 & $*$ \\
\hline $\mathrm{K}(\mathrm{P} 1 \mathrm{xL} 3)$ & $Y=25,036+0,393 x$ & 0,35 & $* *$ \\
\hline $\mathrm{K}(\mathrm{P} 2 \mathrm{xL} 1)$ & $Y=25,050+0,650 x$ & 0,99 & $* *$ \\
\hline $\mathrm{K}(\mathrm{P} 2 \mathrm{xL} 3)$ & $Y=29.950+0,350 x$ & 0,52 & $* *$ \\
\hline
\end{tabular}

\subsubsection{Altura da planta}

As variações temporais dos valores médios de altura das plantas do híbrido de melão Bônus $n^{\circ} 2$ são apresentadas nas Figuras 31 e 32, para os respectivos tratamentos.

Os efeitos das duas menores doses de potássio $\left(\mathrm{K} 0=0 \mathrm{~g}\right.$ de $\mathrm{K}_{2} \mathrm{O} \mathrm{pl}{ }^{-1}$ e $\mathrm{K} 1=6 \mathrm{~g}$ de $\mathrm{K}_{2} \mathrm{O}$ pl$^{-1}$ ) em combinação com os níveis de irrigação e posição dos tubogotejadores são apresentadas na Figura 31 (a, b). Para a dose K0, a menor altura correspondeu ao tratamento K0L1P1 e a maior altura ao tratamento K0L3P2, em todas as fases de desenvolvimento. Para a dose de potássio K1, a menor altura correspondeu ao tratamento $\mathrm{K} 1 \mathrm{~L} 1 \mathrm{P} 1$ e a maior altura ao tratamento K1L3P2, em todas as fases de desenvolvimento. 
a)

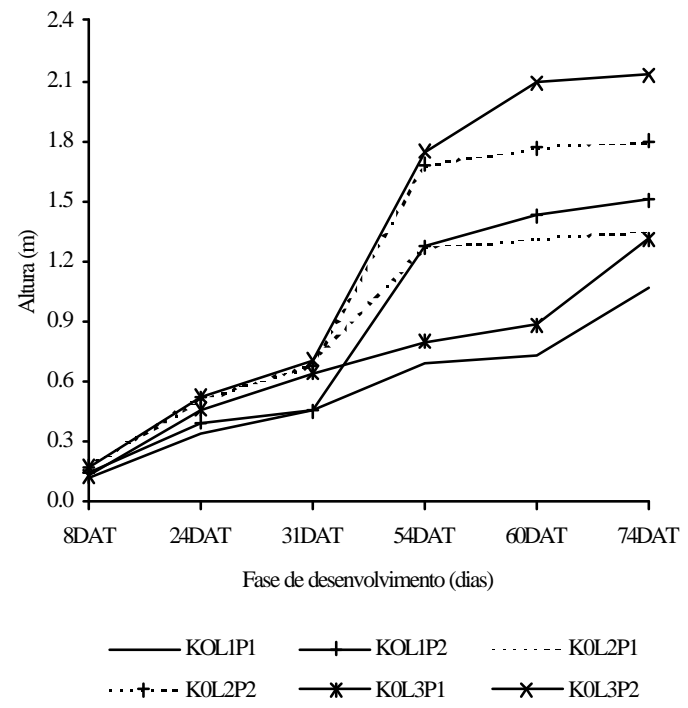

b)

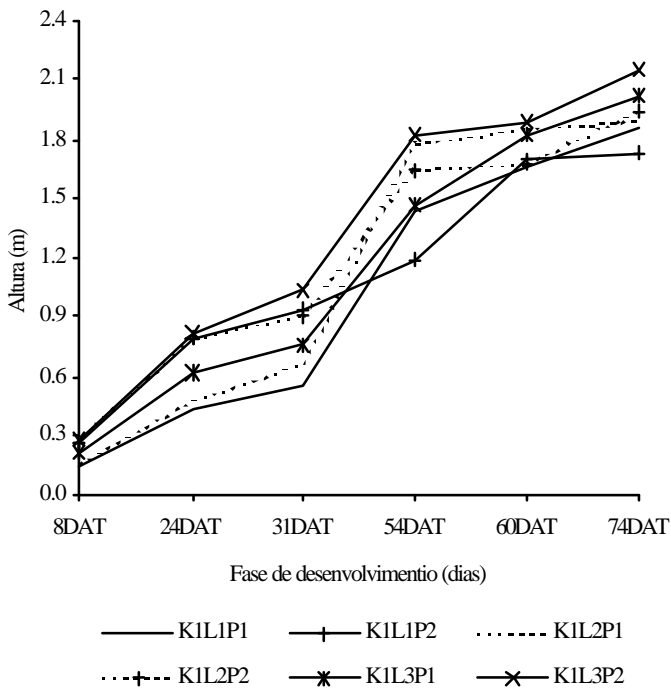

Figura 31 - Altura de plantas (m) nas diferentes fases de desenvolvimento da cultura, para os diferentes tratamentos: a) dose de potássio $\mathrm{K} 0\left(0 \mathrm{~g} \mathrm{~K} 0 \mathrm{pl}^{-1}\right)$; b) dose de potássio $\mathrm{K} 1\left(6 \mathrm{~g} \mathrm{~K}_{2} 0 \mathrm{pl}^{-1}\right)$.

Os efeitos das duas maiores doses de potássio $\left(\mathrm{K} 2=9 \mathrm{~g}\right.$ de $\mathrm{K}_{2} \mathrm{O} \mathrm{pl}{ }^{-1}$ e $\mathrm{K} 3=12 \mathrm{~g}$ de $\mathrm{K}_{2} \mathrm{O} \mathrm{pl}{ }^{-1}$ ) em combinação com os níveis de irrigação e posição dos tubogotejadores são apresentadas na Figura $32(a, b)$. Para a dose K2, a menor altura correspondeu ao tratamento K2L1P1 em todas as fases de desenvolvimento; a maior altura correspondeu ao tratamento K2L2P2 na fase de 8 DAT e ao tratamento K2L3P2 para as demais fases. Para a dose de potássio K3, a menor altura correspondeu ao tratamento K3L1P1 em todas as fases de desenvolvimento e a maior altura correspondeu ao tratamento K3L1P2 na fase de 8 DAT, 24 DAT e 31 DAT, e ao tratamento K3L2P1nas demais fases. 
a)

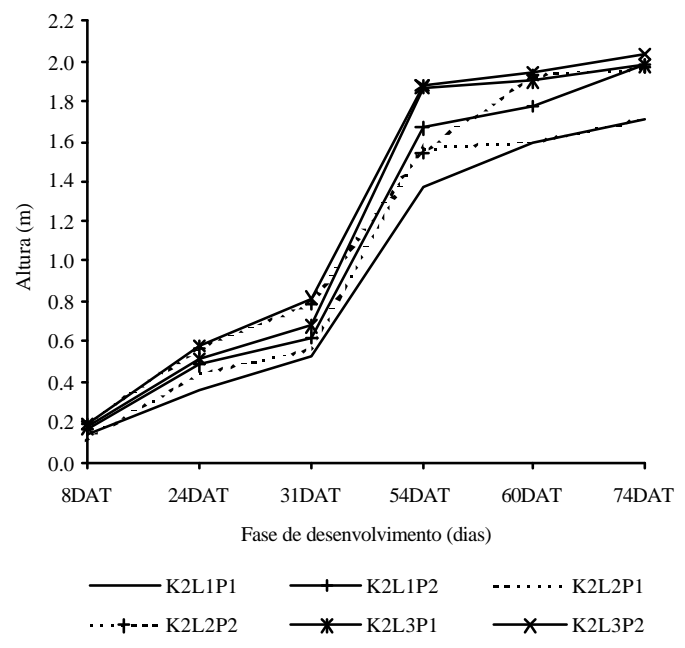

b)

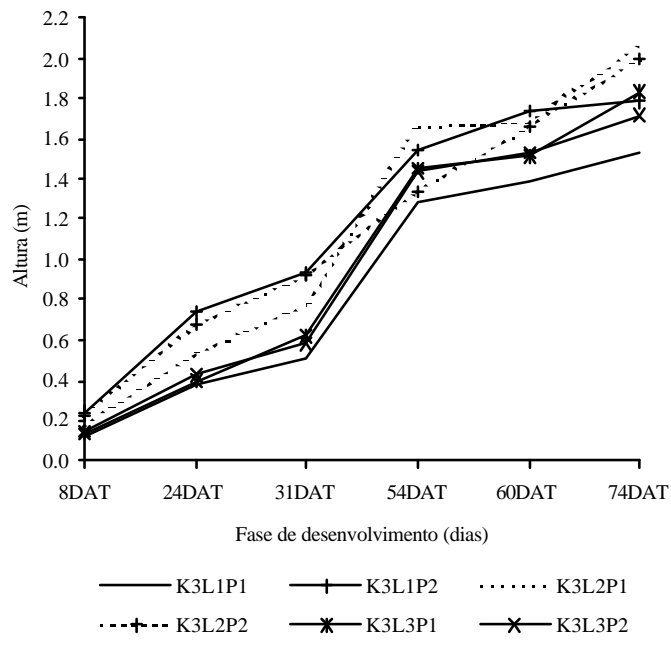

Figura 32 - Altura de plantas (m) nas diferentes fases de desenvolvimento da cultura, para os diferentes tratamentos: a) dose de potássio $\mathrm{K} 2\left(9 \mathrm{~g} \mathrm{~K}_{2} 0 \mathrm{pl}^{-1}\right)$; b) dose de potássio $\mathrm{K} 3\left(12 \mathrm{~g} \mathrm{~K}_{2} 0 \mathrm{pl}^{-1}\right)$.

As comparações das médias de altura de plantas para cada fator separadamente são apresentadas na Tabela 19.

A altura é menor para a dose de potássio $\mathrm{K} 0\left(0 \mathrm{~g}\right.$ de $\left.\mathrm{K}_{2} \mathrm{O} \mathrm{pl}{ }^{-1}\right)$ em todas as fases de desenvolvimento da cultura, é maior para a dose de potássio $\mathrm{K} 1\left(6 \mathrm{~g}\right.$ de $\left.\mathrm{K}_{2} \mathrm{O} \mathrm{pl}^{-1}\right)$ nas fases 8 DAT, 24 DAT e 31 DAT e 74 DAT e para dose de potássio K2 $\left(9 \mathrm{~g} \mathrm{de}_{2} \mathrm{O} \mathrm{pl}^{-1}\right)$ nas fases 54 DAT e 60 DAT. Para o fator níveis de irrigação, a altura é menor para o nível L1 (137,72 mm) em todas as fases de desenvolvimento, é maior para o nível L2 (279,60 mm) nas fases 8 DAT, 24 DAT, 31 DAT e 54 DAT, e para o nível L3 (417,32 mm) nas demais fases. Para o fator posições de instalação dos tubogotejadores em todas as fases de desenvolvimento da cultura, a altura foi menor para a posição P1 $(0,0 \mathrm{~m})$ e maior para a posição $\mathrm{P} 2(0,2 \mathrm{~m})$.

Os valores de altura de plantas que não mostram aumentos seqüenciais durante as fases de desenvolvimento da cultura para as interações dos tratamentos, assim como para os fatores separadamente podem dever-se à superposição de folhas de plantas de outros tratamentos, a horas de sol e inclusive ao intervalo entre uma irrigação e a outra, devido a 
que as válvulas foram abertas seqüencialmente e não de forma simultânea.

Tabela 19. Comparação de médias de altura de plantas $(\mathrm{m})$ para cada nível de fator isolado, nas diferentes fases de desenvolvimento da cultura.

\begin{tabular}{ccccccc}
\hline \multirow{2}{*}{ Nível de fator } & \multicolumn{5}{c}{ Altura de plantas (m) para as diferentes fases de desenvolvimento } \\
& 8DAT & 24DAT & 31DAT & 54DAT & 60DAT & 74DAT \\
\hline K0 & 0,154 & 0,461 & 0,604 & 1,241 & 1,370 & 1,528 \\
K1 & 0,218 & 0,654 & 0,809 & 1,553 & 1,760 & 1,930 \\
K2 & 0,164 & 0,493 & 0,670 & 1,646 & 1,786 & 1,895 \\
K3 & 0,175 & 0,526 & 0,723 & 1,451 & 1,583 & 1,820 \\
L1 & 0,170 & 0,492 & 0,623 & 1,306 & 1,498 & 1,643 \\
L2 & 0,186 & 0,566 & 0,749 & 1,558 & 1,682 & 1,841 \\
L3 & 0,178 & 0,543 & 0,732 & 1,554 & 1,694 & 1,896 \\
P1 & 0,150 & 0,455 & 0,621 & 1,384 & 1,492 & 1,692 \\
P2 & 0,206 & 0,612 & 0,782 & 1,5624 & 1,758 & 1,894 \\
\hline
\end{tabular}

Em decorrência dos resultados obtidos e analisados, pode-se deduzir que a altura de plantas é menor para a dose de potássio $\mathrm{K} 0\left(0 \mathrm{~g}\right.$ de $\left.\mathrm{K}_{2} \mathrm{O} \mathrm{pl}{ }^{-1}\right)$ e aumenta para doses de potássio $\mathrm{K} 1\left(6 \mathrm{~g}_{\text {de }} \mathrm{K}_{2} \mathrm{O} \mathrm{pl}{ }^{-1}\right), \mathrm{K} 2\left(9 \mathrm{~g} \mathrm{de}_{2} \mathrm{O} \mathrm{pl}^{-1}\right)$ e $\mathrm{K} 3\left(12 \mathrm{~g} \mathrm{de}_{2} \mathrm{O} \mathrm{pl}^{-1}\right)$. De igual forma a altura das plantas aumenta na medida em que se incrementam as quantidades de água aplicada e quando o tubogotejadores está na subsuperfície.

A analise de variância (Tabela 20) realizada com as médias de altura de plantas com dados da última fase de desenvolvimento da cultura (74 DAT) não mostrou efeito significativo para as interações triplas dos fatores em estudo. Houve, entretanto efeito significativo $(\mathrm{P}<0,01)$ para doses de potássio, níveis de irrigação e posição dos tubogotejadores e também foram significativos $(\mathrm{P}<0,01)$ a interações duplas $\mathrm{KxL}, \mathrm{KxP}$ e LxP.

Rizzo et al., (2000) encontraram altura média da plantas de híbrido de melão Bônus $\mathrm{n}^{\mathrm{o}} 2$ aos 45 DAT de 1,59 m, enquanto que Cardoso (2002) encontrou como o mesmo híbrido altura de 2,10 m para 38 DAT, valores estes acima dos encontrados no 
presente experimento para as mesmas fases de desenvolvimento.

Tabela 20. Esquema da análise de variância para altura de plantas, com desdobramento dos graus de liberdade de tratamentos, de acordo com o esquema fatorial $2 \times 3 \times 4$.

\begin{tabular}{lcccrc}
\hline \multicolumn{1}{c}{ Causa da variação } & G.L & S.Q & Q.M & F & Prob \\
\hline K & 3 & 1,771 & 0,590 & $21,280^{* *}$ & 0,0000 \\
$\mathrm{~L}$ & 2 & 0,848 & 0,424 & $15,288^{* * *}$ & 0,0000 \\
$\mathrm{P}$ & 1 & 0,731 & 0,731 & $26,355^{* *}$ & 0,0000 \\
KxL & 6 & 0,553 & 0,092 & $3,321^{* *}$ & 0,0084 \\
KxP & 3 & 0,932 & 0,311 & $11,203^{* *}$ & 0,0000 \\
PxL & 2 & 0,008 & 0,004 & $0,149 * *$ & 0,0000 \\
KxLxP & 6 & 0,345 & 0,057 & 2,071 & 0,0751 \\
(Tratamento) & $(23)$ & & & & \\
Blocos & 2 & 0,028 & 0,014 & 0,508 & \\
Resíduo & 46 & 1,276 & 0,028 & & \\
Total & 71 & 6,494 & & & \\
Média (m) & 1,793 & & & & \\
CV $(\%)$ & 9,29 & \multicolumn{5}{l}{} \\
** indica que o teste de F, foi significativo ao nível de 1\% de probabilidade.
\end{tabular}

\subsection{Estado nutricional das plantas}

Considerando que a análise foliar representa com maior aproximação o estado nutricional das plantas, foram analisados os macronutrientes contidos nas folhas após a colheita. Neste estado fenológico existe uma traslocação dos elementos para as demais partes da planta, em virtude da senescência das folhas, diminuição da atividade fotossintética e forte atividade dos frutos, o que ajuda a verificar o estado nutricional em que a plantas foi desenvolvida. 


\subsubsection{Macronutrientes nas folhas}

Foram avaliadas as concentrações dos macronutrientes nas folhas: nitrogênio $(\mathrm{N})$, fósforo $(\mathrm{P})$, potássio $(\mathrm{K})$, cálcio $(\mathrm{Ca})$, magnésio $(\mathrm{Mg})$ e enxofre $(\mathrm{S})$, após a colheita.

Segundo a análise das variâncias apresentadas nas Tabelas 21 e 22, não se constatou efeito significativo para as interações triplas dos fatores em estudo para todos os macronutrientes, contudo pode-se encontrar interações duplas e isoladas de alguns fatores.

Tabela 21. Resumo da análise de variância para os valores médios de nitrogênio $(\mathrm{N})$, fósforo $(\mathrm{P})$ e potássio $(\mathrm{K})$ com desdobramento dos graus de liberdade de tratamentos, de acordo com o esquema fatorial $4 \times 3 \times 2$.

\begin{tabular}{lcccr}
\hline \multirow{2}{*}{ Causas de variação } & G.L. & \multicolumn{3}{c}{ Quadrado médio (significância - Prob. >F) } \\
& & $\mathrm{N}$ & $\mathrm{P}$ & $\mathrm{K}$ \\
\hline $\mathrm{K}$ & 3 & $69,920\left(^{* *}\right)$ & 0,596 & 60,518 \\
$\mathrm{~L}$ & 2 & 16,704 & 0,249 & 59,248 \\
$\mathrm{P}$ & 1 & 40,801 & $3,600^{* *}$ & 0,500 \\
$\mathrm{KxL}$ & 6 & 12,378 & 0,276 & 7,735 \\
$\mathrm{KxP}$ & 3 & 15,705 & $1,401 *$ & 5,044 \\
PxL & 2 & 3,501 & 0,014 & 18,790 \\
KxLxP & 6 & 5,214 & 0,143 & 19,650 \\
(Tratamento) & $(23)$ & & & \\
Blocos & 2 & 18,893 & 0,322 & 65,481 \\
Resíduo & 46 & 11,345 & 0,456 & 23,008 \\
Total & 71 & & & \\
Média & & 16,481 & 2,182 & 27,586 \\
CV $(\%)$ & 20,438 & 30,934 & 17,388 \\
\hline ** e* indicam que o teste de F, foi significativo ao nível de 1\% e de 5\% de probabilidade, respectivamente.
\end{tabular}


Tabela 22. Resumo da análise de variância para os valores médios de cálcio (Ca), magnésio $(\mathrm{Mg})$ e enxofre (S) com desdobramento dos graus de liberdade de tratamentos, de acordo com o esquema fatorial $4 \times 3 \times 2$.

\begin{tabular}{|c|c|c|c|c|}
\hline \multirow{2}{*}{ Causas de variação } & \multirow[t]{2}{*}{ G.L. } & \multicolumn{3}{|c|}{ Quadrado médio (significânia - Prob. >F) } \\
\hline & & $\mathrm{Ca}$ & $\mathrm{Mg}$ & $\mathrm{S}$ \\
\hline$\overline{\mathrm{K}}$ & 3 & 103,453 & 2,504 & $4,949 * *$ \\
\hline $\mathrm{L}$ & 2 & 401,989 & 0,470 & $3,457^{*}$ \\
\hline $\mathrm{P}$ & 1 & $0,014 *$ & 0,714 & $3,873 *$ \\
\hline $\mathrm{KxL}$ & 6 & 149,385 & 6,647 & 0,896 \\
\hline $\mathrm{KxP}$ & 3 & 4,791 & 0,878 & 0,329 \\
\hline PxL & 2 & 166,177 & 0,142 & 0,927 \\
\hline KxLxP & 6 & 68,808 & 6,408 & 0,732 \\
\hline (Tratamento) & (23) & & & \\
\hline Blocos & 2 & 252,582 & 45,303 & 5,950 \\
\hline Resíduo & 46 & 88,086 & 5,667 & 0,981 \\
\hline Total & 71 & & & \\
\hline Média & & 88,058 & 18,020 & 6,051 \\
\hline CV $(\%)$ & & 10,658 & 13,211 & 15,597 \\
\hline
\end{tabular}

As médias das concentrações de macronutrientes (N, P, K, Ca, Mg e S) para cada fator separadamente e para cada tratamento, estão apresentados nas Tabelas 23 e 24 , respectivamente.

Tabela 23. Comparação de médias de macronutrientes nas folhas para cada nível de fator isolado

\begin{tabular}{lrrrrrr}
\hline \multirow{2}{*}{ Nível de fator } & \multicolumn{5}{c}{ Teores médios de macronutrientes $\left(\mathrm{mg} \mathrm{kg}^{-1}\right)$} \\
& $\mathrm{N}$ & $\mathrm{P}$ & $\mathrm{K}$ & $\mathrm{Ca}$ & $\mathrm{Mg}$ & $\mathrm{S}$ \\
\hline K0 & 13.417 & 2.289 & 24.956 & 90.306 & 17.539 & 6.539 \\
K1 & 17.417 & 2.372 & 27.533 & 88.717 & 18.328 & 6.094 \\
K2 & 17.583 & 2.111 & 29.417 & 84.678 & 17.911 & 6.156 \\
K3 & 17.378 & 1.972 & 28.178 & 88.494 & 18.300 & 5.317 \\
L1 & 16.225 & 2.204 & 29.067 & 86.000 & 18.096 & 5.796 \\
L2 & 17.388 & 2.083 & 27.604 & 85.400 & 17.858 & 5.871 \\
L3 & 15.733 & 2.271 & 25.892 & 92.746 & 18.104 & 6.413 \\
P1 & 17.178 & 2.414 & 27.558 & 88.047 & 18.119 & 5.769 \\
P2 & 15.719 & 1.958 & 27.483 & 88.050 & 17.919 & 6.283 \\
\hline
\end{tabular}


Tabela 24. Teores médios de macronutrientes nas folhas para todos os tratamentos

\begin{tabular}{lcccccc}
\hline \multirow{2}{*}{ Tratamento } & \multicolumn{5}{c}{ Teores médios de macronutrientes $\left(\mathrm{mg} \mathrm{kg}^{-1}\right)$} \\
& $\mathrm{N}$ & $\mathrm{P}$ & $\mathrm{K}$ & $\mathrm{Ca}$ & $\mathrm{Mg}$ & $\mathrm{S}$ \\
\hline K0L1P1 & 11,167 & 1,867 & 26,400 & 86,567 & 18,200 & 6,733 \\
K0L1P2 & 11,333 & 2,200 & 25,233 & 81,133 & 17,467 & 6,833 \\
K0L2P1 & 16,533 & 2,100 & 25,467 & 84,767 & 17,200 & 5,067 \\
K0L2P2 & 16,000 & 2,367 & 24,733 & 94,000 & 16,000 & 6,700 \\
K0L3P1 & 11,200 & 2,433 & 23,887 & 100,367 & 17,967 & 7,267 \\
K0L3P2 & 14,266 & 2,767 & 24,033 & 95,000 & 18,400 & 6,633 \\
K1L1P1 & 19,200 & 3,167 & 31,000 & 82,500 & 20,100 & 5,233 \\
K1L1P2 & 17,000 & 1,800 & 28,000 & 85,700 & 17,133 & 5,800 \\
K1L2P1 & 18,100 & 2,633 & 27,633 & 86,933 & 18,500 & 5,833 \\
K1L2P2 & 15,733 & 1,733 & 26,200 & 86,133 & 18,633 & 6,300 \\
K1L3P1 & 19,600 & 2,800 & 25,600 & 97,867 & 17,367 & 6,133 \\
K1L3P2 & 14,867 & 2,100 & 26,767 & 93,167 & 18,233 & 7,267 \\
K2L1P1 & 16,766 & 2,567 & 32,867 & 79,100 & 18,133 & 5,800 \\
K2L1P2 & 17,667 & 1,900 & 29,700 & 88,300 & 17,200 & 6,300 \\
K2L2P1 & 19,267 & 2,467 & 28,100 & 78,733 & 16,233 & 5,667 \\
K2L2P2 & 18,933 & 1,900 & 29,133 & 78,300 & 17,533 & 6,300 \\
K2L3P1 & 17,633 & 2,400 & 25,833 & 96,567 & 19,100 & 6,467 \\
K2L3P2 & 15,233 & 1,433 & 30,867 & 87,067 & 19,267 & 6,400 \\
K3L1P1 & 18,867 & 2,167 & 30,400 & 86,600 & 16,700 & 4,567 \\
K3L1P2 & 17,800 & 1,967 & 28,933 & 98,100 & 19,833 & 5,100 \\
K3L2P1 & 18,767 & 2,133 & 26,433 & 88,867 & 19,767 & 5,167 \\
K3L2P2 & 15,767 & 1,333 & 33,133 & 85,467 & 19,000 & 5,933 \\
K3L3P1 & 19,033 & 2,233 & 27,100 & 87,700 & 18,167 & 5,300 \\
K3L3P2 & 14,033 & 2,000 & 23,067 & 84,233 & 16,333 & 5,833 \\
\hline
\end{tabular}

A menor e maior concentração de nitrogênio nas folhas do híbrido de melão Bônus no 2, 11,167 mg kg-1 e 19,600 mg kg-1 , foram obtidas por os tratamentos de níveis de irrigação, dose de potássio e posição dos tubogotejadores, K0L1P1 e K1L3P1, respectivamente.

As flutuações dos valores, apesar da aplicação de $150 \mathrm{~kg} \mathrm{ha}^{-1}$ de nitrogênio na forma de nitrato de potássio, para todos os tratamentos, podem dever-se a própria quantidade de água aplicada, à posição de instalação dos tubogotejadores, provocando em certos casos, diferentes dinâmicas, facilitando sua menor ou maior absorção pela planta. Outra causa de variação pode ser atribuída ao nitrogênio da própria matéria orgânica aplicada em cobertura (esterco de curral) o que facilitou uma maior ou menor liberação de elemento. 
Verificoutse também que com as dose $\mathrm{K} 1, \mathrm{~K} 2$ e $\mathrm{K} 3\left(6,9\right.$ e $12 \mathrm{~g}$ de $\left.\mathrm{K}_{2} \mathrm{O} \mathrm{pl}^{-1}\right)$ se obtiveram os maiores valores de nitrogênio nas folhas. O nível de irrigação L2 registrou maior valor de nitrogênio em comparação com os níveis L1 e L3, quando os tubogotejadores estiveram na superfície.

Estes valores estão acima dos encontrados por Kano (2002), no mesmo híbrido de melão no período de colheita (97 DAT), utilizando dose de $200 \mathrm{~kg} \mathrm{ha}^{-1}$ de nitrogênio e de potássio similares (300 e $600 \mathrm{~kg} \mathrm{ha}^{-1}$ de $\mathrm{K}_{2} \mathrm{O}$ ) a do presente experimento que foram de 2,35 e 1,75 $\mathrm{mg} \mathrm{pl}^{-1}$, respectivamente; e abaixo dos encontrados por Belfort (1985) ao ar livre em melão cv. Valenciano Amarelo CAC, grupo inodorus, que foi de 2,85\% aos 75 DAT e Tyler et al., (1964) em melão PMR 450, onde a concentração de nitrogênio foi de $2,66 \%$ aos 107 DAT.

Para o fósforo a menor e maior concentração nas folhas, $1,333 \mathrm{mg} \mathrm{kg}^{-1}$ e 3,167 mg $\mathrm{kg}^{-1}$, foram obtidas para os tratamentos K3L2P2 e K1L1P1, respectivamente. Verificaram-se variações menos acentuadas do que para o nitrogênio, sem uma tendência bem definida dos fatores isolados, embora a análise de variância mostre significância ao nível $(\mathrm{P}>0,01)$ e $(\mathrm{P}>0,05)$ para $\mathrm{o}$ fator isolado posição $(\mathrm{P})$ e combinação lamina $\mathrm{x}$ dose $(\mathrm{KxP})$, respectivamente.

Estes valores estão acima dos encontrados por Kano (2002), no mesmo híbrido de melão no período de colheita (94 DAT), utilizando dose de $200 \mathrm{~kg} \mathrm{ha}^{-1}$ de nitrogênio e de potássio similares (300 e $600 \mathrm{~kg} \mathrm{ha}^{-1}$ de $\mathrm{K}_{2} \mathrm{O}$ ) a do presente experimento que foram de 0,25 e $0,200 \mathrm{mg} \mathrm{pl}^{-1}$, respectivamente. Também estão próximos os valores encontrados por Belfort (1985) ao ar livre em melão cv. Valenciano Amarelo CAC, grupo inodorus, que foi de 0,28 \% aos 75 DAT e Tyler et al., (1964) em melão PMR 450, onde a concentração de fósforo foi de $0,32 \%$ aos 107 DAT.

A menor e maior concentração de potássio nas folhas do híbrido de melão Bônus $\mathrm{n}^{\mathrm{o}}$ 2, 23,067 mg kg-1 e 33,133 $\mathrm{mg} \mathrm{kg}^{-1}$, foram obtidas para os tratamentos K3L3P2 e $\mathrm{K} 3 \mathrm{~L} 2 \mathrm{P} 2$, respectivamente. Verificaram-se variações menos acentuadas do que para o nitrogênio.

Nos tratamentos com ausência de potássio (K0) foram constatados menores teores de potássio nas folhas, entre 23,887 e 26,400 mg kg-1 , cujas concentrações cresceram 
linearmente até a dose $\mathrm{K} 2\left(9 \mathrm{~g}\right.$ de $\left.\mathrm{K}_{\mathbf{O}} \mathrm{O} \mathrm{pl}^{-1}\right)$ para logo diminuir com a maior dose, $\mathrm{K} 3$,

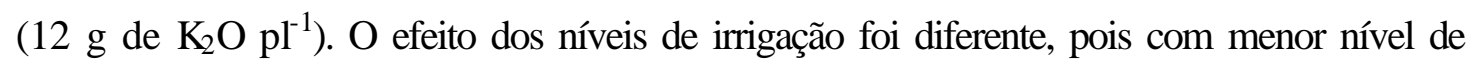
irrigação os valores de conteúdo de potássio na folha foram maiores, variando em média de 25,892 $\mathrm{mg} \mathrm{ka}^{-1}$ para o nível L3 (417,32 mm), 27,604 $\mathrm{mg} \mathrm{kg}^{-1}$ para o nível L2 (279,60 mm) e $29,067 \mathrm{mg} \mathrm{kg}^{-1}$ para o nível L1 (132,72 mm). Para a posição de instalação dos tubogotejadores, os valores de potássio na folha praticamente não apresentaram diferença. Estes valores estão acima dos encontrados por Kano (2002), no mesmo híbrido de melão no período de colheita (97 DAT), utilizando dose de $200 \mathrm{~kg} \mathrm{ha}^{-1}$ de nitrogênio e de potássio similares (300 e $600 \mathrm{~kg} \mathrm{ha}^{-1} \mathrm{de}_{2} \mathrm{O}$ ) a do presente experimento que foram de 3,437 e 2,813 $\mathrm{mg} \mathrm{pl}^{-1}$, respectivamente e próximos aos encontrados por Belfort (1985) ao ar livre em melão cv. Valenciano Amarelo CAC, grupo inodorus, que foi de 3,21 \% aos 75 DAT e Tyler et al., (1964) em melão PMR 450, onde a concentração de potássio foi de $1,40 \%$ aos 107 DAT.

Com relação ao cálcio nas folhas a menor e maior concentração, 78,300 mg kg-1 e $100,367 \mathrm{mg} \mathrm{kg}^{-1}$, foram obtidas para os tratamentos K2L3P2 e K0L3P1, respectivamente. Os tratamentos que não receberam potássio e aqueles que receberam a dose K1 (6 g de $\mathrm{K}_{2} \mathrm{O} \mathrm{pl}^{-1}$ ) apresentaram maior conteúdo de cálcio nas folhas em relação aos que receberam as doses maiores de potássio, $\mathrm{K} 2 \mathrm{e} \mathrm{K} 3$ (9 e $12{\mathrm{~g} \mathrm{de} \mathrm{K}_{2} \mathrm{O} \mathrm{p}}^{-1}$, respectivamente).

Com relação aos níveis de irrigação, o maior valor de cálcio nas folhas foi obtido com o nível máximo L3 $(417,32 \mathrm{~mm})$ e quando a posição dos tubogotejadores estes valores quase não apresentaram diferenças.

Estes valores estão acima dos encontrados por Kano (2002), no mesmo híbrido de melão no período de colheita (97 DAT), utilizando dose de $200 \mathrm{~kg} \mathrm{ha}^{-1}$ de nitrogênio e de potássio similares (300 e $600 \mathrm{~kg} \mathrm{ha}^{-1}$ de $\mathrm{K}_{2} \mathrm{O}$ ) a do presente experimento que foram de 4,816 e 4,188 $\mathrm{mg} \mathrm{pl}^{-1}$, respectivamente, e também acima dos encontrados por Belfort (1985) ao ar livre em melão cv. Valenciano Amarelo CAC, grupo inodorus, que foi de 3,30 \% aos 75 DAT e Tyler et al., (1964) em melão PMR 450, onde a concentração de cálcio foi de $0,50 \%$ aos 107 DAT.

A menor e maior concentração de magnésio nas folhas do híbrido de melão, $16,000 \mathrm{mg} \mathrm{kg}^{-1}$ e 20,100 mg kg${ }^{-1}$, foram obtidas pelos tratamentos K0L2P2 e K1L1P1, 
respectivamente. Entretanto as maiores concentrações de magnésio foram registradas nos tratamentos com dose de $\mathrm{K} 1$ e $\mathrm{K} 3$ (6 e $12 \mathrm{~g}$ de $\mathrm{K}_{2} \mathrm{O}$ planta $^{-1}$ ) com redução nos tratamentos que não receberam potássio.

Os efeitos dos níveis de irrigação foram pequenos, embora o nível L3 (417,32 $\mathrm{mm}$ ) tenha registrado o maior valor de magnésio nas folhas. Com respeito à posição dos tubogotejadores verificou-se um ligeiro aumento na concentração de $\mathrm{Mg}$ nos tratamentos irrigados na superfície. Verificou-se também que as maiores concentrações de potássio e magnésio reduzem a absorção de cálcio, coincidido com o manifestado por Malavolta (1976).

Estes valores estão acima dos encontrados por Kano (2002), no mesmo híbrido de melão no período de colheita (97 DAT), utilizando dose de $200 \mathrm{~kg} \mathrm{ha}^{-1}$ de nitrogênio e de

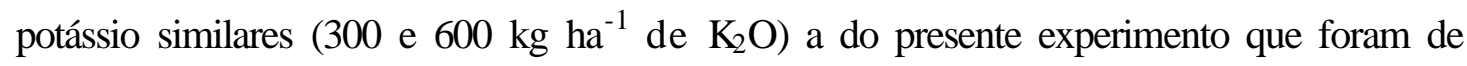
1,50 e 1,20 mg planta $^{-1}$, respectivamente, e também acima dos encontrados por Belfort (1985) ao ar livre em melão cv. Valenciano Amarelo CAC, grupo inodorus, que foi de 0,92 \% aos 75 DAT e próximos aos encontrados por Tyler et al., (1964) em melão PMR 450 , onde a concentração de magnésio foi de 2,66 \% aos 107 DAT.

As menores e maiores concentrações de enxofre nas folhas do meloeiro, 4,566 mg $\mathrm{kg}^{-1}$ e 7,266 mg $\mathrm{kg}^{-1}$, foram obtidas para os tratamentos K3L1P1 e K0L3P1, respectivamente. Os tratamentos que não receberam potássio apresentaram maior valor de enxofre e a maior dose $\mathrm{K} 3\left(12 \mathrm{~g}\right.$ de $\left.\mathrm{K}_{2} \mathrm{O} \mathrm{pl}{ }^{-1}\right)$ o menor teor de enxofre nas folhas. Verificourse também que o valor de enxofre aumenta à medida em que aumenta o nível de irrigação e quando os tubogotejadores estão na superfície.

Estes valores estão acima dos encontrados por Kano (2002), no mesmo híbrido de melão no período de colheita (97 DAT), utilizando dose de $200 \mathrm{~kg} \mathrm{ha}^{-1}$ de nitrogênio e de potássio similares (300 e $600 \mathrm{~kg} \mathrm{ha}^{-1}$ de $\mathrm{K}_{2} \mathrm{O}$ ) a do presente experimento que foram de 1,068 e $0,900 \mathrm{mg} \mathrm{pl}^{-1}$, respectivamente, e também acima dos encontrados por Belfort (1985) ao ar livre em melão cv. Valenciano Amarelo CAC, grupo inodorus, que foi de 0,26 \% aos 75 DAT e próximos dos encontrados por Tyler et al., (1964) em melão PMR 450, onde a concentração de enxofre foi de $0,48 \%$ aos 107 DAT.

Em resumo a ordem de concentração dos macronutrientes nesta etapa fenológica 
foi: $\mathrm{Ca}>\mathrm{K}>\mathrm{Mg}>\mathrm{N}>\mathrm{S}>\mathrm{P}$.

\subsection{Produtividade e classificação de frutos}

\subsubsection{Produtividade total e comercial}

A produtividade total (PT) do híbrido de melão Bonus $\mathrm{n}^{\mathrm{o}} 2$ para o presente experimento, foi considerada tomando em consideração o peso de cada fruto acima de 0,300 kg, visando serem aptos para o consumo e a produtividade comercial (PC) acima de $0,550 \mathrm{~kg}$.

Os valores médios são apresentados na Tabela $25 \mathrm{e}$ foram influenciados significativamente $(\mathrm{P}<0,01)$ pelas doses de potássio, pelos níveis de irrigação e pela posição dos tubogotejadores (Tabela 26). 
Tabela 25. Valores médios de produtividade total e comercial de frutos do híbrido de melão Bonus $\mathrm{n}^{\mathrm{o}} 2$, sob diferentes doses de potássio, níveis de irrigação e posição dos tubogotejadores.

\begin{tabular}{ccc}
\hline Tratamento & Produtividade Total $\left(\mathrm{kg} \mathrm{ha}^{-1}\right)$ & Produtividade Comercial $\left(\mathrm{kg} \mathrm{ha}^{-1}\right)$ \\
\hline K0L1P1 & $9.132,444$ & $2.727,352$ \\
K0L1P2 & $15.159,093$ & $9.183,953$ \\
K0L2P1 & $29.195,330$ & $22.552,370$ \\
K0L2P2 & $35.906,000$ & $28.378,460$ \\
K0L3P1 & $48.440,333$ & $43.991,890$ \\
K0L3P2 & $53.117,000$ & $47.064,620$ \\
K1L1P1 & $12.684,833$ & $7.048,090$ \\
K1L1P2 & $25.683,767$ & $20.603,820$ \\
K1L2P1 & $38.214,667$ & $33.076,090$ \\
K1L2P2 & $35.348,333$ & $27.828,060$ \\
K1L3P1 & $44.886,333$ & $37.586,300$ \\
K1L3P2 & $65.108,333$ & $61.427,600$ \\
K2L1P1 & $8.720,026$ \\
K2L1P2 & $11.563,833$ & $14.398,550$ \\
K2L2P1 & $16.848,667$ & $28.622,530$ \\
K2L2P2 & $34.775,000$ & $27.595,520$ \\
K2L3P1 & $37.757,000$ & $38.021,940$ \\
K2L3P2 & $45.573,533$ & $66.224,310$ \\
K3L1P1 & $69.646,000$ & $7.388,340$ \\
K3L1P2 & $12.431,497$ & $17.945,650$ \\
K3L2P1 & $23.620,667$ & $27.266,800$ \\
K3L2P2 & $35.182,000$ & $26.679,840$ \\
K3L3P1 & $32.735,333$ & $26.884,060$ \\
K3L3P2 & $33.021,333$ & $21.449,280$ \\
\hline
\end{tabular}


Tabela 26. Resumo da análise de variância para os valores médios de produtividade total (PT) e comercial (PC), com desdobramento dos graus de liberdade de tratamentos, de acordo com o esquema fatorial $4 \times 3 \times 2$.

\begin{tabular}{lccc}
\hline \multicolumn{1}{c}{$\begin{array}{c}\text { Causas de } \\
\text { variação }\end{array}$} & G.L. & \multicolumn{2}{c}{ Quadrado médio (significânia- Prob. >F } \\
\hline $\mathrm{K}$ & & $\mathrm{PT}$ & $\mathrm{PC}$ \\
$\mathrm{L}$ & 3 & $434942786,548^{* *}$ & $393705671,226^{* *}$ \\
$\mathrm{P}$ & 2 & $5730333832,458^{* *}$ & $6084172175,688^{* *}$ \\
$\mathrm{KxL}$ & 1 & $1402973654,336^{* *}$ & $900871400,964 * *$ \\
$\mathrm{KxP}$ & 6 & $434942786,548^{* *}$ & $339467412,032^{* *}$ \\
$\mathrm{PxL}$ & 3 & $238751777,122^{* *}$ & $94592297,405^{* *}$ \\
KxLxP & 2 & $434942786,548^{* *}$ & $258926683,884^{* *}$ \\
(Tratamento) & 6 & $238751777,122^{* *}$ & $174947767,337^{* *}$ \\
Blocos & $(23)$ & & \\
Resíduo & 2 & 27152,598 & 385351,171 \\
Total & 46 & 238751777,122 & 14879247,962 \\
Média (kg) & 71 & & 27194,395 \\
CV $(\%)$ & & 34006,027 & 14,184 \\
\hline$* *$ e* indicam que o teste de F, foi significativo ao nível de 1\% e de 5\% de probabilidade, respectivamente.
\end{tabular}

Os efeitos das duas menores doses de potássio em combinação com os níveis de irrigação e posição das linhas laterais para a PT são apresentados na Figuras 33 (a, b). Verifica-se que a maior PT dentro da dose K1 correspondeu ao tratamento K1L3P2 (6 g de $\mathrm{K}_{2} \mathrm{O} \mathrm{pl^{-1 }}, 1,00 \%$ de Evp e 0,20 m de profundidade da linha lateral), apresentando uma PT média de 65.108,33 $\mathrm{kg} \mathrm{ha}^{-1}$ com lâmina total de água aplicada de 417,32 mm e com uma eficiência de uso de $15,60 \mathrm{~kg} \mathrm{~m}^{-3}$. A pior PT de frutos ocorreu no tratamento de combinação K0L1P1 ( $0 \mathrm{~g}$ de $\mathrm{K}_{2} \mathrm{O} \mathrm{pl}{ }^{-1}, 0,33 \%$ de Evp e $0,0 \mathrm{~m}$ de profundidade da linha lateral), com 9.132,44 $\mathrm{kg} \mathrm{ha}^{-1}$ tendo uma redução na lâmina de irrigação de $67 \% \mathrm{em}$ relação ao tratamento K1L3P2 e gerando uma redução média da PT de 55.976,89 kg ha ${ }^{-1}$, equivalente a $85,97 \%$ do tratamento K1L3P2. 
a)

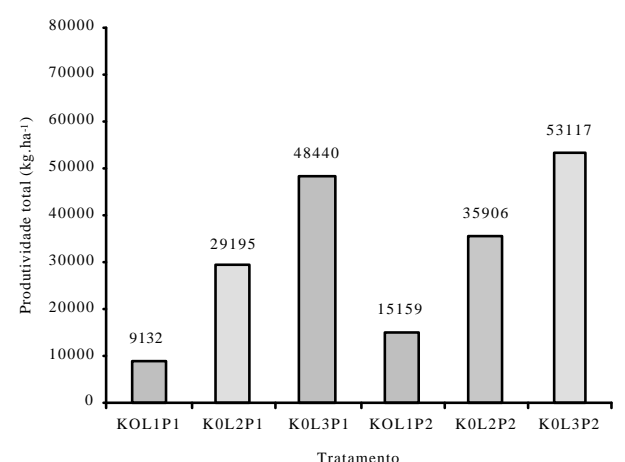

b)

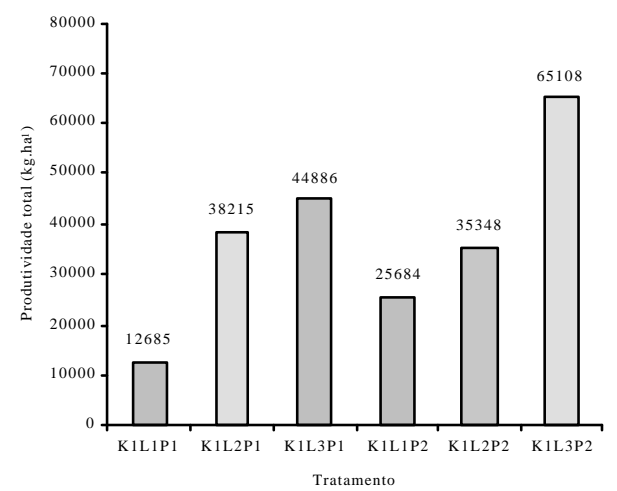

Figura 33 - Produtividade total $\left(\mathrm{kg} \mathrm{ha}^{-1}\right)$ em combinação com três níveis de irrigação e duas posições de instalação dos tubogotejadores: a) dose de potássio K0 (0 g de $\left.\mathrm{K}_{2} \mathrm{O} \mathrm{pl}{ }^{-1}\right)$; b) dose de potássio $\mathrm{K} 1\left(6 \mathrm{~g} \mathrm{de}_{2} \mathrm{O} \mathrm{pl}^{-1}\right)$.

Os efeitos das duas menores doses de potássio em combinação com os níveis de irrigação e posição das linhas laterais para a PC são apresentados na Figuras 34 (a, b). Verifica-se que a maior PC correspondeu ao tratamento K1L3P2 (6g de $\mathrm{K}_{2} \mathrm{O} \mathrm{pl}^{-1}, 1,00 \%$ de Evp e 0,20 m de profundidade do tubogotejador, apresentando uma PC média de 61.427,6 $\mathrm{kg} \mathrm{ha}^{-1}$ com lâmina total de água aplicada de 417,32 mm e com uma eficiência de uso de $14,72 \mathrm{~kg} \mathrm{~m}^{-3}$. A pior PC de frutos ocorreu no tratamento de combinação K0L1P1 (0g de $\mathrm{K}_{2} \mathrm{O} \mathrm{pl}^{-1}, 0,33 \%$ de Evp e 0,0 m de profundidade do tubogotejador), com uma PC média de $2.727,352 \mathrm{~kg} \mathrm{ha}^{-1}$ tendo uma redução na lâmina de irrigação de $67 \% \mathrm{em}$ relação ao tratamento K1L3P2 e gerando uma redução média da PC de 58.700,248 kg ha ${ }^{-}$ ${ }^{1}$, equivalente a $95,56 \%$ do tratamento K1L3P2). 
a)

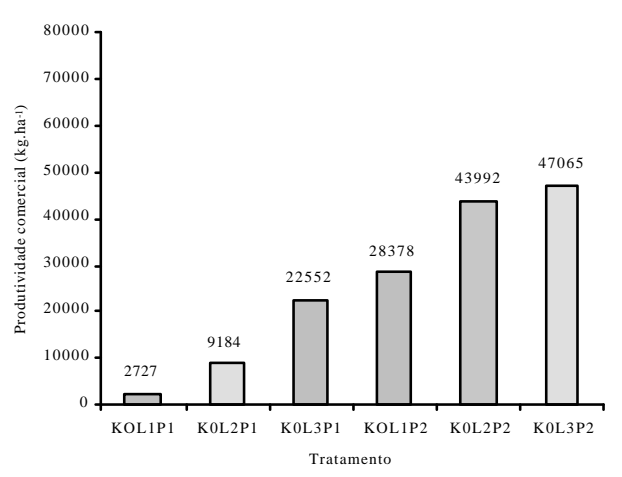

b)

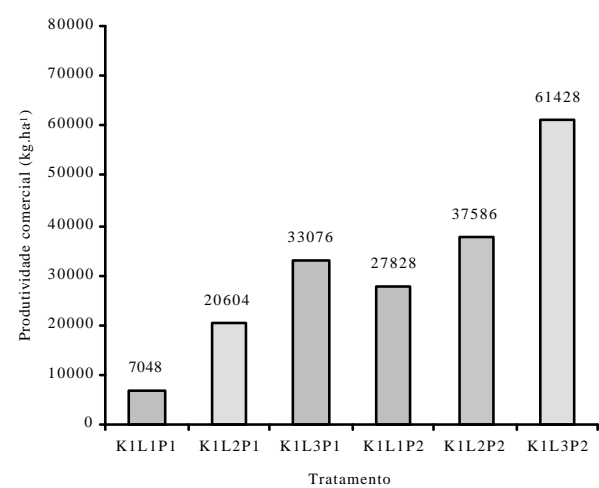

Figura 34 - Produtividade comercial $\left(\mathrm{kg} \mathrm{ha}^{-1}\right)$ em combinação com três níveis de irrigação e duas posições de instalação dos tubogotejadores: a) dose de potássio K2 (9 $\mathrm{g}$ de $\left.\mathrm{K}_{2} \mathrm{O} \mathrm{pl}^{-1}\right)$; b) dose de potássio $\mathrm{K} 3\left(12 \mathrm{~g} \mathrm{de}_{2} \mathrm{O} \mathrm{pl}^{-1}\right)$.

As tendências para este caso é que a maior dose, maior quantidade de água aplicada e posição da linha lateral a $0,20 \mathrm{~m}$ mostram as melhores produtividades.

Goldberg et al., (1976) relatam que pequenos volumes de água podem ser entregues para a cultura por sistemas de irrigação por gotejamento subsuperficial, evitando estresse por falta ou excesso de água e obtendo uma adicional poupança e alta eficiência no seu uso. Do mesmo modo a capacidade do sistema de irrigação por gotejamento subsuperficial deveria ser projetada para reunir de 110 a $120 \%$ da maior taxa de evapotranspiração (Et) esperada de sete dias (ASAE, 1991) e (Conrad, 1992).

Nos tratamentos propostos neste trabalho a produtividade comercial aumenta à medida que aumenta o nível de irrigação, a dose de potássio e quando os tubogotejadores foram instalados na subsuperficie. O tratamento K1L2P1, escapa a esta tendência, revelando maior incremento da produtividade comercial quando os tubogotejadores foram instalados na superfície, isto devido, provavelmente, a redistribuirão de água e nutrientes no solo e pela maior quantidade de frutos acima de $0,550 \mathrm{~kg}$ em relação ao tratamento subseqüente de K1L2P2.

O potássio (K) é um elemento nutritivo essencial para todos os organismos vivos. Os vegetais necessitam de quantidades elevadas deste nutriente sendo semelhante à 
necessidade de nitrogênio (Mengel \& Kirkby, 1987).

O potássio encontra-se em todos os órgãos, movimentando-se facilmente de uma parte a outra da planta cumpre um rol importante na ativação de um número de enzimas (sendo conhecidas mais de 60 ativadas por este cátion), que atuam em diversos processos metabólicos tais como fotossíntese, síntese de proteínas e carboidratos, alem de ter influência no balanço de água e no crescimento meristemático (Mengel \& Kirby, 1987). Ao participar destes processos metabólicos o $\mathrm{K}$ atua favorecendo o crescimento vegetativo, a frutificação, a maturação e a qualidade dos frutos.

Os efeitos das duas maiores doses de potássio, com as mesmas combinações anteriores para a PT estão apresentados na Figura 35 (a, b), mostrando que as tendências não seguem a mesma lógica. O tratamento K2L3P2 $\left(9 \mathrm{~g}\right.$ de $\mathrm{K}_{2} \mathrm{O} \mathrm{pl}^{-1}, 1,00 \%$ de Evp e $0,20 \mathrm{~m}$ de profundidade do tubogotejador) mostra a maior produtividade total, $69.646 \mathrm{~kg}$ ha $^{-1}$ com lâmina total aplicada de $417,32 \mathrm{~mm}$ e eficiência de uso de $16,69 \mathrm{~kg} \mathrm{~m}^{-3}$. O melhor desempenho da cultura nesse nível foi resultado de um adequado balanço de água no solo que permitiu uma melhor disponibilidade de nutrientes para a cultura; as demais combinações mostram resultados contrários.

Kuznetsova \& Agazamova (1974), estudando os efeitos do potássio na cultura do melão, verificaram que altas doses de potássio ocasionaram decréscimo na produção de frutos, sendo o nível ótimo em torno dos $100 \mathrm{~kg} \mathrm{ha}^{-1}$ de óxido de potássio $\left(\mathrm{K}_{2} \mathrm{O}\right)$. De igual

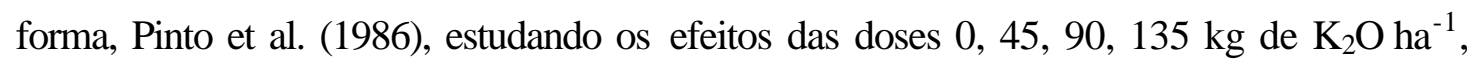
sobre a produção do meloeiro verificaram que as maiores produtividades de frutos comerciais $\left(28 \mathrm{t} \mathrm{ha}^{-1}\right)$ foram obtidas com a dose de $100 \mathrm{~kg}$ de $\mathrm{K}_{2} \mathrm{O} \mathrm{ha}^{-1}$ aplicados por meio de fertirrigação e que a fertirrigação diária superou em produção a frequiência a cada dois dias.

Outros resultados, como os de Sagdullaev \& Umarov (1974) e Jassal et al., (1970) revelaram aumento na qualidade e produção do melão quando foi aplicado $100 \mathrm{~kg}$ de $\mathrm{N}$ $\mathrm{ha}^{-1}$ e $150 \mathrm{~kg}$ de $\mathrm{K}_{2} \mathrm{O}$ ha $^{-1}$, embora a interação $\mathrm{NxK}$ não tenha ocasionado um aumento significativo no peso dos frutos. 
a)

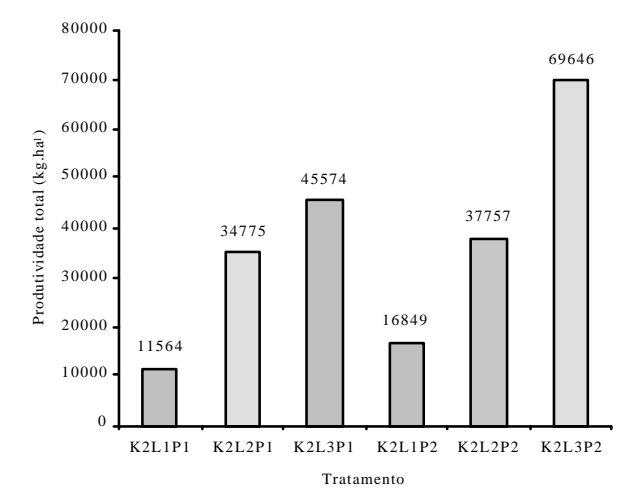

b)

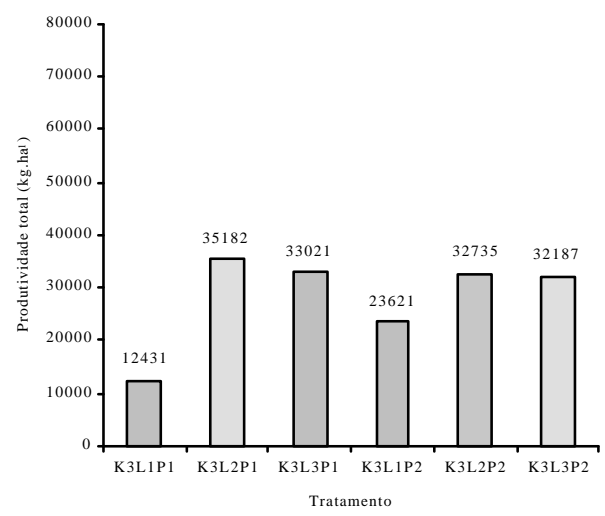

Figura 35 - Produtividade total $\left(\mathrm{kg} \mathrm{ha}^{-1}\right)$ em combinação com três níveis de irrigação e duas posições de instalação dos tubogotejadores: a) dose de potássio K0 (0 g de $\left.\mathrm{K}_{2} \mathrm{O} \mathrm{pl}{ }^{-1}\right)$; b) dose de potássio $\mathrm{K} 1\left(6 \mathrm{~g} \mathrm{de}_{2} \mathrm{O} \mathrm{pl}^{-1}\right)$.

O efeito das duas maiores doses de potássio com as mesmas combinações anteriores para PC estão apresentados na Figura $36(\mathrm{a}, \mathrm{b})$, mostrando que a PC aumenta em média com a dose de potássio $\mathrm{K} 2\left(9 \mathrm{~g}\right.$ de $\left.\mathrm{K}_{2} \mathrm{O} \mathrm{pl}^{-1}\right)$, com o maior nível de irrigação e com a posição dos tubogotejadores instalados na subsuperfície. Com a dose de potássio $\mathrm{K} 3$ (12 $\mathrm{g}$ de $\mathrm{K}_{2} \mathrm{O} \mathrm{pl}^{-1}$ ) em combinação com os demais fatores, a PC diminui, observando alguns aumentos atribuídos unicamente a maior quantidade água, sem nenhuma repercussão das maiores doses de potássio e das posições dos tubogotejadores. Assim sendo, o tratamento K2L3P2 $\left(9 \mathrm{~g}_{\text {de }} \mathrm{K}_{2} \mathrm{O} \mathrm{pl}^{-1}, 1,00 \%\right.$ de Evp e 0,20 m de profundidade

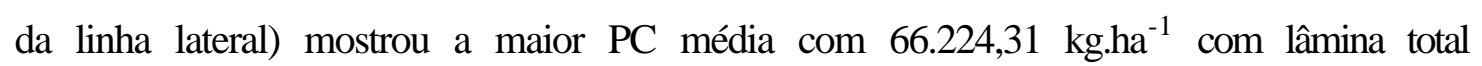
aplicada de 417,32 mm e eficiência de uso de $15,87 \mathrm{~kg} \mathrm{~m}^{-3}$. O melhor desempenho da cultura nesse nível foi resultado de um adequado balanço de água no solo que permitiu uma melhor disponibilidade de nutrientes para a cultura; as demais combinações mostram resultados inferiores. 
a)

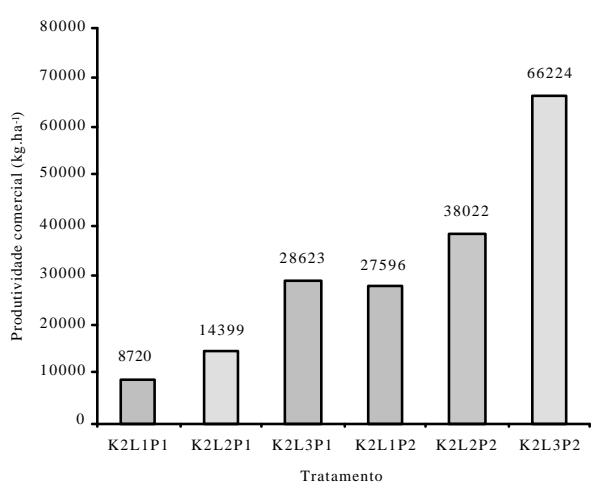

b)

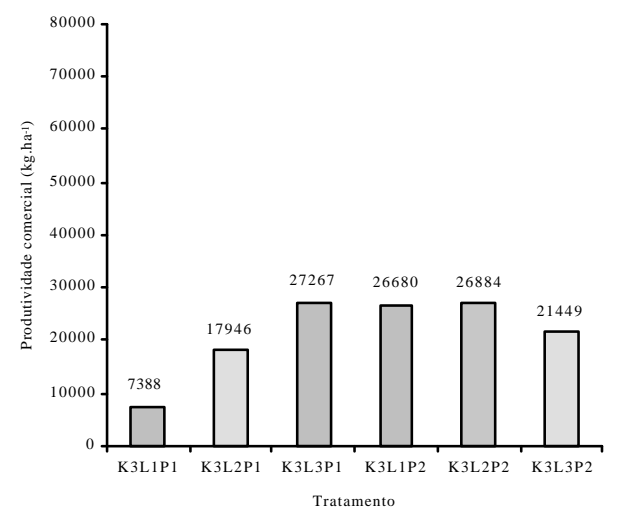

Figura 36 - Produtividade comercial $\left(\mathrm{kg} \mathrm{ha}^{-1}\right)$ em combinação com três níveis de irrigação e duas posições de instalação dos tubogotejadores: a) dose de potássio K2 (9 $\mathrm{g}$ de $\left.\mathrm{K}_{2} \mathrm{O} \mathrm{pl}{ }^{-1}\right)$; b) dose de potássio $\mathrm{K} 3\left(12 \mathrm{~g} \mathrm{de}_{2} \mathrm{O} \mathrm{pl}^{-1}\right)$.

As comparações de PT e PC para cada fator separadamente são apresentadas na Tabela 27, o valor de PT é menor para as doses extremas de potássio K0 e K3 (0 g e 12 g de $\left.\mathrm{K}_{2} \mathrm{O} \mathrm{pl}^{-1}\right)$ e maior para as doses intermediárias de potássio $\mathrm{K} 1$ e $\mathrm{K} 2\left(6 \mathrm{~g}\right.$ e 9 g de $\mathrm{K}_{2} \mathrm{O}$ $\mathrm{pl}^{-1}$ ). Para o fator níveis de irrigação, o valor da PT é menor para o nível L1 (137,72 mm) e maior para o nível L3 $(417,32 \mathrm{~mm})$. Para o fator posições de instalação dos tubogotejadores o valor da PT é maior para a posição P2 $(0,2 \mathrm{~m})$ e menor para a posição P1 (0,0 m).

O valor de PC é menor para as doses extremas de potássio K0 e K3 (0 g e 12 g de $\left.\mathrm{K}_{2} \mathrm{O} \mathrm{pl}^{-1}\right)$ e maior para as doses intermediárias de potássio $\mathrm{K} 1$ e $\mathrm{K} 2\left(6 \mathrm{~g}\right.$ e 9 g de $\mathrm{K}_{2} \mathrm{O} \mathrm{pl}$ $\left.{ }^{1}\right)$. Para o fator níveis de irrigação, o valor da PC é menor para o nível L1 (137,72 mm) e maior para o nível L3 (417,32 mm).

Para o fator posições de instalação dos tubogotejadores o valor da PC é maior para a posição $\mathrm{P} 2(0,2 \mathrm{~m})$, e menor para a posição $\mathrm{P} 1(0,0 \mathrm{~m})$. 
Tabela 27. Comparação de médias de produtividade total e comercial, para cada nível de fator isolado.

\begin{tabular}{ccccc}
\hline \multirow{2}{*}{ Nível de fator } & \multicolumn{4}{c}{ Produtividade total $\left(\mathrm{kg} \mathrm{ha}^{-1}\right)$ por bloco } \\
& I & II & III & Média \\
\hline K0 & 32355,889 & 30271,550 & 32847,670 & 31825,030 \\
K1 & 37385,383 & 37144,830 & 36432,920 & 36987,71 \\
K2 & 35906,333 & 36599,250 & 35576,430 & 36027,340 \\
K3 & 27421,915 & 28432,170 & 28734,830 & 28196,310 \\
L1 & 10907,954 & 12335,220 & 10909,060 & 11384,080 \\
L2 & 34763,625 & 35112,750 & 34791,250 & 34889,210 \\
L3 & 49775,750 & 47745,880 & 49470,830 & 48997,480 \\
P1 & 30241,402 & 30127,040 & 28406,840 & 29591,760 \\
P2 & 36293,358 & 36096,860 & 38389,080 & 36926,430 \\
& & Produtividade comercial & $(\mathrm{kg} \mathrm{ha}$ \\
K0 & 26498,060 & 24560,652 & 25890,610 & 25649,770 \\
K1 & 31099,140 & 32103,722 & 30582,110 & 31261,660 \\
K2 & 31636,990 & 30584,519 & 29569,930 & 30597,150 \\
K3 & 19959,980 & 21676,384 & 22170,620 & 21268,990 \\
L1 & 10662,550 & 11550,726 & 10792,640 & 11001,970 \\
L2 & 27696,270 & 27718,379 & 27835,230 & 27749,860 \\
L3 & 43536,810 & 42424,852 & 42532,090 & 42831,250 \\
P1 & 23849,240 & 24452,981 & 22669,220 & 23657,150 \\
P2 & 30747,840 & 30009,657 & 31437,420 & 30731,640 \\
\hline
\end{tabular}

Devido a que os resultados da analise de variância para a PT e PC mostraram efeitos altamente significativos $(\mathrm{P}<0,01)$ para as interações das variáveis estudadas (KxLxP), procedeu-se ao desdobramento da variável qualitativa de posição dos tubogotejadores (P1 e P2) pelo teste de Tukey, mostrando que a PT aumenta quando os tubogotejadores estão localizados na subsuperfície com um DMS de 5.458,084 kg ha-1 $(\mathrm{P}<0,05)$ e de 7.278,722 $\mathrm{kg} \mathrm{ha}^{-1}(\mathrm{P}<0,01)$. A PC aumenta quando os tubogotejadores estão localizados na subsuperfície com um DMS de 6.349,318 $\mathrm{kg} \mathrm{ha}^{-1}(\mathrm{P}<0,05)$ e em $8.467,242 \mathrm{~kg} \mathrm{ha}^{-1}(\mathrm{P}<0,01)$, sendo o tratamento $\mathrm{P} 2(\mathrm{~L} 3 \mathrm{xK} 2)$ o que mostrou maior PT e PC com 69.649 e $66.224,309 \mathrm{~kg} \mathrm{ha}^{-1}$, respectivamente (Tabela 28). 
Tabela 28. Resumo da análise de significância para rendimento total e comercial pelo teste de Tukey para o fator de posição dos tubogotejadores (P), dentro dos níveis dos fatores de níveis de irrigação (L) e doses de potássio (K) aplicado.

\begin{tabular}{|c|c|c|c|}
\hline \multirow{2}{*}{ Causas de variação } & \multirow{2}{*}{ Média original } & \multicolumn{2}{|c|}{ (significância-Prob. > F) } \\
\hline & & $5 \%$ & $1 \%$ \\
\hline \multicolumn{4}{|l|}{ Rendimento total } \\
\hline P1(L1xK0) & $9.132,444$ & $\mathrm{a}$ & A \\
\hline P2(L1xK0) & $15.159,093$ & $\mathrm{~b}$ & A \\
\hline P1(L1xK1) & $12.684,833$ & $\mathrm{a}$ & A \\
\hline $\mathrm{P} 2(\mathrm{~L} 1 \times \mathrm{x} 1)$ & $25.683,766$ & $\mathrm{~b}$ & $\mathrm{~B}$ \\
\hline $\mathrm{P} 1(\mathrm{~L} 1 \mathrm{XK} 2)$ & $11.563,833$ & $\mathrm{a}$ & $\mathrm{A}$ \\
\hline P2(L1xK2) & $34.775,000$ & $\mathrm{~b}$ & $\mathrm{~B}$ \\
\hline $\mathrm{P} 1(\mathrm{~L} 1 \times \mathrm{K} 3)$ & $12.431,497$ & $\mathrm{a}$ & $\mathrm{A}$ \\
\hline P2(L1xK3) & $23.620,667$ & $\mathrm{~b}$ & B \\
\hline P1(L2xK0) & $29.195,333$ & $\mathrm{a}$ & $A$ \\
\hline P2(L2xK0) & $35.906,000$ & $\mathrm{a}$ & $\mathrm{A}$ \\
\hline P1(L3xK1) & $44.886,333$ & $\mathrm{~b}$ & $\mathrm{~A}$ \\
\hline P2(L3xK1) & $65.108,333$ & $\mathrm{a}$ & $\mathrm{B}$ \\
\hline P1(L3xK2) & $45.573,533$ & $\mathrm{a}$ & $\mathrm{A}$ \\
\hline P2(L3xK2) & $69.649,000$ & $\mathrm{~b}$ & B \\
\hline DMS & & $5.458,084$ & $7.278,722$ \\
\hline \multicolumn{4}{|l|}{ Rendimento comercial } \\
\hline P1 $(\mathrm{L} 1 x K 0)$ & 2727,351 & $\mathrm{a}$ & $\mathrm{A}$ \\
\hline $\mathrm{P} 2(\mathrm{~L} 1 \times \mathrm{K} 0)$ & 9183,952 & $b$ & $\mathrm{~A}$ \\
\hline P1(L1xK1) & 7048,101 & a & A \\
\hline P2(L1xK1) & 20603,822 & $\mathrm{~b}$ & $\mathrm{~B}$ \\
\hline P1(L1xK3) & 7388,339 & $\mathrm{a}$ & A \\
\hline P2(L1xK3) & 17945,651 & $\mathrm{~b}$ & $\mathrm{~B}$ \\
\hline P1(L3xK1) & 37586,299 & $\mathrm{a}$ & A \\
\hline P2(L3xK1) & 61427,603 & $\mathrm{~b}$ & B \\
\hline P1(L3xK2) & 38224,309 & $\mathrm{a}$ & A \\
\hline P2(L3xK2) & 66224,309 & $\mathrm{~b}$ & B \\
\hline DMS & & $6.349,318$ & $8.467,242$ \\
\hline
\end{tabular}

De igual forma, procedeurse ao desdobramento das variáveis quantitativas de níveis de irrigação e dose de potássio pelo teste de regressão polinomial, para a PT e PC, respectivamente o qual é apresentado na Tabela 29. 
Tabela 29. Equações lineares e quadráticas para rendimento total e comercial, resultados do teste de regressão para o fator lâmina de irrigação (L) e dose de potássio (K) aplicado.

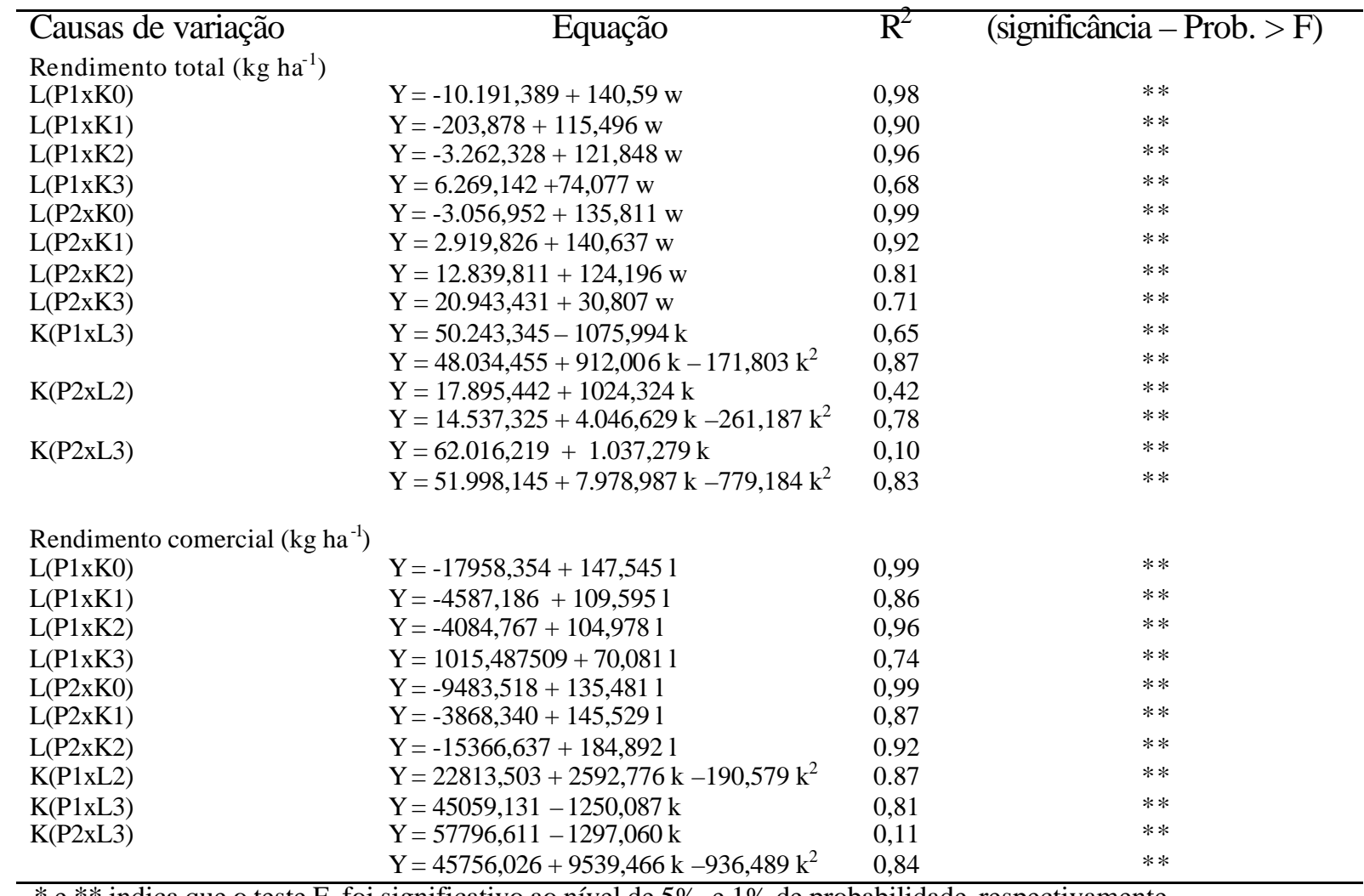

* e ** indica que o teste $\mathrm{F}$, foi significativo ao nível de $5 \%$ e $1 \%$ de probabilidade, respectivamente.

A interação L(P2xK2) evidencia efeito linear crescente para o nível de irrigação até 417,32 mm, com ajuste significativo $(\mathrm{P}<0,01)$ e coeficiente de determinação de $\mathrm{R}^{2}=$ 0,81, com uma produtividade total de $64.669,286 \mathrm{~kg} \mathrm{ha}^{-1}$. Por outro lado, a interação $\mathrm{K}(\mathrm{P} 2 \times \mathrm{L} 3)$ evidencia maior produção e efeito quadrático para a dose de $6 \mathrm{~g}$ de $\mathrm{K}_{2} \mathrm{O} \mathrm{pl}{ }^{-1}$, com ajuste significativo $(\mathrm{P}<0,01)$ e coeficiente de determinação de $\mathrm{R}^{2}=0,83$, chegando a uma produtividade total de $71.821,443 \mathrm{~kg} \mathrm{ha}^{-1}$.

A interação L(P2xK2) evidencia efeito linear crescente para o nível de irrigação ate $417,32 \mathrm{~mm}$, com ajuste significativo $(\mathrm{P}<0,01)$ e coeficiente de determinação de $\mathrm{R}^{2}=$ 0,92, com uma produtividade total de 61.792,492 $\mathrm{kg} \mathrm{ha}^{-1}$. Já a interação $\mathrm{K}(\mathrm{P} 2 \mathrm{xL} 3)$

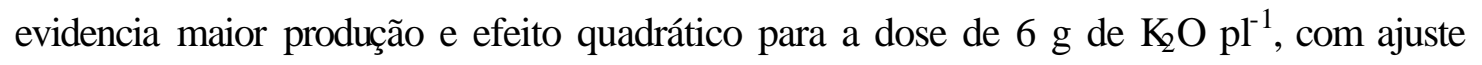


significativo $(\mathrm{P}<0,01)$ e coeficiente de determinação de $\mathrm{R}^{2}=0,84$, chegando a uma produtividade total de $69.279,218 \mathrm{~kg} \mathrm{ha}^{-1}$.

Kano (2002) relata que a dose de $300 \mathrm{~kg} \mathrm{ha}^{-1}$ de $\mathrm{K}_{2} \mathrm{O}$ foi a que proporcionou maior produção de frutos de melão híbrido Bônus $\mathrm{n}^{\mathrm{o}} 2$, sendo a produtividade obtida próxima às obtidas por Sagiv et al. ${ }^{3}$ citados por Bar Yosef (1999) e Rincón Sánchez et al., (1998) que foram de 53,2 a 56,0 $\mathrm{Mg} \mathrm{ha}^{-1}$ ao utilizarem as doses de 350 e $385 \mathrm{~kg} \mathrm{ha}^{-1} \mathrm{de}$ $\mathrm{K}_{2} \mathrm{O}$, respectivamente.

Cardoso (2002) relata que a menor produção comercial $\left(36,72 \mathrm{t} \mathrm{ha}^{-1}\right)$ foi obtida com a dose de $50 \mathrm{~kg} \mathrm{ha}^{-1}$ de $\mathrm{K}_{2} \mathrm{O}$. Os valores de produtividade comercial apresentaram a mesma tendência da produtividade total, verificando-se a ocorrência das maiores produtividades para a dose de $300 \mathrm{~kg} \mathrm{ha}^{-1}$ de $\mathrm{K}_{2} \mathrm{O}$.

\subsubsection{Classificação de frutos}

Pelos valores médios do número de frutos ha ${ }^{-1}$ (Tabela 29), o número de frutos ha 1 enquadrados no peso de 550-800 g, foram os que mais contribuíram para o total da produtividade comercial do híbrido de melão Bunus $\mathrm{n}^{\circ}$. 2, em média 17.292,284 frutos $\mathrm{ha}^{-1}$, seguido pelos pesos entre 800-1.050 g, 1.1050-1.300 g, 1.300-1.550 g e >1.550 g, com participação média na produtividade comercial de 9.963,529, 2.963.933, 2.168.335 e 1.64.635 frutos $\mathrm{ha}^{-1}$, respectivamente. Sendo assim, o número de frutos ha ${ }^{-1}$ diminui para cada tratamento, àmedida que a classificação por peso aumenta.

Pode-se observar também, que o maior número de frutos $\mathrm{ha}^{-1}$, considerando todas as classificações estabelecidas, foram obtidos com as respectivas combinações de dose de potássio, níveis de irrigação e posição dos tubogotejadores (K1L3P2 e K2L3P2), que favorecerem também os maiores valores de produtividade comercial $\left(61.427,60 \mathrm{~kg} \mathrm{ha}^{-1} \mathrm{e}\right.$ $\left.66224,31 \mathrm{~kg} \mathrm{ha}^{-1}\right)$.

\footnotetext{
3 SAGIV, B.; BAR-YOSEF, B.; ELIAH, E. Drip irrigation and fertilization of spring muskmelon at Beso. Israel: Bet Dagan,1980. (The Volcani Center,. p.18-22. Pub,17).
} 
Tabela 30. Classificação de frutos comerciais por peso

\begin{tabular}{|c|c|c|c|c|c|c|}
\hline \multirow{2}{*}{ No. } & \multirow{2}{*}{ Tratamento } & \multicolumn{5}{|c|}{ Número de frutos ha ${ }^{-1}$} \\
\hline & & $550-800 \mathrm{~g}$ & $800-1050 \mathrm{~g}$ & $1050-1300 \mathrm{~g}$ & $1300-1550 \mathrm{~g}$ & $>1550 \mathrm{~g}$ \\
\hline 1 & K0L1P1 & 3952,5 & & & & \\
\hline 2 & K0L1P2 & 5928,8 & 1317,3 & 1317,3 & 1976,2 & \\
\hline 3 & K0L2P1 & 22397,8 & 9221,3 & & & \\
\hline 4 & K0L2P2 & 18445,2 & 15810,2 & 1316,2 & & \\
\hline 5 & K0L3P1 & 17127,6 & 23715,4 & 6587,5 & 1976,2 & \\
\hline 6 & K0L3P2 & 19762,8 & 10540,1 & 7905,1 & 11198,8 & \\
\hline 7 & K1L1P1 & 7905,1 & 1976,2 & & & \\
\hline 8 & K1L1P2 & 16468,9 & 9221,3 & 1316,2 & & \\
\hline 9 & K1L2P1 & 26349,8 & 9222,5 & 2634,3 & 3293,7 & \\
\hline 10 & K1L2P2 & 17127,6 & 15151,3 & 1316,2 & & \\
\hline 11 & K1L3P1 & 21739,1 & 18445,2 & 5268,7 & & \\
\hline 12 & K1L3P2 & 27007,9 & 19103,9 & 6587,5 & 11197,6 & 1316,2 \\
\hline 13 & K2L1P1 & 5928,8 & 3952,5 & 658,6 & & \\
\hline 14 & K2L1P2 & 11197,6 & 6587,5 & 658,8 & & \\
\hline 15 & K2L2P1 & 21739,1 & 10539,5 & 3293,6 & & \\
\hline 16 & K2L2P2 & 21739,1 & 9881,4 & 3293,6 & & \\
\hline 17 & K2L3P1 & 26349,8 & 13833,9 & 5268,7 & 1976,2 & \\
\hline 18 & K2L3P2 & 21739,1 & 15151,3 & 12515,8 & 13833,9 & 1976,2 \\
\hline 19 & K3L1P1 & 5928,8 & 3952,5 & & & \\
\hline 20 & K3L1P2 & 16468,9 & 5268,7 & 2634,3 & & \\
\hline 21 & K3L2P1 & 27009,1 & 5928,8 & 1316,2 & 1976,2 & \\
\hline 22 & K3L2P2 & 19103,9 & 10540,1 & 1976,2 & 1976,2 & \\
\hline 23 & K3L3P1 & 17127,6 & 10540,1 & 3292,4 & 2634,3 & 658,7 \\
\hline 24 & K3L3P2 & 16468,9 & 9222,5 & 1976,2 & & \\
\hline
\end{tabular}

Quando analisados os efeitos de cada fator isolado (Tabela 30), verifica-se que a dose $\mathrm{K} 1$ ( $6 \mathrm{~g}_{\text {de }} \mathrm{K}_{2} \mathrm{O} \mathrm{pl}^{-1}$ ) é a que apresenta maior número de frutos $\mathrm{ha}^{-1}$, seguido pela dose $\mathrm{K} 2\left(9 \mathrm{~g}\right.$ de $\left.\mathrm{K}_{2} \mathrm{O} \mathrm{pl}{ }^{-1}\right)$, enquanto que as doses $\mathrm{K} 0$ e $\mathrm{K} 3\left(0 \mathrm{~g}\right.$ de $\mathrm{K}_{2} \mathrm{O} \mathrm{pl}^{-1}$ e 12 g de $\mathrm{K}_{2} \mathrm{O}$ $\mathrm{pl}^{-1}$ ) são as que apresentam menor valor. Para o fato níveis de irrigação o número de frutos $\mathrm{ha}^{-1}$ aumenta a medida que aumenta os níveis de irrigação testados; no que se refere ao fator de posição dos tubogotejadores, a posição subsuperficial apresenta maior número de frutos $\mathrm{ha}^{-1}$. 
Tabela 31. Comparação de médias para No de frutos comerciais ha $^{-1}$, para cada nível de fator isolado.

\begin{tabular}{crrrrrr}
\hline Nível & \multicolumn{5}{c}{ No de frutos ha $^{-1}$} & \multirow{2}{*}{ Total } \\
de fator & $550-800 \mathrm{~g}$ & $800-1050 \mathrm{~g}$ & $1050-1300 \mathrm{~g}$ & $1330-1550 \mathrm{~g}$ & $>1550 \mathrm{~g}$ & \\
\hline K0 & 14602,503 & 10100,758 & 2854,381 & 2525,231 & & 30082,872 \\
K1 & 19433,103 & 12186,792 & 2853,854 & 2415,237 & 219,368 & 37108,353 \\
K2 & 18115,613 & 9991,074 & 4281,555 & 2635,046 & 329,381 & 35352,668 \\
K3 & 17017,918 & 7575,494 & 1865,942 & 1097,826 & 109,792 & 27666,973 \\
L1 & 9222,480 & 4034,560 & 823,172 & 247,036 & & 14327,248 \\
L2 & 21738,982 & 10786,932 & 1893,330 & 905,795 & & 35325,040 \\
L3 & 20915,390 & 15069,096 & 6175,296 & 5352,174 & 493,906 & 48005,862 \\
P1 & 16962,961 & 9277,372 & 2360,046 & 988,086 & 54,896 & 29643,361 \\
P2 & 17621,607 & 10649,687 & 3567,819 & 3348,584 & 274,374 & 35462,072 \\
\hline
\end{tabular}

\subsection{Pós-colheita}

\subsubsection{Parâmetros físicos}

Muitos dos parâmetros físicos de pós-colheita de frutos de melão estão condicionados por múltiplos fatores, sendo que podem ser mencionados a nutrição da planta, o tempo de colheita e de armazenamento, entre outros.

\subsubsection{Peso médio de frutos}

Os valores de peso médio de frutos (PMF), são apresentados na Tabela 32 sendo que não foram encontrados influencias significativa das interações dos fatores pelo teste de variância. O menor valor de PMF correspondeu ao tratamento K0L1P1 com 0,690 kg e o maior valor de PMF ao tratamento K2L3P2 com 1,015 kg. 
Tabela 32. Peso médio de frutos (PMF)

\begin{tabular}{cccc}
\hline Tratamento & PMF $(\mathrm{kg})$ & Tratamento & PMF $(\mathrm{kg})$ \\
\hline K0L1P1 & 0.690 & K2L1P1 & 0.827 \\
K0L1P2 & 0.871 & K2L1P2 & 0.781 \\
K0L2P1 & 0.713 & K2L2P1 & 0.805 \\
K0L2P2 & 0.798 & K2L2P2 & 0.790 \\
K0L3P1 & 0.890 & K2L3P1 & 0.802 \\
K0L3P2 & 0.953 & K2L3P2 & 1.015 \\
K1L1P1 & 0.713 & K3L1P1 & 0.748 \\
K1L1P2 & 0.763 & K3L1P2 & 0.736 \\
K1L2P1 & 0.797 & K3L2P1 & 0.753 \\
K1L2P2 & 0.828 & K3L2P2 & 0.794 \\
K1L3P1 & 0.827 & K3L3P1 & 0.785 \\
K1L3P2 & 0.942 & K3L3P2 & 0.775 \\
\hline
\end{tabular}

As comparações de PMF para cada fator por separado são apresentadas na Tabela 33. Verifica-se que o PMF diminui com a maior dose de potássio K3 (12g de $\left.\mathrm{K}_{2} \mathrm{O} \cdot \mathrm{pl}^{-1}\right)$. Para o fator níveis de irrigação, o PMF aumenta a medida em que aumenta os níveis de irrigação testados e a posição dos tubogotejadores subsuperfície é a que proporcionou maior PMF.

Tabela 33. Comparação de médias para peso médio de frutos (PMF), para cada nível de fator isolado

\begin{tabular}{cc}
\hline Nível de cada fator & PMF $(\mathrm{kg})$ \\
\hline K0 & 0,819 \\
K1 & 0,812 \\
K2 & 0,837 \\
K3 & 0,765 \\
L1 & 0,766 \\
L2 & 0,745 \\
L3 & 0,874 \\
P1 & 0,779 \\
P2 & 0,837 \\
\hline
\end{tabular}

Estudos realizados durante cinco anos (1979 a 1985) da qualidade de melões em relação ao espaçamento e a fertilização por Prabhakar et al., (1985) levam a afirmar que a aplicação de potássio elevou em $12 \%$ o peso dos frutos, principalmente devido a seu 
papel na translocação de carboidratos para os frutos.

\subsubsection{Diâmetro equatorial e polar dos frutos}

Os valores médios de diâmetro equatorial (DE) e polar (DP) dos frutos estão apresentados na Tabela 34. O valor mínimo e máximo de DE e DP corresponderam ao tratamentos K1L3P2 com 129,0 e 126,0 mm, respectivamente.

Tabela 34. Diâmetro equatorial e polar dos frutos (mm)

\begin{tabular}{cccccc}
\hline Trat. & D. E. $(\mathrm{mm})$ & D. P. $(\mathrm{mm})$ & Trat. & D. E. $(\mathrm{mm})$ & D. P. $(\mathrm{mm})$ \\
\hline K0L1P1 & 131,8 & 128,8 & K2L1P1 & 142,9 & 139,9 \\
K0L1P2 & 150,4 & 147,4 & K2L1P2 & 142,9 & 139,9 \\
K0L2P1 & 135,8 & 132,8 & K2L2P1 & 143,5 & 140,5 \\
K0L2P2 & 133,3 & 130,3 & K2L2P2 & 143,1 & 140,1 \\
K0L3P1 & 141,2 & 138,2 & K2L3P1 & 143,5 & 104,5 \\
K0L3P2 & 133,5 & 130,5 & K2L3P2 & 148,5 & 115,5 \\
K1L1P1 & 136,2 & 133,2 & K3L1P1 & 136,2 & 133,2 \\
K1L1P2 & 142,9 & 139,9 & K3L1P2 & 142,5 & 139,5 \\
K1L2P1 & 151,9 & 148,9 & K3L2P1 & 154,4 & 151,4 \\
K1L2P2 & 142,0 & 139,0 & K3L2P2 & 148,1 & 115,1 \\
K1L3P1 & 141,2 & 138,2 & K3L3P1 & 119,5 & 116,5 \\
K1L3P2 & 129,0 & 126,0 & K3L3P2 & 132,9 & 129,9 \\
\hline
\end{tabular}


De acordo com a analise de variância (Tabela 35), estes parâmetros foram altamente significativos $(\mathrm{P}<0,01)$ para os fatores isolados e suas respectivas interações.

Tabela 35. Resumo da análise de variância para os valores médios de diâmetro equatorial (DE) e diâmetro polar (DP), com desdobramento dos graus de liberdade dos tratamentos, de acordo com o esquema fatorial $4 \times 3 \times 2$.

\begin{tabular}{|c|c|c|c|}
\hline \multirow{2}{*}{$\begin{array}{c}\text { Causas de } \\
\text { variação }\end{array}$} & \multirow{2}{*}{ G.L. } & \multicolumn{2}{|c|}{ Quadrado médio (significância - Prob. >F). } \\
\hline & & DE & $\mathrm{DP}$ \\
\hline $\mathrm{K}$ & 3 & $138,091 * *$ & $194,082 * *$ \\
\hline $\mathrm{L}$ & 2 & $372,117 * *$ & $1183,954 * *$ \\
\hline $\mathrm{P}$ & 1 & $14,851^{* *}$ & $32,940 * *$ \\
\hline $\mathrm{KxL}$ & 6 & $288,788^{* * *}$ & $331,533 * *$ \\
\hline $\mathrm{KxP}$ & 3 & $79,511^{* *}$ & $94,522 * *$ \\
\hline PxL & 2 & $248,271^{* *}$ & $621,202 * *$ \\
\hline KxLxP & 6 & $121,795^{* *}$ & $314,468 * *$ \\
\hline (Tratamento) & (23) & & \\
\hline Blocos & 2 & $167,700 * *$ & 1128,807 \\
\hline Resíduo & 46 & 0,001 & 1,394 \\
\hline Total & 71 & 4707,369 & 10706,801 \\
\hline Média & & 140,301 & 133,435 \\
\hline CV (\%) & & 0,019 & 0,885 \\
\hline
\end{tabular}

As comparações de médias de DE e DP para cada fator separadamente são apresentadas na Tabela 35. O valor de DE aumenta para as doses crescentes de potássio e o DP decresce com as dos maiores does de potássio. Para o fator níveis de irrigação, os valores de DE e DP resultaram maiores para os níveis L2 e L1, respectivamante. De igual forma, o DE e DP aumentam quando os tubogotejadores encontram-se na superfície. 
Tabela 36. Comparação de médias para diâmetro equatorial e polar de frutos, para cada nível de fator isolado.

\begin{tabular}{ccc}
\hline Nível de cada fator & DE $(\mathrm{mm})$ & DP $(\mathrm{mm})$ \\
\hline K0 & 132.6125 & 134.7114 \\
K1 & 133.3245 & 137.5921 \\
K2 & 140.3708 & 130.1309 \\
K3 & 134.7168 & 130.9983 \\
L1 & 136.8528 & 137.7821 \\
L2 & 140.0437 & 137.3281 \\
L3 & 128.8719 & 124.9643 \\
P1 & 135.7267 & 133.8993 \\
P2 & 134.7856 & 132.817 \\
\hline
\end{tabular}

Foram desdobradas as variáveis qualitativas de posição dos tubogotejadores pelo teste de Tukey (Tabela 37) evidenciando que, o DE auemnta quando se aplica fertirrigação na superfície com DMS de 0,044 mm (P<0,05) e 0,059 mm (P<0,01) e o DP também aumenta quando se aplica fertirrigação na subsupeficie com DMS de 0,943 mm $(\mathrm{P}<0,05)$ em 2,591 mm $(\mathrm{P}<0,01)$, segundo as interações mostradas. 
Tabela 37. Resumo da análise de significância para diâmetro equatorial (DE) e diâmetro polar (DP) pelo teste de Tukey para o fator de posição dos tubogotejadores (P), dentro dos níveis dos fatores níveis de irrigação $(\mathrm{L})$ e doses de potássio (K) aplicados.

\begin{tabular}{|c|c|c|c|}
\hline \multirow{2}{*}{ Causas de variação } & \multirow{2}{*}{ Média original } & \multicolumn{2}{|c|}{ (significância - Prob. > F) } \\
\hline & & $5 \%$ & $1 \%$ \\
\hline \multicolumn{4}{|l|}{ Diâmetro longitudinal (DE) } \\
\hline $\mathrm{P} 1(\mathrm{~L} 1 \mathrm{xK} 0)$ & 131,800 & a & A \\
\hline P2(L1xK0) & 150,367 & $\mathrm{~b}$ & $\mathrm{~B}$ \\
\hline P1(L1xK1) & 136,199 & a & A \\
\hline P2(L1xK1) & 142,899 & $\mathrm{~b}$ & $\mathrm{~B}$ \\
\hline P1(L1xK3) & 136,199 & a & A \\
\hline P2(L1xK3) & 142,500 & $\mathrm{~b}$ & $\mathrm{~B}$ \\
\hline P1(L2xK0) & 135,800 & $\mathrm{a}$ & $\mathrm{A}$ \\
\hline $\mathrm{P} 2(\mathrm{~L} 2 \mathrm{xK} 0)$ & 133,300 & $\mathrm{~b}$ & $\mathrm{~B}$ \\
\hline P1(L2xK1) & 151,899 & a & A \\
\hline $\mathrm{P} 2(\mathrm{~L} 2 \mathrm{xK} 1)$ & 142,000 & $\mathrm{~b}$ & $\mathrm{~B}$ \\
\hline P1(L2xK2) & 143,500 & a & A \\
\hline P2(L2xK2) & 143,100 & $\mathrm{~b}$ & $\mathrm{~B}$ \\
\hline P1(L2xK3) & 154,399 & $\mathrm{a}$ & A \\
\hline P2(L2xK3) & 148,100 & $\mathrm{~b}$ & $\mathrm{~B}$ \\
\hline P1(L3xK0) & 141,267 & a & A \\
\hline P2(L3xK0) & 133,500 & $\mathrm{~b}$ & $\mathrm{~B}$ \\
\hline P1(L3xK0) & 141,199 & a & A \\
\hline P2(L3xK1) & 129,000 & $\mathrm{~b}$ & B \\
\hline P1(L3xK2) & 148,500 & $\mathrm{a}$ & A \\
\hline P2(L3xK2) & 143,500 & $\mathrm{~b}$ & B \\
\hline P1(L3xK3) & 132,899 & $\mathrm{a}$ & A \\
\hline P2(L3xK3) & 119,500 & $\mathrm{~b}$ & B \\
\hline DMS & & 0,044 & 0,059 \\
\hline \multicolumn{4}{|l|}{ Diâmetro transversal (DP) } \\
\hline $\mathrm{P} 1(\mathrm{~L} 1 \mathrm{xK} 0)$ & 128,800 & a & A \\
\hline P2(L1xK0) & 147,399 & $\mathrm{~b}$ & $\mathrm{~A}$ \\
\hline $\mathrm{P} 1(\mathrm{~L} 1 \times \mathrm{K} 1)$ & 133,199 & a & A \\
\hline P2(L1xK1) & 139,899 & $\mathrm{~b}$ & $\mathrm{~B}$ \\
\hline P1(L1xK3) & 133,199 & $\mathrm{a}$ & A \\
\hline P2(L1xK3) & 139,500 & $\mathrm{~b}$ & $\mathrm{~B}$ \\
\hline P1(L2xK0) & 132,800 & $\mathrm{a}$ & $\mathrm{A}$ \\
\hline P2(L2xK0) & 130,300 & $\mathrm{~b}$ & $\mathrm{~B}$ \\
\hline $\mathrm{P} 1(\mathrm{~L} 2 \mathrm{xK} 1)$ & 148,799 & $\mathrm{a}$ & A \\
\hline P2(L2xK1) & 139,000 & $\mathrm{~b}$ & $\mathrm{~B}$ \\
\hline P1(L2xK3) & 151,399 & $\mathrm{~b}$ & A \\
\hline P2(L2xK3) & 115,099 & $\mathrm{a}$ & A \\
\hline P1(L3xK0) & 138,199 & $\mathrm{~b}$ & A \\
\hline P2(L3xK0) & 130,500 & $\mathrm{a}$ & B \\
\hline P1(L3xK1) & 138,199 & $\mathrm{~b}$ & A \\
\hline P2(L3xK1) & 126,000 & $\mathrm{a}$ & B \\
\hline P1(L3xK2) & 115,500 & $\mathrm{~b}$ & A \\
\hline P2(L3xK2) & 107,833 & $\mathrm{a}$ & B \\
\hline P1(L3xK3) & 116,500 & $\mathrm{~b}$ & A \\
\hline P2(L3xK3) & 129,899 & $\mathrm{a}$ & B \\
\hline DMS & & 1,943 & 2,591 \\
\hline
\end{tabular}


De igual forma, procedeutse ao desdobramento das variáveis quantitativas de níveis de irrigação e doses de potássio pelo teste de regressão polinomial, o qual é apresentado na Tabela 38. A interação $\mathrm{L}(\mathrm{P} 1 \times \mathrm{x} 2)$ evidencia efeito linear decrescente para o nível de irrigação até $137,72 \mathrm{~mm}$ e um valor máximo de 143,259 mm, com ajuste significativo $(\mathrm{P}<0,01)$ e coeficiente de determinação de $\mathrm{R}^{2}=0,79$. Já a interação $\mathrm{K}(\mathrm{P} 1 x \mathrm{~L} 2)$ evidencia efeito linear para a dose de $12 \mathrm{~g}$ de $\mathrm{K}_{2} \mathrm{O}$ por planta, com ajuste significativo $(\mathrm{P}<0,01)$ e coeficiente de determinação de $\mathrm{R}^{2}=0,62$, chegando a 153,264 mm. O DP segue a mesma tendência observada.

Tabela 38. Equações lineares e quadráticas para diâmetro equatorial (DE) e diâmetro polar (DP), resultados do teste de regressão para o fator lâmina de irrigação (L) e doses de potássio (K) aplicado.

\begin{tabular}{|c|c|c|c|}
\hline Causas de variação & Equação. & $\mathrm{R}^{2}$ & (significância - Prob. > F) \\
\hline \multicolumn{4}{|l|}{ Diâmetro equatorial (mm) } \\
\hline $\mathrm{L}(\mathrm{P} 1 \mathrm{xK} 0)$ & $\mathrm{Y}=126,877+0,034 \mathrm{w}$ & 0,99 & $* *$ \\
\hline $\mathrm{L}(\mathrm{P} 1 \times \mathrm{K} 1)$ & $Y=137,994+0,018 w$ & 0,10 & $* *$ \\
\hline $\mathrm{L}(\mathrm{P} 1 \times \mathrm{K} 2)$ & $Y=142,700+0,002 w$ & 0,76 & $* *$ \\
\hline $\mathrm{L}(\mathrm{P} 1 \times \mathrm{xK} 3)$ & $Y=153,054-0,059 w$ & 0,22 & $* *$ \\
\hline $\mathrm{L}(\mathrm{P} 2 \mathrm{xK} 0)$ & $Y=155,923-0,061 \mathrm{w}$ & 0,75 & $* *$ \\
\hline $\mathrm{L}(\mathrm{P} 2 \times \mathrm{K} 1)$ & $Y=151,737-0,049 w$ & 0,79 & $* *$ \\
\hline $\mathrm{L}(\mathrm{P} 2 \times \mathrm{K} 2)$ & $Y=139,287+0,019 w$ & 0.77 & $* *$ \\
\hline $\mathrm{L}(\mathrm{P} 2 \times \mathrm{K} 3)$ & $Y=150,616-0,034 \mathrm{w}$ & 0.38 & $* *$ \\
\hline $\mathrm{K}(\mathrm{P} 1 \mathrm{xL} 1)$ & $\begin{array}{l}\mathrm{Y}=132,937+0,569 \mathrm{k} \\
\mathrm{Y}=131,353+1,995 \mathrm{k}-0,123 \mathrm{k}^{2}\end{array}$ & $\begin{array}{l}0,40 \\
0,65\end{array}$ & $\begin{array}{l}* * \\
* *\end{array}$ \\
\hline \multirow[t]{2}{*}{$\mathrm{K}(\mathrm{P} 1 \mathrm{xL} 2)$} & $\mathrm{Y}=137,580+1,307 \mathrm{k}$ & 0,62 & $* *$ \\
\hline & $\mathrm{Y}=136,625+2.166 \mathrm{k}-0,074 \mathrm{k}^{2}$ & 0,65 & $* *$ \\
\hline \multirow[t]{2}{*}{$\mathrm{K}(\mathrm{P} 1 \mathrm{xL} 3)$} & $\mathrm{Y}=145,727-1,387 \mathrm{k}$ & 0,40 & $* *$ \\
\hline & $\mathrm{Y}=140,507+3,311 \mathrm{k}-0,406 \mathrm{k}^{2}$ & 0,83 & $* *$ \\
\hline \multirow[t]{2}{*}{$\mathrm{K}(\mathrm{P} 2 \mathrm{xL} 1)$} & $\mathrm{Y}=149,167-0,667 \mathrm{k}$ & 0.81 & $* *$ \\
\hline & $\mathrm{Y}=150,288-1,676 \mathrm{k}+0,087 \mathrm{k}^{2}$ & 0.98 & $* *$ \\
\hline \multicolumn{4}{|l|}{ Diâmetro polar (mm) } \\
\hline $\mathrm{L}(\mathrm{P} 1 \times \mathrm{K} 0)$ & Y 123,921 + 0,034 1 & 0,99 & $* *$ \\
\hline $\mathrm{L}(\mathrm{P} 1 \times \mathrm{K} 1)$ & $Y=134,963+0,0181$ & 0,10 & $* *$ \\
\hline $\mathrm{L}(\mathrm{P} 1 \times \mathrm{K} 2)$ & $\mathrm{Y}=161,152-0,1141$ & 0,73 & $* *$ \\
\hline $\mathrm{L}(\mathrm{P} 1 \times \mathrm{K} 3)$ & $Y=150,054-0,0591$ & 0,22 & $* *$ \\
\hline $\mathrm{L}(\mathrm{P} 2 \mathrm{xK} 0)$ & $Y=152,967-0,0611$ & 0,75 & $* *$ \\
\hline $\mathrm{L}(\mathrm{P} 2 \mathrm{xK} 1)$ & $Y=148,737-0,0491$ & 0,79 & $* *$ \\
\hline $\mathrm{L}(\mathrm{P} 2 \mathrm{xK} 2)$ & $Y=155,988-0,0871$ & 0.74 & $* *$ \\
\hline $\mathrm{L}(\mathrm{P} 2 \mathrm{xK} 3)$ & $Y=137,912-0,0351$ & 0.16 & $* *$ \\
\hline \multirow[t]{2}{*}{$\mathrm{K}(\mathrm{P} 1 \mathrm{xL} 1)$} & $Y=129,937+0,569 k$ & 0,40 & $* *$ \\
\hline & $\mathrm{Y}=128,353+1,995 \mathrm{k}-0,123 \mathrm{k}^{2}$ & 0,65 & $* *$ \\
\hline \multirow[t]{2}{*}{$\mathrm{K}(\mathrm{P} 1 \mathrm{xL} 2)$} & $\mathrm{Y}=134,549+1,308 \mathrm{k}$ & 0,63 & $* *$ \\
\hline & $\mathrm{Y}=133,620+2,143 \mathrm{k}-0,072 \mathrm{k}^{2}$ & 0.65 & $* *$ \\
\hline \multirow[t]{2}{*}{$\mathrm{K}(\mathrm{P} 1 \mathrm{xL} 3)$} & $\mathrm{Y}=140,805-2,314 \mathrm{k}$ & 0.59 & $* *$ \\
\hline & $\mathrm{Y}=139,817-1,425 \mathrm{k}-0,077 \mathrm{k}^{2}$ & 0.60 & $* *$ \\
\hline $\mathrm{K}(\mathrm{P} 2 \mathrm{xL} 1)$ & $Y=146,194-0,669 \mathrm{k}$ & 0.81 & $* *$ \\
\hline
\end{tabular}




\subsubsection{Firmeza da polpa, espessura da casca e espessura da polpa}

Os valores médios de firmeza da polpa (FP), espessura da casca (EC) e espessura da polpa (EP), são aparentados na Tabela 39.

Tabela 39. Valores médios de firmeza da polpa (FP), espessura da casaca (EC) e espessura da polpa (EP) de frutos do híbrido de melão Bonus $\mathrm{n}^{0}$ 2, sob diferentes doses de potássio, níveis de irrigação e posição dos tubogotejadores

\begin{tabular}{cccc}
\hline Tratamento & FP $(\mathrm{N})$ & EC $(\mathrm{mm})$ & EP $(\mathrm{mm})$ \\
\hline K0L1P1 & 6,914 & 5,148 & 30,195 \\
K0L1P2 & 4,448 & 6,214 & 28,184 \\
K0L2P1 & 10,278 & 6,214 & 32,064 \\
K0L2P2 & 7,125 & 5,276 & 29,493 \\
K0L3P1 & 13,566 & 5,648 & 30,195 \\
K0L3P2 & 10,478 & 6,738 & 30,198 \\
K1L1P1 & 12,509 & 6,203 & 31,278 \\
K1L1P2 & 14,938 & 4,918 & 28,274 \\
K1L2P1 & 14,283 & 5,340 & 28,658 \\
K1L2P2 & 14,295 & 5,811 & 30,994 \\
K1L3P1 & 10,131 & 5,031 & 37,723 \\
K1L3P2 & 8,893 & 5,451 & 31,732 \\
K2L1P1 & 15,275 & 6,014 & 32,800 \\
K2L1P2 & 17,506 & 6,321 & 30,598 \\
K2L2P1 & 13,899 & 6,280 & 29,079 \\
K2L2P2 & 7,997 & 5,605 & 29,699 \\
K2L3P1 & 13,651 & 4,853 & 31,050 \\
K2L3P2 & 6,395 & 5,951 & 34,034 \\
K3L1P1 & 17,465 & 7,041 & 31,189 \\
K3L1P2 & 11,928 & 5,996 & 31,858 \\
K3L2P1 & 8,016 & 6,261 & 31,576 \\
K3L2P2 & 9,217 & 6,422 & 30,699 \\
K3L3P1 & 5,659 & 7,575 & 28,169 \\
K3L3P2 & 9,296 & 5,235 & 30,701 \\
\hline
\end{tabular}

Os valores mínimo e máximo de firmeza da polpa corresponderam aos tratamentos K0L1P2 e K2L1P2 com 4,448 N e 17,506 N, respectivamente. Para espessura da casca o valor mínimo correspondeu ao tratamento K2L3P1 com 4,853 mm e 
o máximo ao tratamento K3L3P1 com 7,575 mm. Os valores mínimo e máximo de espessura da polpa corresponderam aos tratamentos K3L3P1 e K1L3P1 com 28,169 mm e $37,723 \mathrm{~mm}$, respectivamente.

A analise de variância (Tabela 40), para firmeza da casca foi altamente significativa $(\mathrm{P}<0,01)$ para o fator $\mathrm{K}$ e a interação $\mathrm{KxL}$, e significativa $(\mathrm{P}>0,05)$ para $\mathrm{o}$ fator L e a interação LxP, com C. V de 31,78 \% e média geral de 11,007 N. Para espessura da casca foi altamente significativa $(\mathrm{P}<0,01)$ para $\mathrm{o}$ fator $\mathrm{K}$ e as interações $\mathrm{KxL}, \mathrm{KxP}$ e KxPxL, significativo $(\mathrm{P}<0,05)$ para o fator $\mathrm{P}$, mostrando um baixo $\mathrm{C}$. $\mathrm{V}$ de 5,27 \% e uma média geral de 5,899 mm. A análise de variância para espessura da casca demonstra que este parâmetro não teve significância estatística para os fatores isolados, nem para as interações duplas. Para a interação dos três fatores em conjunta existe uma significância estatística $(\mathrm{P}<0,05)$, com um C.V. de 2,318\% e uma média de 30,933 mm.

Tabela 40. Resumo da análise de variância para os valores médios de firmeza da polpa (FP), espessura da casaca (EC) e espessura da polpa (EP), com desdobramento dos graus de liberdade dos tratamentos, de acordo com o esquema fatorial $4 \times 3 \times 2$.

\begin{tabular}{|c|c|c|c|c|}
\hline \multirow{2}{*}{ Causas de variação } & \multirow[t]{2}{*}{ G.L. } & \multicolumn{3}{|c|}{ Quadrado médio (significânia - Prob. >F) } \\
\hline & & FP & $\mathrm{EC}$ & $\mathrm{EP}$ \\
\hline $\mathrm{K}$ & 3 & $58,586^{* *}$ & $2,826 * *$ & $9,512 * *$ \\
\hline $\mathrm{L}$ & 2 & $51,662 *$ & 0,177 & $11,337 * *$ \\
\hline $\mathrm{P}$ & 1 & 45,743 & 0,360 & $19,309 * *$ \\
\hline $\mathrm{KxL}$ & 6 & $70,327 *$ & $0,490 * *$ & $18,992 * *$ \\
\hline $\mathrm{KxP}$ & 3 & 17,609 & $1,964 *$ & $20,618 * *$ \\
\hline PxL & 2 & 2,588 & 0,196 & $3,895 * *$ \\
\hline KxLxP & 6 & 25,400 & $2,307 * *$ & $6,189 * *$ \\
\hline (Tratamento) & (23) & & & \\
\hline Blocos & 2 & 59,438 & 0,253 & $2,292 * *$ \\
\hline Resíduo & 46 & 12,239 & 0,096 & 0,514 \\
\hline Total & 71 & & & \\
\hline Média & & $11,007(\mathrm{~N})$ & $5,899(\mathrm{~mm})$ & $30,933(\mathrm{~mm})$ \\
\hline $\mathrm{CV}(\%)$ & & 31,784 & 5,265 & 2,318 \\
\hline
\end{tabular}


As comparações de FP, EC e EP para cada fator por separado são apresentadas na Tabela 41.

Tabela 41. Comparação de médias de firmeza da polpa, espessura da casca e espessura da polpa para cada nível de fator isolado.

\begin{tabular}{|c|c|c|c|c|}
\hline \multirow{2}{*}{ Nível de fator } & \multicolumn{4}{|c|}{ Firmeza da polpa (N) por bloco } \\
\hline & $\mathrm{I}$ & II & III & Média \\
\hline $\mathrm{K} 0$ & 10.866 & 6.962 & 8.576 & 8.801 \\
\hline K1 & 14.110 & 11.701 & 11.713 & 12.508 \\
\hline $\mathrm{K} 2$ & 15.004 & 9.904 & 12.454 & 12.454 \\
\hline K3 & 10.789 & 9.738 & 10.263 & 10.263 \\
\hline L1 & 14.246 & 10.817 & 12.805 & 12.623 \\
\hline $\mathrm{L} 2$ & 10.613 & 11.147 & 10.064 & 10.608 \\
\hline L3 & 13.114 & 6.807 & 9.355 & 9.758 \\
\hline P1 & 14.506 & 8.945 & 11.960 & 11.804 \\
\hline \multirow{2}{*}{$\mathrm{P} 2$} & 10.879 & 10.207 & 9.543 & 10.210 \\
\hline & \multicolumn{4}{|c|}{ Espessura da casca $(\mathrm{mm})$ por bloco } \\
\hline K0 & 5.946 & 5.809 & 5.877 & 5.877 \\
\hline K1 & 5.572 & 5.346 & 5.459 & 5.459 \\
\hline $\mathrm{K} 2$ & 6.054 & 5.621 & 5.837 & 5.837 \\
\hline K3 & 6.435 & 6.409 & 6.422 & 6.422 \\
\hline L1 & 6.130 & 5.833 & 5.982 & 5.982 \\
\hline $\mathrm{L} 2$ & 6.040 & 5.769 & 5.905 & 5.905 \\
\hline L3 & 5.834 & 5.787 & 5.810 & 5.810 \\
\hline $\mathrm{P} 1$ & 6.149 & 5.790 & 5.970 & 5.970 \\
\hline \multirow[t]{2}{*}{$\mathrm{P} 2$} & 5.854 & 5.803 & 5.828 & 5.828 \\
\hline & \multicolumn{4}{|c|}{ Espessura da polpa (mm) por bloco } \\
\hline K0 & 30.295 & 29.815 & 30.055 & 30.055 \\
\hline K1 & 31.999 & 31.519 & 31.759 & 31.759 \\
\hline $\mathrm{K} 2$ & 31.699 & 30.720 & 31.210 & 31.210 \\
\hline K3 & 30.965 & 30.432 & 30.699 & 30.699 \\
\hline $\mathrm{L} 1$ & 31.047 & 30.046 & 30.547 & 30.547 \\
\hline $\mathrm{L} 2$ & 30.881 & 30.161 & 30.521 & 30.521 \\
\hline L3 & 31.791 & 31.657 & 31.724 & 31.724 \\
\hline P1 & 31.983 & 30.914 & 31.448 & 31.448 \\
\hline $\mathrm{P} 2$ & 30.496 & 30.329 & 30.413 & 30.413 \\
\hline
\end{tabular}

O valor de firmeza da polpa é menor para a doses de potássio extremas K0 e K3 $\left(0 \mathrm{~g}\right.$ de $\mathrm{K}_{2} \mathrm{O} \mathrm{pl}{ }^{-1}$ e $12 \mathrm{~g}$ de $\left.\mathrm{K}_{2} \mathrm{O} \mathrm{pl}{ }^{-1}\right)$ e maior para as doses de potássio intermediárias $\mathrm{K} 1 \mathrm{e}$ 
$\mathrm{K} 2$ (6 g de $\mathrm{K}_{2} \mathrm{O} \mathrm{pl}^{-1}$ e $9{\mathrm{~g} \text { de } \mathrm{K}_{2} \mathrm{O} \mathrm{pl}}^{-1})$. Para o fator níveis de irrigação, o valor de firmeza da polpa é menor para o nível L3 (417,32 mm) e maior para o nível L1 (137,72 mm), em quanto para o fator posições de instalação dos tubogotejadores a firmeza da polpa foi menor para a posição $\mathrm{P} 2(0,2 \mathrm{~m})$.

$\mathrm{O}$ valor da espessura da casca aumenta para as doses extremas de $\mathrm{K} 0$ e $\mathrm{K} 3$ e diminui para as doses intermediárias de $\mathrm{K} 1$ e $\mathrm{K} 2\left(6 \mathrm{~g} \mathrm{de}_{2} \mathrm{O} \mathrm{pl}^{-1}\right.$ e 9 g de $\left.\mathrm{K}_{2} \mathrm{O} \mathrm{pl}{ }^{-1}\right)$. Para o fator níveis de irrigação, o valor de espessura da casca aumenta quando diminui a quantidade de água aplicada; de igual forma aumenta quando os tubogotejadores encontram-se na superfície.

O valor de espessura da polpa diminui com os valores extremos de dose de potássio $\mathrm{K} 0$ e $\mathrm{K} 3\left(0 \mathrm{~g}\right.$ de $\mathrm{K}_{2} \mathrm{O} \mathrm{pl}{ }^{-1}$ e. $\left.12 \mathrm{~g}_{\text {de }} \mathrm{K}_{2} \mathrm{O} \mathrm{pl}^{-1}\right)$ e aumenta com os valores de dose de potássio intermediários de $\mathrm{K} 1$ e $\mathrm{K} 2\left(6 \mathrm{~g}_{\text {de }} \mathrm{K}_{2} \mathrm{O} \mathrm{pl}{ }^{-1}\right.$ e. $\left.9 \mathrm{~g} \mathrm{de}_{2} \mathrm{O} \mathrm{pl}^{-1}\right)$. Para o fator níveis de irrigação, o valor de espessura da polpa mostrou pouca variação, não entanto confirma-se uma tendência de aumentar a espessura da polpa quanto maior for a quantidade de água aplicada. Para o fator posições de instalação dos tubogotejadores o valor de espessura da polpa diminui para a posição subsuperficial.

Estes resultados permitem a afirmar que doses baixas e altas de potássio quando favorecidos por quantidades razoáveis de água para o híbrido de melão Bonus ñ. 2, não propiciam uma boa firmeza de polpa para os frutos, conduzindo a pensar por tanto, em uma baixa durabilidade na prateleira e susceptibilidade ao transporte.

A Tabela 42 mostra o desdobramento da variável qualitativa de posição dos tubo portagotejadores pelo teste de Tukey, evidenciando que a espessura da polpa e espessura da casca se incrementam quando se aplica fertirrigação na superfície de acordo com interações apresentadas. 
Tabela 42. Resumo da análise de significância para espessura da casca (EC) e espessura da polpa (EP) pelo teste de Tukey para o fator de posição dos tubogotejadores (P), dentro dos níveis dos fatores de níveis de irrigação (L) e doses de potássio (K) aplicado.

\begin{tabular}{|c|c|c|c|}
\hline \multirow{2}{*}{ Causas de variação } & \multirow{2}{*}{$\begin{array}{l}\text { Médias originais } \\
\text { (mm) }\end{array}$} & \multicolumn{2}{|c|}{ (significância - Prob. > F) } \\
\hline & & $5 \%$ & $1 \%$ \\
\hline \multicolumn{4}{|l|}{ Espessura da casca } \\
\hline P1 (L1xK0) & 5,148 & $\mathrm{a}$ & A \\
\hline P2(L1xK0) & 6,148 & $\mathrm{~b}$ & B \\
\hline P1(L1xK1) & 6,203 & $\mathrm{a}$ & A \\
\hline P2(L1xK1) & 4,918 & $\mathrm{~b}$ & B \\
\hline P1(L1xK3) & 7,041 & $\mathrm{a}$ & A \\
\hline P2(L1xK3) & 5,996 & $\mathrm{~b}$ & B \\
\hline P1(L2xK0) & 6,241 & $\mathrm{a}$ & A \\
\hline P2(L2xK0) & 5,276 & $\mathrm{~b}$ & B \\
\hline P1(L2xK2) & 6,280 & $\mathrm{a}$ & A \\
\hline P2(L2xK2) & 5,605 & $\mathrm{~b}$ & B \\
\hline P1(L3xK0) & 5,648 & $\mathrm{a}$ & A \\
\hline P2(L3xK0) & 6,738 & $\mathrm{~b}$ & B \\
\hline P1(L3xK2) & 4,853 & $\mathrm{a}$ & A \\
\hline P2(L3xK2) & 5,951 & $\mathrm{~b}$ & B \\
\hline P1(L3xK3) & 7,575 & $\mathrm{a}$ & A \\
\hline P2(L3xK3) & 5,235 & $\mathrm{~b}$ & B \\
\hline DMS & & 0,551 & 0,628 \\
\hline \multicolumn{4}{|l|}{ Espessura da polpa } \\
\hline \multicolumn{4}{|l|}{ P1(L1xK0) } \\
\hline P2(L1xK0) & 30,195 & $\mathrm{a}$ & A \\
\hline P1(L1xK1) & 28,184 & $\mathrm{~b}$ & B \\
\hline P2(L1xK1) & 31,278 & $\mathrm{a}$ & A \\
\hline P1(L1xK2) & 28,274 & $\mathrm{~b}$ & B \\
\hline P2(L1xK2) & 32,799 & $\mathrm{a}$ & A \\
\hline P1(L2xK0) & 30,598 & $\mathrm{~b}$ & B \\
\hline P2(L2xK0) & 32,064 & $\mathrm{a}$ & A \\
\hline P1(L2xK1) & 29,493 & $\mathrm{~b}$ & B \\
\hline P2(L2xK1) & 32,064 & $\mathrm{a}$ & A \\
\hline P1(L3xK1) & 29,493 & $\mathrm{~b}$ & B \\
\hline P2(L3xK1) & 37,723 & $\mathrm{a}$ & A \\
\hline P1(L3xK2) & 31,723 & $\mathrm{~b}$ & B \\
\hline P2(L3xK2) & 31,050 & $\mathrm{a}$ & A \\
\hline P1(L3xK3) & 34,034 & $\mathrm{~b}$ & B \\
\hline & 28,701 & $\mathrm{a}$ & A \\
\hline \multirow{2}{*}{ DMS } & 30,169 & $\mathrm{~b}$ & B \\
\hline & & 1,180 & 1,574 \\
\hline
\end{tabular}

Medias seguida por letras distintas deferem entre si ao nível de significância indicado.

De igual forma a Tabela 43 mostra o desdobramento das variáveis quantitativas de níveis de irrigação e doses de potássio pelo teste de regressão polinomial, para as 
variáveis de espessura da casca e espessura da polpa.

Tabela 43. Equações lineares e quadráticas para espessura da casaca (EC) e espessura da polpa (EP), resultados do teste de regressão para o fator lâmina de irrigação (L) e doses de potássio (K) aplicados.

\begin{tabular}{|c|c|c|c|}
\hline Causas de variação & Equação & $\mathrm{R}^{2}$ & (significância-Prob. > F) \\
\hline \multicolumn{4}{|l|}{ Espessura da casaca } \\
\hline L(P1xK1) & $Y=6,694-0,0041$ & 0,94 & ** \\
\hline L(P1xK2) & $Y=6,863-0.0041$ & 0,58 & ** \\
\hline L(P1xK3) & $Y=6,438+0,0021$ & 0,16 & $*$ \\
\hline $\mathrm{L}(\mathrm{P} 2 \times \mathrm{KK} 1)$ & $Y=4,857+0,0021$ & 0,36 & * \\
\hline $\mathrm{L}(\mathrm{P} 2 \times \mathrm{K} 3)$ & $Y=6,634-0,0031$ & 0,39 & $* *$ \\
\hline $\mathrm{K}(\mathrm{P} 1 \times \mathrm{L} 1)$ & $\mathrm{Y}=5,150+0,141 \mathrm{k}$ & 0,86 & ** \\
\hline K(P1xL2) & $Y=6,189-0,199 k+0,018 K^{2}$ & 0,54 & $* *$ \\
\hline \multirow[t]{2}{*}{$\mathrm{K}(\mathrm{P} 1 \mathrm{Xl} 3)$} & $\mathrm{Y}=5,023+0,112 \mathrm{k}$ & 0,21 & $* *$ \\
\hline & $\mathrm{Y}=5,725-0,519 \mathrm{k}+0,055 \mathrm{k}^{2}$ & 0,86 & $* *$ \\
\hline $\mathrm{K}(\mathrm{P} 2 \times \mathrm{L} 1)$ & $\mathrm{Y}=6,129-0,245 \mathrm{k}+0,021 \mathrm{k}^{2}$ & 0,37 & $*$ \\
\hline $\mathrm{K}(\mathrm{P} 2 \times \mathrm{x} 2)$ & $\mathrm{Y}=5,234+0,081 \mathrm{k}$ & 0,74 & ** \\
\hline $\mathrm{K}(\mathrm{P} 2 \times \mathrm{x} 3)$ & $Y=6,589-0,110$ & 0.72 & ** \\
\hline \multicolumn{4}{|l|}{ Espessura da polpa } \\
\hline $\mathrm{L}(\mathrm{P} 1 \times K 1)$ & & 0,83 & ** \\
\hline L(P1xK2) & $\mathrm{Y}=27,299+0,0231$ & 0,23 & $* *$ \\
\hline L(P1xK3) & $Y=32,746-0,0061$ & 0,65 & $* *$ \\
\hline $\mathrm{L}(\mathrm{P} 2 \times \mathrm{xK})$ & $\mathrm{Y}=33,297-0,0111$ & 0,98 & $* *$ \\
\hline L(P2xK1) & $\mathrm{Y}=27,285+0,0071$ & 0,97 & ** \\
\hline L(P2xK2) & $Y=26,403+0,0121$ & 0,56 & ** \\
\hline \multirow{2}{*}{$\mathrm{K}(\mathrm{P} 1 \mathrm{xL} 1)$} & $Y=28,051+0,0121$ & 0,39 & $* *$ \\
\hline & $\mathrm{Y}=30,485+0,130 \mathrm{k}$ & 0,66 & $*$ \\
\hline K(P1xL2) & $\mathrm{Y}=30,092+0,485 \mathrm{k}-0,031 \mathrm{k}^{2}$ & 0,18 & * \\
\hline \multirow[t]{2}{*}{ K(P1xL3) } & $\mathrm{Y}=31,991-0,118 \mathrm{k}$ & 0,05 & $* *$ \\
\hline & $\mathrm{Y}=33,015-0,182 \mathrm{k}$ & 0,82 & ** \\
\hline \multirow[t]{2}{*}{ K(P2xL1) } & $\mathrm{Y}=30,488+2,092 \mathrm{k}-0,197 \mathrm{k}^{2}$ & 0,79 & ** \\
\hline & $\mathrm{Y}=27,615+0,313 \mathrm{k}$ & 0,94 & ** \\
\hline \multirow[t]{3}{*}{ K(P2xL3) } & $\mathrm{Y}=28,114-0,135 \mathrm{k}+0,039 \mathrm{k}^{2}$ & 0,15 & ** \\
\hline & $\mathrm{Y}=30,796+0,129 \mathrm{k}$ & 0,58 & $* *$ \\
\hline & $\mathrm{Y}=30,016+0,831 \mathrm{k}-0,061 \mathrm{k}^{2}$ & & \\
\hline
\end{tabular}

$* \mathrm{e} * *$ indica que o teste $\mathrm{F}$, foi significativo ao nível de 5 e $1 \%$ de probabilidade, respectivamente.

Os valores de firmeza da polpa estão próximos a os encontrado por Santos (2002) em híbridos Orange Flesh (15,65 e 15,66 N) e Galileo (6,74 e 5,32 N) submetidos a duas diferentes soluções nutritivas, aplicadas por meio da técnica do NFT e inferiores aos encontrados por Filgueira et al., (2000), para ocasião da colheita de frutos destinados a exportação, cujos valores são 30 e $22 \mathrm{~N}$, respectivamente. 
Segundo Lester \& Shelli (1992), melões tipo Honey Dew, totalmente maduros, avaliados 10 dias após armazenamento a cerca de $18{ }^{\circ} \mathrm{C}$, apresentaram valor de $16,45 \mathrm{~N}$ de firmeza da polpa.

O melão tem problemas de firmeza após a colheita, o que traz como consequiência uma menor vida pós-colheita. A firmeza dos frutos é o critério de qualidade mais significativo na comercialização internacional. A firmeza nos frutos tem origem fisiológica e nutricional associada à absorção e translocacão do cálcio em primeiro lugar e do potássio em segundo lugar. A desordem fisiológica que resulta da deficiência localizada de cálcio dentro da planta, é atribuída mais a uma pobre distribuição deste elemento, do que a uma restrição em sua absorção. O cálcio é transportado pelo xilema e pelo floema, sendo que o transporte do soluto pode ser particularmente crítico em órgãos que são naturalmente baixos em cálcio, tais como os frutos e as folhas jovens (Kirkby \& Pilbean, 1984).

O cálcio encontra-se presente como parte da estrutura orgânica (Rodriguez, 1992). Mantém a estrutura e características próprias de permeabilidade das membranas dando rigidez à célula e seu conteúdo aumenta com a idade (Stutte, 1995). O cálcio encontra-se principalmente na parede celular formando sais insolúveis ao reagir com os ácidos da lamina média, a qual é formada de pectatos de cálcio e entra no metabolismo de formação do núcleo e mitocondrias (Street, 1969; Rojas \& Rovalo, 1985). Além disso, forma parte do sistema amortizador na seiva da planta e em componentes das radicelas numa ação direta (Uvalle, 1992).

Wiersum (1979) indica que os efeitos sobre a absorção de cálcio por meio da manipulação do meio radical parecem ser principalmente causado por mudanças na competência ou disponibilidade de cálcio e íons tais como potássio, nitrato e alguns outros.

\subsubsection{Parâmetros químicos}

Muitos dos parâmetros químicos de pós-colheita de frutos de melão estão condicionados por múltiplos fatores, podendo ser mencionados a nutrição da planta, o 
tempo de colheita e de armazenamento, entre outros. Evidências tem sido aprestadas pelo impacto de fatores tais como nutrição mineral (Brantley \& Warren, 1961, Jacob \& WhiteStevens 1941, Flocker et al., 1965), umidade do solo (Wells \& Nugent, 1980), fatores genéticos (Lippert \& Legg, 19972), condições do tempo (Brantley \& Warren 1961; Browkamp et al., 1978) e reguladores de crescimento (Bosland et al., 1979).

\subsubsection{Sólidos solúveis totais ( ${ }^{0}$ Brix), pH e acidez total titulável (ATT)}

De acordo com a Tabela 44, houve efeito significativo para a característica ${ }^{\circ}$ Brix $(\mathrm{P}<0,01)$ para fatores isolados dose de potássio $(\mathrm{K})$ e níveis de irrigação $(\mathrm{L})$, para interação duplas (KxL, KxP e PxL), e também para interação tripla (KxLxP). O pH foi influenciado significativamente $(\mathrm{P}<0,05)$ pelo fator isolado de posição dos tubogotejadores $(\mathrm{P})$, pelas interações duplas $(\mathrm{KxL}$ e $\mathrm{PxL})$, e também $(\mathrm{P}<0,01)$ pela interação tripla $(\mathrm{KxLxP})$. Já para ATT, somente houve efeito significativo $(\mathrm{P}<0,5)$ para o fator níveis de irrigação (L).

Tabela 44. Resumo da análise de variância para os valores médios de SST, pH e ATT, com desdobramento dos graus de liberdade de tratamentos, de acordo com o esquema fatorial $4 \times 3 \times 2$.

\begin{tabular}{lcccc}
\hline \multirow{2}{*}{ Causas de variação } & G.L. & \multicolumn{3}{c}{ Quadrado médio (significânia - Prob. >F) } \\
& & SST $\left({ }^{\circ}\right.$ Brix) & pH & ATT $(\mathrm{mg})$ \\
\hline K & 3 & $9,902^{* *}$ & 0,030 & 0,989 \\
$\mathrm{~L}$ & 2 & $10,323^{* *}$ & 0,047 & $1,818^{*}$ \\
$\mathrm{P}$ & 1 & 2,831 & $0,177^{*}$ & 2,059 \\
$\mathrm{KxL}$ & 6 & $6,890^{* *}$ & $0,050^{*}$ & 1,155 \\
$\mathrm{KxP}$ & 3 & $0,745^{* *}$ & 0,066 & 1,097 \\
PxL & 2 & $8,615^{* *}$ & $13,693^{*}$ & 1,369 \\
KxLxP & 6 & $4,966^{* *}$ & $0,125^{* *}$ & 0,939 \\
(Tratamento) & $(23)$ & & & \\
Blocos & 2 & 2,503 & 0,021 & 0,918 \\
Resíduo & 46 & 0,830 & 0,017 & 0,513 \\
Total & 71 & & & \\
Média & & 9,636 & 6,214 & 0,109 \\
CV $(\%)$ & 9,456 & 2,120 & 20,720 \\
\hline$* * e^{*}$ indicam que o teste de F, foi significativo ao nível de 1\% e de 5\% de probabilidade, respectivamente.
\end{tabular}


Observa-se Tabela 45 que o conteúdo de sólidos solúveis totais (SST) dos frutos de melão foram crescentes com o aumento das doses de potássio até a dose $\mathrm{K} 2$, havendo uma redução com a dose maior (K3). Os valores médios de SST variaram de 6,99 \% a 13,25 \%, para as combinações K0L1P1 e K2L2P1, respectivamente. Esse aumento no conteúdo de sólidos solúveis, também foi observado por Pereira (1997) que encontrou média geral dos açúcares totais em híbrido de melão Gold Mine com a dosagem de $90 \mathrm{~kg}$ $\mathrm{ha}^{-1}$ de $\mathrm{K}_{2} \mathrm{O}$. De acordo com Hubbard (1990) fatores nutricionais como deficiência de potássio reduzem drasticamente a fotossíntese e conseqüentemente o acúmulo de sacarose no fruto, resultando em melões de baixa qualidade. Assim os baixos valores de SST encontrados neste trabalho podem ser atribuídos ao baixo conteúdo de $\mathrm{K}_{2} \mathrm{O}$ no solo.

Para o fator níveis de irrigação, o aumento da quantidade de água aplicada promove aumento dos SST até a aplicação do nível L2 e redução para o maior nível de irrigação aplicado (L3). Na posição de instalação dos tubogotejadores, as plantas produziram frutos com maior conteúdo de SST em tubogotejadores instalados na superfície (P1).

Muitos países adotam os valores do conteúdo de sólidos solúveis totais como uma guia de mercado para aceitabilidade, com uma variação mínima de 8 a $10 \%$. Alguns valores médios obtidos neste estudo estão abaixo do mínimo exigido pelo mercado, entretanto, se esse caráter for analisado isoladamente como um atributo de qualidade pode ser falho (Menezes et al, 1998). Os teores de sólidos solúveis totais encontrados no melão neste experimento são praticamente iguais aos teores de sólidos solúveis produzidos nos melões do Brasil, aproximando-se dos valores encontrados por Prabhakar et al. (1985).

Ainda em relação à Tabela 45, verifica-se uma variação do $\mathrm{pH}$ dos frutos entre 6,00 (K3L3P2) a 6,43 (K2L3P2), resultando em ligeiro incremento com o aumento da dose de potássio. Com nível intermediário de irrigação (L2) os frutos tem maior pH, em relação aos níveis extremos (L1 e L3). Já para a posição de instalação dos tubogotejadores, maiores valores de $\mathrm{pH}$ foram obtidas nos tratamentos com linhas instaladas subsuperfícialmente (P2). Verifica-se que a menor Acidez Total Titulável (ATT) ocorreu no tratamento K0L2P2 (0,080 mg ác. cítrico por $100 \mathrm{ml}$ de suco) e a maior no tratamento 
K2L1P1 (0,156 mg ác. cítrico por $100 \mathrm{ml}$ de suco), demonstrando um ligeiro incremento de ATT até a dose $\mathrm{K} 3$ e ainda um ligeiro decréscimo quando se aumenta o nível de irrigação com linhas portagotejadores enterradas. Pinto (1996) reporta que $100 \mathrm{~kg}$ de $\mathrm{K}_{2} \mathrm{O}$ ha $^{-1}$ e $90 \mathrm{~kg}$ de $\mathrm{N} \mathrm{ha}^{-1}$ via água de irrigação em um Latossolo Vermelho-Amarelo em Petrolina-PE, não proporcionou diferenças significativas para a característica do teor de SST de frutos de melão.

Tabela 45. Valores médios de sólidos solúveis totais (SST), pH e Acidez Total Titulável (ATT) de frutos de melão, para as diferentes doses de potássio, níveis de irrigação e posição dos tubogotejadores.

\begin{tabular}{cccc}
\hline Tratamentos & SST $\left({ }^{\circ}\right.$ Brix $)$ & $\mathrm{pH}$ & ATT $(\mathrm{mg})$ \\
\hline K0L1P1 & 6,99 & 6,19 & 0,089 \\
K0L1P2 & 7,75 & 6,12 & 0,102 \\
K0L2P1 & 10,88 & 6,04 & 0,155 \\
K0L2P2 & 8,16 & 6,42 & 0,083 \\
K0L3P1 & 8,73 & 6,20 & 0,102 \\
K0L3P2 & 10,53 & 6,12 & 0,109 \\
K1L1P1 & 11,25 & 6,05 & 0,112 \\
K1L1P2 & 10,13 & 6,42 & 0,114 \\
K1L2P1 & 10,30 & 6,07 & 0,132 \\
K1L2P2 & 10,38 & 6,37 & 0,122 \\
K1L3P1 & 9,00 & 6,10 & 0,083 \\
K1L3P2 & 9,13 & 6,16 & 0,089 \\
K2L1P1 & 11,13 & 6,20 & 0,157 \\
K2L1P2 & 11,34 & 6,02 & 0,110 \\
K2L2P1 & 13,25 & 6,31 & 0,121 \\
K2L2P2 & 8,91 & 6,09 & 0,110 \\
K2L3P1 & 7,06 & 6,22 & 0,114 \\
K2L3P2 & 8,75 & 6,43 & 0,099 \\
K3L1P1 & 10,13 & 6,04 & 0,118 \\
K3L1P2 & 9,31 & 6,41 & 0,125 \\
K3L2P1 & 9,81 & 6,31 & 0,098 \\
K3L2P2 & 10,13 & 6,51 & 0,080 \\
K3L3P1 & 9,50 & 6,37 & 0,095 \\
K3L3P2 & 8,75 & 6,00 & 0,105 \\
\hline
\end{tabular}

A Tabela 46 mostra o desdobramento da variável qualitativa de posição dos tubogotejadores pelo teste de Tukey, evidenciando o aumento do SST com uma DMS de 
$1,50{ }^{\circ}$ Brix $(\mathrm{P}<0,05)$ e $2,00{ }^{\circ}$ Brix $(\mathrm{P}<0,01)$ quando se aplica fertirrigação na superfície já para o $\mathrm{pH}$ os valores de DMS foram de 0,22 unidades $(\mathrm{P}<0,05)$ e 0,29 unidades $(\mathrm{P}<0,01)$ quando se aplica fertirrigação na subsupeficie de acordo com as interações mostradas.

Tabela 46. Resumo da análise de significância para SST e pH pelo teste de Tukey para o fator de posição dos tubogotejadores $(\mathrm{P})$, dentro dos níveis dos fatores de níveis de irrigação (L) e doses de potássio (K) aplicado.

\begin{tabular}{|c|c|c|c|}
\hline \multirow{2}{*}{ Causas de variação } & \multirow{2}{*}{ Medias original } & \multicolumn{2}{|c|}{ (significância - Prob. > F) } \\
\hline & & $5 \%$ & $1 \%$ \\
\hline \multicolumn{4}{|l|}{ SST ( ${ }^{\circ}$ Brix) } \\
\hline $\mathrm{P}_{1}\left(\mathrm{~L}_{2} \mathrm{xK}_{0}\right)$ & 10,88 & $\mathrm{a}$ & A \\
\hline $\mathrm{P}_{2}\left(\mathrm{~L}_{2} \mathrm{XK}_{0}\right)$ & 8,16 & $\mathrm{~b}$ & B \\
\hline $\mathrm{P}_{1}\left(\mathrm{~L}_{2} \mathrm{XK}_{2}\right)$ & 13,25 & a & A \\
\hline $\mathrm{P}_{2}\left(\mathrm{~L}_{2} \mathrm{XK}_{2}\right)$ & 8,91 & $\mathrm{~b}$ & B \\
\hline $\mathrm{P}_{1}\left(\mathrm{~L}_{3} \mathrm{xK}_{0}\right)$ & 8,73 & a & A \\
\hline $\mathrm{P}_{2}\left(\mathrm{~L}_{3} \mathrm{xK}_{0}\right)$ & 10,53 & $\mathrm{~b}$ & A \\
\hline $\mathrm{P}_{1}\left(\mathrm{~L}_{3} \mathrm{XK}_{2}\right)$ & 7,06 & $\mathrm{a}$ & A \\
\hline $\mathrm{P}_{2}\left(\mathrm{~L}_{3} \mathrm{XK}_{2}\right)$ & 8,75 & $\mathrm{~b}$ & A \\
\hline DMS & & 1,50 & 2,00 \\
\hline \multicolumn{4}{|l|}{$\mathrm{pH}$} \\
\hline $\mathrm{P}_{1}\left(\mathrm{~L}_{1} \mathrm{xK}_{1}\right)$ & 6,05 & $\mathrm{a}$ & A \\
\hline $\mathrm{P}_{2}\left(\mathrm{~L}_{1} \times \mathrm{K}_{1}\right)$ & 6,42 & $\mathrm{~b}$ & B \\
\hline $\mathrm{P}_{1}\left(\mathrm{~L}_{1} \mathrm{xK}_{3}\right)$ & 6,04 & $\mathrm{a}$ & A \\
\hline $\mathrm{P}_{2}\left(\mathrm{~L}_{1} \mathrm{XK}_{3}\right)$ & 6,41 & $\mathrm{~b}$ & B \\
\hline $\mathrm{P}_{1}\left(\mathrm{~L}_{2} \mathrm{xK}_{0}\right)$ & 6,04 & a & A \\
\hline $\mathrm{P}_{2}\left(\mathrm{~L}_{2} \mathrm{XK}_{0}\right)$ & 6,42 & $\mathrm{~b}$ & B \\
\hline $\mathrm{P}_{1}\left(\mathrm{~L}_{2} \mathrm{XK}_{1}\right)$ & 6,06 & $\mathrm{a}$ & A \\
\hline $\mathrm{P}_{2}\left(\mathrm{~L}_{2} \mathrm{xK}_{1}\right)$ & 6,37 & $\mathrm{~b}$ & B \\
\hline $\mathrm{P}_{1}\left(\mathrm{~L}_{3} \mathrm{xK}_{3}\right)$ & 6,37 & $\mathrm{a}$ & A \\
\hline $\mathrm{P}_{2}\left(\mathrm{~L}_{3} \mathrm{XK}_{3}\right)$ & 6,00 & $\mathrm{~b}$ & B \\
\hline DMS & & 0,22 & 0,29 \\
\hline
\end{tabular}

O desdobramento das variáveis quantitativas de níveis de irrigação e doses de potássio pelo teste de regressão polinomial é apresentado na Tabela 47. A interação L(P1xK2) evidencia maior ${ }^{\circ}$ Brix e efeito linear decrescente para o nível de irrigação até $137,72 \mathrm{~mm}$ e um valor máximo de $12,552{ }^{\circ}$ Brix , com ajuste significativo $(\mathrm{P}<0,01)$ e coeficiente de determinação de $\mathrm{R}^{2}=0,41$. Por outro lado, a interação $\mathrm{K}(\mathrm{P} 1 \times \mathrm{xL} 1)$ evidencia maior ${ }^{\circ}$ Brix e efeito linear para a dose de $\mathrm{K} 2\left(6 \mathrm{~g} \mathrm{de}_{2} \mathrm{O} \mathrm{p{ } ^ { - 1 }}\right)$, com ajuste significativo 
$(\mathrm{P}<0,01)$ e coeficiente de determinação de $\mathrm{R}^{2}=0,55$, chegando a $11,379{ }^{\circ}$ Brix. Estes resultados corroboram com os encontrados por Pew \& Garnwer (1983) os quais relatam que irrigação excessiva pode prejudicar o crescimento das plantas de melão. Durante a colheita, o amadurecimento é mais propenso a queimaduras com prejuízos para o fruto, e conseqüentemente, há redução em rendimento de mercado e conteúdos de sólidos solúveis. Pérez \& Cigales (2001) concluíram que a tendência foi diminuir de 10 para 9,2 ${ }^{o}$ Brix ao se aumentar o teor de umidade do solo; ou seja, ao se reduzir o estresse hídrico (umidades com tensão acima de $35 \mathrm{kPa}$ ) reduziu-se a percentagem de sólidos solúveis do melão.

Welles \& Buitelaar (1988) verificaram que o conteúdo de sólidos solúveis diminui significativamente com a diminuição da área foliar, ou seja, quanto maior a área foliar das plantas maior sua capacidade fotossintética. Soares (2001), encontrou valores médios de sólidos solúveis totais de frutos de melão variedade Cantalupensis Naud, híbrido Don Carlos, que variaram de 12,8 a 9,8 ${ }^{\circ}$ Brix para as combinações K3L3 (140 L de água por planta por ciclo e $150 \mathrm{~kg}$ de $\mathrm{K}_{2} \mathrm{O} \mathrm{ha}^{-1}$ ) e $\mathrm{K} 2 \mathrm{~L} 1$ (70 L de água por planta por ciclo e $90 \mathrm{~kg}$ de $\mathrm{K}_{2} \mathrm{Oha}^{-1}$ ), respectivamente.

Ainda em relação à Tabela 47, a interação L(P2xK2) evidencia maior valor de $\mathrm{pH}$ e efeito linear crescente para o nível de irrigação até 417,32 mm atingindo valor máximo de $\mathrm{pH}$ de 6,603 , com ajuste significativo $(\mathrm{P}<0,01)$ com $\mathrm{R}^{2}=0,88$, enquanto que a interação $\mathrm{K}(\mathrm{P} 1 \times \mathrm{xL}$ ) evidencia maior $\mathrm{pH}$ e efeito linear crescente até 6,309. Cardoso (2002), estudando melão rendilhado "Bônus 2" com $50 \mathrm{~kg} \mathrm{ha}^{-1}$ de $\mathrm{K}_{2} \mathrm{O}$, encontrou acidez total de 0,1134 mg ác. málico anidro por $100 \mathrm{ml}$ de suco e com $150 \mathrm{~kg}^{\mathrm{de}} \mathrm{K}_{2} \mathrm{O} \mathrm{ha}^{-1}$ adicionado a 165,0 $\mathrm{kg} \mathrm{ha}^{-1}$ de $\mathrm{CO}_{2}$ 0,1174 mg ác. málico anidro por $100 \mathrm{ml}$ de suco, enquanto que os valores de $\mathrm{pH}$ não resultaram em diferenças significativas.

Os baixos resultado obtido neste trabalho com relação ao SST, devem-se, provavelmente, aos níveis inferiores de água aplicados na superfície e valores extremos de $\mathrm{K}_{2} \mathrm{O}$ (0 e $12 \mathrm{~g}$ de $\mathrm{K}_{2} \mathrm{O}$ por planta), condição de preparo dos canteiros com impedimento de cobertura plástico e da camada de impedimento do solo in cinto, efeitos de padronização de épocas de colheita de frutos, sem completo desenvolvimento do tecido de abscisão e ausência do completo desprendimento do fruto do pedúnculo 
(Bleinroth, 1994). Os valores de SST dos frutos abaixo 5 de ${ }^{\circ}$ Brix podem ter ocorrido devido à alta percentagem de água contida na polpa, causando diminuição dos teores de sólidos solúveis totais pelo efeito de diluição (Wells \&Nugen, 1980).

Tabela 47. Equações lineares e quadráticas para SST ( ${ }^{\circ}$ Brix) e pH, resultados do teste de regressão para o fator lâmina de irrigação (L) e doses de potássio (K) aplicados.

\begin{tabular}{|c|c|c|c|}
\hline Causas de variação & Equação. & $\mathrm{R}^{2}$ & (significância-Prob. > F) \\
\hline \multicolumn{4}{|l|}{ SST $\left({ }^{\circ}\right.$ Brix $)$} \\
\hline L(P1xK0) & $\mathrm{Y}=7,107+0,006 \mathrm{~L}$ & 0,21 & $*$ \\
\hline $\mathrm{L}(\mathrm{P} 1 \times \mathrm{K} 1)$ & $\mathrm{Y}=12,418-0,008 \mathrm{~L}$ & 0,99 & $* *$ \\
\hline $\mathrm{L}(\mathrm{P} 1 \mathrm{xK} 2)$ & $Y=14,480-0,014 \mathrm{~L}$ & 0,41 & ** \\
\hline $\mathrm{L}(\mathrm{P} 2 \mathrm{xK} 0)$ & $Y=6,061+0,010 \mathrm{~L}$ & 0,85 & $* *$ \\
\hline $\mathrm{L}(\mathrm{P} 2 \mathrm{xK} 2)$ & $\mathrm{Y}=12,249-0,009 \mathrm{~L}$ & 0,80 & $* *$ \\
\hline \multirow[t]{2}{*}{$\mathrm{K}(\mathrm{P} 1 \mathrm{xL} 1)$} & $\mathrm{Y}=7,935+0,287 \mathrm{~K}$ & 0,55 & $* *$ \\
\hline & $\mathrm{Y}=7,003+1,125-0,072 \mathrm{~K}^{2}$ & 0,99 & $* *$ \\
\hline \multirow[t]{2}{*}{$\mathrm{K}(\mathrm{P} 2 \mathrm{xL} 1)$} & $Y=8,389+0,184 \mathrm{~K}$ & 0,39 & $* *$ \\
\hline & $\mathrm{Y}=7,661+0,839 \mathrm{~K}-0,057 \mathrm{~K}^{2}$ & 0,87 & $* *$ \\
\hline $\mathrm{K}(\mathrm{P} 2 \mathrm{xL} 2)$ & $\mathrm{Y}=8,508+0,131 \mathrm{~K}$ & 0,42 & $*$ \\
\hline $\begin{array}{c}\mathrm{K}(\mathrm{P} 2 \mathrm{xL} 3) \\
\mathrm{pH}\end{array}$ & $\mathrm{Y}=10,341-0,156 \mathrm{~K}$ & 0,89 & $* *$ \\
\hline $\mathrm{L}(\mathrm{P} 1 \times \mathrm{K} 3)$ & $\mathrm{Y}=5,912+0,001 \mathrm{~L}$ & 0,88 & $* *$ \\
\hline $\mathrm{L}(\mathrm{P} 2 \mathrm{xK} 1)$ & $\mathrm{Y}=6,578-0.001 \mathrm{~L}$ & 0,88 & $*$ \\
\hline $\mathrm{L}(\mathrm{P} 2 \mathrm{xK} 2)$ & $Y=5,768+0,002 \mathrm{~L}$ & 0,88 & $* *$ \\
\hline $\mathrm{L}(\mathrm{P} 2 \mathrm{xK} 3)$ & $Y=6,708-0,001 \mathrm{~L}$ & 0,56 & $* *$ \\
\hline $\mathrm{K}(\mathrm{P} 1 \mathrm{xL} 2)$ & $\mathrm{Y}=6,009+0,025 \mathrm{~K}$ & 0,75 & $* *$ \\
\hline $\mathrm{K}(\mathrm{P} 2 \mathrm{xL} 2)$ & $\mathrm{Y}=6,439-0,070 \mathrm{~K}+0.006 \mathrm{~K}^{2}$ & 0,37 & $*$ \\
\hline $\mathrm{K}(\mathrm{P} 2 \mathrm{xL} 3)$ & $Y=6,095+0,070 \mathrm{~K}-0.006 \mathrm{~K}^{2}$ & 0,37 & $*$ \\
\hline
\end{tabular}

\subsection{Eficiência de uso de água.}

Neste trabalho determinourse a eficiência do uso da água (EUA) considerando os diferentes níveis de água aplicados pelas linhas portagotejadores superficiais e subsuperficiais ( planta $^{-1}$ ciclo $^{-1}$ ) e a produtividade comercial do híbrido de melão Bônus $\mathrm{n}^{\mathrm{o}} 2\left(\mathrm{~kg} \mathrm{ha}^{-1}\right)$ obtidas com as doses de potássio K0, K1, K2 e K3, que são mostrados na Figura 37 (a, b, c). 
a)

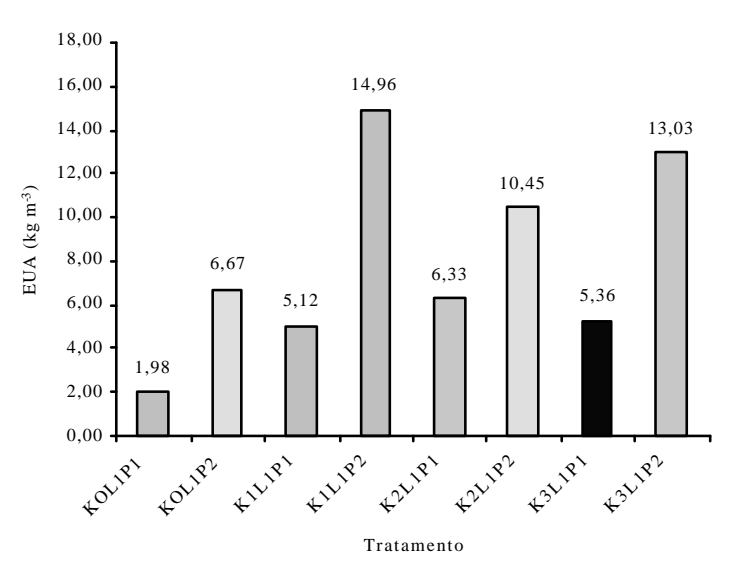

b)

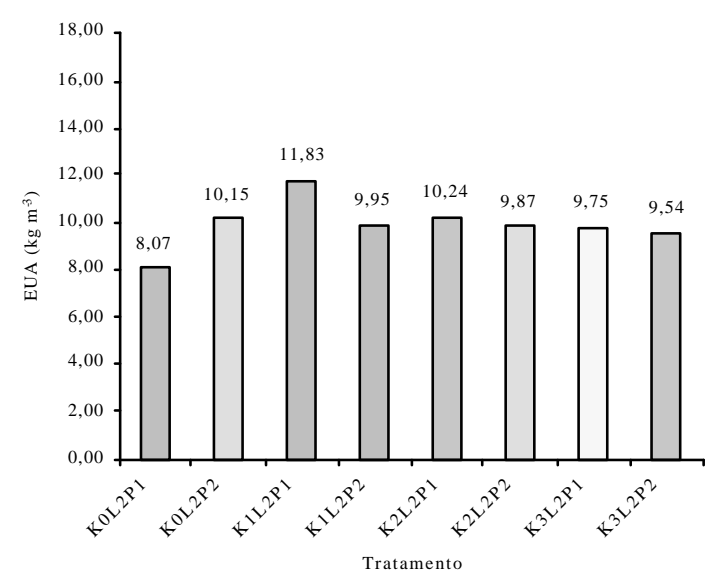

c)

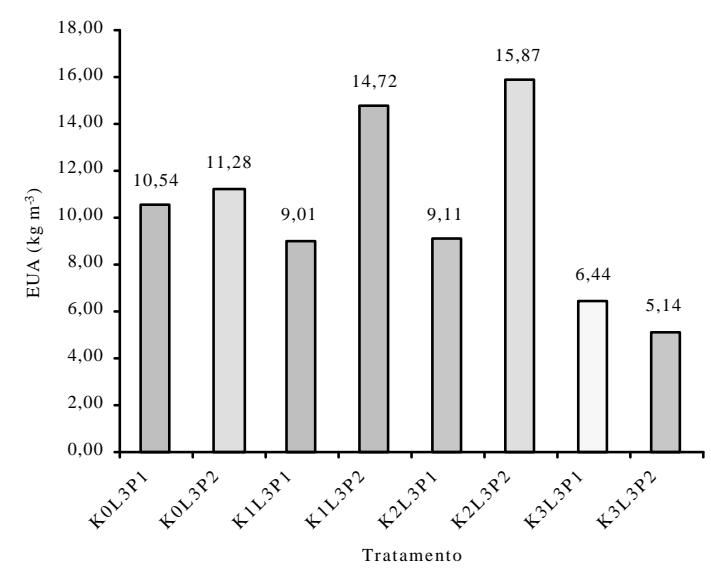

Figura 37 - Eficiência de uso de água $\left(\mathrm{kg} \mathrm{m}^{-3}\right)$ em combinação com três níveis de irrigação e duas posições de instalação das linhas portagotejadores. a) Nível de irrigação L1 (132, 72 mm); b) Nível de irrigação L2 (272,30 mm) Nível de irrigação L3 (417,32 mm).

Numa análise geral do comportamento da EUA em função dos níveis de irrigação, constataram-se acréscimos desta com o aumento da quantidade de água aplicada, exceto 
nos tratamento K1L1P2 e K3L1P2, onde foram observados um pequeno acréscimo com o nível mínimo de irrigação aplicado $(132,72 \mathrm{~mm})$. Observa-se também que o nível intermediário de irrigação $(272,30 \mathrm{~mm})$, proporcionou maior EUA para os tratamentos $\mathrm{K} 1 \mathrm{~L} 2 \mathrm{P} 1, \mathrm{~K} 2 \mathrm{~L} 2 \mathrm{P} 1, \mathrm{~K} 3 \mathrm{~L} 2 \mathrm{P} 1$. Isto demonstra que os maiores e menores valores de EUA pelo híbrido de melão bônus $\mathrm{n}^{0} 2$ foram obtidos com os respectivos maiores e menores volumes de água aplicados, descordando com Sousa et al., (1998) e Sousa et al., (2000b), que mencionam que na maioria das vezes o aumento da EUA pode ser obtido devido ao decréscimo da quantidade de água aplicada.

Os valores de EUA quando comparados dentro de cada fator por separado demonstram que as doses intermediarias de potássio $\mathrm{K} 1$ e $\mathrm{K} 2$ (6 e $9 \mathrm{~g} \mathrm{~K}_{2} \mathrm{O} \mathrm{pl}^{-1}$ ) possuem maior EUA $\left(10,932 \mathrm{~kg} \mathrm{~m}^{-3}\right.$ e 10,312 $\mathrm{kg} \mathrm{m}^{-3}$ ) em relação a dose extremas K0 e K3 (0 e 12 g de $\mathrm{K}_{2} \mathrm{O}$ planta $\left.{ }^{-1}\right)\left(9,115 \mathrm{~kg} \mathrm{~m}^{-3}\right.$ e $\left.8,210 \mathrm{~kg} \mathrm{~m}^{-3}\right)$, com relação ao efeito das lâminas observa-se que estas aumentam a EUA com os incrementos de níveis de irrigação L1, L2 e L3 (132, 72mm, 272,30 e 417,32 mm) com valores de 7,989 $\mathrm{kg} \mathrm{m}^{-3}, 9,800 \mathrm{~kg} \mathrm{~m}^{-3} \mathrm{e}$ $10,264 \mathrm{~kg} \mathrm{~m}^{-3}$. Observa-se que a EUA tem um valor de $7,815 \mathrm{~kg} \mathrm{~m}^{-3}$ quando os tubogotejadores estão na superfície e quando os tubogotejadores estão enterradas de $16,454 \mathrm{~kg} \mathrm{~m}^{-3}$.

\subsection{Coeficiente e evapotranspiração da cultura}

Os valores de Kc e ETc do híbrido de melão Bônus ñ 2 para as diferentes fases de desenvolvimento, foram calculados com a equação 7, em função da área foliar e evaporação do mini tanque evaporimétrico e estão apresentados na Tabela 48. Vale ressaltar que os dados obtidos foram originados de cultivo em ambiente protegido.

Estes valores são ligeiramente inferiores aos encontrados pela FAO $(\mathrm{Kc}=1,2) \mathrm{em}$ Allem et al., (1998) para cultivo de melão amarelo em campo. 
Tabela 48. Coeficiente $(\mathrm{Kc})$ e evapotranspiração da cultura (ETc), paras o híbrido de melão Bônus $n^{0} 2$, nas diferentes fases de desenvolvimento.

\begin{tabular}{ccc}
\hline DAT & Kc & ETc $\left(\mathrm{mm} \mathrm{dia}^{-1}\right)$ \\
\hline 8 & 0,39 & 1,148 \\
24 & 0,43 & \\
31 & 0,46 & 1.908 \\
54 & 0,55 & \\
60 & 0,66 & \\
74 & 0,63 & 2,864 \\
80 & 0.77 & \\
\hline
\end{tabular}

Estes valores são coerentes com os encontrados por Caron et al., (2000), trabalhando com melão híbrido Galia em estufa plástica, mediante balanço hídrico simplificado do solo, obtiverem coeficiente de cultura pelo razão entre o consumo de água e a evaporação de referencia, calculadas a partir de métodos de Penman e PenmanMonteith, de 0,34 no subperíodo vegetativo, compreendido desde o transplantio até o inicio do florescimento, de 0,70 no período compreendido entre a abertura da primeira flor feminina e a colheita do primeiro fruto e de 0,76 durante a colheita.

De igual forma coincidem com Van der Post et al., (1974); Montero et. al, (1985); Prados, (1986); Rosenberg et al., (1989) que afirmam que a evapotranspiração no interior da estufa em geral, é menor do que a verificada externamente, o que se atribui, basicamente, à parcial opacidade da cobertura plástica à radiação solar e à redução do efeito aerodinâmico, que são os principais fatores da demanda evaporativa da atmosfera. 


\section{CONCLUSÕES}

Os níveis de irrigação L2 e L3 (279,60 mm e 417,32 mm) não proporcionaram restrições de água para a cultura de meloeiro em tudo seu ciclo de desenvolvimento, principalmente quando as tubogotejadores estiveram na subsuperfície.

As doses de potássio, os níveis de irrigação e as posições dos tubogotejadores influenciaram a concentração e a distribuição espacial e temporal de $\mathrm{K}^{+}$, sendo mais afetados pela quantidade de água e de fertilizante aplicadas por fertirrigação que pela posição dos tubogotejadores.

Os parâmetros de qualidade dos frutos do meloeiro analisados encontram-se dentro das faixas adequadas para seu desenvolvimento e produção com níveis de irrigação L2 e L3 (279,60 mm e 417,32 mm) e doses de potássio intermediaras K1 e K2 $\left(6 \mathrm{~g} \mathrm{de}_{2} \mathrm{O} \mathrm{pl}{ }^{-1}\right.$ e $\left.9 \mathrm{~g} \mathrm{de}_{2} \mathrm{O} \mathrm{pl}^{-1}\right)$.

Os teores de macronutrientes nas folhas do meloeiro após a colheita não foram influenciados pelas doses de potássio, níveis de irrigação e posição dos tubogotejadores.

A aplicação das doses de potássio $\mathrm{K} 1$ e $\mathrm{K} 2\left(6 \mathrm{~g} \mathrm{de}_{2} \mathrm{O} \mathrm{pl}^{-1}\right.$ e $9 \mathrm{~g}$ de $\mathrm{K}_{2} \mathrm{O}$ pl$\left.^{-1}\right)$ em combinação com os níveis de irrigação L3 $(417,32 \mathrm{~mm})$ e posição dos tubogotejadores P2 (0,2 m) favoreceu a obtenção de maiores produtividades total $\left(65.108,33 \mathrm{~kg} \mathrm{ha}^{-1} \mathrm{e}\right.$ 69.646,00 kg ha-1) e comercial (61.427,60 $\mathrm{kg} \mathrm{ha}^{-1}$ e 66.224,31 $\left.\mathrm{kg} \mathrm{ha}^{-1}\right)$. 
Os parâmetros de qualidade do fruto de meloeiro analisados encontram-se dentro das faixas adequadas de comercialização.

Os maiores e menores valores de eficiência de uso da água pelo meloeiro, foram obtidos com os respectivos menores e maiores volumes de água plicados.

$\mathrm{O}$ Kc e ETc da cultura de meloeiro em ambiente protegido pode ser estimado com muita boa aproximação pelo modelo testado, mostrando a importância de levar em consideração a área foliar da planta. 


\section{REFERÊNCIAS BIBLIOGRÁFICAS}

AMERICAN SOCIETY OF AGRICULTURAL ENGINEERS. Standards. 38.ed. St. Joseph, 1991. p.518-521: EP405: Design and Installation of Micro-irrigation Systems. Engineering and Practices.

AMERICAN SOCIETY OF AGRICULTURAL ENGINEERS. Standards. 43.ed. St. Joseph, 1996. p. 627-230: S526: Soil and water terminology.

ANUARIO ESTATÍSTICO DO BRASIL - 1996, v.55, p.718-721, 1996.

ARAÜJO, J. P. Cultura de melão. Petrolina: EMBRAPA, CPATSA, 1980. 40p.

ARAUJO, J. P. Número de ramos e de frutos por planta e sua influencia no tamanho dos frutos do meloeiro (Cucumis melo L. cv. Valenciano). Piracicaba, 1979. 63p. Dissertação (Mestrado) - Escola Superior de Agricultura "Luiz de Queiroz", Universidade de São Paulo.

AULENBACH, B. B.; WORTHINGTON, J. T. Sensory evaluation of muskmelon: is soluble solids content a good quality index. HortScience, v.9, p.136-137, 1974.

AYERS, R. S.; WESTCOT, D. F. A qualidade da água na agricultura. Trad. de H. R. Gheyi et al. Campina Grande: UFPB, 1999. 153p. (Estudos FAO. Irrigação e Drenagem, 29) 
BARBER, S. A. Mechanism of potassium absorption by plants. In.: KILMER, V. S.; YOUNTS, S. E.; BRADY, N. C. (Ed.). The role of potassium in agriculture. Madison: American Society of Agronomy, 1968. p. 293 - 310.

BAR-YOSEF, B. Advances in fertigation. Advances in Agronomy, v. 65, p.1-77, 1999.

BAR-YOSEF, B.; SAGIV, B. Response of tomatoes to $\mathrm{N}$ and water applied via a trickle irrigation system. I Nitrogen. Agronomy Journal, v.74, p.633-637, 1986a.

BAR-YOSEF, B.; SAGIV, B. Response of tomatoes to $\mathrm{N}$ and water applied via a trickle irrigation system. II Water. Agronomy Journal, v.74, p. 637-639, 1986 b.

BAR-YOSEF, B.; SAGIV, B.; MARKOVITCH, T. Sweet corn response to surface and subsurface trickle phosphorus fertigation. Agronomy Journal, v.81, n.3, p. 443447, 1989.

BELFORT, C. C. Acumulação de matéria seca e recrutamento de nutrientes em melão (Cucumis melo L. cv. Valenciano amarelo CAC) cultivado em Latossolo Vermelho Amarelo em presidente Wenceslau - S. P. Piracicaba, 1985. 72p. Tese (Doutorado)Escola Superior de Agricultura “Luiz de Queiroz”, Universidade de São Paulo.

BEN-ASHER, J.; PHENE C. J. Analysis of surface and subsurface drip irrigation using a numerical model. In: Subsurface drip irrigation: theory: practices and application. Fresno: California State University, 1993. p.185-202 (CATI Publication 92 1001).

BERNARDI, J. B. Instruções práticas: a cultura do melão. Boletim Informativo do Instituto Agronômico de Campinas, v.1, n.2, p.73-90, 1974. 
BHELLA, H. S. Effect of trickle irrigation and black mulch on growth, yield and mineral composition of watermelon. HortScience, v.23, n.1, p.123-125, 1988.

BHELLA, H. S.; WILCOX, G. E. Yield and comparation of muskmelon as influenced by preplant and trickle applied nitrogen. HortScience, v. 21, n.1, p.86, 1986.

BOGLE, C. R.; HARTZ, T. K.; NUNEZ, C. Comparison of subsurface trickle and furrow irrigation on plastic-mulched and bare soil for tomato production. Journal of the American for Society Horticultural Science, v.144, n. 1, p.40-43, 1986.

BORRELLI , Cultivar e densità d investimento nela produzione del melone in cultura protetta . Science Agrarian University Student Napoli, v.5, p.298-309, 1971.

BOSLAND, J. M.; HUGHES, D. L.; YAMAGUCHI, M. Effects of glyphosine and triacontanol on growth, yield and soluble solids content of "PMR-45" muskmelons. HortScience, v.14, p.729-730, 1979.

BOUÇAS FARTAS, J. R.; BERGAMASCHI H.; MARTINS, S. R. Evapotranspiração no interior de estufas plásticas. Revista Brasileira de Agrometeorologia, v.2, p.17$22,1994$.

BOUWKAMP, J. C.; ANGELL, F. F.; SCHALES, F. D. Effect of weather conditions on soluble solids of muskmelon. Scientia Horticulturae, v.8, p. 265 - 271, 1978.

BRALTS, V. F.; KESNER, C. D. Drip irrigation field uniformity estimation. Transactions of the ASAE, v.26, n.5, p.1369-1374, 1983.

BRANTLEY, B. B.; WARREN, G. F. Effect of nitrogen nutrition on flowering, fruiting and quality in the muskmelon. Proceedings of the American Society for Horticultural Science, v.77, p.424-431, 1961. 
BRESLER, E. Analysis of trickle irrigation with application to design problems. Irrigation Science, v.1, p.3-17, 1978.

BUCKS, D. A.; ERIE, L. J.; FRENCH, O. F. et al. Subsurface trickle irrigation management with multiple cropping. Transactions of the ASAE, v.24, n.6, p.14821489. 1981.

BUI, W.; OSGOOD, R. V.. Subsurface irrigation trial for alfalfa in Hawaii. In: NATIONAL IRRIGATION SYMPOSIUM, 3., St Joseph, 1990. Proceedings. St. Joseph: ASAE, 1990. p.658-660.

BURIOL, G. A.; STRECK, N. A.; PETRY, C. et al. Transmissibilidade à radiação solar do polietileno de baixa densidade utilizado em estufas. Ciência Rural, v.25, n.1, p.1-4, 1995.

CAMP, C. R.; SADLER, E. J.; BUSSCHER, W. J. Subsurface and alternante-middle micro irrigation for the southeastern Coastal Plain. Transactions of the ASAE,v.32, n.2, p.451-456, 1989.

CAMP, C. R.; GARRETT, J. T.; SADLER, E. J. at al. Microirrigation management for double-cropped vegetables in a humid area. Transactions of the ASAE, v.36, n.6, p. 1639-1644, 1993.

CARDOSO, S. S. Dose de $\mathrm{CO}_{2}$ e de potássio aplicados através de irrigação no meloeiro rendilhado (Cucumis melo L.) cultivado em ambiente protegido. Piracicaba, 2002. 101p. Tese (Doutorado) - Escola Superior de Agricultura "Luiz de Queiroz", Universidade de São Paulo. 
CARLESSO, R.; SANTOS, R. F. Déficit hídrico e os processos morfológico e fisiológico das plantas. Revista Brasileira de Engenharia Agrícola e Ambiental, v.2, n.3, p.287-294, 1998.

CARNEIRO FILHO, J. Produção e qualidade de frutos de melão cataloupe influenciado pela poda e pelo tutoramento, em condições de estufa e de campo. Viçosa, 2001. 102p. Dissertação (Mestrado) - Universidade federal de Viçosa.

CAVALCANTE, M. A. A.; ARAÚJO, J. P. Influência do nitrogênio, fósforo e números de frutos por planta a produção de melão. In: QUEIROZ, N. A.; AGUIAR, P. A. A., PEREIRA, J. R. et al. Relatório de Atividades de Pesquisa Petrolina: EMBRAPA, CPATSA, 1977. v.1, p.102-104.

CHACE, E. M.; CHURCH, C. G.; DENNY, F. E. Relation between the compositions of California catalupes and their commercial maturity. Washington: USDA, 1924. (Dept. Agr. Buletin, 1250).

CLOUGH G. H.; LOCASCIO, S. J.; OLSON, S. M. Yield succesively cropped polyethylene mulched vegetables as effected by irrigation method and fertilization management. Journal of the American Society for Horticultural Science, v.115, p.884-887, 1990.

COELHO, M. B.; OLITA, A. F. L.; ARAÚJO, J. P. Influência dos métodos de irrigação por sulco e gotejo na cultura do melão. In: CONGRESSO BRASILEIRO DE IRRIGAÇÃO E DRENAGEM, 4., Salvador, 1978. Anais. Salvador: Associação Brasileira de Irrigação e Drenagem, 1978. p.48.

COHEN, R. A; HICKS, J. R. Effect of storage on quality and sugars in muskmelon. Journal of the American Society for Horticultural Science, v.111, n.4, p.553557, Apr. 1986. 
CONRAD, M. F. Applications. In: Subsurface drip irrigation: theory, practices and applications. Fresno: California State University, 1992. p.59-64. (CATI Publication, 92-1001).

COSTA, C. P.; PINTO, C. A. B. Melhoramento de hortaliças. Piracicaba: ESALQ, Departamento de genética, 1977.319p.

DAVIS, G. M.; MEINERT, V. G. H. The effect of plant spacing and fruit pruning on the fruits of P. M. R. No. 45 Cataloupe. Journal of the American Society for Horticultural Science, v.87, p.299-302, 1965.

DAVIS, R. M.; JUNIOR, G. N.; DAVIS, H. et al. Development aspects of field-to-field variations in selected cataloupe characteristics (Cucumis melo L. var. reticulatus Naud.). Hilgardia, v.38, p.165-180. 1967.

DAVIS, S.; NELSON, D. Subsurface irrigation today and tomorrow In: INTERNATIONAL DRIP IRRIGATION CONGRESS, 7., St. Joseph, 1970. Proceedings. St. Joseph: ASAE, 1970. p.1-8.

DAVIS, S.; PUGH, W. J. Drip irrigation: surface and subsurface compared with sprinkler and furrows. In: INTERNATIONAL DRIP IRRIGATION CONGRESS, 2., San Diego, 1974. Proceedings. San Diego: ASAE, 1974. p.109-114.

DETAR, W. R.; PHENE, C. J; CLARK,D. A. Subsurface drip vs. furrow irrigation: 4 years of continuous cotton on sandy soil. IN: BELLOWED COTTON CONFERENCE, Memphis, 1994. Proceedings Memphis: Nat. Cotton Council, 1994. p.542-545. 
DETAR, W. R.; BROWNE G. T.; PHENE C. J. et al. Real-time irrigation scheduling of potatoes with sprinkler and subsurface drip systems. In: INTERNATIONAL CONFERENCE ON EVAPOTRANSPIRATION AND IRRIGATION SCHEDULING, St. Joseph, 1996. Proceedings St. Joseph: ASAE, 1996. p.812824.

DIDENKO, L. P. The effect of spacing on growth development and productivity of melons in heated greenhouses. Horticultural Abstracs, v.47, n.1, p.471-172, 1976.

DIEST, A. van. Factors affecting the availability of potassium in soils. In: CONGRESS OF THE INTERNATIONAL POTASS INSTITUTE, 11., Bern, 1978. Proceedings Bern: International Potash Institute, 1979. p. 75-97.

DOMINGO, S. F. Demanda de nitrógeno y eficiencia de la fertilización de melón retuculado (Cucumis melo L. Var. Reticulatus Noud). Ciencia e Investigación Agraria, v. 18, n. 3, p.101-109, 1991.

DORENBOS, J.; KASSAM, A. H. Efectos del agua sobre el rendimiento de los cultivos. Roma: FAO, 1998. 212p. (FAO Boletín, 33).

DORENBOS, J.; PRUITT, W. O. Las necesidades de agua de los cultivos. Roma: FAO, 1976. 194p. (FAO Boletín, 24).

DUNCAN, J. Buried drip gains more ground. Grape Grower, v.25, n.4, p.20-23, 1993.

DUSI, A. N. Melão para exportação: aspectos técnicos da produção. Brasília: DENACOOP;FRUPEX, 1992. 32p. (DENACOOP. Serie Publicações Técnicas, 1). 
EL-AIDY, F. The effect of plastic tunnel orientation on yield of some cucumber varietis in Egypt. Acta Argonomica, v.38, n.4, p.349-352, 1989.

ELAMIN, O. M. WILCOX, G. E. Effect of soil acidity and magnesium on muskmelon leaf composition on fruit yield. Journal of the American Society for Horticultural Science, v.3, p.682-685, 1986.

EL-GINDY, A. M.; EL-ARABY, A. M. Vegetable crop response to surface and subsurface drip under calcareous soil. In: INTERNATIONAL CONFERENCE ON EVAPOTRANSPIRATION AND IRRIGATION SCHEDULING, St. Joseph, 1996. Proceedings St. Joseph: ASAE, 1996. p.1021-1028.

EMPRESA BRASILEIRA DE PESQUISA AGROPECUARIA. Centro Nacional de Pesquisa de Solos. Manual de métodos de análise de solos. 2. ed. Rio de Janeiro: EMBRAPA, 1997. 212p.

EMPRESA BRASILEIRA DE PESQUISA AGROPECUARIA. Centro Nacional de Pesquisa de Solos. Sistema brasileiro de classificação de solos. 1. ed. Rio de Janeiro: EMBRAPA, 1999. 412p.

FERREIRA, F.; PEDROSA, J. F.; ALVARENGA, M. A. R. Melão: cultivares e métodos culturais. Informe Agropecuário, v. 8, n.85, p.26-28, 1982.

FILGUEIRA, F. A. R. Manual de olericultura: Cultura e comercialização das hortaliças. 2. ed. São Paulo: Agronômica Ceres, 1981.v.2, p. 223-233: Pós-colheita.

FILGUEIRA, F.A.R. Novo manual de olericultura: agrotecnologia moderna na produção e comercialização de hortaliças. Viçosa: UFV, 2000. cap. 10, p. 333-338: Pós-colheita. 
FILGUEIRAS, H.A.; MENEZES, J.B.; ALVES, R.E. et al. Colheita e manuseio em póscolheita. In: ALVES, R.E. (Org.) Melão: pós-colheita. Brasília: EMBRAPA, 2000. cap. 3, p. 23-40. (Frutos do Brasil, 10).

FLOCKER, W. J.; LINGLE, J. C.; DAVIS, R. M.; MILLER, R. J. Influence of irrigation and nitrogen fertilization on yield, quality and size of cantaloupes. Proceedings of the American Society for Horticultural Science, v. 86, p.424-432, 1965.

FNP CONSULTORIA \& COMERCIO. Agrianual 2002: anuário estatístico da agricultura brasileira. São Paulo, 2002. p.412-414: Melão.

GAYET, J. P. Comercialização de frutos tropicais. Paris: s. ed., s. d. 10p.

GIANELLO, C.; MIELNICZUK, J. Características químicas e físicas de solo que afetam a absorção de potássio em plantas de milho. Revista Brasileira de Ciências do Solo, v.5, p.109 - 114, 1981.

GILLEY, J. R.; ALRED, E. R. Infiltration and root extraction tromp subsurface irrigation laterals. Transactions of the ASAE, v.17, n.5, p.927-933. 1974a.

GILLEY J. R.; ALRED, E. R. Optimum lateral placement for surface irrigation systems. In: INTERNATIONAL DRIP IRRIGATION CONGRESS TRANSACTION, 2., Riverside, 1974. Proceedings. Riverside: California University, 1974b. p.234-239.

GIMÉNEZ, M. M.; RINCÓN S. L. Fertirrigación por goteo del melón. Murcia: Universidad Politécnica Superior, Centro Regional de Investigaciones Agrarias de Murcia. Orihuela: Elche, 1985. 8.p 
GOLBERG, D.; SHMUELI, M. Drip irrigation: a method used under arid desert conditions of high water and soil salinity. Transactions of the ASAE, v.13, p.3841, 1970.

GOLDBERG, D. B.; CORNAT; D. RIMON, P. Drip irrigation: principles, design and agricultural practices. Shmaryahu, Israel: Drip Irr. Sci. Publ., 1976. 296p.

GUROVICH, L. A. Relatorio final de consultoría en manejo de suelos y agua. Petrolina: EMBRAPA,CPATSA, 1979. 10p.

GUTTORMSEN, G. Effects of root medium and watering on transpiration, growth and development of glasshouse crops: II. The relationship between evaporation pan measurements and transpiration in glasshouse crops. Plant and Soil, v. 40, p. 461478, 1974.

HANSON, E. G.; PETTERSON, T. C. Vegetable production and water-use efficiencies as influenced by drip, sprinkler, subsurface, and furrow irrigation methods. In: INTERNATIONAL DRIP IRRIGATION CONGRESS, 2. San Diego, 1974. Proceedings San Diego: Drip Irrigation, 1974. p.97-102.

HANSON, B.; SCHWANKL, L.; GRATTAN, S. et al. Drip irrigation for row crops. Davis: University of California, 1994. 159p. (Water management series publication, 93-05).

HARTZ, T. K. Effects of drip irrigation scheduling on muskmelon yield and quality. Scientia Horticulturae, v.69, p.117-122, 1997.

HENGGELER, J.; KINNIBRUGH, J.; MULTER, W. et al. Economic impact resulting from the adoption of drip irrigation cotton: result demonstration report. College Station: Texas A\&M University, 1996. 8p. 
HENGGELER, J. C. A history of drip-irrigated cotton in Texas. In: INTERNATIONAL MICROIRRIGATION CONGRESS, 3., St. Joseph Mich., 1995. Proceedings. St Joseph: ASAE, 1995. p.669-674.

HERNANDEZ, F. B. T. Efeitos da supressão hídrica nos aspectos produtivos e quantitativos da cultura de melão. Piracicaba, 1995. Tese (Doutorado) - Escola Superior de Agricultura “Luiz de Queiroz”, Universidade de São Paulo.

HUBBARD, N. L.; PHARR, D. M.; HUBER, S. C. Sucrose metabolism in ripening muskmelon fruit as affected by leaf area. Journal of American Society for Horticultural Sciece, v.115, p.798-802. 1990.

HUDSON, T.; HARTMANN, T.; FlOCKER, W. J. et al. Plant science: growth, development and utilization of cultivated plants. New York: Prentice-Hall, 1981, p.551-552: Vegetable crops groun for fruits or seeds.

HUTMACHER, R. B.; PHENE, C. J.; DAVIS, K. R. et al. Evapotranspiration, fertility management for subsurface drip acala and pima cotton. In: INTERNATIONAL MICROIRRIGATION CONGRES S, 5., St. Joseph, 1995. Proceeedings St. Joseph: ASAE, 1995. p.147-151.

JACOB, W. L.; WHITE-STEVENS, R. H. Studies in the minor element nutrition of vegetable crops plants. II. The interaction of potash, boron and magnesium upon the flavor and sugar content of melons. Proceedings of the american Society of Horticultural Science, v.39, p.369-374, 1941.

KELLER, J.; BLIESLE, R.D. Sprinkle and trickle irrigation. New York: Van Nostrand Reinhold, 1990. 65p.

KIEHL, E. J. Fertilizantes orgânicos. .São Paulo: Agronômica Ceres, 1985, 147p. 
KNOTT, J. E. A cultura de melão. Piracicaba: ESALQ,USP, 1951. p.186.

KOFOED, A. D. The potassium cycle in cropping systems. In: CONGRESS OF THE INTERNATIONAL POTASH INSTITUTE, 11., Bern, 1978. Proceedings: Potassium research - review and trends. Bern: International potash institute, 1979. p.435-449.

KUZVETSOVA, N. C. E.; AGZAMOVA, N. A. The effect of potassium on seed quality and its after-affecter on the resistence of melons to wilt on grey soil. Horticultural Abstracts, n.45, 1974. p.841.

LESTER, G.; SHELLIE, K. C. Postharvest sensory and physicochemical attributes of Honey Dew melon fruits. HortScience, v.27, n. 9, p. 356-360.

LIPPERT., L. F.; LEGG, P. D. Appearence and quality characters in muskmelon fruit evaluated by a tencultivar diallel cross. Journal of the American Society of Horticultural Science, v.97, p.84-86, 1972.

LOY, J. B.; WELLS, O. S. Response of hybrid muskmelons to polyethylene row covers and black polyethylene mulch. Scientia Horticulturae, v. 3, p.223-230, 1975.

MAGALHÃES, M.I. Uniformidade da fertirrigação em um sistema de irrigação por gotejamento. Fortaleza, 1996. 60p. Dissertação de (Mestrado) - Universidade Federal do Ceará.

MALAVOlTA E.; VITTI G. C.; OLIVEIRA, S. A. Avaliação do estado nutricional das plantas: princípios e aplicações. 2.ed. Piracicaba: Potafos, 1997. 319p. 
MALAVOLTA, E.; CROCOMO, O. J. Função do potássio nas plantas. In: SIMPÓSIO SOBRE POTÁSSIO NA AGRICULTURA BRASILEIRA, Londrina, 1982. Anais. Piracicaba: Instituto da Potassa e Fosfato, 1982. p.95-162.

MANCINA, F. V. Rendimento del cultivo de melón, bajo conditiones di riego por goteo en la region Laguneira. In: SEMINÁRIO LATINO-AMERICANO SOBRE RIEGO POR GOTEO, 2., México, 1977. Anais. México: Torreon, 1977. p.445.

MARCON D. L. C.; HELDWEIN A. B.; BURIOL G. A. et al. Consumo de água do tomateiro tipo salada em estufa plástica. Revista Brasileira de Agrometeorologia, v.5, n.1, p.61-67, 1997.

MARUYAMA, W.I.; BRAZ,L.T.; CECÍLIO FILHO, A.B. Condução de melão rendilhado sob cultivo protegido. Horticultura Brasileira. v.18, n.3, p.175-178, 2000.

MASS, E. V.; HOFFMAN, G. J. Crop salt tolerance: evaluation of existing data. In: INTERNATIONAL SALINITY CONFERENCE, Texas, 1997. Proceedings. Texas: Tech. Univ. Lubbock, 1997. p 187-198.

MENEZES, J. B. Qualidade pós-colheita de melão tipo "Galia" durante a maturação e o armazenamento. Lavras: UFLA, 1996. 87p.

MENGEL, K.; VON BRAUNCHWEIG, L. C. The effect of soil moisture upon the availability potassium and its influence on the growth of young maize plants (Zea mays L). Soil Science, v.114, n.2, p.142 - 148, 1972.

MILLAR, A. A.; CHOUDHURY, E. N. A. Model to define operational irrigation frequency for maximum yield of crops. Turrialba, v.30, n.4, p.391-398, 1980. 
MILLAR, A. A. Manejo racional da irrigação: uso de informações básicas sobre diferentes culturas. Brasília: IICA, 1984. 57p. (IICA, Série Publicações miscelâneas, 461).

MONTERO, J. I.; CASTILLAN, N.; GUTIERREZ de RAVÉ, E. et al. Climate under plasticin the Almeria. Acta Horticultura, n. 170, p.227-234, 1985.

NOGUEIRA, L.C.; NOGUEIRA, L.R.Q.; GORNAT, B. et al. Gotejamento subsuperficial: uma alternativa para a exploração agrícola dos solos dos tabuleiros costeiros. Aracaju: EMBRAPA, CPATC, 1997. 19p. (EMBRAPA.CPATC, 6).

NYE, P. H. Localized movement of potassium ions in soils. In: COLOQUIUM OF THE INTERNATIONAL POTASH INSTITUTE, 9., Landshut, 1972. Proceedings: Potassium in soil. Bern: International Potash Institute, 1972. p.147-155.

ORON, G.; DEMALACH, Y.; GILLERMAN, L. et al. Pear response to saline water application under subsurface drip irrigation. In: LNTERNATIONAL MICROIRRIGATION CONGRESS, 5., St. Joseph, 1991. Proceedings St. Joseph: ASAE, 1991. p.97-103.

PEÑALBER, P. J. Cultivo del melón al aire libre. In: NAMESNY, A. Melones, Madrid: Ediciones de Horticultura, 1997. cap.7, p.58-65.(Compendios de Horticultura, 10).

PEIRCE, L. C.; PETERSON, L. T. The response of muskmelon to spacing, seeding date and plant container. Journal of the American Society for Horticultural Science. v.77, p.432-439, 1961.

PEREIRA, A. J. Produção e qualidade de melão amarelo submetido à pulverização com duas fontes de cálcio. Lavras, 1997. 46p. Dissertação (Mestrado) - Universidade Federal de Lavras. 
PÉREZ Z. Green manure use for muskmelon production in Colima, México. In: SYMPOSIUM FERTILIZER TECHNOLOGY: ITS EFFICIENT USE FOR CROP PRODUCTION. TRANS. WORLD CONGRESS OF SOIL SCINCE, 5. Acapulco, 1994. Proceedings. Acapulco, 1994. p.420-421.

PÉREZ Z., O.; RIVERO M. C. Tensión de humedad del suelo y fertilización nitrogenada en melón Cantaloupe, híbrido Ovation. Tepames, Colima, México. Agrociencia, v.35, p.479-488, 2001.

PÉREZ Z., O.; LÓPEZ, O.; OROZCO, M.. Efecto de la incorporación de abonos verdes en la producción de melón en Colima. México.Terra, v.13, n.3, p.360-367, 1995.

PEW, W. D.; GARNER B. R. Effects of irrigation practices on vine growth, yield, and quality of muskmelon. Journal of the American Society Horticultural Science, v.108, p. 134-137, 1983.

PHENE, C. J.; BEALE, O. W. Hihg frequency irrigation for water and nutrient management in the humid regions. Soil Sciencia Society American Journal, v.40, p.430-436, 1976.

PHENE, C. J.; SANDERS, D. C. High-frequency trickle irrigation and row spacing effects on yield and quality of potatoes. Agronomy Journal, v.68, p.773-776, 1976.

PHENE, C. J.; BEALE, O. W. Influence of twin-raw spacing and nitrogen rates on highfrequency trickle-irrigated sweet corn. Soil Science Society of America Journal, v.43, n.6, p.1216-1221, 1979. 
PHENE, C. J.; DETAC, W. R.; CLARK, D. A. Real-time irrigation scheduling of cotton with an automated pan evaporation system. Applied Engineering in Agriculture, v.8, n.6, p.787-793, 1992a.

PHENE, C. J.; FOUSS, J. L.; SANDERS, D. C. Water-nutrient management of potatoes with trickle irrigation. American Potato Journal, v.56, p.51-59, 1989.

PHENE, C. J.; DAVIS, K. R.; HUTMACHEC, R. B. et al. Advantages subsurface irrigation for processing tomatoes. Acta Horticulturae, n.200, p.101-114, 1987.

PHENE, C.; DAVIS, K. R.; HUTMACHER, R. B. et al. Effect of high frequency subsurface and surface drip irrigation on root distribution of sweet corn. Irrigation Science, v.12, p.135-140, 1990.

PHENE, C. J.; HUTMACHER, R. B.; AYARS, J. E. et al. Maximizing water use efficiency with subsurface drip irrigation. St. Joseph: ASAE. 1992b. (ASAE Paper 92-2090).

PINTO J. M. Sistema de cultivo de melão com aplicação de fertilização via água de irrigação, Petrolina: EMBRAPA, CNPTSA 1986. 24p. (Circular Técnica, 36).

PINTO, J. M; SOARES, J. M.; CHOUDHURY, E. N. et al. Adubação via água de irrigação na cultura do melão. Pesquisa Agropecuária Brasileira,v.28, n.3, p.323327, 1993.

PINTO, J. M.; SOARES, J. M.; CHOUDHURY, E. N. et al. Efeitos de períodos e de freqüências da fertirrigação nitrogenada na produção do melão. Pesquisa Agropecuária Brasileira, v.29, n.9, p.1345-1350, 1994. 
PINTO, J. M.; SOARES, J. M.; COSTA, N. D. et al. Aplicações de N e K via água de irrigação em melão. Horticultura Brasileira, v.13, n. 2, p. 192-195, nov. 1995.

PINTO, J. M.; SOARES, J. M.; PEREIRA, J. R.. et al. Sistemas de cultivo de melão com aplicação de fertilizantes. Petrolina: EMBRAPA, CPATSA/Petrobrás, 1976. 24p. (EMBRAPA. CPATSA. Circular Técnica, 36).

PRABHAKAR, B. S.; SRINIVAS, K.; SHUKLA, V. Yield and quality of muskmelon (cv. Hara Madhu) in relation to soacing and fertilization. Progressive Horticulture, v. 17 , n. 1, p. 51-55. 1985.

PRADO, O. T. Espaçamento, adubação e poda de cucurbitáceas. Hortaliças, n.4, p.1-6, 1960.

PRADOS, N. C. Contribución al estudio de los cultivos enarenados en Almería: necesidades hídricas y extracción del nutriente del cultivo de tomate de crecimiento indeterminado en abrigo de polietileno. Madrid, 1986. 195p. Tesis (Doctoral) Universidad Miguel Hernández.

RAIJ, B. van; CANTARELA, H.; QUAGGIO, J. A. et al. Recomendações de adubação e calagem para o Estado de São Paulo. 2.ed. Campinas: IAC, 1986.p.181:Melão. (IAC.Boletim, 100)

RAWLINS, S. L. Principles of managing high-frequency irrigation. Soil Science Society of America Proceedings, v.37, p.626-629, 1973.

REISSER JUNIOR. C. Evapotranspiração de alface em estufa plástica e ambiente natural. Santa Maria, 1991. 78p. Dissertação (Mestrado) - Universidade Federal de Santa Maria. 
RIBAS, F.; CABEllO, M. J.; MORENO, M. M. Et d. Influencia del riego y de la aplicación de potasio en la producción del melón (Cucumis melo L.). Investigation Agronomy: Producción y Protección Vegetal, v.16, n.2, p.283-296 2201.

RIBAS, F.; CABELlO, M. J.; MORENO, M. Necesidades de riego del melón y respuesta del cultivo a riegos diferenciales en la provincia de Ciudad Real. In: JORNADAS TÉCNICAS SOBRE RIEGOS, 13., Tenerife,1995. Resuménes. Tenerife, 1995. p.12-20.

RINCÓN, Z. L.; SÁEZ, S. J.; PÉREZ, C. J. A.; et al. Growth and nutrient absortion by muskmelon crop under greenhouse conditions. Acta Horticulture, v.458, n. 3, p.153-159, 1998.

RIZZO, A.A.N.; BRAZ, L.T. Características de cultivares de melão rendilhado cultivadas em casa de vegetação. Horticultura Brasileira, v.19, n.3, p.420-423, 2001.

RIZZO, A.A.N.; QUIJANO, F.G.; LAURA, V.A. Efeito da idade de mudas no desenvolvimento do melão rendilhado. Horticultura Brasileira, v.18, p.468-469, 2000. Suplemento.

ROBLEDO, F. P.; MARTÍN, L. V. Aplicación de los plásticos en la agricultura. Madrid: Mundi-Prensa, 1981. 552 p.

RODRÍGUEZ, C. J.; OCHOA, M. A.; VALENZUELA, I. M. et al. Eficiencia en el uso de agua y nitrógeno por el cultivo de melón (Cucumis melo L.) bajo riego por goteo. In: CONGRESO NACIONAL DE IRRIGACIÓN. Culiacán, 1999. Proceedings. Culiacán: s.ed. 1999. p.27-29. 
ROSE, J. L.; CHAVEZ, R. L.; PHENE, C. J. et al. Subsurface drip irrigation of processing tomatoes. In: SPECIALLY CONFERENCE ON ENVIRONMENTALLY SOUND WATER AND SOIL NANAGEMET, New York, 1982. Proceedings. New York: ASAE, 1982. p.369-376.

ROSENBERG, N. J.; McKENNEY, M. S.; MARTIN, P. Evapotranspiration in a greenhouse-warmed world: a review and a simulation. Agricultural and Forest Meteorology, v. 47, p. 303-320, 1989.

SAGDULlAEV, M. M.; UMAROV, K. Z.. The effect of phosphorus fertilizer on the yeld and quality of melons. Horticultural Abstracts, v.45, n.1, p.27. 1974.

SAMMIS. T. W. Comparison ot sprinkler, trickle, subsurface. and furrow irrigation methods for row crops. Agronomy Journal, v.72, n.5, p.701-704, 1980.

SAMMIS, T. W.; WU, I. P. Effect of drip irrigation design and management on crop yield. Transactions of the ASAE, v.28, n.3, p.832-8328, 1985.

SAMPAIO, S.; YAMASHIRO, T. Melão: vencendo as primeiras etapas. Correio Agrícola, v.1, n.79, p. 186-189, 1979.

SANCHÉZ, L.R.; SIRONI, J.S.; CRESPO, J.A.P. et al. Growth and nutrient absorption by musk melon crop under greenhouse conditions. In: INTERNATIONAL SIMPOSIUM ON WATER QUALITY AND QUANTITY IN GREENHOUSE HORTICULTURE, Acta Horticulture, n.458, 1996. 7p.

SANTOS, R. N. C. dos. Avaliação da relação K:N e híbridos de melão em cultivo hidropônico. Piracicaba, 2002. 98p. Dissertação (Mesterado) - Escola Superior de Agricultura “Luiz de Queiroz”, Universidade de São Paulo. 
SARRUGE, J. R.; HAAG, H. P. Análises químicas em pantas. Piracicaba: ESALQ, Departamento de Química, 1974. 56p.

SCHWANKEL. L. J.; GRATTAN, S. R.; MIYAO, E. M. Drip irrigation burial depth and seed planting depth effects on tomato germination. In.: NATIONAL IRRIGATION SYMPOSIUM, 3., St. Joseph, 1990. Proceeedings. St. Joseph: ASAE, 1990. p.682-687.

SHANNON, M. C.; FRANCOIS, L. E. Salt tolerance of three muskmelon cultivars. Journal of the American Society Horticultural Science, v.103, p.127 - 130, 1978.

SHMUELI, M.; GOLDBERG, D. Sprinkler, forrow, and trickle irrigation of muskmelon in arid zone. Horticultural Science, v. 6, n.6, p.557-559. 1971.

SINGOGO, W. W.; LAMONT, W. L.; MARR, CH. W.. Legumes alone and combination with manure and fertilizers in an intensive muskmelon production system. HortScience, v.26, n.1, p.1431.1991.

SOARES, A. J. Efeitos de três lâminas de irrigação e de quatro doses de potássio via fertirrigação no meloeiro em ambiente protegido. Piracicaba, 2001. 67p. Dissertação (Mestrado) - Escola Superior de Agricultura 'Luiz de Queiroż', Universidade de São Paulo.

SOLOMON, K. H. Yield related interpretations of irrigation uniformity and efficiency measures. Irrigation Science, v.5, p.161-172, 1984. 
SOUSA V. F. de. Frequiência de aplicação de $\mathrm{N}$ e $\mathrm{K}$ via água de irrigação por gotejamento no meloeiro (Cucumis melo L. cv. Eldorado 300) em solo de textura arenosa. Botucatu, 1993, 131p Tese de (Mestrado) - Facultade de Ciências, Agronômicas. Universidade Estadual Paulista "Julio de Mesquita Filho".

SOUSA, V. F. de; COELHO, E. F.; BASTOS, E. A. et al. Doses de nitrogênio e potássio por fertirrigação na produtividade do meloeiro. In: BALBUENA, R. H.; BENEZ, S. H; JORAJURIA, D. Avances en el manejo del suelo y agua en la ingeniería rural latinoamericana, La Plata, 1978. p.195-200.

SOUSA, V. F. de; COELHO, E. F.; SOUZA, V. A. B. Freqüência de irrigação em meloeiro cultivado em solo arenoso. Pesquisa Agropecuária Brasileira, v.34, n.4, p.659-664, 1999.

SOUSA, V. F. de; SOUSA, A. P. Efeito da frequência de aplicação de N e K por gotejamento no na cultura do meloeiro (Cucumis melo L.). Engenharia Agrícola, v.17, n.3, p.36-45, 1998.

TYLER, K. B.; LORENZ O. A. Nutrient absorption and growth of four muskmelon varieties. Journal of the American Society for Horticultural Science. v. 84, n.1, p.191-195, 1964.

VAN BAVEL, C. H.; AHMED, M. J.; BHUIYAN, S. I. et al. Dynamic simulation of automated subsurface irrigation systems. Transactions of the ASAE, v.16, n.6, p.1095-1099. 1973.

VANDER POST, C. J.; VAN-SHIE, J. J.; GRAAF, R. Basic problems of water relationship: energy balance and water supply in glasshouse in the WestNetherlands. Acta Horticulturae, n.1, v. 35, p. 13-21, 1974. 
VAZIRI, C. M.; GIBSON, W. Subsurface and drip irrigation for Hawaiian sugarcane. Ln: REPORT HAWAIIAN SUGAR TECHNOLOGY ANNUAL CONFERENCE, Honolulu, 1972. Proceedings. Honolulu: Hawaiian Sugar Planters Assoc., 1972. p.18-22.

VIEIRA, E. Índice de maturação para melão (Cucumis melo L.) In: HEREDIA, M. C. V. DE E CASALS, V. W. D. (Coord). Seminário de olericultura. Viçosa, 1984. v.10, p.48-67.

WARRICK, A. W.; SHANI, U.; XUE, S. et al. Soild limiting flow from subsurface emitters. I: Pressure measurements. Journal of Irrigation and Drainage Engeneering, v.122, n.5, p.291-295, 1996.

WARRICK, A. W.; LOMEN, D. O.; AMOOZEGAR-FARD, A. Linearized moisture tlow with root extraaion for three dimensional steady conditions. Soil Science Society of America Journal, v.44, n.5, p.911-914. 1980.

WELLES G. W. H.; BUITELAAR, K.. Factors affecting soluble solids content of muskmelon (Cucumis melo L.). Netherlands Journal of Agricultural Science, v.36, p.239-246, 1988.

WELLS J. A.; NUGENT, P. E. Effect of high soil moisture on quality of muskmelon. HortScience, v.15, p.258-259, 1980.

WENDT, C. W.; ONKEN, A. B.; WILKE, O. C. et al. Ettect of irrigation systems on the water requirement of sweet com. Soil Science of Society America Journal, v.41, n.4, p.785-788. 1977. 
WESTERN Fertilizers Handbook. Sacramento: California Association, 1975. 250p.

WHITNEY, L. F. Review of subsurface irrigation in the Northeast. In. NATIONAL IRRIGATION SYMPOSIUM, St Joseph., 1970. Proceedings. St Joseph: ASAE, 1979 p. $1-8$.

WILlARDSON, L. S.; BOHN, G. W.; HOBER, M. J. Catalupe response to drip irrigation. In: INTERNATIONAL DRIP IRRIGATION CONGRESS, 2., San Diego, 1974. Proceedings. San Diego: ASAE, 1974. p.474-477.

WU, I. P. Linearized water application function for drip irrigation schedules. Transactions of the ASAE, v.31, n.6, p.1743, 1749.

WU, I. P.; GITLIN. Drip irrigation application efficiency and schedules. Transactions of the ASAE, v.26, n.1, p.92-909, 1983.

ZANINI, J. R. Hidráulica da fertirrigação por gotejamento utilizando tanque de derivação de fluxo e bomba injetora. Piracicaba, 1987. 103p. Tese (Doutorado) Escola Superior de Agricultura “Luiz de Queiroz”, Universidade de São Paulo.

ZERMEÑO, G.; PÉREZ, J. Fertilización foliar en el cultivo de melón:. notas científicas. In: CONGRESO DE HORTICULTURA. MANZANILlO, 8., México, 1999. Proceeedings. México: Col. Mex. 1999. p.1-229.

ZETZSEN, J. B.; NEWMAN, J. S. Subirrigation with plastic pipe. Agricultural Engineering, v.47, n.1, p.74-75, 1966.

ZOLDOSKE, D. F.; GENITO, S.; JORGENSEN, G. S. Subsurface drip irrigation (SDI) on turtgrass: A university experience. In.: MICROIRRIGATION CONGRESS, 5. St. Joseph, 1995. Proceedings St. Joseph: ASAE, 1995. p.300-302. 